Chemical Technology Division

\title{
DEVELOPMENT AND DEPLOYMENT OF A FULL-SCALE CROSS-FLOW FILTRATION SYSTEM FOR TREATMENT OF LIQUID LOW-LEVEL WASTE AT OAK RIDGE NATIONAL LABORATORY
}

"NUKEM Nuclear Technologies, Columbia, S.C.; formerly of the ORNL Chemical Technology Division. ${ }^{\dagger}$ BWXT Y-12, Engineering Division.

\author{
T. E. Kent \\ J. H. Wilson* \\ J. R. Farmer ${ }^{\dagger}$
}

Date Published: June 2001

\author{
Prepared by the \\ OAK RIDGE NATIONAL LABORATORY \\ Oak Ridge, Tennessee 37831-6285 \\ managed by \\ UT-BATTELLE, LLC \\ for the \\ U.S. DEPARTMENT OF ENERGY \\ under contract DE-AC05-00OR22725
}




\section{CONTENTS}

LIST OF TABLES $\ldots \ldots \ldots \ldots \ldots \ldots \ldots \ldots \ldots \ldots \ldots \ldots \ldots \ldots \ldots \ldots \ldots \ldots \ldots \ldots$

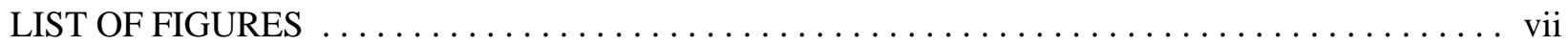

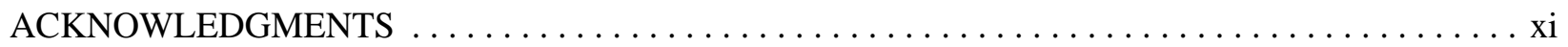

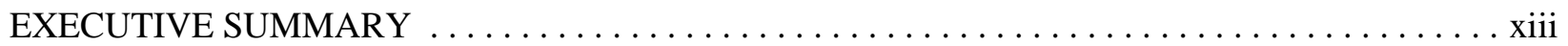

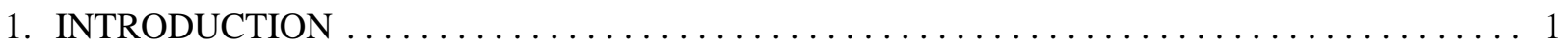

2. SUMMARY OF SINGLE-ELEMENT TEST RESULTS $\ldots \ldots \ldots \ldots \ldots \ldots \ldots \ldots \ldots \ldots$

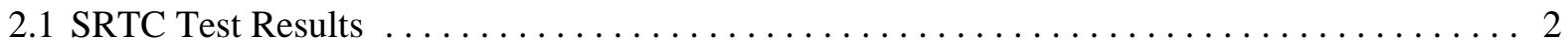

2.2 ORNL Testing with the Cell Unit Filter System $\ldots \ldots \ldots \ldots \ldots \ldots \ldots \ldots \ldots \ldots \ldots$

3. DESIGN AND FABRICATION OF THE SLS SYSTEM $\ldots \ldots \ldots \ldots \ldots \ldots \ldots \ldots \ldots \ldots \ldots 5$

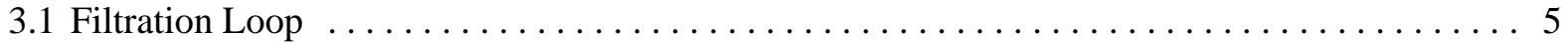

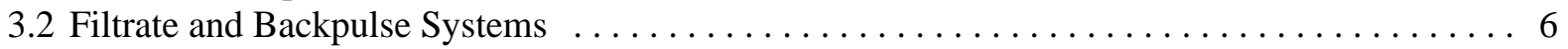

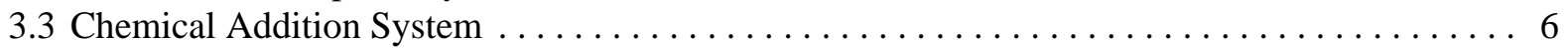

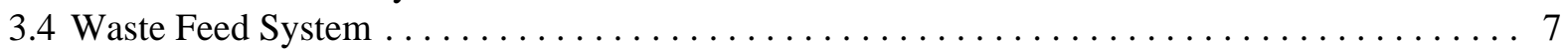

3.5 Equipment Specifications for the SLS System $\ldots \ldots \ldots \ldots \ldots \ldots \ldots \ldots \ldots \ldots$

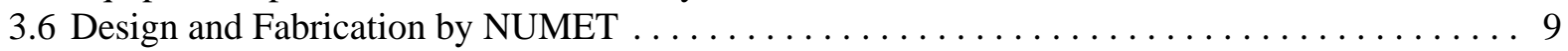

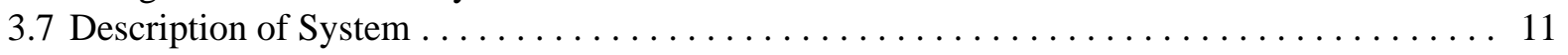

4. INSTALLATION OF SLS SYSTEM AT THE MVST FACILITY $\ldots \ldots \ldots \ldots \ldots \ldots \ldots \ldots$

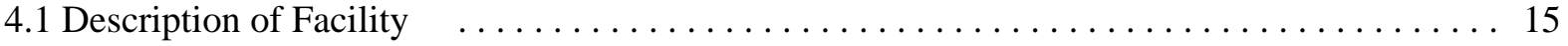

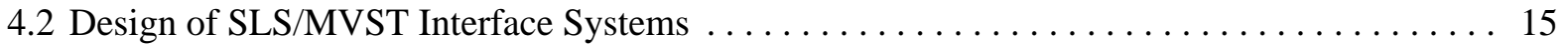

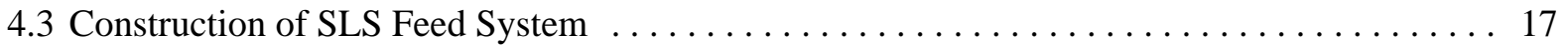

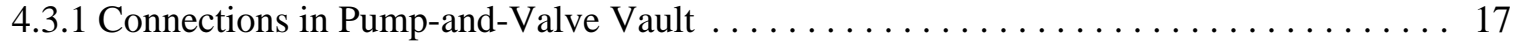

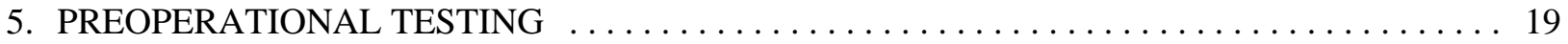

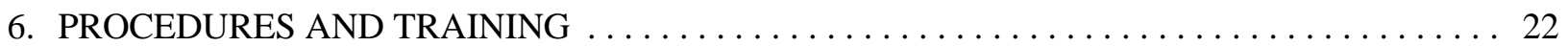

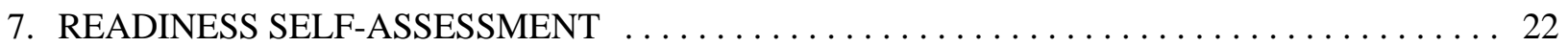

8. OPERATIONS AND PERFORMANCE EVALUATION $\ldots \ldots \ldots \ldots \ldots \ldots \ldots \ldots \ldots \ldots$

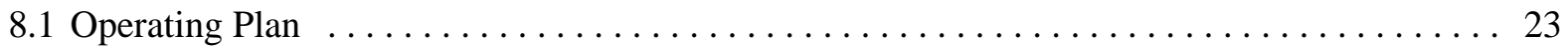

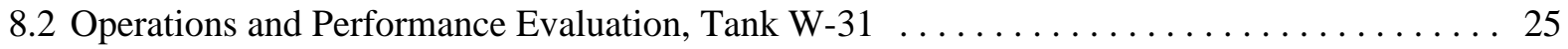

8.2.1 SLS Performance Tests and Operations Data, Tank W-31 . . . . . . . . . . . 26

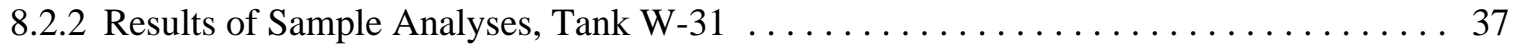

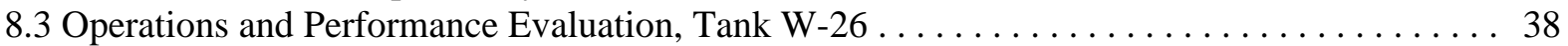

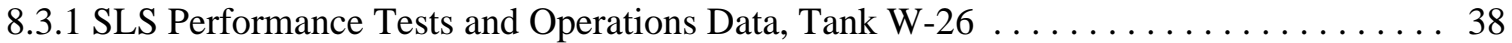

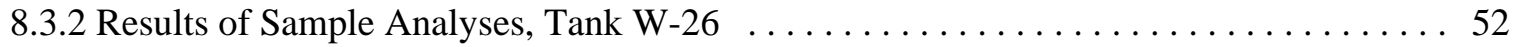

8.4 Comparison of Experimental and Full-Scale Performance $\ldots \ldots \ldots \ldots \ldots \ldots \ldots \ldots \ldots$ 


\section{CONTENTS (continued)}

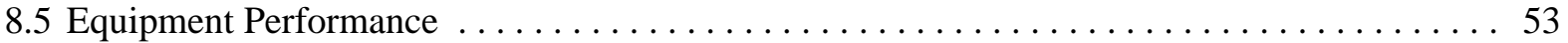

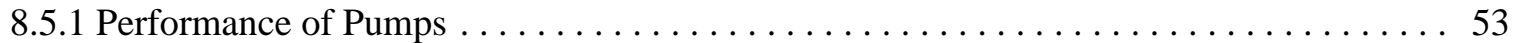

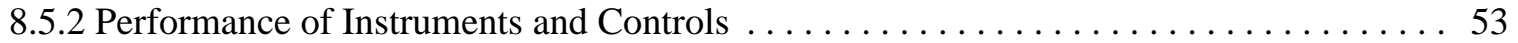

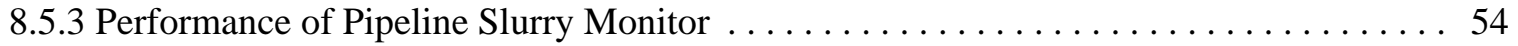

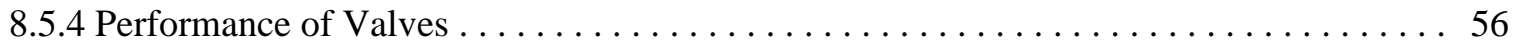

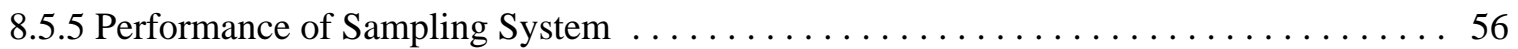

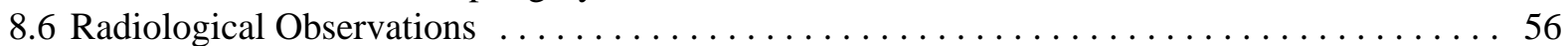

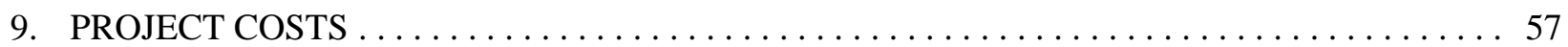

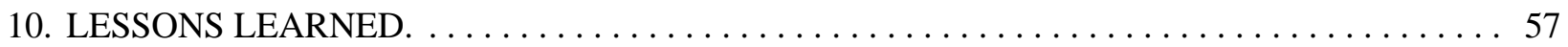

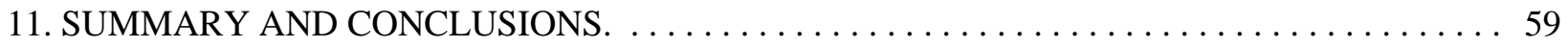

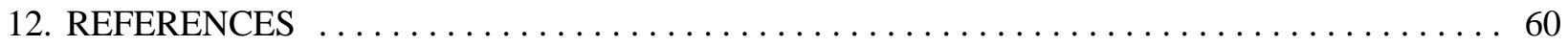

Appendix A. SAMPLE ANALYSIS RESULTS $\ldots \ldots \ldots \ldots \ldots \ldots \ldots \ldots \ldots \ldots \ldots \ldots \ldots \ldots \ldots \ldots$

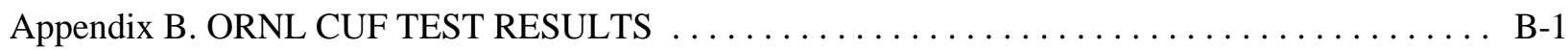

Appendix C. INFORMATION ON SLS DESIGN SPECIFICATION $\ldots \ldots \ldots \ldots \ldots \ldots \ldots \ldots \ldots$ C-1

Appendix D. SLS SYSTEM DRAWINGS $\ldots \ldots \ldots \ldots \ldots \ldots \ldots \ldots \ldots \ldots \ldots \ldots \ldots \ldots \ldots \ldots \ldots \ldots \ldots$

Appendix E. TABLE OF CONTENTS FOR NUMET SLS MANUALS $\ldots \ldots \ldots \ldots \ldots \ldots \ldots$ E-1

Appendix F. SLS PROJECT EVIDENCE FILE INDEX $\ldots \ldots \ldots \ldots \ldots \ldots \ldots \ldots \ldots \ldots \ldots \ldots$ F-1

Appendix G. SLS OPERATING PLAN $\ldots \ldots \ldots \ldots \ldots \ldots \ldots \ldots \ldots \ldots \ldots \ldots \ldots \ldots \ldots \ldots \ldots \ldots \ldots \ldots$ 


\section{LIST OF TABLES}

Number

$\underline{\text { Title }}$

$\underline{\text { Page }}$

Results of SLS Test Series 1, tank W-31.

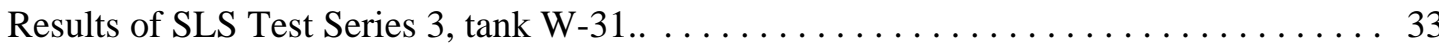

Comparison of results for Test Series 1 and 3 , tank W-31 . . . . . . . . . . . 34

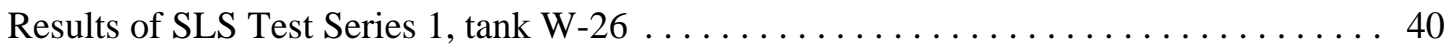

Results of SLS Test Series 2, tank W-26 . . . . . . . . . . . . . . . 43

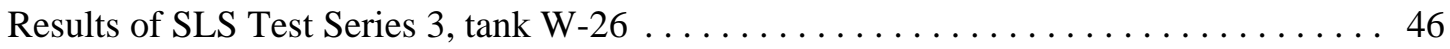

Results of SLS Test Series 4, tank W-26.

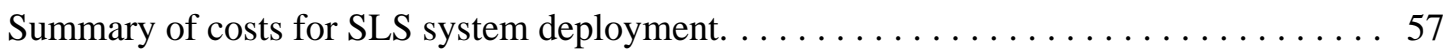

A-1 Characterization data for samples used in CUF tests $\ldots \ldots \ldots \ldots \ldots \ldots \ldots \ldots$

A-2 Laboratory analyses of the MVST W-31 supernatant. . . . . . . . . . . A-5

A-3 Analytical results from samples taken during Series 1 tests, tank W-31 ....... A-6

A-4 Analytical results from samples taken during Series 2 tests, $\operatorname{tank} W-31 \ldots \ldots \ldots$ A-7

A-5 Analytical results from samples taken during Series 3 tests, tank W-31 . . . . . A -8

A-6 Analytical data from routine operational samples, tank $W-31 \ldots \ldots \ldots \ldots \ldots$ A-9

A-7 Laboratory analysis of the MVST W-26 supernatant.. $\ldots \ldots \ldots \ldots \ldots \ldots \ldots \ldots$ A-10

A-8 Analytical results from samples taken during Series 1 tests, tank W-26. . . . . . . A-11

A-9 Analytical results from samples taken during Series 4 tests, tank W-26 . . . . . . A-12

A-10 Analytical data from routine operational samples, tank $\mathrm{W}-26 \ldots \ldots \ldots \ldots \ldots$ A-13 


\section{LIST OF FIGURES}

$\underline{\text { Figure }}$

$\underline{\text { Title }}$

$\underline{\text { Page }}$

$1 \quad$ Flowsheet of SLS filtration loop and feed system $\ldots \ldots \ldots \ldots \ldots \ldots \ldots \ldots \ldots$

2 SLS system during acceptance testing at the NUMET facility $\ldots \ldots \ldots \ldots \ldots \ldots \ldots \ldots$

$3 \quad$ SLS system components prior to installation of shielding $\ldots \ldots \ldots \ldots \ldots \ldots \ldots \ldots \ldots$

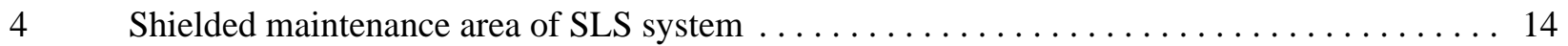

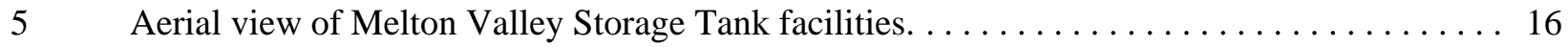

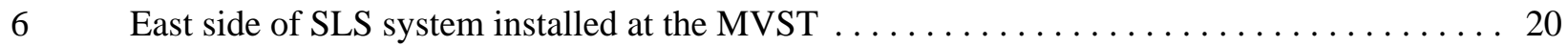

$7 \quad$ West side of SLS system with MVST vault interface piping and shield partition $\ldots \ldots \ldots 20$

$8 \quad$ North side of SLS system with access to sample cabinet and shielded maintenance area . ... 21

9 South side of SLS system with deionized water and chemical feed station $\ldots \ldots \ldots \ldots \ldots 21$

10 Flowsheet for solid/liquid separation system in series with cesium removal

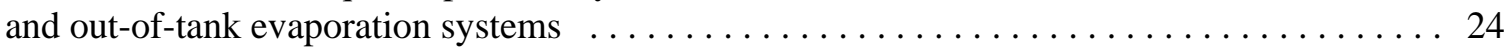

11 Filtrate flow, feed mass flow, and feed TSS as a function of time during initial

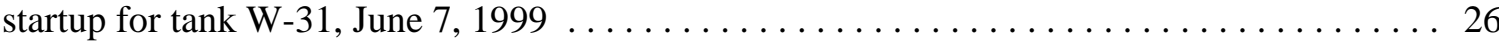

12 Filtrate flow, transmembrane pressure, and axial flow as a function of time, Series 1,

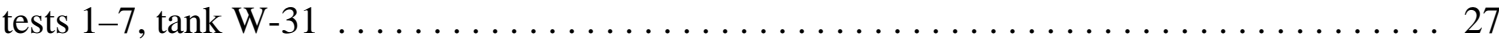

13 Filtrate flow, transmembrane pressure, and axial flow as a function of time, Series 1,

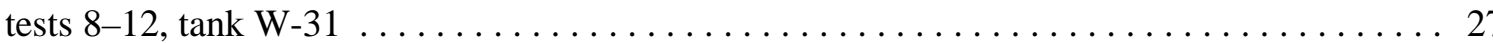

14 Filtrate flow, feed TSS, and feed mass flow as a function of time, Series 1,

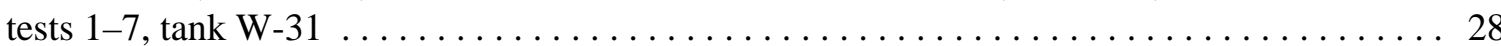

15 Filtrate flow, feed TSS, and feed mass flow as a function of time, Series 1,

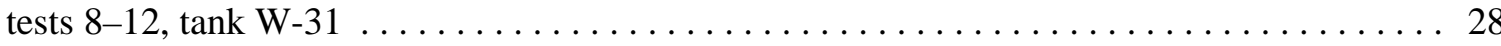

16 Average filtrate flux as a function of transmembrane pressure, Test Series 1, tank W-31 . . 30

17 Average filtrate flux as a function of axial velocity, Test Series $1, \operatorname{tank} W-31 \ldots \ldots$

18 Filtrate flow, transmembrane pressure, and axial flow as a function of time

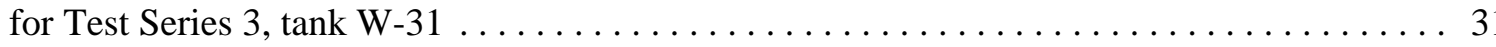




\section{LIST OF FIGURES (continued)}

Figure

$\underline{\text { Title }}$

19 Feed TSS, filtrate flow, and feed mass flow as a function of time for Test Series 3,

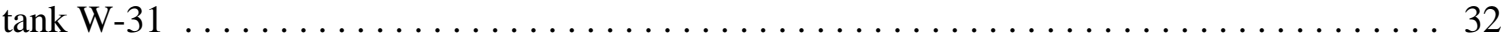

20 Average filtrate flux as a function of transmembrane pressure, Test Series 3, tank W-31 . . 32

21 Average filtrate flux as a function of axial velocity, Test Series 3, tank W-31 . . . . . 33

22 Feed TSS, filtrate flow, and feed mass flow as a function of time near the end

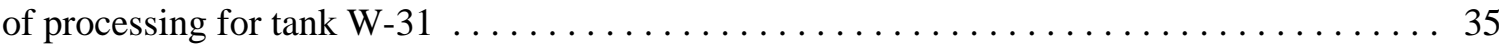

23 Filtrate flow, axial flow, and transmembrane pressure as a function of time near

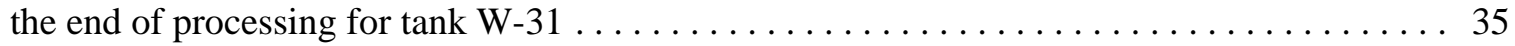

24 Feed TSS and mass flow as a function of time, tank W-31, June 25, $1999 \ldots \ldots \ldots \ldots$

25 Feed density and mass flow as a function of time, tank W-31, June $25,1999 \ldots \ldots \ldots$

26 Filtrate flow, transmembrane pressure, and axial flow as a function of time

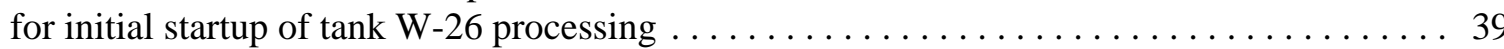

27 Feed mass flow and feed TSS as a function of time for initial startup of

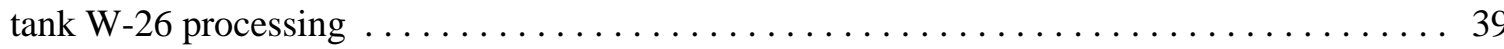

28 Filtrate flow, axial flow, and transmembrane pressure as a function of time

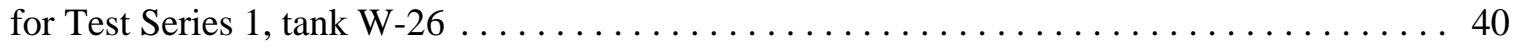

29 Feed mass flow and TSS as a function of time, Test Series $1, \operatorname{tank} \mathrm{W}-26 \ldots \ldots \ldots \ldots$

30 Average filtrate flux as a function of transmembrane pressure, Test Series 1, tank W-26 . . 41

31 Average filtrate flux as a function of axial velocity, Test Series 1, tank W-26 . . . . . . . 42

32 Filtrate flow, transmembrane pressure, and axial flow as a function of time,

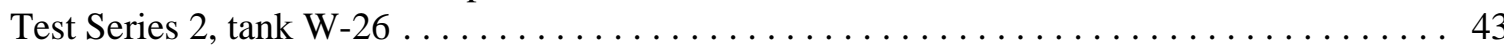

33 Feed mass flow and TSS as a function of time, Test Series $2, \operatorname{tank} W-26 \ldots \ldots \ldots \ldots$

34 Average filtrate flux as a function of transmembrane pressure, Test Series 2, tank W-26 . . 44

35 Average filtrate flux as a function of axial velocity, Test Series $2, \operatorname{tank} W-26 \ldots \ldots \ldots$

36 Feed mass flow, feed TSS, and filtrate flow as a function of time for Test Series 3,

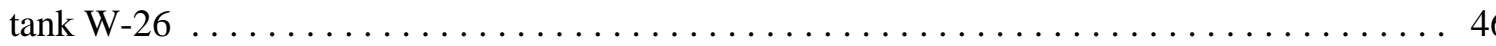




\section{LIST OF FIGURES (continued)}

$\underline{\text { Figure }}$

Title

$\underline{\text { Page }}$

37 Filtrate flow, axial flow, and transmembrane pressure as a function of time

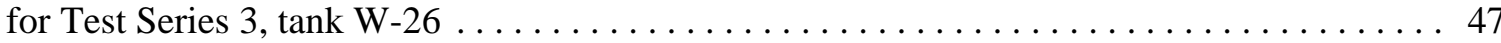

38 Average filtrate flux as a function of transmembrane pressure for Test Series 3, tank W-26 . . . . . . . . . . . . . . . . . . . . . . . . . . . . . 47

39 Average filtrate flux as a function of axial velocity for Test Series 3, tank W-26 . . . . . . 48

$40 \quad$ Feed TSS and feed mass flow as a function of time for Test Series 4, tank W-26 _ . . . . 49

41 Filtrate flow, transmembrane pressure, and axial flow as a function of time

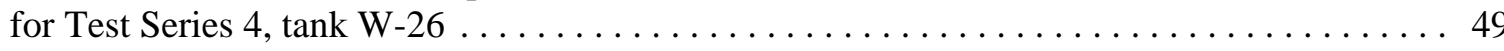

42 Average filtrate flux as a function of transmembrane pressure for Test Series 4,

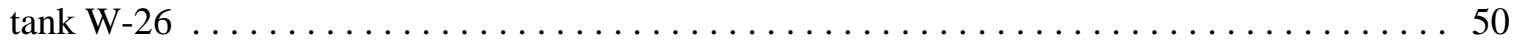

43 Average filtrate flux as a function of axial velocity for Test Series 4, tank W-26 . . . . 50

44 Average filtrate flux as a function of test chronological order for tank W-26 . . . . . 51

B-1 Filtrate flux as a function of transmembrane pressure for $\mathrm{W} 3-\mathrm{W} 4$ sample mixture $\ldots \ldots \ldots$ B-3

B-2 Filtrate flux as a function of axial velocity for W3-W4 sample mixture $\ldots \ldots \ldots \ldots \ldots$ B-3

B-3 Filtrate flux as a function of transmembrane pressure for W6-W10 sample mixture . . . . . B-4

B-4 Filtrate flux as a function of axial velocity for W6-W10 sample mixture $\ldots \ldots \ldots \ldots$ B-4

B-5 Filtrate flux as a function of transmembrane pressure for $\mathrm{W}-25$ sample $\ldots \ldots \ldots \ldots$ B-5

B-6 Filtrate flux as a function of axial velocity for $\mathrm{W}-25$ sample $\ldots \ldots \ldots \ldots \ldots \ldots \ldots$ 


\section{ACKNOWLEDGMENTS}

The successful completion of this project was made possible through a dedicated team effort involving many individuals and organizations over the span of several years. The U.S. Department of Energy (DOE) Tank Focus Area (TFA) was the major provider of funding for the project and made possible the integration of technical support from several different DOE sites where state-of-the-art filtration technologies were being developed and evaluated. The TFA recognized that the support of this project would benefit environmental management activities at Oak Ridge and across the DOE complex by providing local processing capability and evaluating the performance of a full-scale solid/liquid separation (SLS) system for potential application in tank waste pretreatment at other DOE sites. The program contributions of C. Mims and J. R. Noble-Dial, of DOE-Oak Ridge Operations, were vital to the project. Their vision of the SLS system as an integral part of the Bethel Valley Watershed remediation activity was critical. S. M. Robinson and C. P. McGinnis, of the ORNL Chemical Technology Division, have provided dedicated support through their coordination of the project with TFA, DOE- ORO, and Waste Operations since the inception of the project in 1996. V. L. Fowler and J. D. Hewitt, also of the ORNL Chemical Technology Division, performed early filtration tests with tank waste samples that indicated that cross-flow filtration (the selected technology for the SLS system) could be used successfully. The Savannah River Technology Center, with D. J. McCabe and R. A. Peterson, provided excellent technical support and generated important test data with simulated wastes during the early test phases of the program. J. H. Wilson and A. J. Lucero, of the ORNL Chemical Technology Division, led the follow-on effort involving filtration tests using several waste samples from the Melton Valley Storage Tanks and gunite tanks. J. H. Wilson and J. R. Farmer (BWXT Y-12, Engineering Division) led the development of design specifications for the system and selected NUMET Engineering, Ltd., as the design and fabrication subcontractor for the full-scale SLS system. J. R. Farmer and R. D. Gray (Quality Engineering) performed thorough quality assurance inspections during fabrication of the SLS system by NUMET. Chris McMeekin and the design/fabrication team at NUMET provided a well-designed, highquality, and well-documented SLS system that performed in nearly flawless fashion. The Bechtel Jacobs Company LLC Waste Operations Project team under the management of C. E. Frye and C. B. Scott provided excellent field operations and maintenance support for the project. The field operations shift leaders from the Engineering Development Section of the ORNL Chemical Technology Division provided outstanding, dedicated support of the operation. This team included R. L. Cummins, B. S. Evans, L. L. Farr, J. D. Hewitt, H. L. Jennings, S. A. Richardson, P. A. Taylor, and J. F. Walker. 


\section{EXECUTIVE SUMMARY}

A full-scale modular solid/liquid separation (SLS) system was designed, fabricated, installed, and successfully deployed for treatment of liquid low-level waste from the Melton Valley Storage Tanks (MVSTs) at Oak Ridge National Laboratory (ORNL). The SLS module, utilizing cross-flow filtration, was operated as part of an integrated tank waste pretreatment system (otherwise known as the Wastewater Triad) to remove suspended solids and prevent fouling of ion-exchange materials and heat exchange surfaces. The system was designed and fabricated under contract with NUMET Engineering, Limited in Peterborough, Ontario, based on specifications developed by ORNL. Installation at the MVST facility was performed under contract with the MK-Ferguson Company, and the system was operated by the ORNL Chemical Technology Division and the Bechtel Jacobs Company, LLC.

Development testing was performed by the Savannah River Technology Center and the ORNL Chemical Technology Division in 1996. The information gained from this testing was used to complete design specifications for the full-scale modular SLS system in May 1997. The contract for detailed design and fabrication of the system was awarded to NUMET in July 1997, and the design was completed in January 1998. Fabrication began in March 1998, and the completed system was delivered to ORNL on December 29, 1998. Installation of the system at the MVST facility was completed in May 1999. After completing an operational readiness assessment, approval was given to commence hot operations on June 7, 1999.

Operations involving two of the eight MVSTs were performed safely and with very little unscheduled downtime. Filtration of supernatant from tank W-31 was completed on June 24, 1999 and W-26 processing was completed on August 20, 1999. The total volume processed during these two campaigns was about 45,000 gal. The suspended solids content of the liquid processed from tank W-31 was lower than expected, resulting in higher-than-expected filtrate production for nearly the entire operation. The liquid processed from tank W-26 was higher in suspended solids content, and filtrate production was lower, but comparable to the rates expected based on the results of previous pilot-scale, single-element filtration tests. The quality of the filtrate consistently met the requirements for feed to the downstream ion-exchange and evaporation processes. From an equipment and controls standpoint, the modular system (pumps, valves, sensors, monitors, controls, shielding, and containment) functioned very well during each campaign. Evaluation of the Endress+Hauser Promass 63F Mass Flowmeter (a secondary objective of the project) indicated reasonably accurate and reliable performance. This instrument was installed on the feed pipeline for the SLS system, and it provided very accurate mass flow and density data, and reasonably accurate solids content data. Near the end of tank W-31 processing, the solids content of the feed to the SLS system increased to a very high concentration. This behavior was caused by the increased mixing of liquid and sludge phases within MVST Tank 31 as the level of liquid being decanted from the tank approached the level of the settled sludge. The physical properties of the heavy sludge caused some difficulties in draining and flushing of the system. Other minor equipment problems were encountered, but none resulted in significant downtime or safety issues.

Operational data collected during the campaign were useful in evaluating the performance of the system. The $50-\mathrm{ft}^{2}$ cross-flow filter was designed to provide filtrate at the rate of 1 to $5 \mathrm{gal} / \mathrm{min}$ (flux range of 0.02 to $0.1 \mathrm{gal} \mathrm{min}^{! 1} \mathrm{ft}^{! 2}$ ) of filtrate, and actual production was between 0.6 and $8.0 \mathrm{gal} / \mathrm{min}$ (flux range of 0.012 to $0.16 \mathrm{gal} \mathrm{min}^{! 1} \mathrm{ft}^{\prime 2}$ ). Additional operating data will be needed, however, to assess the long-term

performance of the system with wider variations in the composition of the tank waste feed. The SLS will be employed in further processing campaigns during FY 2000, and more performance data will be collected. 


\section{INTRODUCTION}

The purpose of this task is to develop, design, and deploy solid/liquid separation (SLS) technology and provide information regarding implementation of the technology to U.S. Department of Energy (DOE) sites for treatment of underground storage tank wastes. SLS technology is needed at several DOE sites, including Hanford, Savannah River, Idaho, and Oak Ridge for pretreatment of waste liquids stored in tanks.

Since the late 1980s, several DOE facilities have participated in developing and testing SLS technologies for removal of suspended solids from radioactive tank waste liquids: Savannah River Technology Center (SRTC), Pacific Northwest National Laboratory (PNNL), Idaho National Environmental and Engineering Laboratory (INEEL), and Oak Ridge National Laboratory (ORNL). In FY 1996, the SRTC performed a comprehensive evaluation of SLS technologies for all DOE sites that were planning remediation of underground storage tank systems. Alternative SLS technologies were reviewed, and commercial vendors were consulted to recommend equipment that would best suit the particular site conditions. ${ }^{1}$ After down-selecting several technologies, SRTC prepared simulant formulations for Oak Ridge and other DOE site wastes and tested several SLS methods. SRTC recommended either cross-flow filtration or dead-end filtration for ORNL wastes, depending on the characteristics of the tank liquids. ${ }^{2}$ ORNL had performed preliminary testing of cross-flow filtration in 1989 and obtained encouraging results. ${ }^{3}$ These results and the operational constraints associated with dead-end filtration led ORNL to pursue cross-flow filtration for further development.

Cross-flow filters, which are manufactured commercially, consist of porous tubular filter elements constructed in a metal sintering process that controls the size of the pores. The tubes are typically assembled as a bundle within an enclosure, similar to a shell-and-tube heat exchanger. The process stream is pumped through the inside of the filter elements in the axial direction at velocities in the range of 6 to $12 \mathrm{ft} / \mathrm{s}$. The high velocity and turbulence of the process stream minimizes buildup of filtered solids on the inner surface of the tubes. Pressure is applied to the process stream to force liquid through the tube walls and into the shell side of the tube bundle for filtrate collection. The concentrated stream is returned to the tank from which the feed is taken. This technology is adaptable to high-radiation applications for the following reasons: (1) tubular sintered-metal filter elements are not degraded in high radiation fields, (2) the system is relatively simple to operate and amenable to remote control, and (3) the filter elements can be backflushed and chemically cleaned if they become plugged and rarely require replacement.

The deployment of a full-scale cross-flow filter system was originally planned as an important element of the Oak Ridge Environmental Restoration (EM-40) Gunite and Associated Tank (GAAT) Treatability Study. The treatability study was evaluating various technologies for remediation of ORNL radioactive waste storage tanks, mainly the out-of-service (inactive) tanks constructed in the early 1940s to store waste from pilot testing of uranium and plutonium processing systems. SLS technology was needed to process sluice water used to mobilize and transport the tank sludge heels from the GAAT system to the ORNL active waste system. In execution of additional development work, SRTC used characterization information from the GAAT studies to prepare a simulant of the tank sludge and to conduct singleelement filter testing. Using data from the SRTC tests along with GAAT site engineering information, preliminary design specifications were prepared by ORNL for a full-scale cross-flow filtration system. However, the plans for deploying the system changed when the overall ORNL site plans for tank remediation were reviewed and modified by DOE-Oak Ridge Operations (DOE-ORO) in FY 1997. The new Integrated Tank Waste Management Plan ${ }^{4}$ indicated that the SLS system would be better utilized at 
the Melton Valley Storage Tank (MVST) facility to improve systems for managing the large volumes of liquids that would be generated during retrieval and consolidation of all Oak Ridge tank sludges at that facility. These sludges, which included those from the Bethel Valley Evaporator Service Tanks, the Old Hydrofracture Facility tanks, and the GAAT system, were to be consolidated with existing sludge at the MVST. The projected liquid volume necessary for transfer of these sludges was far in excess of the volume capacity of the MVSTs. As such, the plan called for the use of the SLS system for filtering the excess liquids, the cesium removal system (CsR) for removing radiactive cesium from the filtered supernatant, and the out-of-tank evaporator (OTE) system for evaporating excess water and reducing the liquid volume. The concentrated, low activity liquid from the process was to be stored in the Melton Valley Capacity Increase Project (CIP) tanks. The modified deployment approach required that the preliminary design specifications be revised and updated using test information and site engineering data for the MVST application.

\section{SUMMARY OF SINGLE-ELEMENT TEST RESULTS}

Since GAAT sludges constitute a significant fraction of the total quantity of sludge to be consolidated in the MVST, the SRTC testing conducted using GAAT simulants was still considered useful for the design specifications. To validate the SRTC simulant tests and to evaluate filter performance for additional sludge compositions, ORNL conducted small-scale hot-cell filtration tests with real-waste samples of GAAT and MVST tank sludges. The information from both tests programs was used to obtain scale-up information for design of a full-scale system for the MVST.

\subsection{SRTC TEST RESULTS}

The SRTC tests with simulated tank waste indicated that cross-flow filtration was effective using both a Mott (Mott Metallurgical Corporation) 0.5-Fm filter element and a Graver titania-coated 0.1-Fm filter element. The Mott element was recommended for filtration of more-concentrated slurries, while the Graver element performance was superior for more-dilute solutions. The Mott element was favored because the system was expected to receive a more-concentrated slurry feed from the MVST.

The results from the cross-flow filtration testing campaign at SRTC included the following:

C The filtrate "flux" (filtrate flow per unit of filter surface area) from cross-flow filtration ranged from 0.02 to $0.14 \mathrm{gal} \mathrm{min}^{! 1} \mathrm{ft}^{\prime 2}$ for feed suspended solids concentrations of 0.1 to $15 \mathrm{wt} \%$ in the feed.

C The Graver filter produced the highest filtrate flux for low-solids-content feed $(0.1 \mathrm{wt} \%)$. This flux was $0.14 \mathrm{gal} \mathrm{min}^{! 1} \mathrm{ft}^{! 2}$.

C The $0.5 \mathrm{Fm}$ (pore size) Mott filter produced the highest filtrate flux for high-solids-content feed (5 wt \%). This flux was $0.15 \mathrm{gal} \mathrm{min}^{11} \mathrm{ft}^{! 2}$.

C At \#5 wt \% feed solids in cross-flow filtration with the Mott filter, the filtrate flux was controlled by transmembrane pressure drop. At $15 \mathrm{wt} \%$ feed solids, the flux was controlled by axial velocity through the filter element.

C The filtrate quality was comparable for all filter types and satisfied criteria for downstream processes. 
SRTC also provided the following guidelines for the design and operation of cross-flow filtration technology.

C A sintered stainless steel filter with a 0.5 -Fm pore size should be used.

C The slurry circulating pump should be of the "low- shear" type to avoid reducing the particle size distribution of the suspended solids. Suspended solids with small particle size tend to plug the pores of the cross-flow filters, resulting in a high pressure drop across the filters and decreased filtrate production.

C To maintain adequate filtrate production at very high solids content (10 to $15 \mathrm{wt} \%$ ), the axial velocity of the filter should be 10 to $12 \mathrm{ft} / \mathrm{s}$.

C The chemical cleaning system should be designed to operate with acid as well as caustic. The acid is required for cleaning; both chemicals may be used for $\mathrm{pH}$ adjustment.

C A floating suction should be used for decanting the waste tank waste liquids in order to minimize the uptake of grit.

\subsection{ORNL TESTING WITH THE CELL UNIT FILTER SYSTEM}

To validate the simulant data collected by SRTC and to obtain data for design of a larger-scale system, ORNL obtained samples of tank supernatant and sludge from the GAAT and MVST tank farms for testing with small-scale filtration equipment in a shielded hot cell facility. SRTC provided the Cell Unit Filter (CUF) apparatus to ORNL, design specifically for hot cell testing of cross-flow filtration. The tests were designed to evaluate the effects of critical process parameters such as transmembrane pressure, axial velocity, and suspended solids content on the filtrate flux. This information was used to size the full-scale cross-flow filter and to determine the range of acceptable operating conditions.

The GAAT sludges used for the tests were prepared by combining GAAT samples taken from several different tanks. Samples from tank W-3 and W-4 of the GAAT North Tank Farm were combined to provide liters of waste, designated Composite 1. Three liters of Composite 2 resulted from combining samples from tanks W-6, W-8, W-9, and W-10 from the GAAT South Tank Farm. The weights and compositions of the individual samples were used to estimate the composition of the mixture. Samples of the sludge and the supernatant from MVST tank W-25 were also used in the test program. Information on the composition of these samples is provided in Appendix A, Table A-1.

Filtration tests with actual sludge/supernatant samples were performed in Hot Cell B at Building 4501. The sample was circulated through the CUF filtration loop using a low-shear progressive-cavity pump. The fluid flowed in series through the pump, a magnetic flowmeter, the cross-flow filter element, and a manual backpressure control valve, and was returned to the feed tank in a recirculating mode. The cross-flow filter element, manufactured by the Mott Filter Corporation, consisted of a single 6-in.-long, 0.5- in.-diameter sintered metal filter element mounted within a tubular housing for collecting the filtrate. The pore size of the filter was $0.5 \mathrm{Fm}$.

Prior to operations, several baffles were added to the CUF system feed tank and the feed recirculation pipeline was repositioned to improve mixing characteristics and to prevent settling of solids. Operating data were collected for transmembrane pressures from 10 to 34 psig and axial velocities from 2.5 to 
$8.1 \mathrm{ft} / \mathrm{s}$. Useful data were obtained for all three sample mixtures at a range of suspended solids concentrations from 0.33 to $15.6 \mathrm{wt} \%$. Graphs showing the relationship between filtrate flux and the various operating parameters are given in Appendix B, Figs. B-1 through B-6.

Figure B-1 indicates that at practically all levels of solids content in the W3-W4 samples, increased transmembrane pressure results in a higher filtrate flux. The effect of transmembrane pressure is more pronounced at a lower solids content. It should be noted, however, that groups of tests were performed beginning at a low solids content $(0.33 \mathrm{wt} \%)$ and increasing stepwise to $13.2 \mathrm{wt} \%$. As a consequence, the initial tests at low solids content were more likely to show very high initial filtrate flux and also the initial effects of filter fouling. The order of the tests within a group, however, was determined statistically to avoid bias for tests performed at a particular solids content. The total range of filtrate flux

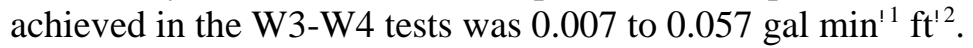

Test data for the W3-W4 simulant containing $0.33 \mathrm{wt} \%$ suspended solids (Fig. B-2) indicated that increasing the axial velocity causes a decease in filtrate flux. For simulants containing higher solids contents, increasing the axial velocity showed little effect on filtrate flux. This was unexpected because increasing the axial velocity normally increases filtrate flux when the solids content is high, and should never cause a decrease in flux. The unusual behavior in the test at $0.33 \mathrm{wt} \%$ solids may have been due to particle attrition caused by the shear effects of increased flow turbulence through piping, turbulence upon passing through the backpressure control valve restriction, and the increasing number of passes through the pump at a higher flow rate. Small particle size distribution will generally cause filter fouling and decreased filtrate production. The lack of axial flow influence at higher solids concentrations was also experienced during SRTC simulant testing at solids concentrations of $5 \mathrm{wt} \%{ }^{5}$ With a highersolids-content feed, a layer of solids or filter cake will develop on the surface of the filter and cause additional resistance to filtrate flow. This resistance is typically counteracted by increasing the axial velocity and turbulence within the tube to decrease the thickness and resistance of the cake. However, if the cake has not been given the opportunity to form, increasing the axial flow will have no effect. It is suspected that the short duration of the CUF tests (about 90 min per test series at constant solids content) and frequent backpulsing (30 min) prevented development of filter cake within the filter element, even at solids contents up to $13.2 \mathrm{wt} \%$. As in the test performed at $0.33 \mathrm{wt} \%$ solids, particle attrition may also have inhibited the effects of increased axial velocity.

Filter performance during processing of the W6-W10 sample was similar to that of the W3-W4 sample with respect to the effects of transmembrane pressure, axial flow, and flux range at high solids content. This sample was prepared at two solids concentrations, 6.3 and $7.9 \mathrm{wt} \%$. As shown in Fig. B-3, the filtrate flux increased with higher transmembrane pressure and the flux was slightly lower at the higher of the two solids concentrations. Figure B-4 indicates that increased axial velocity did not significantly increase the filtrate flux because of the possible effects described for the W3-W4 tests. The range of flux achieved in these tests was 0.0087 to 0.0176 gal $\min ^{! 1} \mathrm{ft}^{\prime 2}$, which is similar to that $(0.0094$ to $0.0218 \mathrm{gal}$ $\min ^{! 1} \mathrm{ft}^{! 2}$ ) achieved for the W3-W4 tests at 6.6 and $9.9 \mathrm{wt} \%$ solids.

Filter performance for the W-25 MVST sample was slightly better than that achieved for the GAAT samples. These tests were performed at three solids content levels: 9.9, 12.7, and $15.6 \mathrm{wt} \%$. The range of filtrate flux achieved in these tests was significantly higher than GAAT sample flux range. The range of flux for the GAAT samples between solids levels of 6.6 and $13.2 \mathrm{wt} \%$ was 0.0069 to $0.0218 \mathrm{gal} \mathrm{min}^{! 1}$ $\mathrm{ft}^{\prime 2}$. The range of filtrate flux achieved for all of the W-25 tests was 0.0237 to $0.0441 \mathrm{gal} \mathrm{min}^{! 1} \mathrm{ft}^{\prime 2}$. The influence of transmembrane pressure and axial velocity was similar to that experienced for the GAAT samples. As shown in Figs. B-5 and B-6, increasing the transmembrane pressure increased the filtrate 
flux; however, increased axial flow did not appear to cause a trend of either increasing or decreasing flux.

In comparing the results of the ORNL CUF tests with those of the SRTC simulant tests, some interesting similarities and differences were noted. Increasing the transmembrane pressure caused an increase in filtrate flux in both SRTC simulant and CUF tests. In most cases, increases in axial flow had little effect on filtrate flux for both the simulant and the CUF tests. However, for SRTC simulant tests performed at $15 \mathrm{wt} \%$ solids, an increase in axial flow caused an increase in filtrate flux. This was in contrast to CUF tests at 13.2 and $15.6 \mathrm{wt} \%$ solids, which did not show a significant increase in flux when the axial flow was increased. Test conditions were similar from the standpoint of duration (60 to $90 \mathrm{~min}$ ) and backpulse frequency (every $30 \mathrm{~min}$ ). It is suspected that the lack of influence from axial velocity in the CUF tests was due to a higher degree of fouling possibly caused by particle attrition, and evidenced by the overall lower filtrate flux for the CUF tests.

The overall range in filtrate flux of 0.0069 to $0.057 \mathrm{gal} \mathrm{min}^{11} \mathrm{ft}^{\prime 2}$ for the GAAT and MVST samples in the CUF unit was lower than what was achieved in the simulant testing $\left(0.02\right.$ to $\left.0.14 \mathrm{gal} \mathrm{min}^{! 1} \mathrm{ft}^{! 2}\right)$. The reason for this difference is likely related to the differences between composition and particle size of the simulant and the actual waste samples. Particle size distribution analyses were performed on as-received sludge samples, and on a sludge sample after processing in the CUF unit. The average as-received particle size of the W-25 sample was approximately $13 \mathrm{Fm}$, as compared with $0.7 \mathrm{Fm}$ and $1.6 \mathrm{Fm}$ for the W3-W4 and W6-W10 samples, respectively. This difference may explain the higher filtrate flux achieved for the W-25 sample. The particle size of the GAAT sludge was reduced to $0.36 \mathrm{Fm}$ by processing in the CUF unit and may have had a negative impact on filtrate flux at higher axial velocities. Analysis of the simulants prepared at SRTC indicated that $80 \%$ of the particles were within a size range of approximately 1.2 to $7.2 \mathrm{Fm}$ both before and after testing. ${ }^{6}$ The larger particle size range, differences in the equipment design, and lack of particle attrition could have had a positive influence on filtrate flux for the simulant tests.

\section{DESIGN AND FABRICATION OF THE SLS SYSTEM}

The full-scale SLS system was designed on the basis of the experimental data described above and the process requirements for the ORNL waste systems. Early in the project, the system was designed to meet the needs of the GAAT program. After a comprehensive analysis of the ORNL waste systems, it was decided that the SLS system should be applied at the MVST to improve the management of existing supernatant and sluice waters to be received at the MVST during tank sludge consolidation activities. In response to the analysis and the new waste management plan, the SLS system designed for GAAT was modified to meet the needs of the MVST application.

\subsection{FILTRATION LOOP}

The SLS system was designed to provide filtered feed to the CsR and OTE evaporator systems or to filter the supernatant for direct storage in the Melton Valley Capacity Increase Tank system. The typical processing rate achievable for the OTE system was 1 to $2 \mathrm{gal} / \mathrm{min}$; the ion-exchange system was capable of processing a maximum of $5 \mathrm{gal} / \mathrm{min}$. The existing MVST settle-decant system can process up to $50,000 \mathrm{gal}$ of clarified supernatant in a minimum time of about one month. This calculates to a maximum processing rate of about $1 \mathrm{gal} / \mathrm{min}$. Based on CUF test data, a $0.5-\mathrm{Fm}$ Mott filter would be expected to provide filtrate flux in the range of 0.0069 to $0.057 \mathrm{gal} \mathrm{min}^{! 1} \mathrm{ft}^{! 2}$. However, the performance of the filter used in the CUF system was adversely impacted by high-shear forces that are not expected in 
full-scale operations. In addition, a higher fraction of sludge from the MVSTs with larger particle size was anticipated, which was expected to result in a higher range of filtrate flux. Based on these considerations, the design-basis flux range chosen for the full-scale system was 0.02 to $0.1 \mathrm{gal} \mathrm{min}^{! 1} \mathrm{ft}^{\prime 2}$. With this flux range and a filter surface area of $50 \mathrm{ft}^{2}$, the full-scale system was expected to provide the required filtrate flow range of 1 to $5 \mathrm{gal} / \mathrm{min}$.

The standard Mott filter unit, which has a 50- $\mathrm{ft}^{2}$ surface area, uses a bundle of about 30 tubular filter elements, each nominally $3 / 4 \mathrm{in}$. in diameter and $10 \mathrm{ft}$ long. To minimize filter cake buildup on the filter surface, the system was designed for an axial velocity through the tubes of 6 to $10 \mathrm{ft} / \mathrm{s}$. At $10 \mathrm{ft} / \mathrm{s}$, the total axial flow rate would be approximately $410 \mathrm{gal} / \mathrm{min}$. The pump chosen for this service was a Discflo ${ }^{\mathrm{TM}}$ pump, which is designed for pumping fluids with high solids contents and large particle sizes with low-shear requirements. Although progressive-cavity Moyno pumps had been used successfully in small-scale testing, the physical size and cost were prohibitive for a Moyno pump with this flow capacity.

\subsection{FILTRATE AND BACKPULSE SYSTEMS}

Despite the high velocity flow through the filter elements, a layer of solids tends to build up on the surface of the filter elements. In addition, some of the smaller sludge particles penetrate and become lodged in the pores of the filter elements, reducing filtrate production. Therefore, a backpulse mechanism was included with the Mott filter units to periodically remove accumulated sludge. Backpulsing involves the application of a pulse of fluid in the reverse direction of the filtrate flow to push the solids away from the tube wall and into the flow stream, which flushes them out of the tube. The solids removed from the filter are returned to the storage tank where they settle out. Backpulsing requires only seconds to perform. A filtrate reservoir collects liquid for the backpulse, and air pressure is used to force the filtrate from the reservoir in the reversed direction. The reservoir provides a volume of filtrate for the backpulse equal to at least two times the volume held by the filter bundle. Additional filtrate reservoir capacity is provided to prevent introducing air into the filter tubes during the backpulse operation. Backpulsing frequency is determined during startup optimization testing but is typically performed at a frequency of once per hour or less. Frequent backpulsing exposes filter pores to smaller penetrating particles that would otherwise be removed by the layer of solids on the filter surface.

The filtrate that penetrates the filter element bundle collects in the shell side of the unit and flows by gravity to the filtrate collection tank. The collection tank was designed for a working capacity of 100 gal, with a transfer system capable of pumping filtrate to other treatment systems or tank farms in the immediate vicinity of the MVST. To provide a uniform sample of filtrate, a mixing system was also required for the tank.

\subsection{CHEMICAL ADDITION SYSTEM}

In addition to the backpulse system, a chemical cleaning system is required to chemically dissolve sludge particles that penetrate the pores and the filter and cannot be removed by backpulsing. The cleaning system was designed for the use of dilute nitric acid and sodium hydroxide in separate flushes. The use of deionized water was required for flushing the system after cleaning to avoid the precipitation of tap-water carbonate compounds within the pores of the filter. 


\subsection{WASTE FEED SYSTEM}

A separate pumping system was installed within the MVST pump and valve vault to deliver the feed to the filtration loop from the underground storage tanks. With the filtration system installed aboveground, the elevation difference between the system and the MVST liquid level is in the range of 8 to18 ft, depending on the volume of waste in the tank. Early in the design phase, several options were considered for providing waste feed to the SLS system from the MVST. One of the initial concepts involved connecting a pumping system to an existing MVST decant system, which included piping to allow decanting of supernatant from two of the MVST tanks. The diameter of the decant pipes, however, was too small, and replacing the pipes was considered too complex and costly. Another option considered was to provide a new floating suction line for the MVSTs as recommended by SRTC; however, tank access is very limited and physical modifications to the tanks would require physical integrity assessments and major construction expense. One of the more attractive concepts involved the use of the existing progressive-cavity Moyno pumps which, through minor modifications and extensions of existing piping, could provide pressurized feed to the SLS system. In further discussions of this concept, however, several drawbacks to this approach were identified, including (1) the Moyno pumps are not designed for long-term continuous operation and are very expensive to maintain, (2) the low flows necessary for feeding the SLS system (50 gal/min or less) could cause overheating of the DC pump drive motor, (3) the Moynos must be primed with water before starting, and (4) the high-pressure capability of the Moynos presented significant concerns over the possibility of accidentally overpressurizing the SLS system feed piping. In consideration of these drawbacks, it was decided to provide separate feed pumps for the SLS system. Two air-operated double-diaphragm (D/D) pumps (nominal rating, $100 \mathrm{gal} / \mathrm{min}$ each) were specified for the feed system. Through minor piping modifications, these pumps were connected to the existing suction and discharge piping headers used by the existing Moynos. Using the existing piping allowed for interface of the SLS system with any of the eight 50,000-gal waste storage tanks. The only complication of this approach was that the suction legs for this system are located near the bottom of the tanks, well below the level of the accumulated sludge in the tanks. To avoid transferring concentrated sludge to the SLS system, the Moyno pumps would be operated initially to recirculate the sludge in the tank and clear the sludge surrounding the suction leg. After clearing the sludge from the dip leg, the Moynos would be deenergized and operation of the D/D pumps could begin.

Figure 1 shows the flowsheet for the filtration loop and feed system. The feed rate from the waste tank to the cross-flow filtration loop (using the D/D pumps) was specified for a flow of 30 to $50 \mathrm{gal} / \mathrm{min}$. Since the maximum filtrate production rate was expected to be about $5 \mathrm{gal} / \mathrm{min}$, the concentrate production rate (feed rate minus filtrate rate) was only slightly less than the feed slurry rate. Consequently, the solids concentration of the concentrate is only slightly higher than the solids concentration of the feed slurry. The concentrate stream is returned to the tank from which the feed is taken; therefore, a gradual increase in the solids content of feed is expected. The rate at which the solids content rises will depend upon the extent to which the suction leg remains clear of sludge, the amount of liquid in the tank, and the extent to which solids settle in the tank before the liquid is pumped through the filter again. 


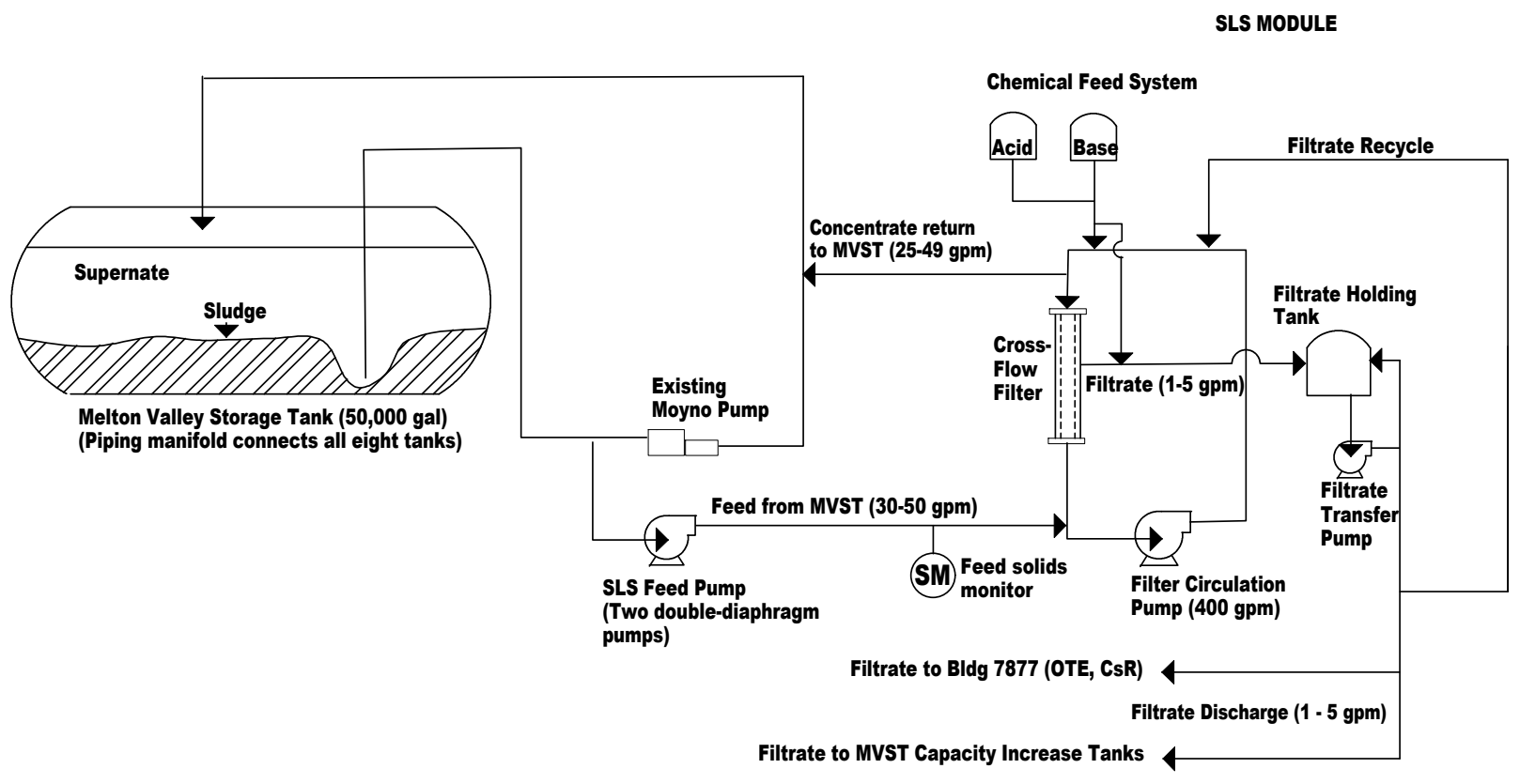

Fig. 1. Flowsheet of SLS filtration loop and feed system.

\subsection{EQUIPMENT SPECIFICATIONS FOR THE SLS SYSTEM}

Based on the above design factors, an equipment specification ${ }^{7}$ was developed to define minimum requirements for the design, fabrication, testing, inspection, and delivery of the SLS system. The specification called for a stainless steel skid-mounted system with radiation shielding and an enclosure for contamination control. According to the specification, the system was to have the following functions: 
C process a radioactive supernatant feed from a company waste tank at the rate of 30 to $50 \mathrm{gal} / \mathrm{min}$ containing 0.1 to $10 \mathrm{wt} \%$ suspended solids,

C minimize radiation exposure to workers and the environment,

C protect process equipment from adverse environmental conditions,

C operate by remote control using a PC-based control system,

C produce a filtrate stream at a rate of 1 to $5 \mathrm{gal} / \mathrm{min}$,

C maintain an axial velocity in the cross-flow filter tubes of 6 to $10 \mathrm{ft} / \mathrm{s}$,

C operate at filter inlet pressures of up to $50 \mathrm{psig}$ (subject to filter vendor's recommendations), and

C operate at a filter axial pressure drop of \#10 psi (subject to filter vendor's recommendations).

Additional design and equipment requirements taken from the specification are provided in Appendix C.

\subsection{DESIGN AND FABRICATION BY NUMET}

The equipment specification was submitted to ORNL Procurement for open competitive bid by private industry. There was no attempt to sole-source the contract because many potential suppliers had the capability of designing and fabricating this type of system. In June 1997, bid requests were sent to TTI Engineering; Cumberland Valve and Fitting; NUMET Engineering Ltd.; Ionics, Inc.; International Technology Corporation; Carl Eric Johnson Company; Chem Nuclear; and Harmony Corporation. Surprisingly, only two bids were received, and NUMET Engineering was awarded the design contract based on technical and cost considerations. NUMET's estimates for design and fabrication were $\$ 145 \mathrm{~K}$ and $\$ 790 \mathrm{~K}$, respectively. Since only enough funding was available to pay for design of the system in FY 1997, the contract included an option to build in FY 1998, pending receipt of the necessary funds for fabrication. NUMET proceeded with design activities in September 1997. In October, NUMET offered to perform detailed shielding calculations to optimize shielding design. The specification called for providing the equivalent of 1-in. thickness of lead for shielding the high-radiation sources such as the filtrate holding tank and the filter modules. Optimizing the shielding thickness would avoid unnecessary weight and costs from potential overshielding of the system. ORNL agreed to fund the cost of the shielding calculations and the revisions in design of the shield walls. Since ORNL was experiencing problems with disposal of contaminated lead at this time, NUMET was asked to use steel instead of lead to construct the shield walls. Other smaller design changes included addition of a high-level alarm for the filtrate holding tank, addition of containment pan moisture detection devices, additional 2-in. access ports on top of the outer enclosure, and two additional manual valves for draining the system in the event of process valve actuator failure. These changes resulted in an estimated additional cost of $\$ 39,600.00$ for design and fabrication.

The design was completed in December 1997, and funds for fabricating the system were received in January 1998. NUMET then immediately began to prepare manufacturing drawings, order supplies, and prepare technical specifications for key components such as control valves and instrumentation that had not been designated in the ORNL procurement specification. These specifications were submitted for review by ORNL prior to ordering by NUMET. Fabrication activities began in April 1998 following ORNL review and approval of manufacturing drawings. Delivery of certain valves and tanks took longer than expected, and revisions to the equipment design had to be made to accommodate changes in the design of ball valves and to rework deficiencies in the valves provided by the manufacturer. This delayed the fabrication schedule by several months. 
ORNL visited the NUMET fabrication facility on two occasions to review quality-assurance (QA) documentation and to inspect the equipment after certain phases of the construction. A QA deficiency resulted from a misunderstanding in the interpretation of weld inspection requirements. NUMET had expected to visually inspect only $5 \%$ of the welds according to their interpretation of the design code ASME B31.3 called out in the specification. However, the text of the specification required visual inspection of all welds. NUMET conceded to perform $100 \%$ visual inspection, but the schedule was delayed an additional month due to the number of welds (551) and the difficulty of inspecting the welds in small-diameter piping.

On November 30, 1998, fabrication and component checks were completed, and a five-person team from ORNL visited the NUMET facility to make a final QA surveillance and perform acceptance testing of the system. Fabrication of the outer enclosure was in progress at this time, and the shield walls were not in position during the testing to allow for correcting potential problems with instruments and process equipment. NUMET had previously submitted a detailed plan for acceptance testing, which had been reviewed and approved by ORNL. NUMET had also performed hydrostatic testing of the system, operational checks of system components (valves, actuators, pumps, switches, alarms, etc.), and calibration of instruments and had prepared a detailed record of the test results. The acceptance testing involved operating the SLS system with filtered, deionized water as the process fluid while evaluating the performance of individual components as well as the integrated system.

Control system tests involved evaluating the system performance in various computer-automated operational modes. The control system included a computer-based operator interface using FIX-32 software by Intellution. The software was installed on a personal computer with an I/O module (MTL, Inc.) for interfacing the control system with the process equipment. The user interface consisted of a color monitor, mouse, and graphical user interface (GUI) flowsheet display, including updated instrument readouts, valve status, alarms, and data archiving. The GUI display for the filtrate production mode is shown in Appendix D. The control program was written to provide automated operation of the system in several different modes or cycles. There are separate automated cycles for filling the system with water, filling with waste feed, draining the system, draining the filtrate tank, chemical cleaning, and filtrate production. A supervisory mode is provided to set the critical operating parameters, and manual operation is also provided to allow the operator to manipulate any of the individual system components (valves, pumps, samplers, etc.).

Alarms and emergency shutdown systems were tested in many different modes of operation. The video camera systems located within the system enclosure were also tested. One of the cameras was repositioned to provide a better view of the system piping. Several problems identified in execution of the automated cycles were corrected and retested. Minor improvements to the GUI screen layouts were requested. Quality assurance inspections and documentation were finalized, and the shipping plan was reviewed and approved prior to formal acceptance of the system. The system was shipped to ORNL on December 16 and was unloaded onto the new foundation adjacent to the MVSTs on December 30. Several weeks after shipment of the system, NUMET provided manuals for installation, operation, and maintenance of the system (in accordance with the contract). The manuals provided important detailed descriptions of the system, instructions for installing and commissioning, detailed operating instructions, trouble-shooting instructions, drawings, and vendor manuals for each component of the system with an index showing the component number and section number for the manuals. NUMET also provided a manual of historical data submittals, including inspection results, certifications, calibration data, hydrostatic test results, material traceability logs, and other information. These manuals were critical to 
the timely completion of installation, readiness assessments, and startup of the system. The table of contents for these manuals is given in Appendix E.

\subsection{DESCRIPTION OF SYSTEM}

The process flowsheet and instrumentation drawing, isometric drawing of the SLS piping system, and system enclosure drawing prepared by NUMET are provided in Appendix D. Photographs of the system are shown in Figs. 2- 4. The system was constructed on a single skid about $20.5 \mathrm{ft}$ long, $10.5 \mathrm{ft}$ wide, and $12.5 \mathrm{ft}$ high. The cross-flow filter consists of two Mott HyPulse LSX Filter modules connected in series, each consisting of a $5 \mathrm{ft}$-long-bundle of 31 elements with a 0.75 -in. outside diameter and a $0.5 \mathrm{Fm}$ pore size. The tube side of the filter modules is connected to the circulation loop and the Discflo pump. The shell, or filtrate, side of the modules is connected to the filtrate holding tank with a working volume of $120 \mathrm{gal}$. A $30-\mathrm{gal} / \mathrm{min}$ filtrate transfer pump is connected to the filtrate holding tank with a recirculation loop for obtaining optimum pump performance and maintaining a uniform filtrate composition. The Mott filter modules are enclosed on four sides by heavy shield walls. The filtrate tank, Discflo pump liquid end, and larger-diameter piping (4 in. diam) are also located within a heavily shielded enclosure. The filtrate pump, feed piping (1.5 in. diam), concentrate return piping (1.5 in. diam), filtrate piping (0.5 in. diam), sample tubing (0.375 in. diam), and various valve actuators, control valves, flow transmitters, and other instrument components are located in a shielded maintenance area. Since many of the components in this area may require maintenance, a shielded door (about 1.5-in.-thick steel) was included for access. The filtrate tank and filter modules were not expected to require frequent maintenance and do not include access doors. These areas can only be accessed by making a confined space entry over the shield wall or by removing one of the shield walls by overhead crane.

Three Isolok (Bristol Equipment Company) sample devices are provided in a central location near the shielded area doorway. Tubing for sampling the filtrate, feed, and concentrate liquids is connected to the samplers from high- and low-pressure taps on the system to establish flow through the sample cell and collect real-time samples. The samples are deposited into bottles within a shielded cabinet. The system is automated by the control system and provides interlocks to prevent sampling while the shielded cabinet door is open. The system also provides an audible alarm if liquid is detected in a containment pan located under the sample bottle rack.

The chemical feed system consists of two 50-gal tanks for acid and caustic solutions with positivedisplacement transfer pumps piped from the tanks to the SLS system. Chemicals can be fed to both the filtration loop piping and the filtrate piping systems. External to the SLS system, a small deionizer/filter system is provided for treatment of tap water used for preparation of chemicals and for the final rinse or long-term lay-up solution for the filter modules.

Magnetic flowmeters are used for monitoring the process water supply flow, feed flow, concentrate flow, filtrate flow, and axial flow of the system. A Coriolis mass flowmeter by Endress+Hauser is installed on the feed piping outside the SLS enclosure to monitor the mass flow and suspended solids content of the feed. Pressure sensors are provided for the Discflo pump discharge pressure, the transmembrane pressure, the backpulse air reservoir pressure, and the axial-flow pressure drop across the filter modules. A level controller is provided for the filtrate tank, and level monitoring is provided for the chemical 


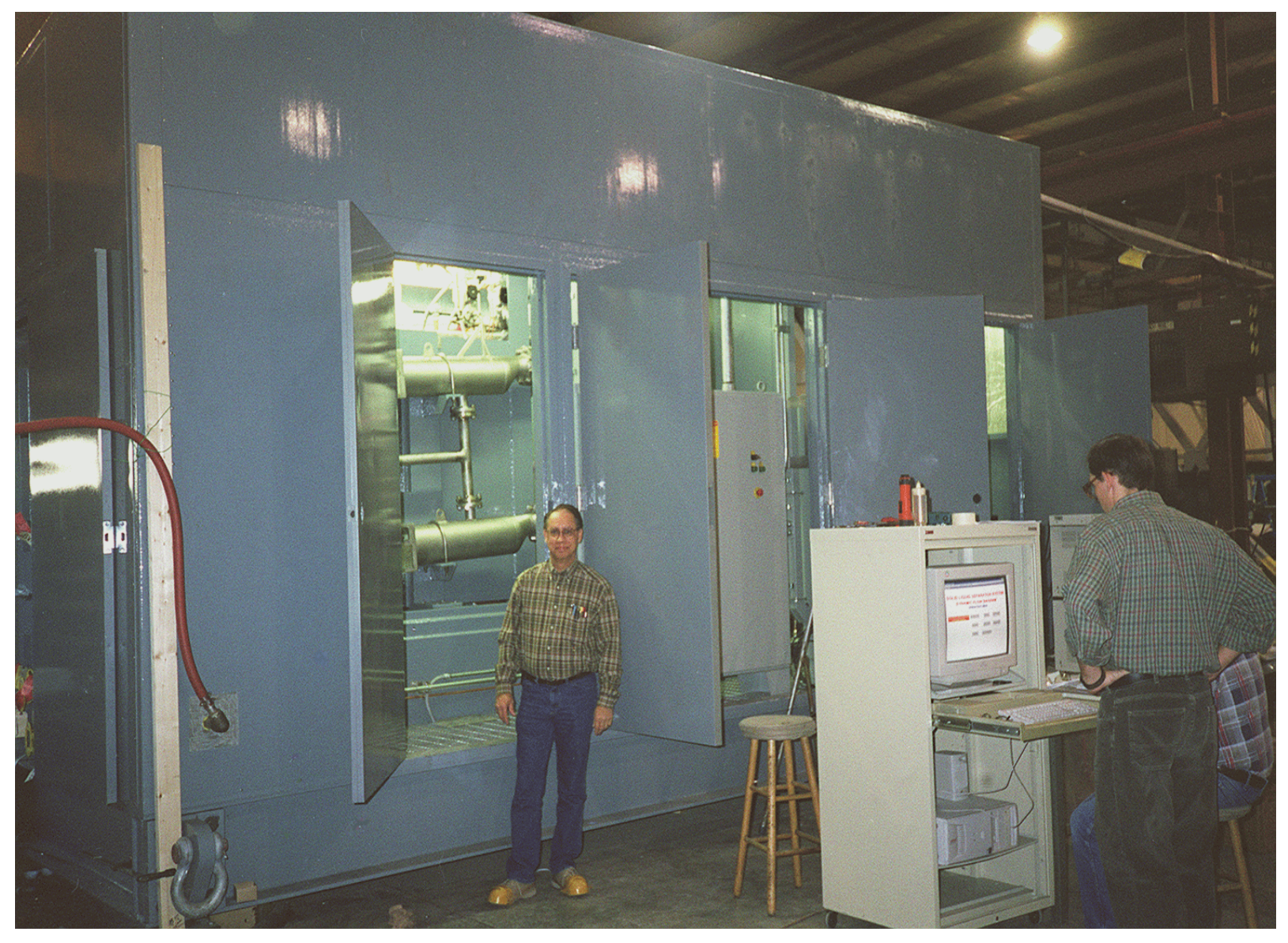

Fig. 2. SLS system during acceptance testing at the NUMET facility. 


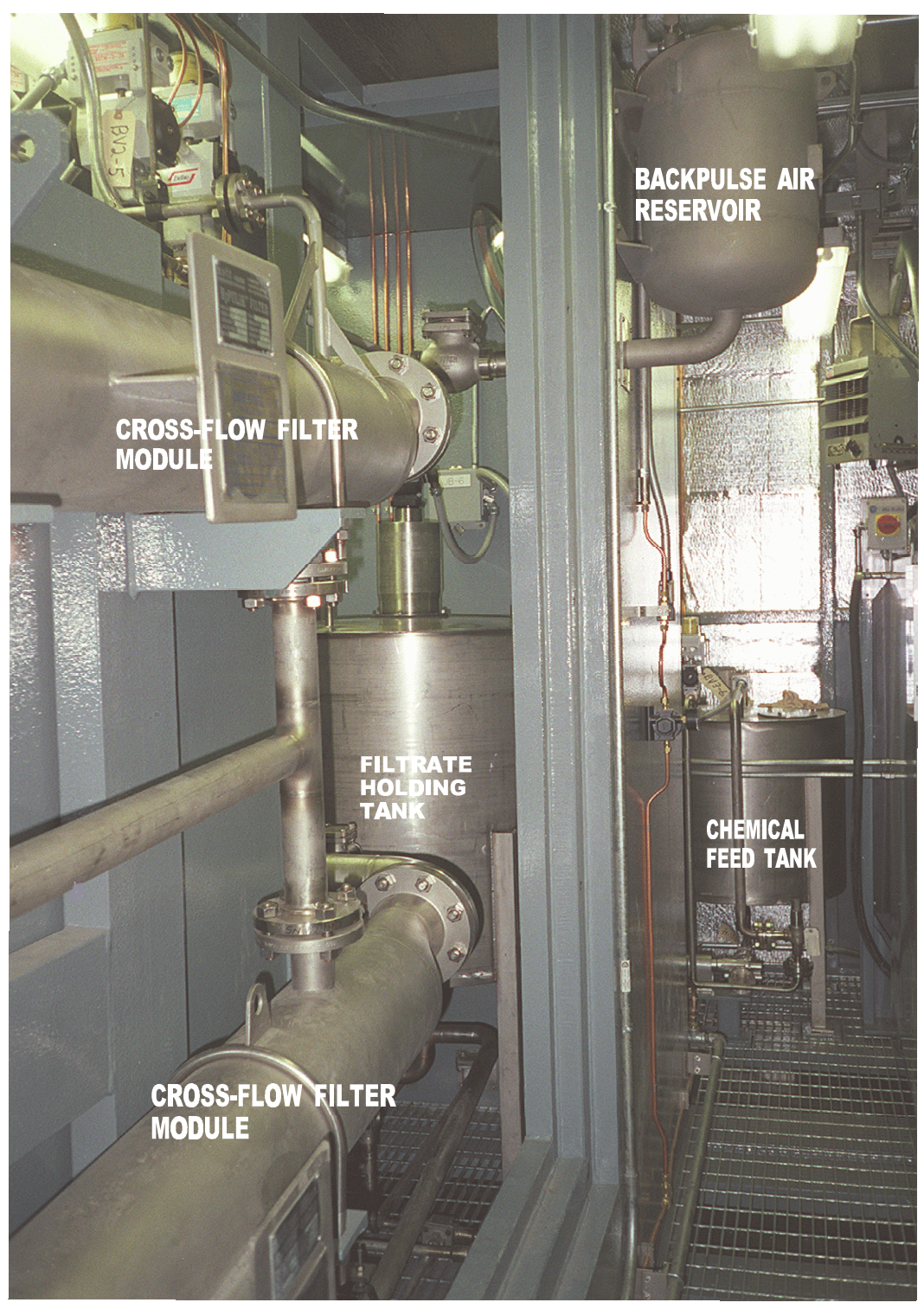

Fig. 3. SLS system components prior to installation of shielding. 


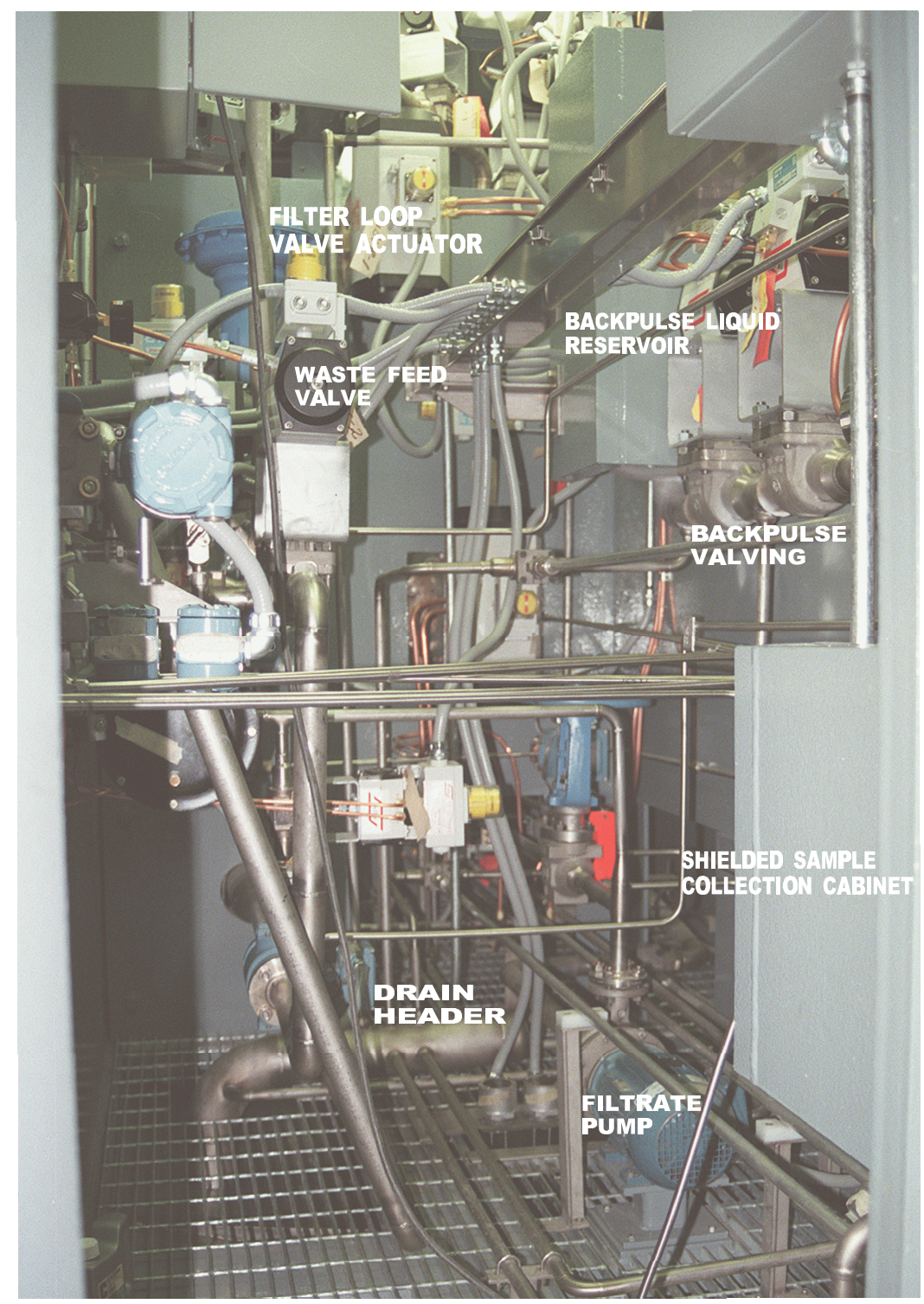

Fig. 4. Shielded maintenance area of the SLS system. 
feed tanks. Ultrasonic sensors are used for level detection. A temperature indicator is provided for the filtration loop to monitor the temperature increase from Discflo pump operation. To automate the filling and draining processes for the system, flow sensors and switches are provided on the principal vents and drains of the system. A backpressure control valve is provided on the concentrate return piping, and a filtrate control valve is provided on the filtrate discharge piping. For visual monitoring of the system, a pan-and-tilt camera is provided for the shielded maintenance area and a fixed camera is provided for the chemical feed area. After the system was received at ORNL, modifications were made to include a pan-and-tilt camera for the heavily shielded filtrate tank area and to add pan- and-tilt capability for the camera in the chemical feed area.

\section{INSTALLATION OF SLS SYSTEM AT THE MVST FACILITY}

\subsection{DESCRIPTION OF FACILITY}

The MVST facility consists of eight 50,000-gal stainless steel horizontal tanks, each about $60 \mathrm{ft}$ long and $12 \mathrm{ft}$ in diameter. The tanks are built within an underground concrete vault with a stainless steel liner for spill containment. The walls and ceiling of the vault provide containment and radiation shielding. The facility also includes a pump-and-valve vault (PVV), where piping is routed for the tank feed lines, drain lines, sample lines, and other connections. The waste transfer piping for the tanks is routed within the PVV to two large progressive-cavity pumps designed for cross-site and intertank transfers. The vault also includes a HEPA-filtered ventilation system for control of airborne contamination. An above-ground control room (Building 7830) housing the tank level instrumentation, ventilation system controls, and pump controls is located adjacent to the south side of the vault. A photograph of the MVST facility is shown in Fig. 5.

In the early 1980s it became apparent that a supernatant treatment system was needed to create additional storage capacity in the MVSTs. In response to this need, Building 7877 was constructed adjacent to Building 7830 as a containment facility for mobile grouting systems. To provide clarified supernatant feed to the grout facility, a decant system was added to the MVSTs. The decant system included the installation dip-leg piping into tanks W-29 and W-30 to allow decanting of about one-half of the working volume of these tanks. The dip legs were piped to a shielded double-diaphragm pump located within a containment structure on top of the vault. The discharge piping of the pump was routed within a shielded pipe chase along the top of the vault into Building 7877. The equipment and materials for the grouting operation were provided through a subcontract to a private service company specializing in mobile radioactive waste treatment services. After several grouting campaigns, the modular OTE system and CsR system were installed in this building for processing the MVST supernatant as an alternative to the grouting process. These systems reduced the volume and activity of the MVST supernatant such that additional grout campaigns were not necessary. An additional tank farm, the Melton Valley Capacity Increase Project (CIP), was placed in service in 1998 for future storage of LLLW. The MVST and CIP were piped together to allow transfer of waste liquids between tank farms. The SLS system was designed to filter supernatant from any of the eight MVSTs and provide filtered feed to the OTE and/or the CsR system for additional treatment or the CIP for storage.

\subsection{DESIGN OF SLS/MVST INTERFACE SYSTEMS}

Design of the piping, electrical, and structural interfaces between the SLS system and the MVST facility was provided by ORNL Engineering. This involved evaluation of several plans for locating and piping the system and selecting the most practical and cost-effective option. It was decided to locate the SLS 


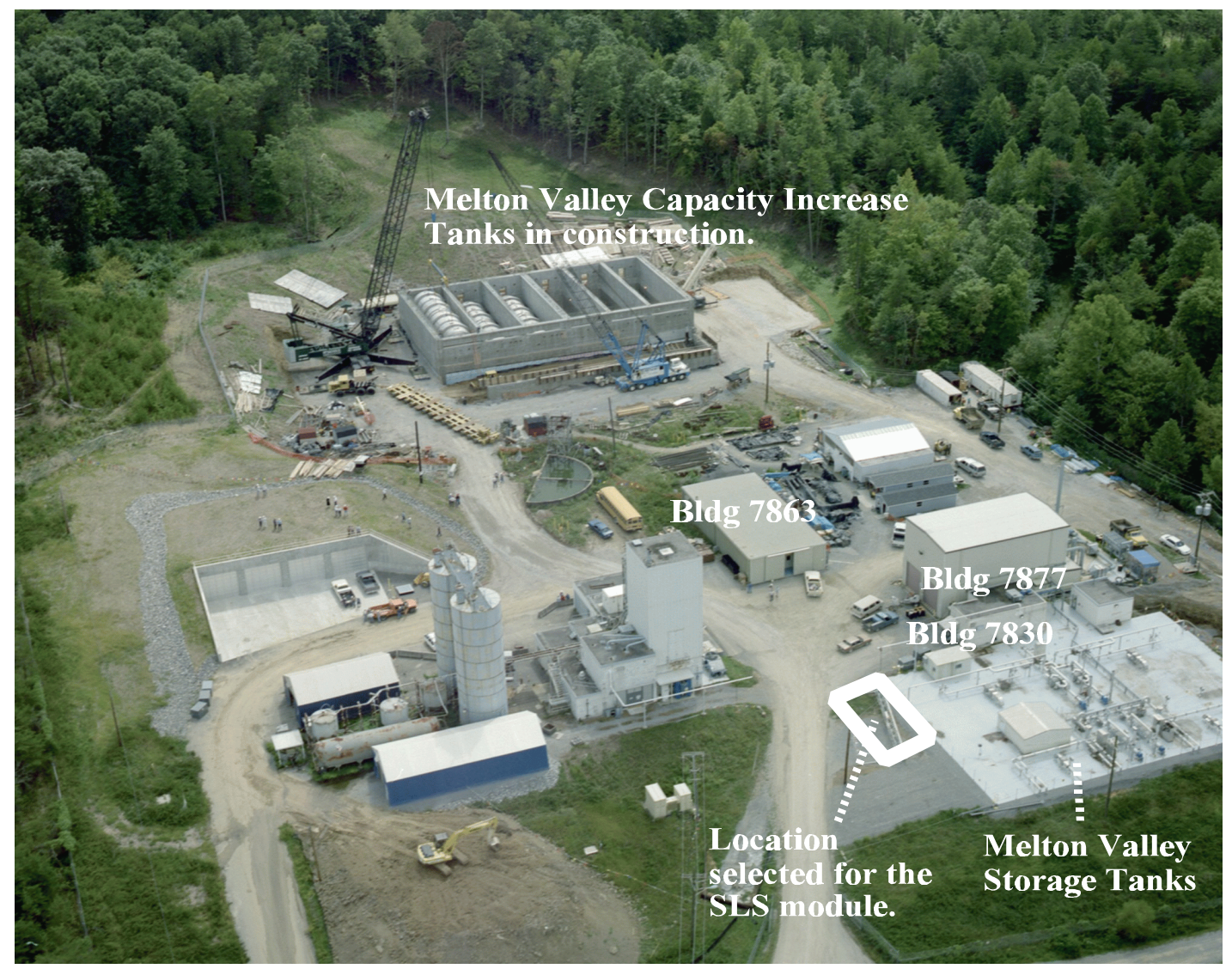

Fig. 5. Aerial view of Melton Valley Storage Tank facilities. 
system on a new foundation adjacent to the east end of the MVST tank vault and to install the feed pumps and interface piping within the existing PVV. The design for this option was reviewed by ORNL Safety Engineering to determine its impact on the facility safety basis and associated documentation for the MVST facility (Building 7830), which is a Class II nuclear facility. Several design modifications were made to the interface systems to improve containment and reduce the risk to personnel and the environment from the potential consequences of tornados, earthquakes, and other accident scenarios. In addition, several facility safety documents required revisions to incorporate the SLS operation. New processes such as the SLS system that involve modifications of a Class II facility cannot be started until the affected safety documents are approved. These revisions required several months to implement and involved careful preparation, ORNL site review and approval, and DOE-ORO review and approval. Revisions of the Building 7830 Operational Safety Requirements and the Building 7856 Technical Safety Requirements were necessary for the SLS system. In addition, preparation of two Unresolved Safety Question Determination documents were required for installation and operation of the SLS system.

\subsection{CONSTRUCTION OF SLS FEED SYSTEM}

Installation of the feed system was to involve piping the discharge of the D/D pumps, located belowgrade in the PVV, to the SLS module located above-grade and adjacent to the northeast corner of the MVST tank vault. Connecting the D/D pumps to the SLS module would require that several hundred feet of rigid stainless steel (SS) pipe be routed within the PVV, where working space is limited and the background radiation is high. Because the facility is classified as a Class II nuclear facility, special welding procedures and QA inspections would have resulted in planning for lengthy stay-times in the PVV. To reduce worker exposure and piping costs, the use of flexible piping materials compatible with the MVST radiological/chemical conditions was evaluated and approved as a suitable alternative to SS piping. A limited amount of hard piping was provided for short interface connections and at locations where the piping penetrates the vault roof. A drawing of the feed system and SLS system interface piping is provided in Appendix D.

A work order for installing the SLS unit and feed system was prepared for MK-Ferguson (MKF), the ORNL site construction contractor. Fortunately, MKF had just completed a construction project at a similar facility with similar site conditions and radiation hazards. Consequently, a group of trained and experienced mechanical and electrical workers were available to begin work almost immediately. A construction specification ${ }^{8}$ was prepared by ORNL Engineering, and a cost estimate was prepared by MKF prior to beginning the work. MKF's initial cost estimate, including labor and materials, was $\$ 537,000$. MKF was given authorization to begin work in September 1998, and construction of the concrete foundation for the SLS unit was completed on November 30. The unit (weighing over 40 tons with shielding) was unloaded by crane from the transport truck and placed on the foundation on December 30, 1998.

\subsubsection{Connections in Pump-and-Valve Vault}

Working within the confines and moderately high radiation background of the MVST PVV required careful planning, preparations, and special designs. Access to the PVV was limited to two $4 \times 4 \mathrm{ft}$ hatches located in the top of the 3-ft-thick cover at each end of the tank vault. To reduce radiation exposure, the PVV interior floor and piping was initially washed down with high-pressure water, and lead blankets were placed on hot spots of the existing piping system. To reduce the time in the PVV during installation, the piping for the SLS feed system was fabricated in sections that had to be small enough to fit through the vault hatches. Once in the vault, the piping sections were connected using 
either standard flange connections or a "lock-ring" technique as an acceptable alternative to welding. The lock-ring is a compression pipe fitting suitable for use in high-pressure systems. It is ASME approved and is widely used in the U.S. Navy and in commercial nuclear power plants. Flexible piping sections with flanged connections were used for the lengthy sections of transfer line. Pipeline hangers were used to support the flexible pipe and facilitate gravity draining to the tank system. Manual ball valves used in the SLS piping within the PVV were designed for operation from the top of the vault. A Teleflex remote operator system was used, which consists of a valve station actuator mounted to the valve in the PVV, which is connected to a operator station actuator (located on the vault roof) via a helix steel cable in a lined jacket. The operator actuator converts rotary motion to linear motion, and the valve actuator reconverts the linear motion to rotary, thereby turning the valve stem. Each valve extension and piping penetration required a core drill through the 3-ft-thick vault roof. Fourteen core holes in the vault were required for installation of the Teleflex operators and piping interfaces.

The 2-in. diam suction piping of the two D/D pumps was connected to a spare valve on the suction manifold of the existing MVST Moyno pumps. The discharge of the D/D pumps was routed through 2 -in. flexible pipe to the rigid SS piping that penetrated the vault roof and interfaced with the feed piping for the SLS system. An Endress+Hauser Promass 63, model F Coriolis mass flowmeter sensor was mounted in the feed pipeline within the PVV in a vertical position about $1 \mathrm{ft}$ below the vault penetration. To allow for routine calibrations and maintenance, the flowmeter transmitter was installed inside the SLS cubicle adjacent to the main controls interface cabinet outside the shielded areas. The waste feed line also included a pressure relief valve with 150-psig set pressure mounted just below the mass flowmeter sensor in the PVV. The 2-in. SLS concentrate return line was routed through the vault roof and into the PVV, where it was connected to a spare pipeline and valve that, in turn, was connected to the existing discharge header piping for the Moyno pumps. A 1-in. filtrate line was routed from the SLS system through the vault roof, into the PVV, and then through 1-in. flexible pipe to a location in the proximity of the D/D pumps. At this point, the filtrate line was split at a tee and valved to allow flow to either Building 7877 (OTE and CsR) or the MVST Capacity Increase Project (CIP) tank system. The Building 7877 filtrate line penetrated the vault roof and was routed through shielded piping into the building via a small piping alcove. A remote operated valve was installed on the pipe within the alcove and routed directly to the CsR system feed tank. The filtrate line to the CIP system was interfaced with an existing pipeline within the PVV, which allowed for transfer to the CIP tanks. A 4-in. drain line from the SLS system containment pans and drain piping was routed through the vault roof to a tee connection where the flow combines with the concentrate discharge fluids that are routed back to the tank from which the feed is taken. The drain line was also sized to provide the ventilation air space connection between the SLS system and the PVV. The PVV uses an existing ventilation system with HEPA filtration to control potential airborne contamination. A level detector was installed within the 4-in. drain line to detect backup of fluid in case the discharge piping became plugged with sludge or a valving error was made. Backup overflow piping connected to the SLS drain line routes the waste liquids to the existing sump within the PVV. A level detector in the sump will sound an alarm at the Waste Operations Control Center (WOCC) to alert them that the sump level is rising. The WOCC would then alert operations to shut down the SLS system.

All piping spool pieces and flexible piping sections were inspected and hydrostatically tested prior to being installed in the PVV. MKF had completed the fabrication of the piping sections and most of the vault core drilling and had begun installing the piping in the PVV by mid-February. Core drilling and installation of Teleflex valve operators took longer than expected due to the need to relocate the core holes to avoid embedded conduit within the concrete vault. Some of the in-vault piping had to be modified to mate the Teleflex operators with the valves. Interface piping at the SLS system module was 
completed in February; however, routine waste transfer activities delayed MKF construction activities by several weeks due to the high radiation fields in the PVV during the transfers. By the end of March, MKF had completed the PVV piping required in the original contract, but an additional valve was needed to ensure isolation from the existing Moyno pump discharge piping. Utility tie-ins were also completed in March. During April, MKF installed the additional valve and added access platforms and framework for shielding the process interface piping. MKF completed leak repairs, pipe labeling, and installation of shielding around the process interface piping to complete the work scope by the end of May. Photographs of the installed system are shown in Figs. 6-9.

\section{PREOPERATIONAL TESTING}

Preoperational testing of the SLS system components began in March 1999 as soon as MKF had made the necessary electrical tie-ins for the system. In early April, MKF completed temporary connections of the SLS system to water and air supplies so that testing of the system operation could begin. A "cold" test plan was prepared which included leak-testing, calibration, and testing of safety-related instrumentation, testing of alarm and shutdown systems, and testing the SLS control system using clean process water. Leak-testing revealed several leaks in the MVST interface piping system that were promptly repaired by MKF. Several control system issues were encountered that required control program modifications to interface with valves and instruments of the SLS feed system and to interface the controls with the OTE and CsR operations. A representative from NUMET provided onsite support for the program modifications (as part of the original NUMET contract).

Several weeks after beginning the control system checks, the hard drive of the computer provided by NUMET for the control system failed and the computer had to be replaced. In addition, the level sensor installed in the filtrate holding tank malfunctioned and was replaced with the same type of instrument (ultrasonic), but a different manufacturer. The original level instrument with sensor and transmitter was installed on top of the filtrate tank, within a shielded area. To improve maintainability, the transmitter for the replacement instrument was installed outside the shield wall with only the sensor located at the filtrate tank. The pressure of the instrument air supply for the facility at the MVST, at 90 to 95 psig, was found to be insufficient for operating some of the larger pneumatic valves of the SLS system. To boost the air pressure, a small air compressor was installed within the SLS module and piped to the SLS air supply piping.

After the repairs and modifications had been completed, the SLS system was operated with water to test each of the eight automated operating cycles while interfacing with systems in Building 7877 and at the CIP tank system. During the final follow-up leak check of the SLS feed piping, two additional leaks (that had not shown up during the initial checks) were identified. One of these leaks, located in the PVV piping, was easily repaired; however, the second leak involved a pressure relief valve on the SLS piping that had begun prematurely unseating at pressures below its set point. This was caused by earlier leak-testing, where the valve was repeatedly pressurized up to the pressure at which it was set to relieve. The relief set pressure was $100 \mathrm{psi}$, and leak checks of the piping system were performed at the line pressure of the process water system (usually $100 \mathrm{psi}$ ). Since the valve was slightly contaminated internally, it could not be reset and had to be replaced, which caused a several-day delay in the schedule. 


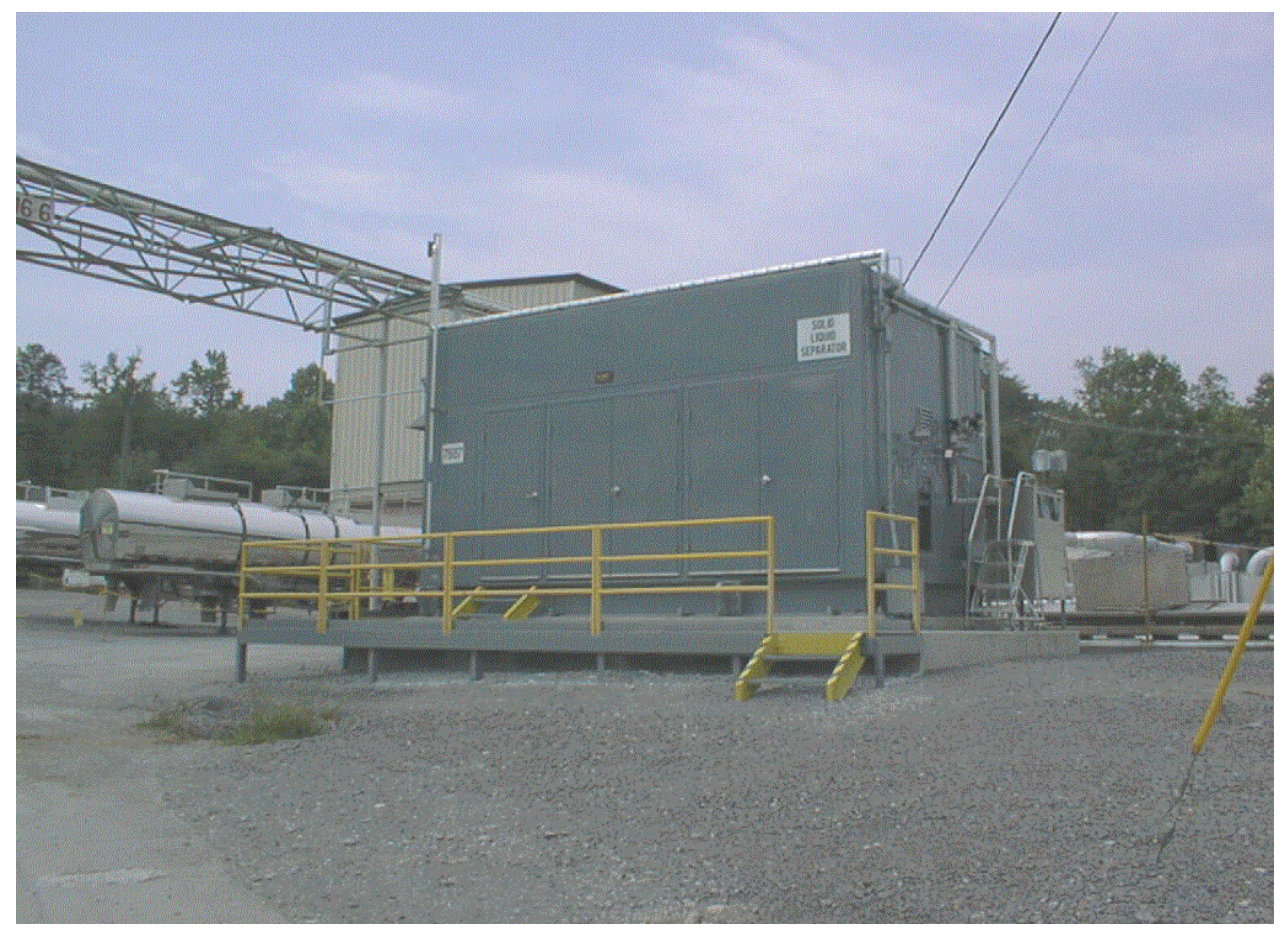

Fig. 6. East side of SLS system installed at the MVST.

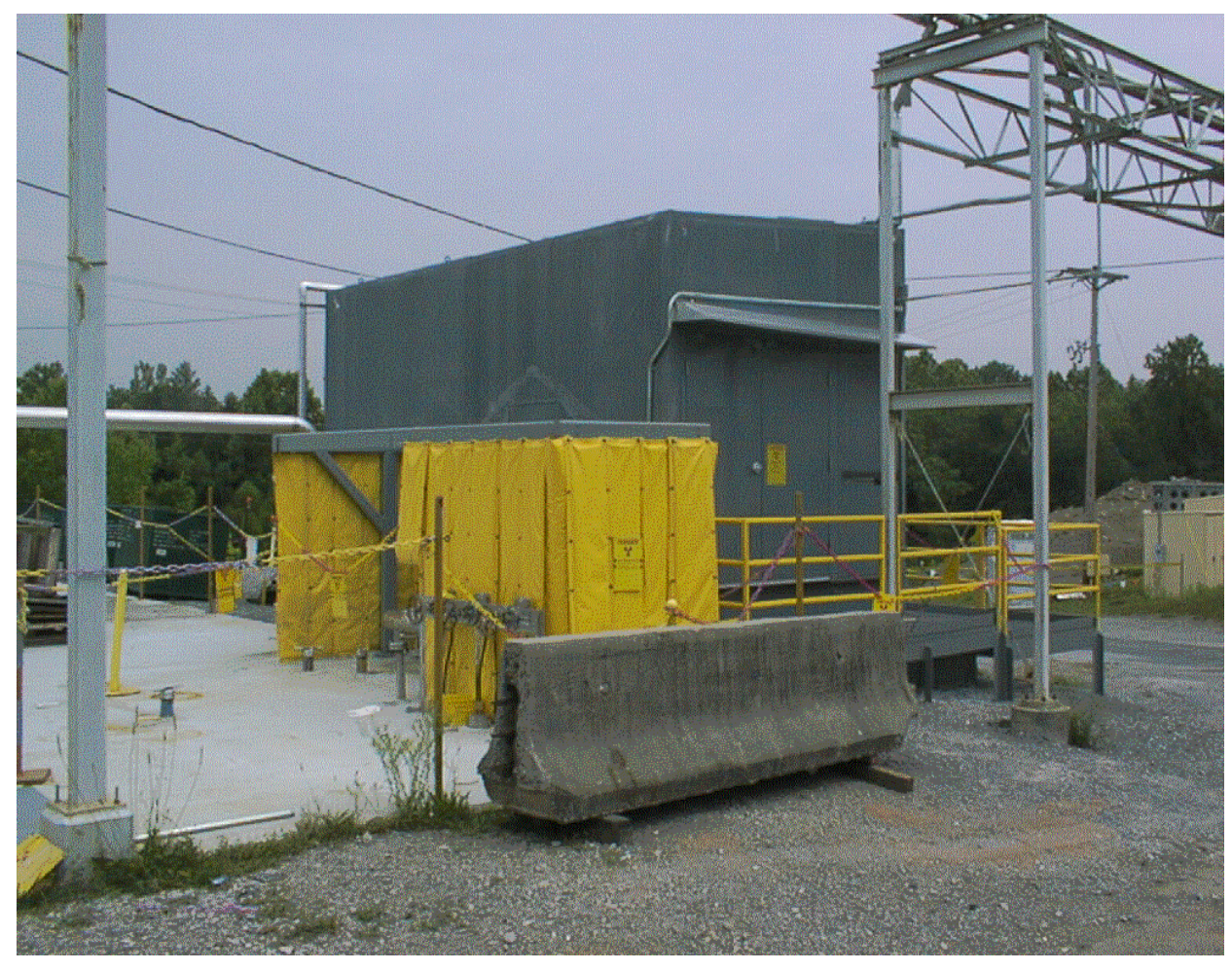

Fig. 7. West side of SLS system with MVST vault interface piping and shield partition. 


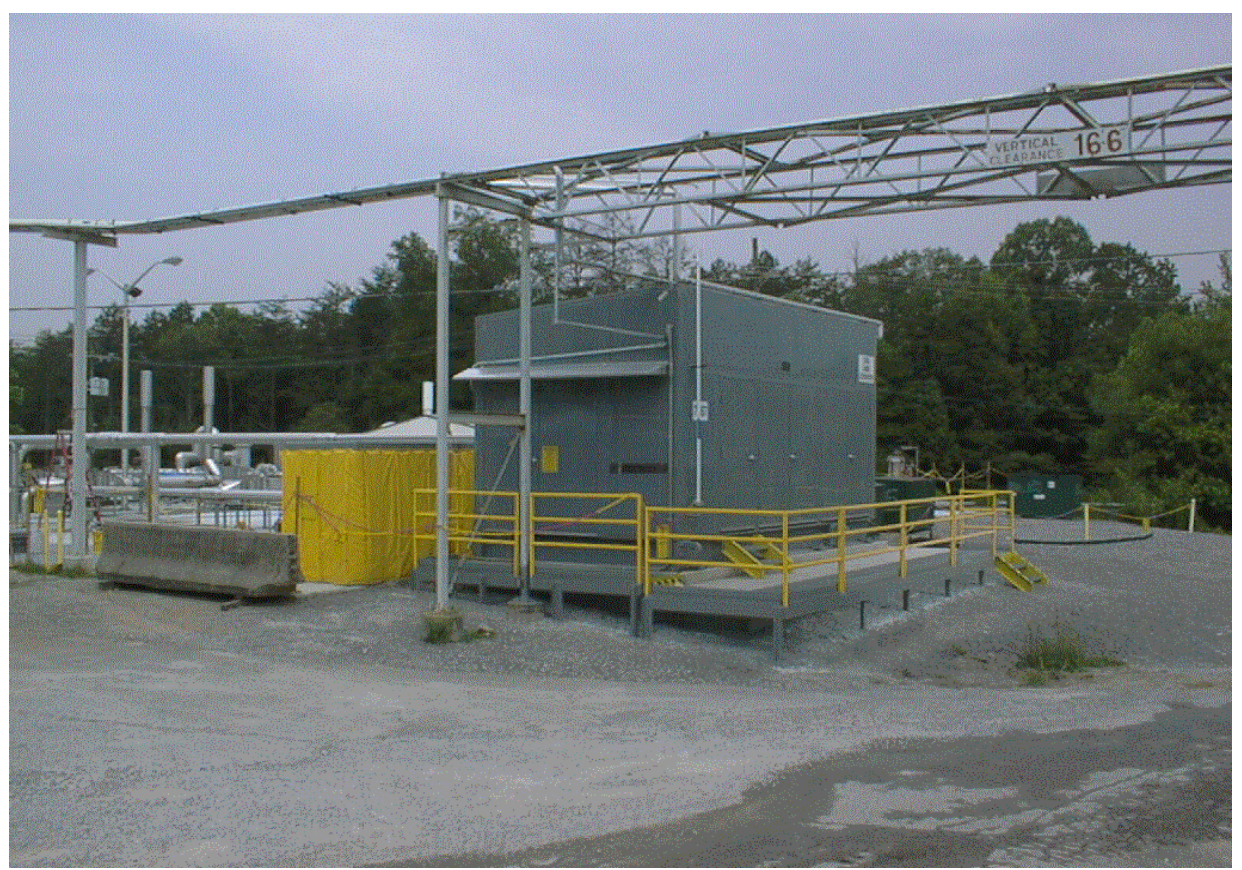

Fig. 8. North side of SLS system with access to sample cabinet and shielded maintenance area.

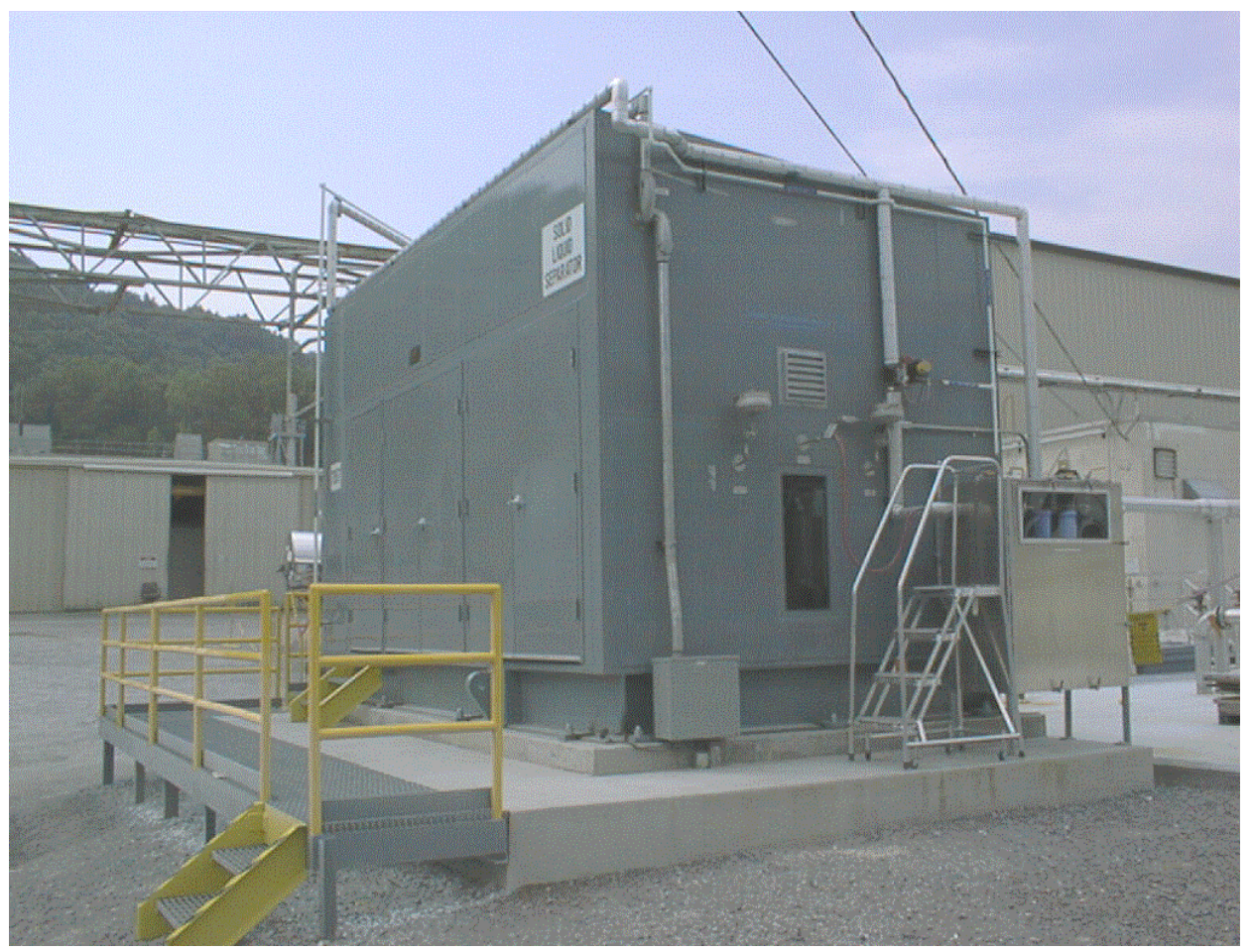

Fig. 9. South side of SLS system with deionized water and chemical feed station. 


\section{PROCEDURES AND TRAINING}

Because the SLS system was eventually to become the responsibility of the Bechtel Jacobs Company (BJC) Liquid and Gaseous Waste Operations Project (LGWOP), the operating procedures were prepared using a format consistent with that used by LGWOP. This task saved the time and cost of future procedure revisions. In addition, the LGWOP Training Department assumed responsibility for preparing the training plan and coordinating the training of both CTD and LGWOP operators. CTD assisted in the preparation of training materials and performed the actual classroom and on-the-job training of the operators.

Preparation of procedures was made easier by obtaining an electronic file of the SLS operating procedures prepared by NUMET and revising them to include changes to the control system programming, to add procedures for operating the feed system, and to achieve the proper format. The procedures included a review of the job hazards, review of facility safety requirements, preoperational checks, valving alignment and verification, step-by-step operating instructions, data collection instructions and log sheets, and emergency procedures. After the first draft had been prepared, the procedures were validated by using them to simulate actual startup and operations. Following validation, the procedures were issued and used as a basis for operator training. After the classroom overview training, operators completed a Procedure User Examination (PUE), which involved reading the procedure and completing a written test on the procedure. A Performance Documentation Checklist (PDC) was prepared by LGWOP Training and used to document on-the-job training. The PDCs include a detailed list of operational tasks that must be performed correctly and witnessed by a "subject matter expert" from CTD. The BJC operators completed the PDCs during hot operations.

\section{READINESS SELF-ASSESSMENT}

The Readiness Self-Assessment, which is required by DOE orders, involves preparation of documentation ensuring that equipment and personnel are ready and management controls are in place for the start of hot operations. There are different levels of rigor for these assessments, depending on the potential safety, environment, facility, and cost impacts of the operation. Based on the characteristics of this project, a Readiness Self-Assessment was recommended and accepted by DOE-ORO. The equivalent of this task for BJC LGWOP was an Internal Field Evaluation (IFE). Since BJC had very recently become responsible for operation of all waste systems at ORNL, DOE-ORO worked closely with BJC to ensure that the IFE was sufficiently rigorous and satisfied the intent of a complete self-assessment. DOE-ORO provided a Readiness Criteria list to BJC to use as a guide for the self-assessment.

The criteria list was broken down into three categories-Personnel Availability and Training, Procedures and Management Controls, and Facilities and Equipment. STEP, Inc., was subcontracted by ORNL to coordinate the assessment based on their experience in coordinating similar assessments with BJC and DOE-ORO. Using the DOE criteria list, STEP personnel created an index showing the criteria and the appropriate documentation and evidence that must be collected to satisfy the criteria. Appendix F includes the latest draft of the index. STEP worked with CTD to prepare and collect the necessary documentation and evidence for the criteria. The IFE process involved organizing a Line Management Team to collect the evidence, an Independent Review Team to review the evidence collected for the criteria, a BJC Evaluation Review Board to approve the evidence, and a DOE Evaluation Review Board to review and approve the entire IFE process and evidence. This was an intensive and costly effort that 
began in February and ended in June 1999. On June 7, 1999, with DOE approval of the assessment, BJC management gave approval for SLS hot operations.

\section{OPERATIONS AND PERFORMANCE EVALUATION}

\subsection{OPERATING PLAN}

A brief plan was prepared for startup (see copy in Appendix G) and evaluation of the performance of the SLS system. This plan was based on the Plan for Evaluating and Optimizing the Performance of the Solid/Liquid Separation System for Processing of Melton Valley Storage Tank Waste at Oak Ridge National Laboratory, which was submitted to the DOE TFA in November 1998. The ability to implement this test plan depended on the performance of the SLS system and the ability to have some control over key variables. Many uncontrolled variables in field operation can make it difficult or impossible to determine the influence of a particular operating parameter on performance. The tests defined in the operating plan required the ability to maintain control of feed composition, feed flow rate, transmembrane pressure, and axial velocity during the performance of the test series. Control of transmembrane pressure and axial velocity was not expected to be a problem; however, the design of the feed system was expected to make control of the feed flow rate and composition difficult due to the location of the feed pump suction leg.

Figure 10 shows the SLS flowsheet, including the CsR and OTE systems. The suction legs of the MVST transfer piping are located below the sludge layer in the tanks, about 6 in. from the tank bottom. To minimize the transfer of concentrated sludge to the SLS system, the existing Moyno pumps were to be used to recirculate the waste tank at a high flow rate $(200 \mathrm{gal} / \mathrm{min}$ or greater $)$ until a depression developed in the sludge layer around the suction leg. When the Moyno pumps are turned off, the D/D pumps are turned on and the liquid diverted to the SLS system. Control of the suspended solids content of the feed was dependent upon the stability of the depression in the sludge layer. The solids content of the feed was expected to fluctuate and possibly become too high to process if sludge tended to fill the depression. If the depression was stable, the solids content was expected to be consistently low. Tank W-31 was chosen for the initial SLS operation because the sludge content was comparably low at 10,000 to 11,000 gal ( $20 \%$ of the tank volume) and the sludge was expected to have a higher density and be more stable than others because it had been stored in the tank, undisturbed, since 1984.

As shown in Appendix A, Table A-2, the supernatant for W-31 contained high levels of cesium and dissolved salts. In operation of the SLS system, the concentrate return stream containing suspended solids from the filter operation is returned to the waste tank; therefore, the solids concentration in the feed was expected to show a steady increase as the supernatant was processed. The tests defined in the plan were intended to be performed during a time when the feed flow rate and the solids content were reasonably consistent. If the feed flow and the solids content were variable, the test plans could be altered to extend the duration of the test so that these two parameters could be averaged over time.

The backpulsing system was set at a frequencey of once per hour. Operators were instructed not to backpulse more frequently unless approved by supervision. (More frequent backpulsing tends to expose the pores of the filter to plugging by smaller-size particles, which would otherwise be removed by the boundary layer of filtered solids.) 


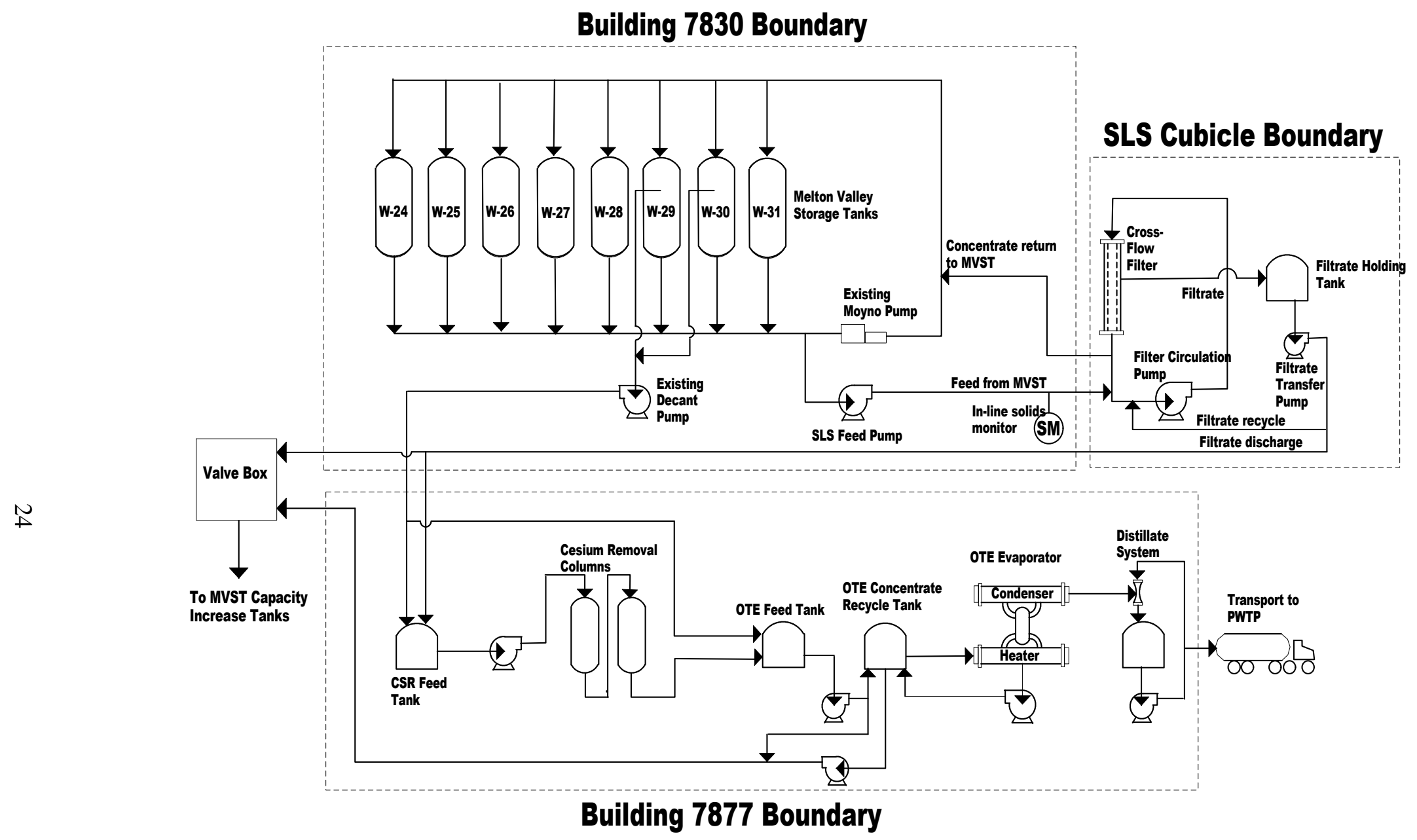

Fig. 10. Flowsheet for solid/liquid separation system in series with cesium removal and out-of-tank evaporation systems. 
Termination of SLS processing was determined by the solids content of the SLS feed. The solids content of the feed was expected to reach very high levels when the level of the tank supernatant approached the sludge/liquid interface. The SLS pumping and processing systems are not capable of treating the "as-settled" heavy sludge in the MVST.

\subsection{OPERATIONS AND PERFORMANCE EVALUATION, TANK W-31}

On June 7, 1999, approval for operation was given by BJC, and the SLS system began hot operations. The initial startup was successful; however, about $30 \mathrm{~min}$ later, the filtrate transfer pump shut down due to an amperage overload trip switch. A maintenance engineer and an electrician were able to trace the problem to a mechanical modification of the pump that was made during the installation. The pump impeller had been replaced with a larger unit to increase the pressure and flow capability of the pump. The amperage overload trip setting of the motor had not been adjusted to accommodate the increased load on the pump. The pump operated properly once the trip setting was readjusted.

The system was restarted the next day and operated in filtrate recycle mode, which involved recycling the processed filtrate into the system feed rather than transferring it to Building 7877 for OTE/CsR operations. It was necessary to recycle the filtrate until verification was obtained that the composition was acceptable for treatment through OTE and CsR processes. The concentration of transuranic (TRU) constituents, mainly plutonium and americium, in the filtrate had to be less than $1814 \mathrm{~Bq} / \mathrm{mL}$ in order to avoid the potential for contaminating the ion-exchange material (IONSIV IE-911) and having it be classified as a TRU waste. [The designated disposal facility (the Nevada Test Site) for cesium-loaded IE-911 will not accept TRU waste for disposal.] The initial samples of filtrate collected from the system indicated less than $100 \mathrm{~Bq} / \mathrm{L}$ for all alpha constituents; therefore, the operational mode was switched to allow transfer of the filtrate to the CsR and OTE systems in Building 7877.

During the initial startup, the TSS of the feed, as monitored by the Coriolis mass flowmeter installed on the feed line, showed a small increase from zero to about 4\%. Figure 11 shows the initial feed flow, percent TSS, and filtrate flow during the initial $30 \mathrm{~min}$ of startup. After the system had been restarted the following day, the TSS of the feed gradually decreased to $1 \%$, and then to zero during the next $7.5 \mathrm{~h}$ of operation. The percent solids increase indicates that some loose solids from the depression in the tank sludge were being picked up by the D/D pumps; once these were removed, however, the suction leg remained clear of sludge. The feed remained very low in TSS for the next 2 weeks of operation. The low TSS content of the feed was favorable for high filtrate production during most of the operation.

Operation of the feed system operation was somewhat erratic during the campaign. The feed mass flow varied between about 275 and $625 \mathrm{lb} / \mathrm{min}$ ( 30 and $60 \mathrm{gal} / \mathrm{min}$ ). The flow sometimes decreased to much lower values, but this could be attributed to periodic shutdown of the feed system to allow backpulsing of the filters. Although pulsation dampeners are provided for the feed pumps, the nature of doublediaphragm pump operation is a pulsed flow. These pumps were used because the MVSTs are situated in an underground vault, with the PVV and the SLS system located above the tanks. The negative suction lift can be as high as $18 \mathrm{ft}$ if the tank liquid level is low. Diaphragm pumps are designed for high negative suction lift and are self-priming, which essentially eliminates the need for priming water to fill the suction piping. These pumps are also low-maintenance types and relatively inexpensive. Although the feed flow was inconsistent at times, the pumps did provide reasonably consistent pressure, which was necessary for filtrate production. 


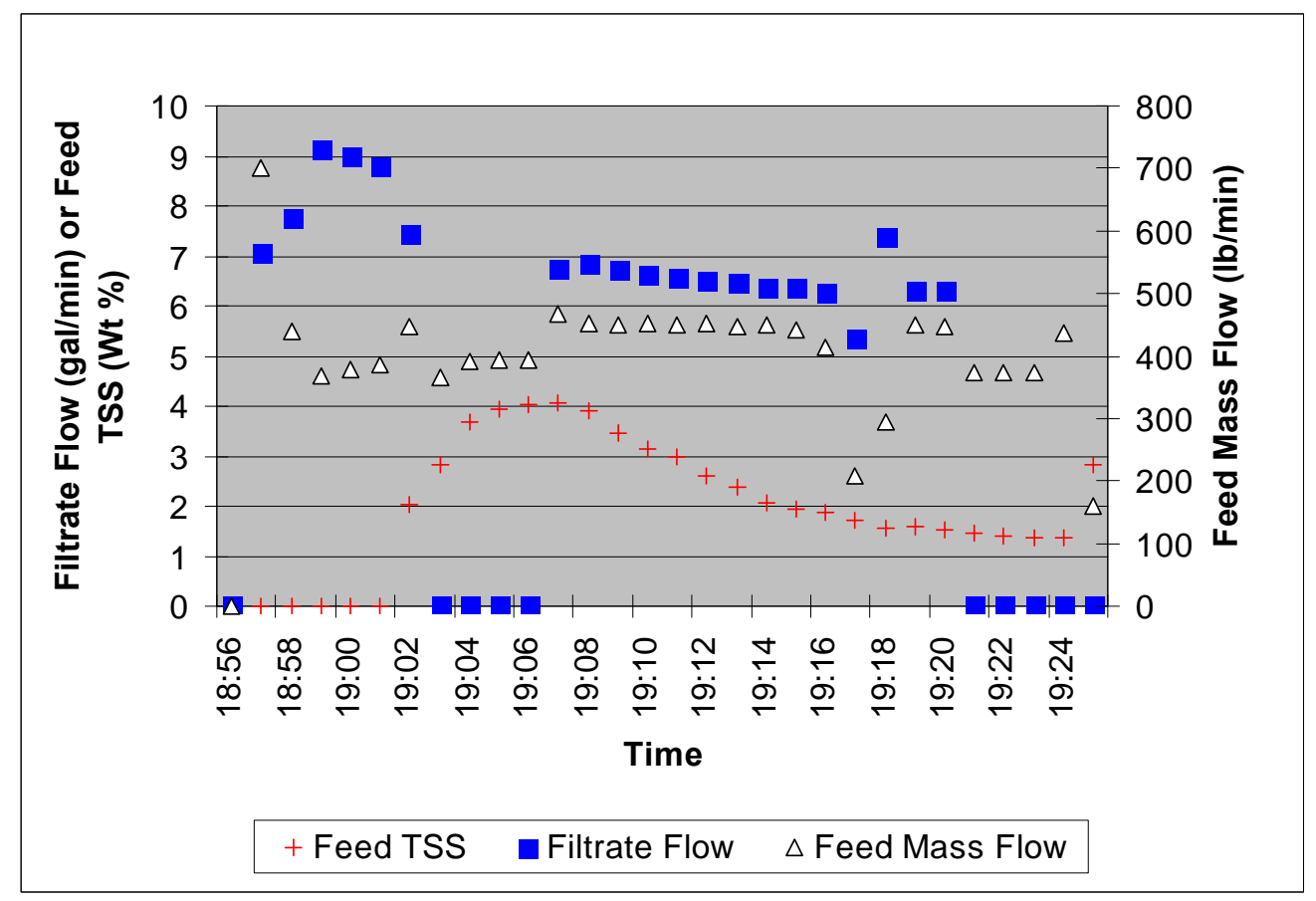

Fig. 11. Filtrate flow, feed mass flow, and feed TSS as a function of time during initial startup for tank W-31, June 7, 1999.

\subsubsection{SLS Performance Tests and Operations Data, Tank W-31}

The test series defined in the test plan (Appendix G) were performed during the W-31 processing operation to evaluate the influence of SLS operating conditions on filtrate production. The results of Series 1 and Series 3 tests are provided in the following tables and graphs. The test results for Series 2 (not included in this report) are essentially the same as those for Series 1. A basic factorial experimental design was used as the basis for the test conditions and the tests were conducted in random order.

Figures 12 and 13 show data for axial flow rate, transmembrane pressure, and filtrate flow rate vs time during the Series 1 tests for tank W-31. While axial flow is very stable, the transmembrane pressure varies significantly around the set point. This is principally due to the operating characteristics of the $\mathrm{D} / \mathrm{D}$ feed pumps. Despite the use of pulsation dampeners on the D/D discharge piping, the discharge pressure was erratic, causing equally erratic transmembrane pressure. The filtrate production drops to zero periodically because the filtrate is produced in batches with a variable hold-time between batches. The filtrate discharge valve closes when the filtrate hold tank reaches the high-level setpoint and a batch is ready for transfer to the CsR system feed tank. The SLS system is programmed to transfer to the CsR system only when the CsR feed tank level is low enough to receive a full 80 -gal batch. If the CsR feed tank level is too high, the SLS system will not discharge filtrate but will continue to operate and circulate new feed slurry through the processing loop. If a 90-min maximum wait time is exceeded, the SLS system will automatically enter a deenergized standby mode. In this campaign, the filtrate flow was usually between 5 and $8 \mathrm{gal} / \mathrm{min}$ and exceeded the need of the other two systems, which were processing in the filtrate at about $2 \mathrm{gal} / \mathrm{min}$. Figures 14 and 15 show trends of filtrate flow, feed mass and 


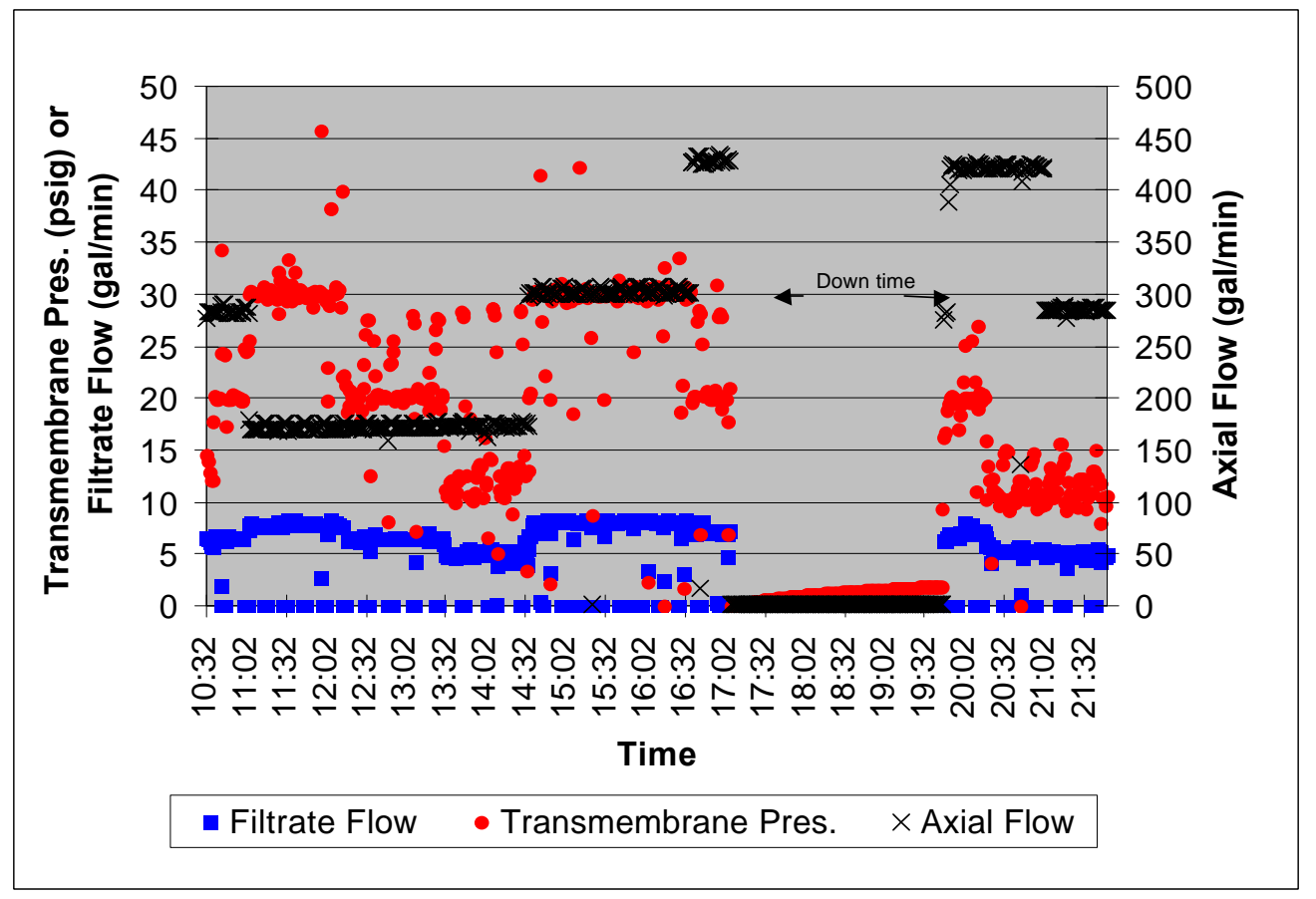

Fig. 12. Filtrate flow, transmembrane pressure, and axial flow as a function of time, Series 1, tests 1-7, tank W-31.

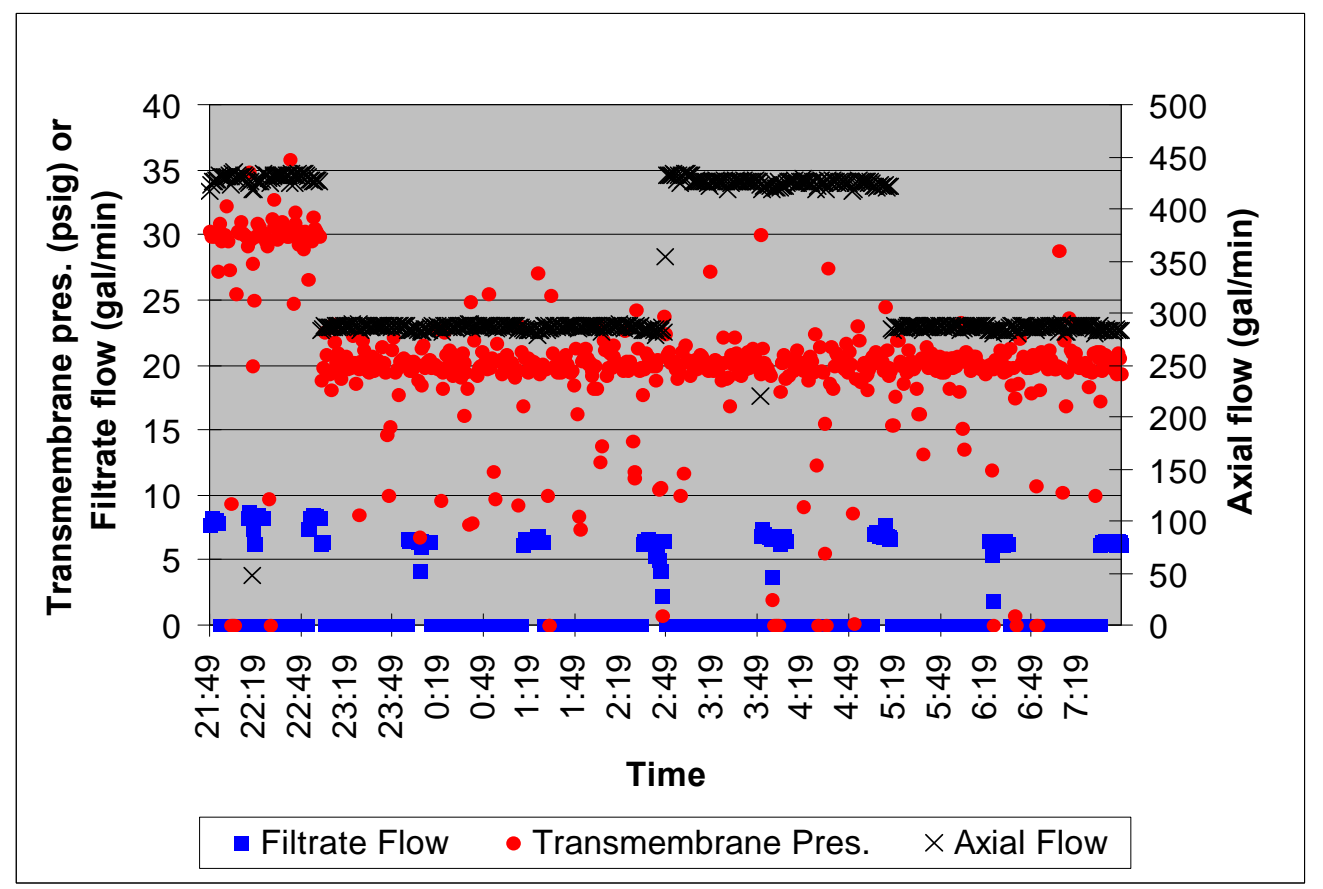

Fig. 13. Filtrate flow, transmembrane pressure, and axial flow as a function of time, Series 1 , tests 8-12, tank W-31. 


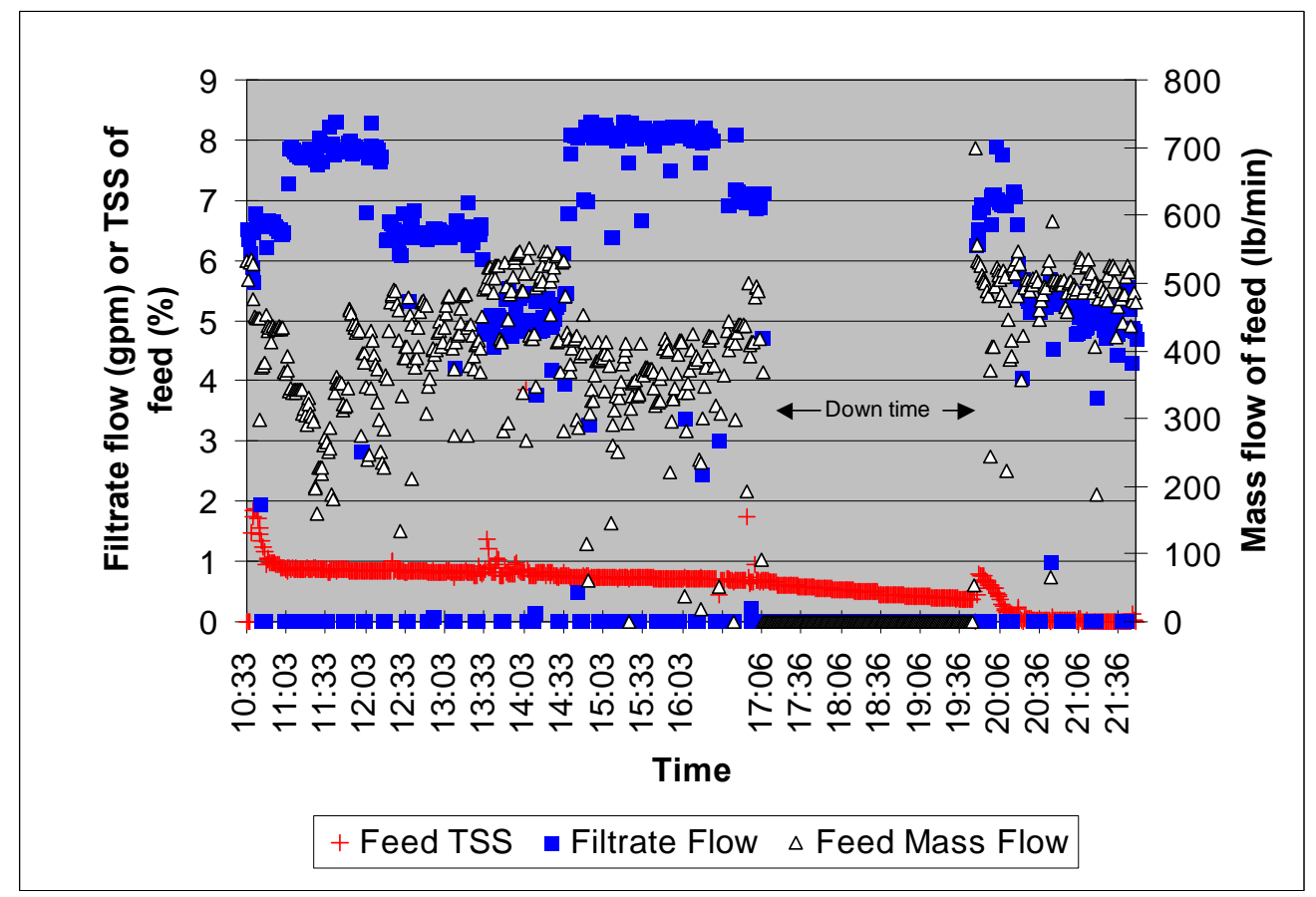

Fig. 14. Filtrate flow, feed TSS, and feed mass flow as a function of time, Series 1, tests $1-7$, tank W-31.

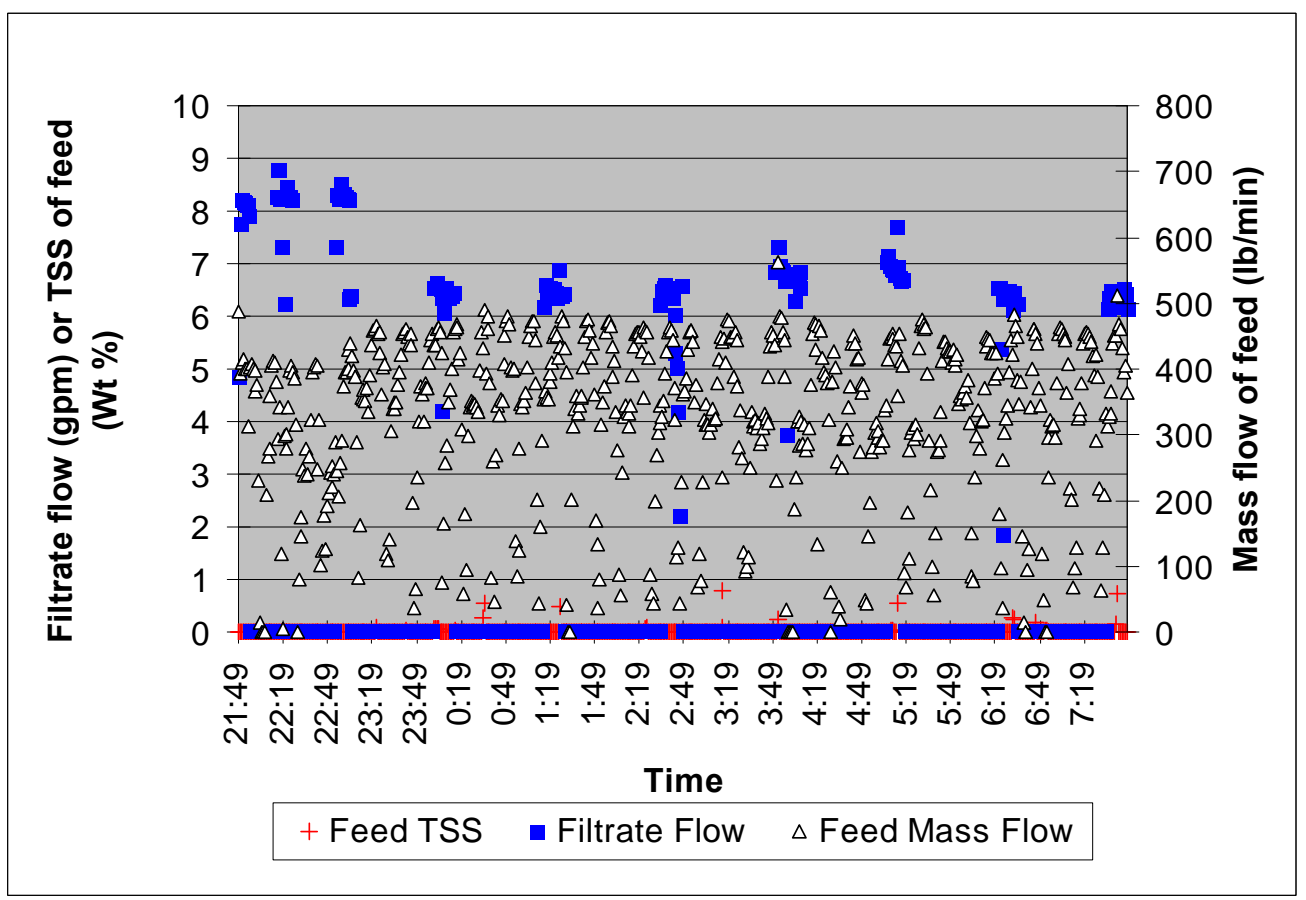

Fig. 15. Filtrate flow, feed TSS, and feed mass flow as a function of time, Series 1, tests $8-12$, tank W-31. 
solids content versus time. The feed mass flow varies significantly during the processing due to the $\mathrm{D} / \mathrm{D}$ pump operating characteristics. The suspended solids content of the feed shows a gradually declining trend, beginning at $2 \mathrm{wt} \%$ and slowly dropping to zero.

The W-31 performance data indicate the expected behavior for cross-flow filtration when the TSS is low $(<0.5 \%)$. The filtrate production is only slightly improved when the axial velocity is increased; however, an increase in transmembrane pressure increases filtrate production significantly. This behavior is consistent throughout most of the W-31 operation. Table 1 summarizes the results of the Series 1 tests. Figures 16 and 17 give plots of the average filtrate flux as a function of transmembrane pressure and axial flow. The results show that an increase in axial velocity from 4 to $10 \mathrm{ft} / \mathrm{s}$ increases filtrate production by no more than $10 \%$, or 0.01 gal $\min ^{! 1} \mathrm{ft}^{! 2}$, while increasing the transmembrane pressure from 10 to 30 psig increases filtrate flux by about $60 \%$, or 0.06 gal $\min ^{! 1} \mathrm{ft}^{! 2}$. The high filtrate flux and minor influence of axial velocity are indications that filter cake is not accumulating on the surface of the filter elements. The range of filtrate flux of 0.1 to $0.16 \mathrm{gal} \mathrm{min}^{! 1} \mathrm{ft}^{\prime 2}$ is in the upper range of the performance data for single-element tests with waste simulants. Tests repeated under the same operating conditions at later times show little change in filtrate flux, indicating minimal fouling of filter surfaces over the 19-h time period of Series 1 tests.

\begin{tabular}{|c|c|c|c|c|c|c|c|c|}
\hline \multicolumn{9}{|c|}{ Table 1. Results of SLS Test Series $1, \operatorname{tank} W-31^{a}$} \\
\hline \multirow{2}{*}{$\begin{array}{l}\text { Transmembrane } \\
\text { pressure (psig) }\end{array}$} & \multicolumn{2}{|c|}{ Axial flow } & \multirow{2}{*}{$\begin{array}{l}\text { Test } \\
\text { order }\end{array}$} & \multicolumn{2}{|c|}{ Avg. filtrate } & \multirow{2}{*}{$\begin{array}{l}\text { Filtrate } \\
\text { max. }\end{array}$} & \multirow{2}{*}{$\begin{array}{c}\text { Filtrate } \\
\text { min. }\end{array}$} & \multirow{2}{*}{$\begin{array}{l}\text { Avg. trans. } \\
\text { pres. (psig) }\end{array}$} \\
\hline & $\mathrm{gal} / \mathrm{min}$ & $\mathrm{ft} / \mathrm{s}$ & & $\mathrm{gal} / \mathrm{min}$ & gal $\min ^{! 1} \mathrm{ft}^{\prime 2}$ & & & \\
\hline 10 & 170 & 4 & 3 & 5.02 & 0.10 & 5.4 & 4.2 & 11.8 \\
\hline 10 & 300 & 7 & 7 & 4.98 & 0.10 & 5.58 & 4.3 & 11.0 \\
\hline 10 & 425 & 10 & 6 & 5.38 & 0.108 & 5.97 & 4.54 & 10.6 \\
\hline 20 & 170 & 4 & 2 & 6.46 & 0.129 & 6.96 & 5.32 & \\
\hline 20 & 300 & 7 & 9 & 6.45 & 0.129 & 6.68 & 6.05 & \\
\hline 20 & 300 & 7 & 12 & 6.37 & 0.127 & 6.55 & 6.13 & \\
\hline 20 & 300 & 7 & 10 & 6.35 & 0.127 & 6.60 & 5.30 & \\
\hline 20 & 425 & 10 & 11 & 6.88 & 0.138 & 7.70 & 6.31 & \\
\hline 20 & 425 & 10 & 5 & 7.02 & 0.14 & 7.18 & 6.85 & \\
\hline 30 & 170 & 4 & 1 & 7.83 & 0.157 & 8.31 & 6.82 & \\
\hline 30 & 300 & 7 & 4 & 8.11 & 0.162 & 8.31 & 7.8 & \\
\hline 30 & 425 & 10 & 8 & 8.21 & 0.164 & 8.78 & 7.33 & \\
\hline \multicolumn{9}{|c|}{$\begin{array}{l}{ }^{a} \text { Other test conditions: (1) Test was conducted over a } 21 \text {-h period beginning June } 8,1999 . \\
\text { (2) Mass flow of feed averaged } 406 \mathrm{lb} / \mathrm{min} \text {. (3) Time between backpulse, } 60 \text { min. (4) TSS content } \\
\text { of feed, } \leq 1 \mathrm{wt} \% \text {. } \\
{ }^{b} \text { The average transmembrane pressure is provided due to limitations in the ability to maintain } \\
10 \text { psig. }\end{array}$} \\
\hline
\end{tabular}




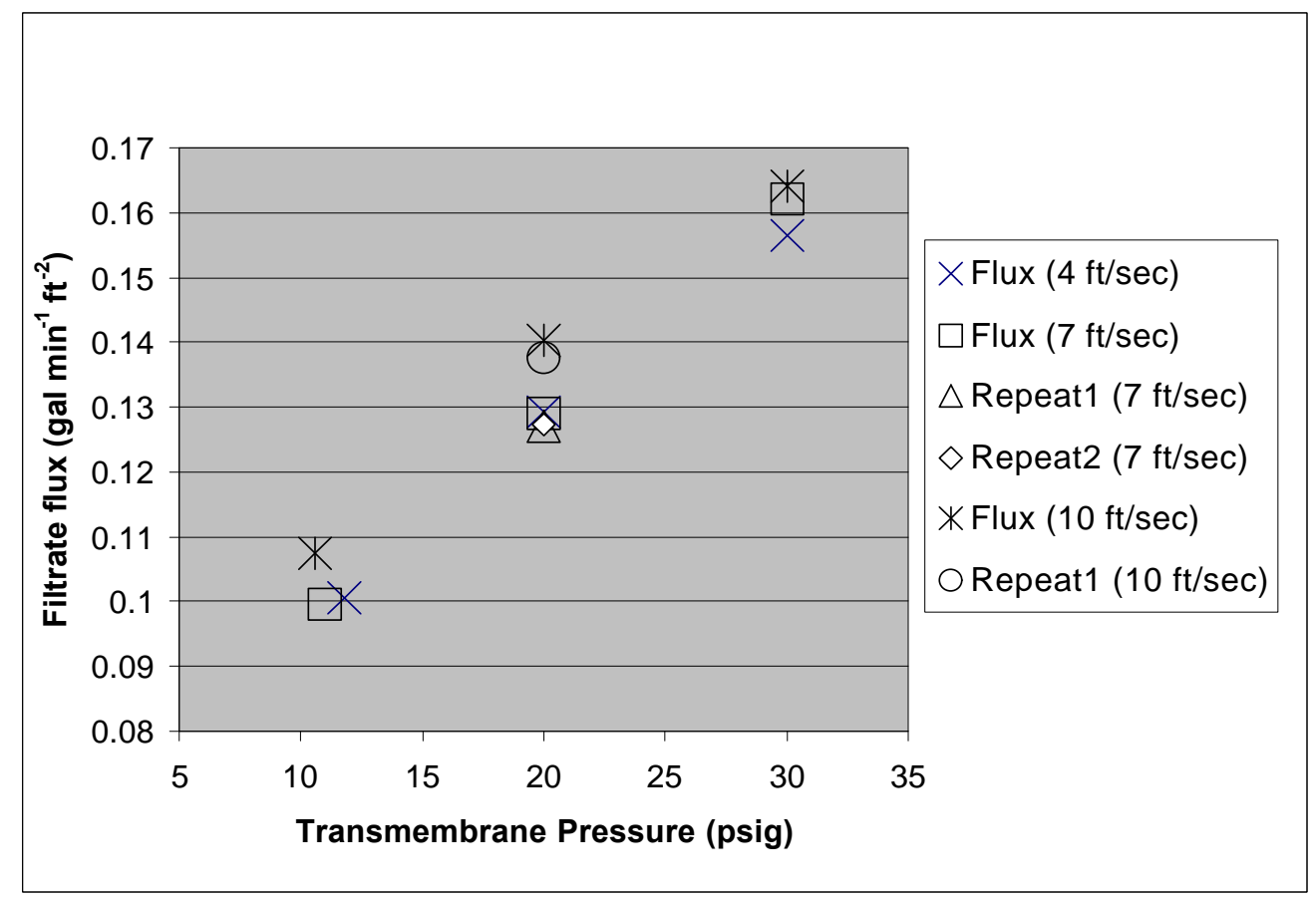

Fig. 16. Average filtrate flux as a function of transmembrane pressure, Test Series 1, tank W-31.

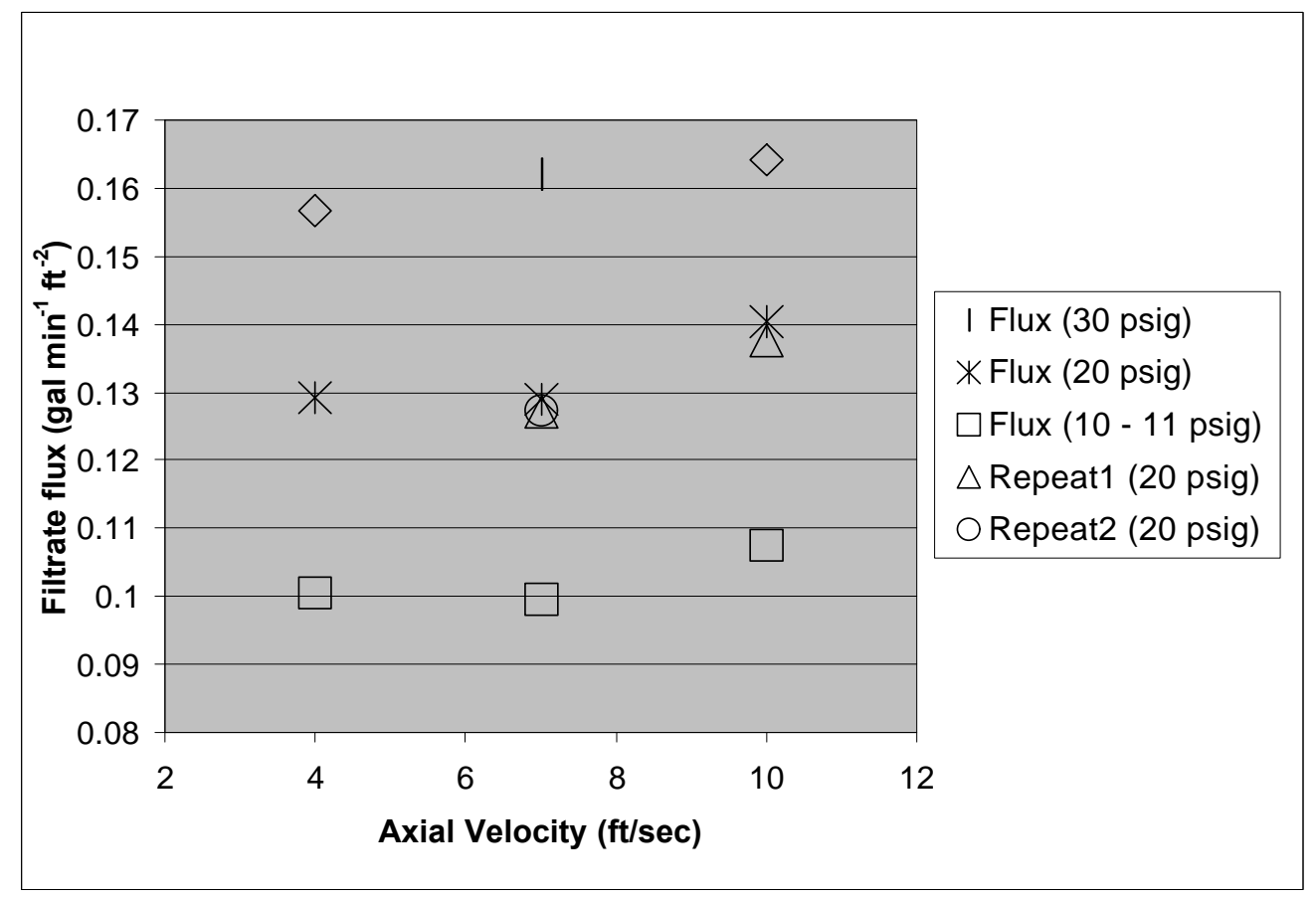

Fig. 17. Average filtrate flux as a function of axial velocity, Test Series 1, tank W-31. 
After 20,000 gal of supernatant had been treated, Series 3 tests were conducted. Figures 18 and 19 show the operating data collected during the performance of Series 3 tests. The TSS content of the feed was essentially zero during this test series, and the D/D pump operation continued to cause fluctuation of the feed mass flow and transmembrane pressure for the system. As shown in Fig. 20, an increase in the transmembrane pressure from 15 to 30 psig resulted in an increase in the filtrate flux of about $40 \%$, while Fig. 21 shows that an increase in velocity from 4 to $10 \mathrm{ft} / \mathrm{s}$ caused an increase in filtrate flux of only about $6 \%$. Table 2 summarizes the results of these tests. The overall range of filtrate flux was 0.096 to 0.143 gal $\min ^{11} \mathrm{ft}^{\prime 2}$, indicating an overall drop in filtrate production of about $10 \%$ as compared with Series 1 data due to gradual, but minor, fouling of the filter. Table 3 shows a side-by-side comparison of the Series 1 and 3 data.

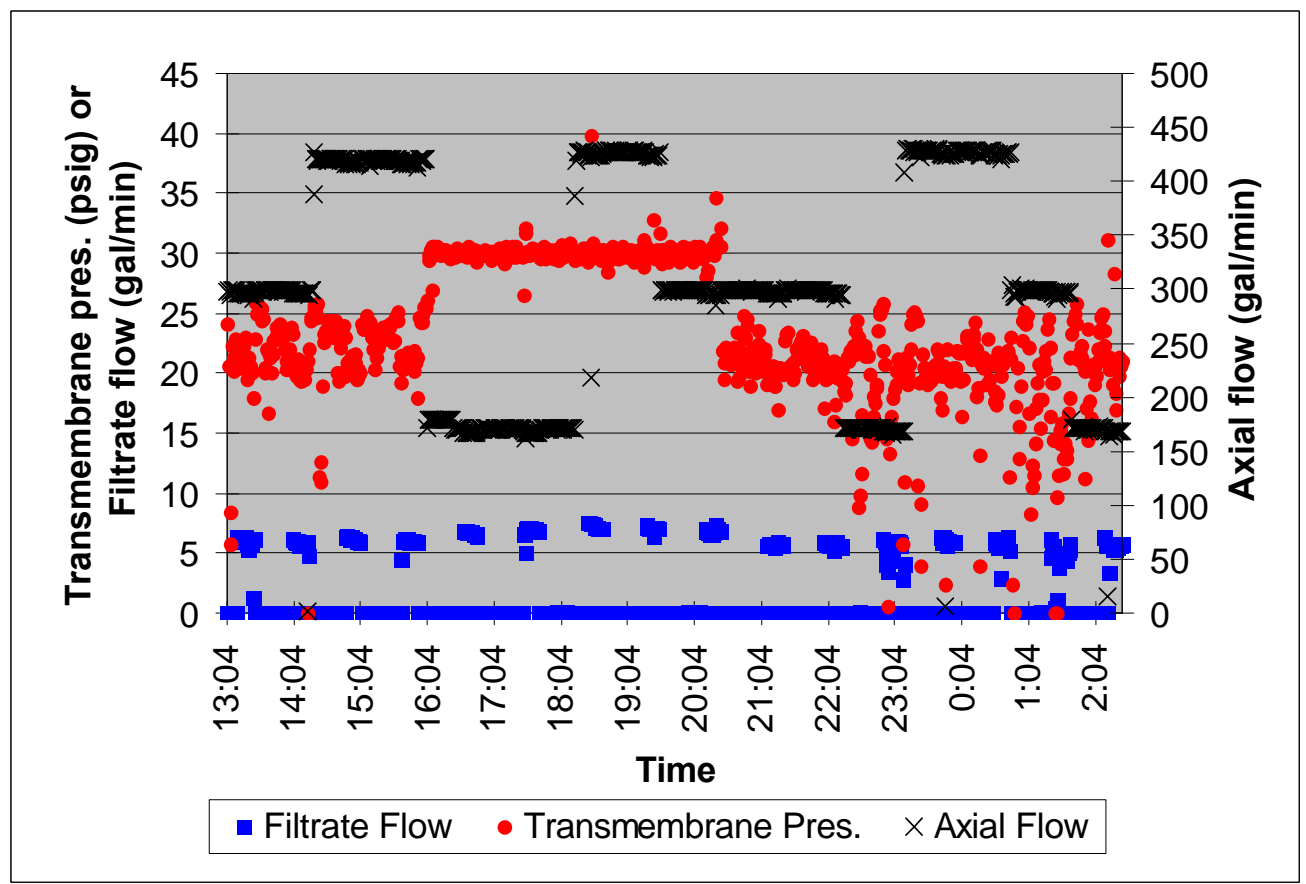

Fig. 18. Filtrate flow, transmembrane pressure, and axial flow as a function of time for Test Series 3, tank W-31. 


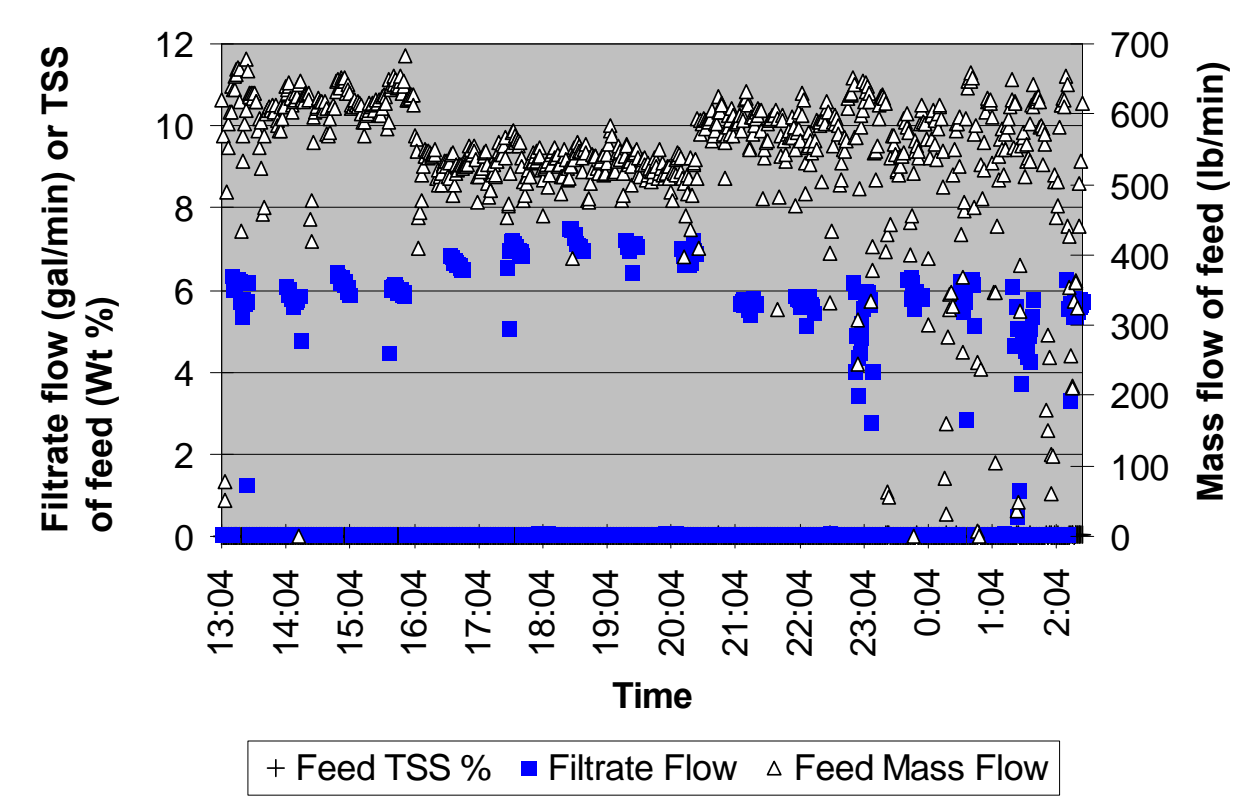

Fig. 19. Feed TSS, filtrate flow, and feed mass flow as a function of time for Test Series 3, tank W-31.

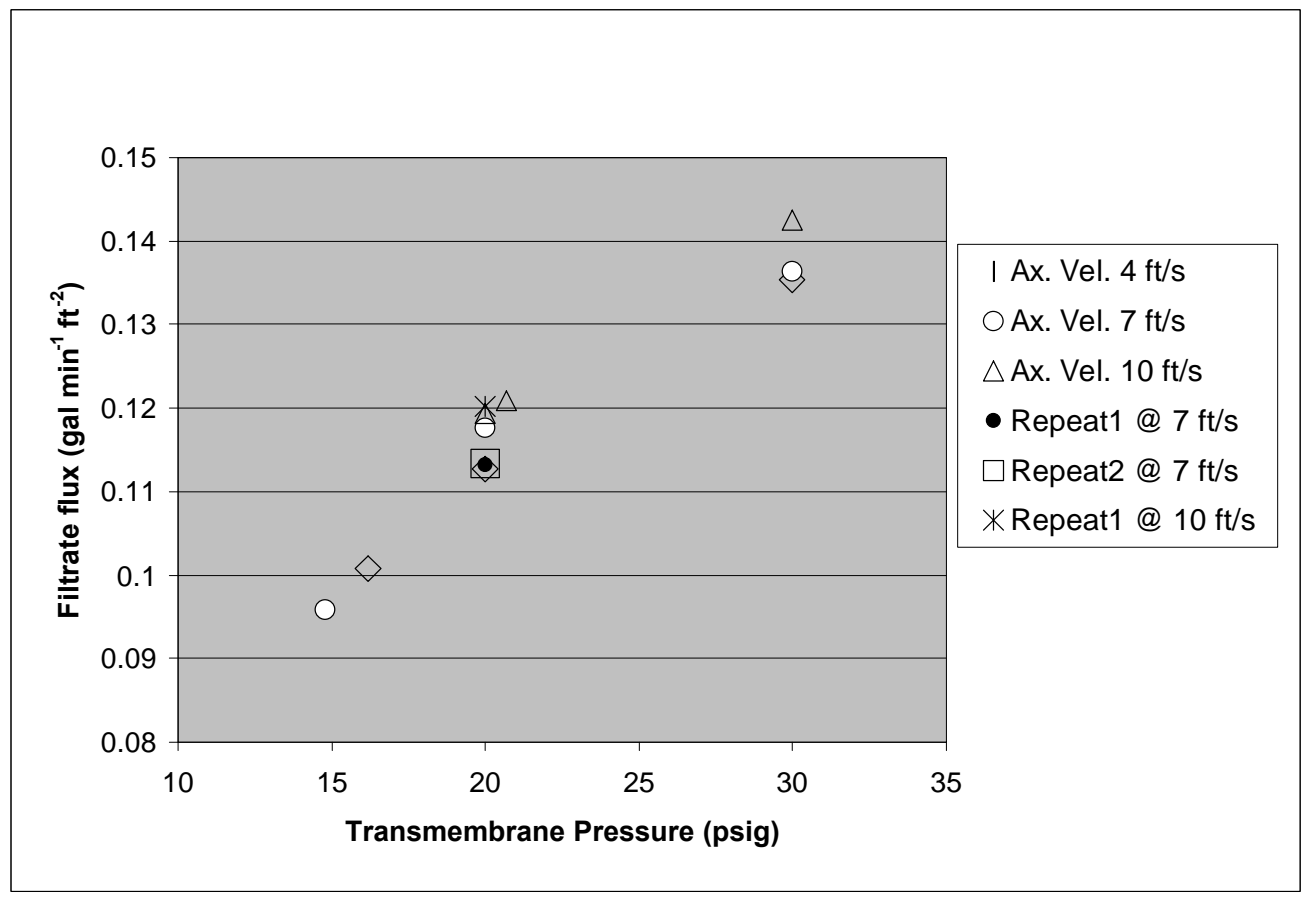

Fig. 20. Average filtrate flux as a function of transmembrane pressure, Test Series 3, tank W-31. 


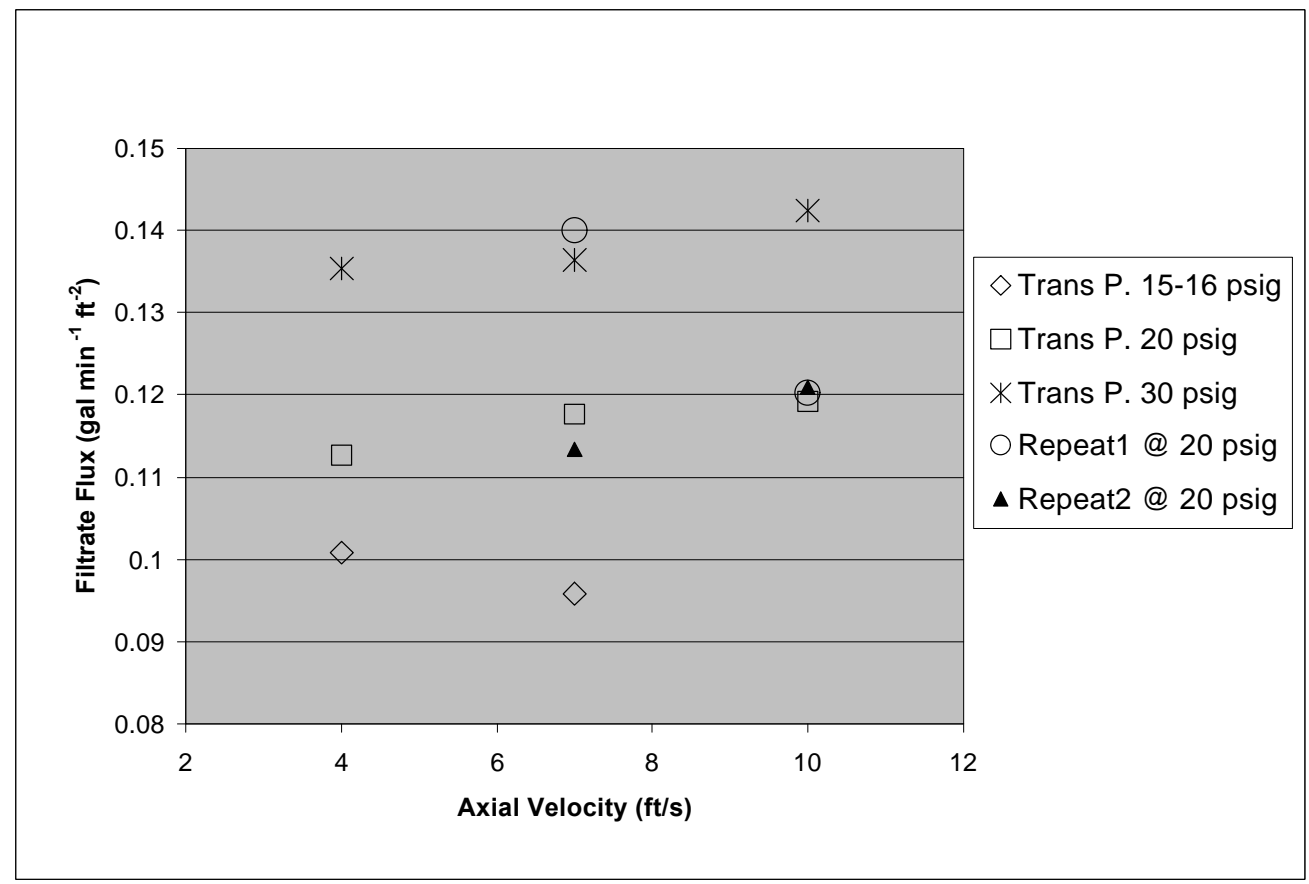

Fig. 21. Average filtrate flux as a function of axial velocity, Test Series 3, tank W-31.

\begin{tabular}{|c|c|c|c|c|c|c|c|c|}
\hline \multirow{2}{*}{$\begin{array}{l}\text { Transmembrane } \\
\text { pressure (psig) }\end{array}$} & \multicolumn{2}{|c|}{ Axial flow } & \multirow{2}{*}{$\begin{array}{l}\text { Test } \\
\text { order }\end{array}$} & \multicolumn{2}{|c|}{ Avg. filtrate } & \multirow{2}{*}{$\begin{array}{c}\text { Filtrate } \\
\text { max. }\end{array}$} & \multirow{2}{*}{$\begin{array}{c}\text { Filtrate } \\
\text { min. }\end{array}$} & \multirow{2}{*}{$\begin{array}{l}\text { Avg. trans } \\
\text { pres. }^{b}\end{array}$} \\
\hline & $\mathrm{gal} / \mathrm{min}$ & $\mathrm{ft} / \mathrm{s}$ & & $\mathrm{gal} / \mathrm{min}$ & gal min ${ }^{11} \mathrm{ft}^{\prime 2}$ & & & \\
\hline 10 & 170 & 4 & 8 & 5.04 & 0.101 & 6.17 & 2.8 & 16.18 \\
\hline 10 & 300 & 7 & 11 & 4.79 & 0.096 & 5.76 & 3.73 & 14.83 \\
\hline 10 & 425 & 10 & 2 & 6.04 & 0.121 & 6.43 & 4.5 & 20.68 \\
\hline 20 & 170 & 4 & 12 & 5.63 & 0.113 & 6.29 & 5.35 & \\
\hline 20 & 300 & 7 & 1 & 5.88 & 0.118 & 6.37 & 4.77 & \\
\hline 20 & 300 & 7 & 6 & 5.66 & 0.113 & 5.82 & 5.4 & \\
\hline 20 & 300 & 7 & 7 & 5.67 & 0.113 & 5.84 & 5.16 & \\
\hline 20 & 425 & 10 & 10 & 6.01 & 0.12 & 6.25 & 5.48 & \\
\hline 20 & 425 & 10 & 9 & 5.96 & 0.119 & 6.32 & 5.57 & \\
\hline 30 & 170 & 4 & 3 & 6.77 & 0.135 & 7.21 & 5.05 & \\
\hline 30 & 300 & 7 & 5 & 6.82 & 0.136 & 7.24 & 6.64 & \\
\hline 30 & 425 & 10 & 4 & 7.13 & 0.143 & 7.52 & 6.44 & \\
\hline \multicolumn{9}{|c|}{$\begin{array}{l}{ }^{a} \text { Other test conditions: (1) Test was conducted over a } 15-\mathrm{h} \text { period beginning June } 21,1999 . \\
\text { (2) Mass flow of feed averaged } 538 \mathrm{lb} / \mathrm{min} \text {. (3) Time between backpulse: } 60 \mathrm{~min} \text {. (4) TSS } \\
\text { content of feed was not measurable. } \\
{ }^{b} \text { The average transmembrane pressure is provided due to inability to maintain } 10 \mathrm{psig.}\end{array}$} \\
\hline
\end{tabular}




\begin{tabular}{|c|c|c|c|c|c|c|}
\hline \multirow[t]{2}{*}{$\begin{array}{l}\text { Transmembrane } \\
\text { pressure (psig) }\end{array}$} & \multicolumn{2}{|c|}{ Axial flow } & \multicolumn{2}{|c|}{$\begin{array}{l}\text { Avg. filtrate } \\
\text { (gal/min) }\end{array}$} & \multicolumn{2}{|c|}{$\begin{array}{l}\text { Avg. trans. pres. } \\
(\mathrm{psig})^{a}\end{array}$} \\
\hline & $\mathrm{gal} / \mathrm{min}$ & $\mathrm{ft} / \mathrm{s}$ & Series 1 & Series 3 & Series 1 & Series 3 \\
\hline 10 & 170 & 4 & 5.02 & 5.04 & 11.8 & 16.18 \\
\hline 10 & 300 & 7 & 4.98 & 4.79 & 11.0 & 14.83 \\
\hline 10 & 425 & 10 & 5.38 & 6.04 & 10.6 & 20.68 \\
\hline 20 & 170 & 4 & 6.46 & 5.63 & & \\
\hline 20 & 300 & 7 & 6.45 & 5.88 & & \\
\hline 20 & 300 & 7 & 6.37 & 5.66 & & \\
\hline 20 & 300 & 7 & 6.35 & 5.67 & & \\
\hline 20 & 425 & 10 & 6.88 & 6.01 & & \\
\hline 20 & 425 & 10 & 7.02 & 5.96 & & \\
\hline 30 & 170 & 4 & 7.83 & 6.77 & & \\
\hline 30 & 300 & 7 & 8.11 & 6.82 & & \\
\hline 30 & 425 & 10 & 8.21 & 7.13 & & \\
\hline
\end{tabular}

On June 23, the TSS content of the feed began a steady increase over a 14-h period to very high values. This increase was caused by the gradual collapse of the depression in the W-31 sludge layer. Figure 22 shows the increase in feed TSS from 1.5 to $16.7 \%$ and the corresponding decrease in filtrate production from 6 to about $1 \mathrm{gal} / \mathrm{min}\left(0.12\right.$ to $\left.0.02 \mathrm{gal} \mathrm{min}^{{ }^{1}} \mathrm{ft}^{! 2}\right)$. Figure 23 illustrates the decrease in axial flow caused by the increase in feed density and solids content. The axial flow decreased because the Discflo pump was controlled by speed (rpm) feedback rather than flow control feedback. Although the speed was constant, the pump was not able to maintain a constant flow of fluid as the density and solids content increased. The plot also shows that the transmembrane pressure was maintained between 20 and 25 psig, indicating that the decline in filtrate flow was caused by the accumulation of filter cake and the decline in axial flow.

Unfortunately, the rapidly increasing TSS content of the feed made it impossible to attempt an additional test series. When the TSS of the feed reached 17\%, the decision was made to shut down the SLS system and try to reestablish a depression in the MVST tank W-31 sludge layer. Upon restart, however, the TSS of the feed remained at $14 \%$ or above for about $20 \mathrm{~min}$, then sharply increased to nearly $25 \%$. Figures 24 and 25 show data from the Coriolis mass flowmeter used to monitor the feed conditions. Once the feed TSS climbed above $22 \%$ with a density of $1.37 \mathrm{~g} / \mathrm{mL}$, the flow provided by the double-diaphragm feed pumps began to decline. When the feed flow dropped to $100 \mathrm{lb} / \mathrm{min}(9 \mathrm{gal} / \mathrm{min})$, the SLS system was shut down and operations were terminated after a total of about 28,400 gal had been processed.

Problems were encountered during the draining and flushing of the SLS system due to the flow characteristics of the heavy sludge present in the system. The system drained very slowly, and the flow sensors used on the drain line would not clear readily. The sludge moved very slowly in the drain system piping, and when water flushes followed the initial drain, the material in the drain piping backed up into the containment pan of the SLS system. This caused an automatic shutdown of the system when the leak detectors in the containment pan sensed the presence of liquid. The system was allowed to drain 


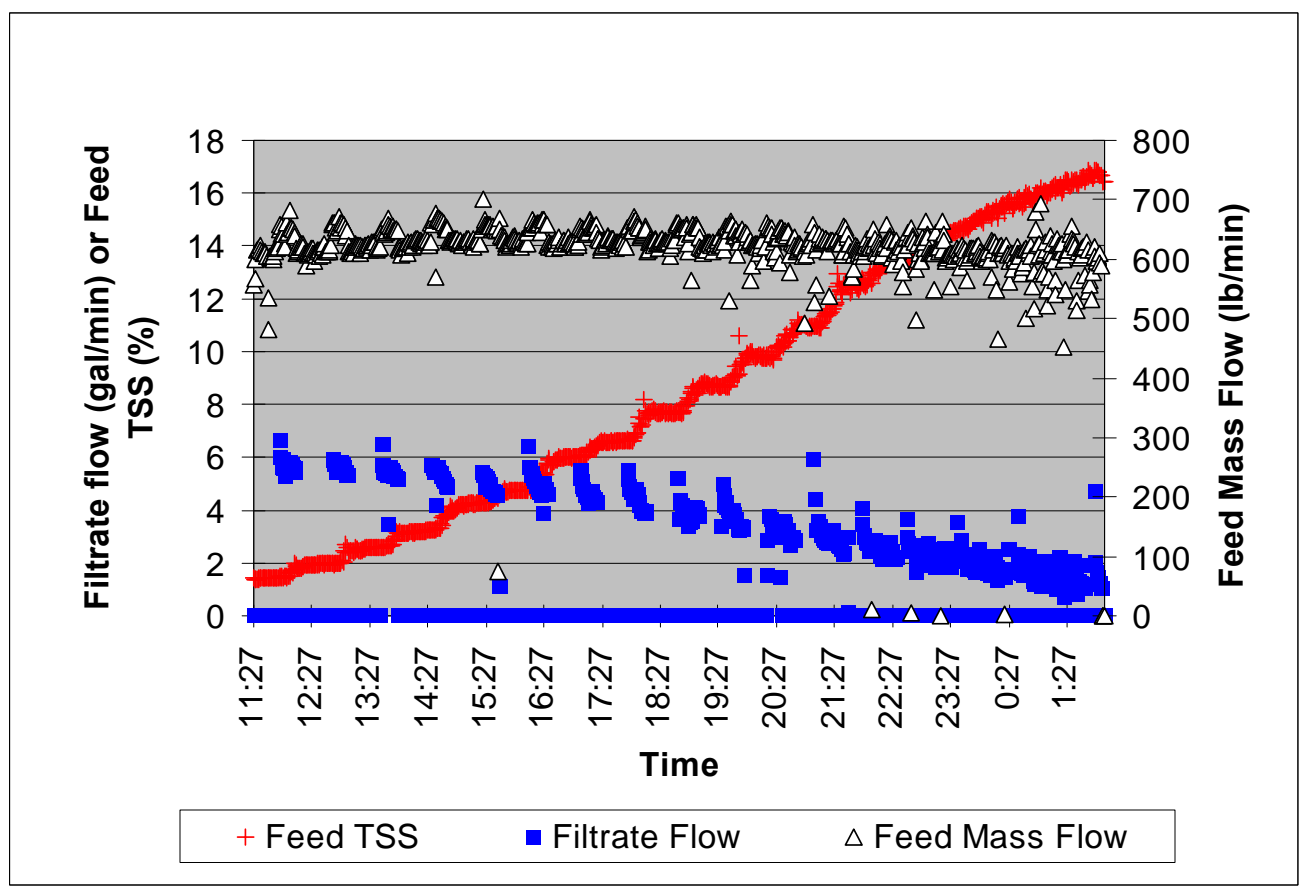

Fig. 22. Feed TSS, filtrate flow, and feed mass flow as a function of time near the end of processing for tank W-31.

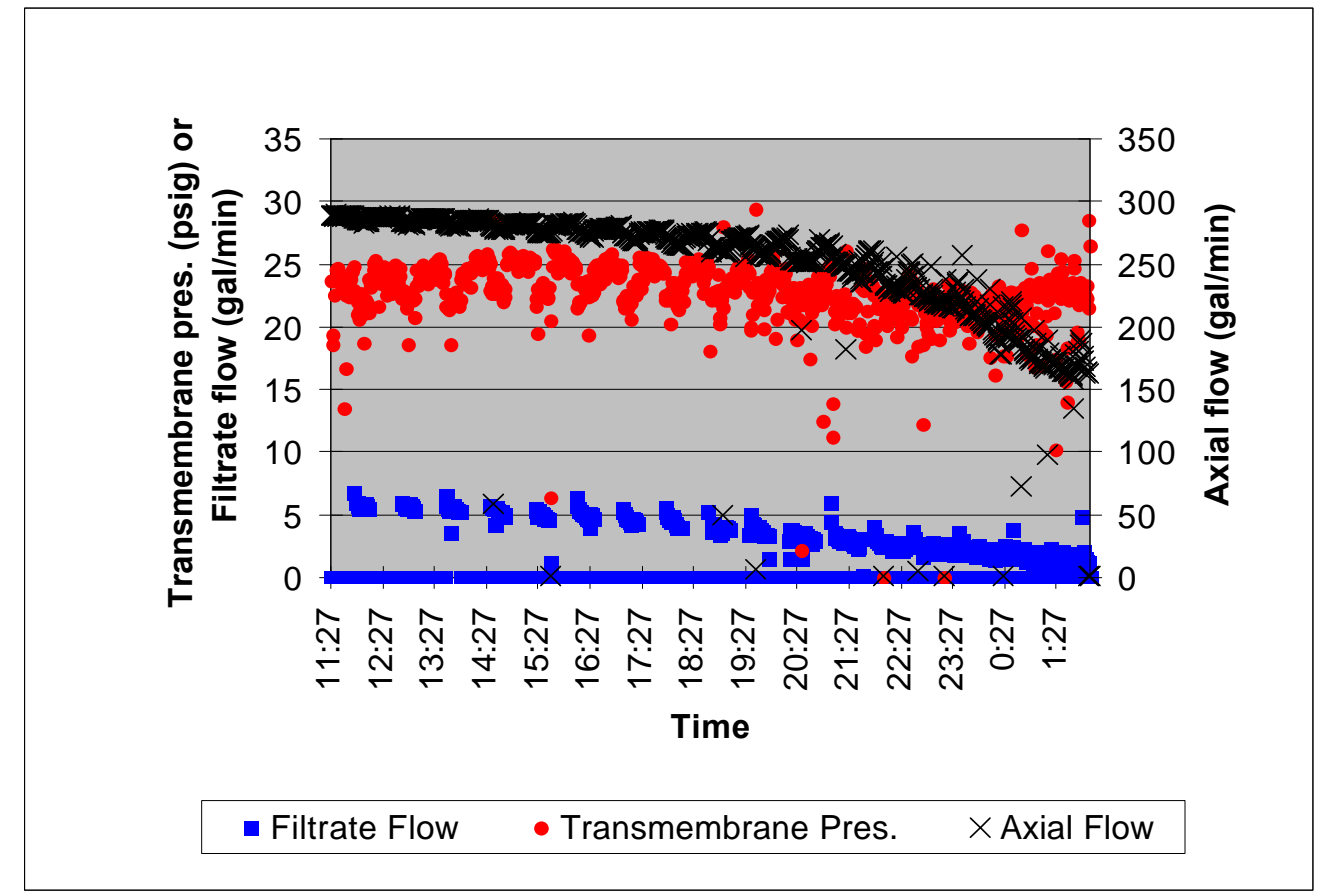

Fig. 23. Filtrate flow, axial flow, and transmembrane pressure as a function of time near the end of processing for tank W-31. 


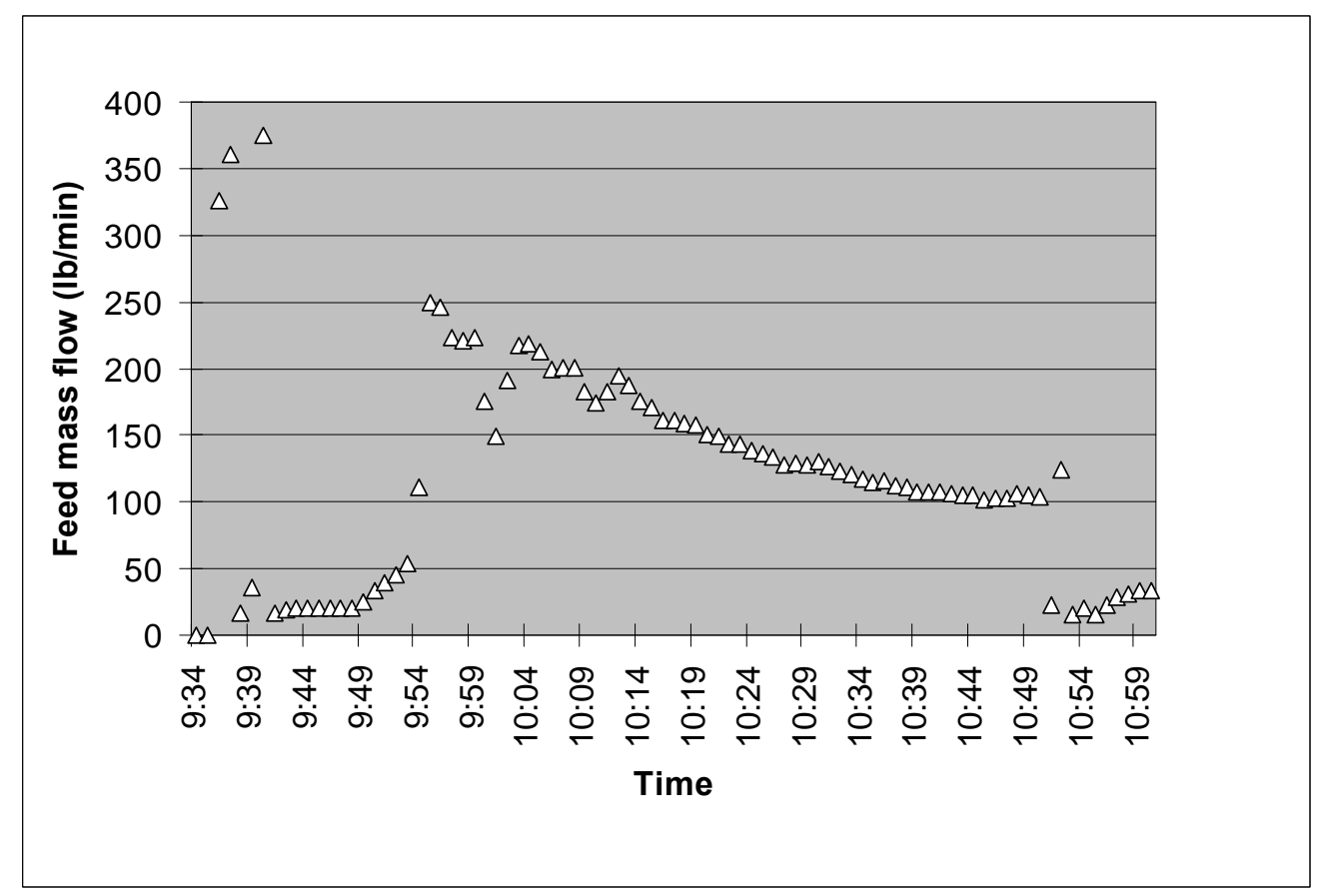

Fig. 24. Feed TSS and mass flow as a function of time, tank W-31, June 25, 1999.

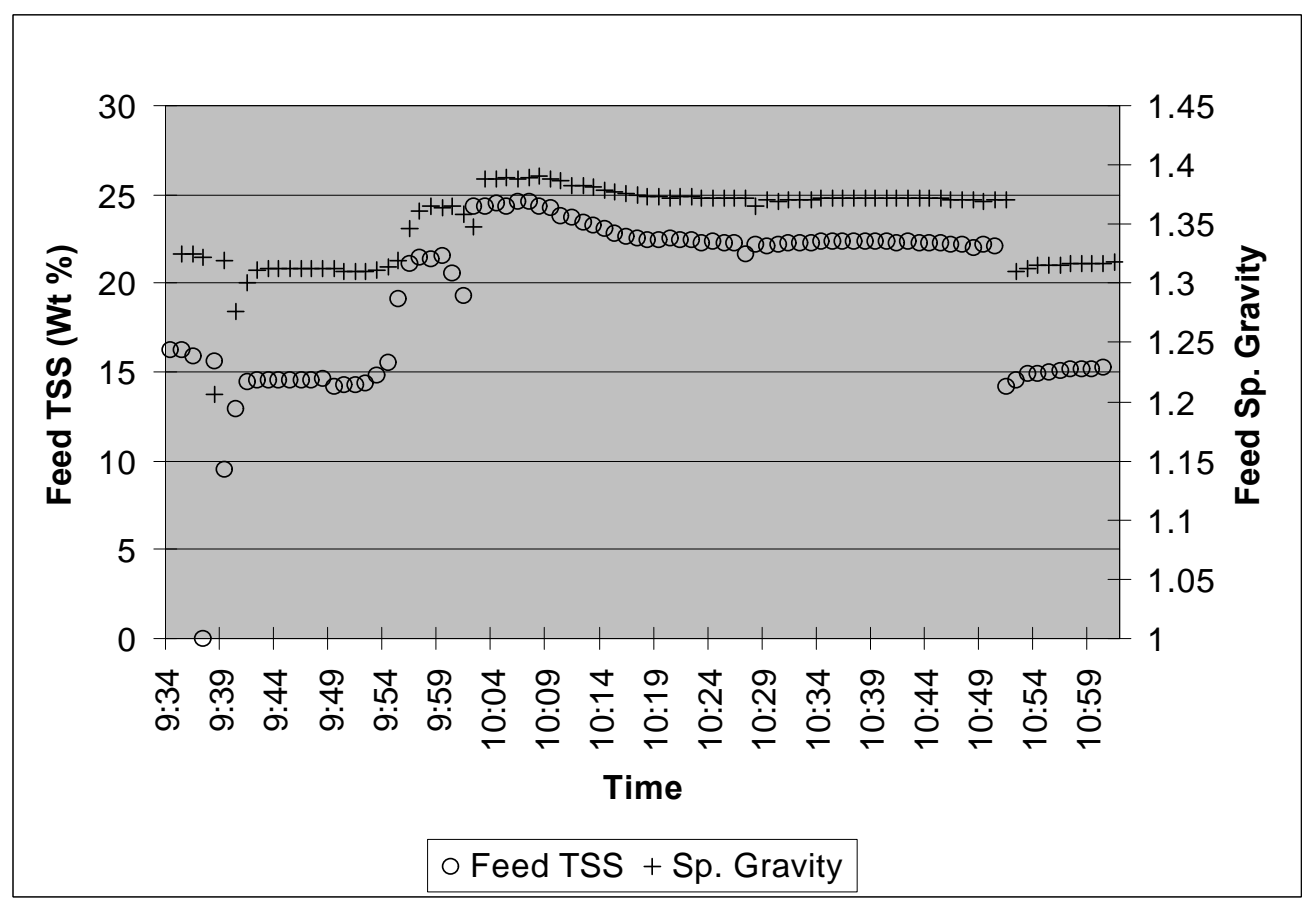

Fig. 25. Feed density and mass flow as a function of time, tank W-31, June 25, 1999. 
for several days before attempting any further cleanout measures. The system feed piping and filtration loop were flushed out using the process water supply piped into the suction side of the D/D pumps. The flush water was routed directly to MVST W-31 through the SLS concentrate return piping. After the system had been flushed out with water, the radiation background was low enough to use a lance to wash down the containment pan within the shielded maintenance area. With the drain piping operational, the SLS chemical feed system was used in an automated cleaning cycle. After this operation, the containment pan was rinsed with a dilute solution of nitric acid. These operations greatly reduced the radiation background within the shielded maintenance area, and the SLS system was placed in safe standby mode for the next operating campaign.

This experience revealed a significant flaw in the design of the containment pan drainage system. The drain header connecting the piping drain and containment pan drain was constructed at the same elevation as the bottom of the containment pan. This design allows liquids from drainage of the piping to easily back up onto the containment pan when downstream drainage piping is partially plugged. A small, 1-in.-tall crescent-shaped dam had been placed in the header to prevent liquid from entering the pan, but the liquid flowed over the dam. Once liquid entered the pan, the dam prevented drainage of a 1-in.-deep layer of liquid (about $1 \mathrm{~L}$ ) in the bottom of the pan low-point sump. In future designs, the containment pan drainage piping should be equipped with a check valve to prevent contaminated liquids from backing up into the pan. In addition, the drain header should be located at a lower elevation with respect to the bottom of the containment pan. This would increase the overall height of the system but would help prevent potential contamination of the containment pan.

\subsubsection{Results of Sample Analyses, Tank W-31}

Samples of feed, concentrate, and filtrate were obtained and analyzed for key constituents for evaluation of filter performance during operations. The feed, filtrate, and concentrate were sampled during each of the three test series; additional samples were taken at other times during the campaign to monitor filtrate quality. The results are shown in Appendix A, Tables A-3, A-4, and A-5.

The low TSS and high dissolved solids contents of the feed caused difficulties in evaluating filter performance. TSS analyses for samples containing high levels of dissolved salts are difficult because salt can be retained in the filter media and cause false positive results when the TSS is low $(<0.5 \%)$. Cations (e.g., calcium and magnesium) present in the tank sludge that are normally insoluble at high $\mathrm{pH}$ levels were not detected in either the feed or the filtrate for early samples. Aluminum, which is amphoteric in nature, is detected in both the feed and the filtrate. Gross alpha content is usually a key indicator of the level of undissolved solids in the feed; however, the gross alpha content of the feed was very low, possibly reaching the level at which some alpha isotopes are soluble. Filtrate samples consistently showed a lower gross alpha content than the feed, but only by a factor of 2:1 at the most. The concentration of transuranic (TRU) constituents, plutonium and americium, in the filtrate remained well below the limit of $1814 \mathrm{~Bq} / \mathrm{mL}$, necessary to maintain the IONSIV IE-911 ion exchanger as non-TRU waste.

Analyses of the initial samples shown in Table A-3 showed virtually no difference between the feed and filtrate except for TSS content, which was shown to be much higher in the filtrate than in the feed. This was likely a false result caused by trapping of dissolved solids in the filter media during sample analysis. Had there been actual breakthrough of insoluble solids into the filtrate, the concentrations of insoluble cations such as calcium would have been much higher than those shown for this sample. Data from samples taken during Series 2 tests (see Table A-4) give similar results. The feed sample taken on 
June 21 (Table A-5), however, had a higher suspended solids content and contained detectable levels of insoluble cations from the sludge. The ratio of the calcium $(\mathrm{Ca})$ content of the filtrate and feed indicates

a decontamination factor ( $\mathrm{DF}=$ feed Ca conc./filtrate Ca conc.) of 10. Zinc was detected in both the feed and the filtrate at similar levels; however, like aluminum, it is soluble at both high and low $\mathrm{pH}$ levels. The highest DF from the Series 3 test data was achieved for uranium at $>98$.

Additional samples were taken routinely to ensure that the concentration of TRU components remained within acceptable limits. These results are summarized in Table A-6. The clearest indication that the filter was performing well was shown in the samples of filtrate and concentrate taken on June 24 . These samples were withdrawn during the time when the feed TSS was about $15 \mathrm{wt} \%$ according to the Coriolis mass flowmeter. The concentrate sample taken during this time period indicated a TSS content of $151,000 \mathrm{mg} / \mathrm{L}$, which corresponds to about $11.6 \mathrm{wt} \%$. The TSS of the filtrate sample was $250 \mathrm{mg} / \mathrm{L}$, or about $0.02 \mathrm{wt} \%$, giving a calculated DF (concentrate wt \%/filtrate wt \%) of 580 .

\subsection{OPERATIONS AND PERFORMANCE EVALUATION, TANK W-26}

The second operating campaign for the SLS system began on July 26, 1999. Tank W-26 was chosen for this operation; this tank had recently received sludge from the retrieval and transfer of tank W-9 of the GAAT South Tank Farm. It was estimated that this tank held about 20,000 gal of sludge, roughly double that in tank W-31. With the larger volume of sludge and the limited settling time, the SLS system feed was expected to contain much higher amounts of suspended solids. As in the W-31 operation, the SLS system was to provide feed to the CsR and OTE systems for evaporation and removal of radioactive cesium. The composition of the W-26 supernatant is given in Appendix A, Table A-7. The W-26 supernatant was more dilute and thus had a much lower density than the $\mathrm{W}-31$ supernatant. This is attributed to the use of process water in the mobilization and transfer of sludges from the GAAT tank farm to the MVST. Although the W-26 supernatant was more dilute than the W-31 supernatant, its ${ }^{137} \mathrm{Cs}$ content was only slightly lower than that of W-31.

\subsubsection{SLS Performance Tests and Operations Data, Tank W-26}

Figure 26 shows the initial trend of filtrate flow at a transmembrane pressure of 25 psig and an axial flow of $350 \mathrm{gal} / \mathrm{min}(8 \mathrm{ft} / \mathrm{s})$. Both axial flow and transmembrane pressure were reasonably stable. Filtrate flow varied from about 2.2 to $4.2 \mathrm{gal} / \mathrm{min}\left(0.044\right.$ to $\left.0.084 \mathrm{gal} \mathrm{min}^{! 1} \mathrm{ft}^{\prime 2}\right)$ with the higher flow achieved following the hourly backpulse cycle. Filtrate flow was stopped periodically due to the batchwise production of filtrate. As shown in Fig. 27, the solids content of the feed during the initial $16 \mathrm{~h}$ of operation varied from 3.2 to $7.5 \mathrm{wt} \%$. The feed mass flow was fairly consistent at 280 to $350 \mathrm{lb} / \mathrm{min}$.

On the morning of July 28 , Series 1 testing began with the same approach as that used in the W-31 operation. Table 4 shows the list of conditions and results of the tests performed. The tests encompassed a 26-h period and were interrupted by two unplanned outages for OTE evaporator maintenance. As shown in Fig. 28, axial flow and transmembrane pressure were reasonably well controlled during the tests. Figure 29 shows that the suspended solids content was generally stable with the exception of several short-term spikes in concentration. These spikes occurred during restart activities after the maintenance shutdowns and were caused by partial collapse of the depression in the W-26 sludge layer. For most of the tests, however, the solids content was about $0.3 \mathrm{wt} \%$. Figures 30 and 31 show the trends of filtrate flux as a function of transmembrane pressure and axial velocity. The trends are similar to those experienced in the W-31 operation. The data in Fig. 30 data indicate increased filtrate flux as the transmembrane pressure was increased, and Fig. 31 shows little or no increase in filtrate flux as the 


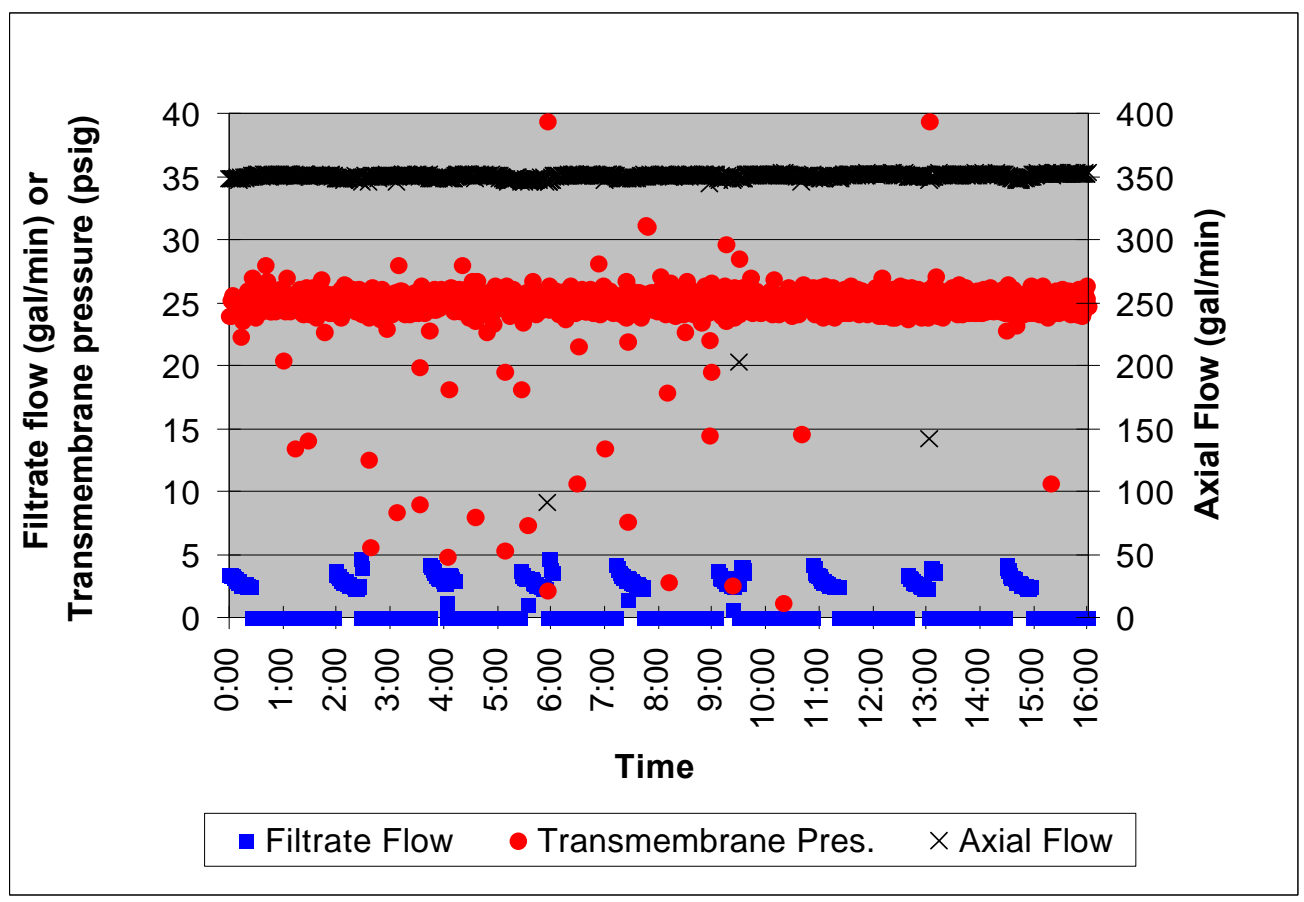

Fig. 26. Filtrate flow, transmembrane pressure, and axial flow as a function of time for initial startup of tank W-26 processing.

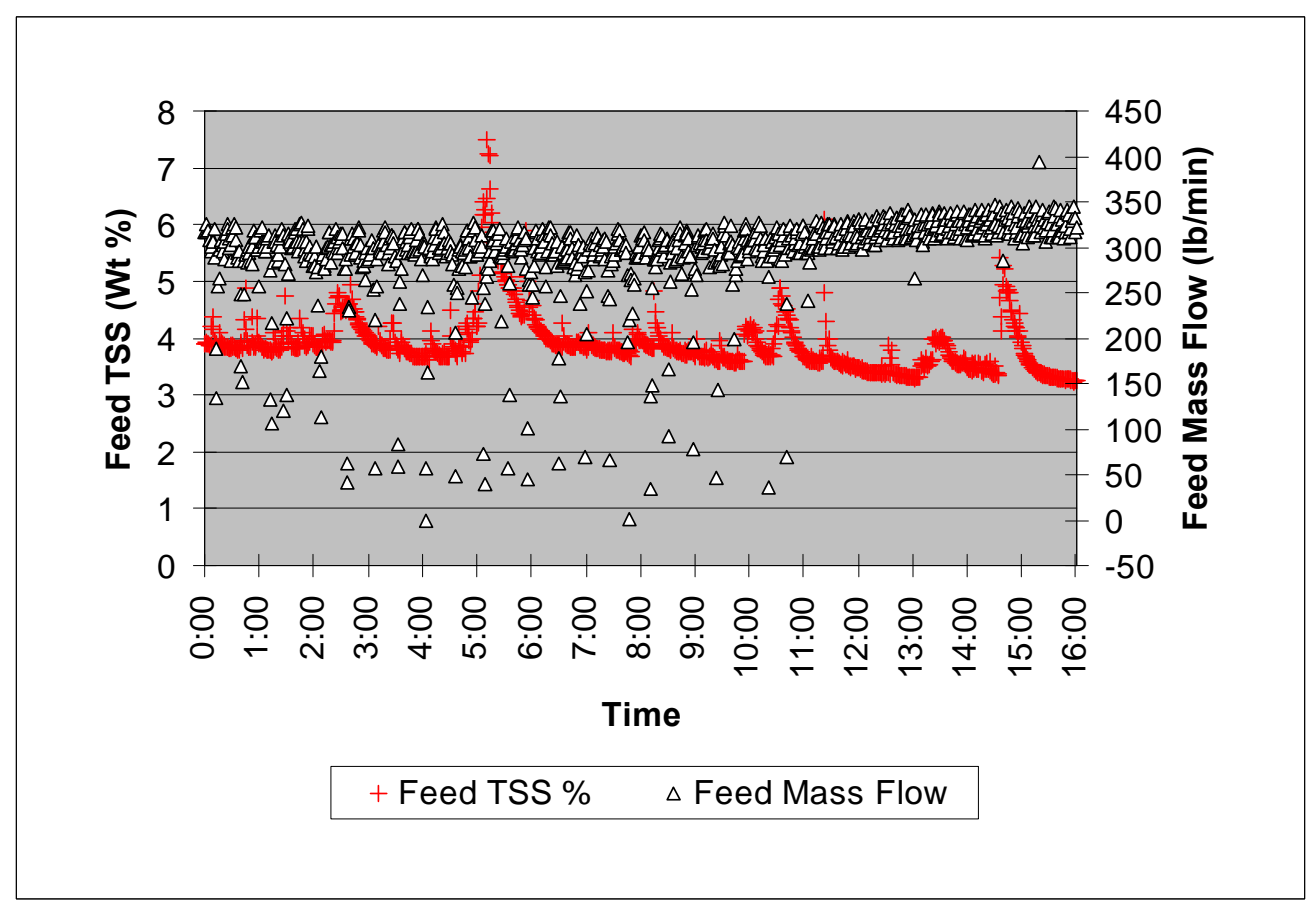

Fig. 27. Feed mass flow and feed TSS as a function of time for initial startup of tank W-26 processing. 


\begin{tabular}{|c|c|c|c|c|c|c|c|}
\hline \multirow{2}{*}{$\begin{array}{l}\text { Transmembrane } \\
\text { pressure (psig) }\end{array}$} & \multicolumn{2}{|c|}{ Axial flow } & \multirow{2}{*}{\begin{tabular}{|} 
Test \\
order \\
\end{tabular}} & \multicolumn{2}{|c|}{ Avg. filtrate } & \multirow{2}{*}{$\begin{array}{c}\text { Filtrate } \\
\text { max. } \\
\end{array}$} & \multirow{2}{*}{$\begin{array}{c}\text { Filtrate } \\
\text { min. }\end{array}$} \\
\hline & $\mathrm{gal} / \mathrm{min}$ & $\mathrm{ft} / \mathrm{s}$ & & $\mathrm{gal} / \mathrm{min}$ & gal $\min ^{! 1} \mathrm{ft}^{! 2}$ & & \\
\hline 20 & 170 & 4 & 11 & 1.38 & 0.0276 & 3.62 & 1.10 \\
\hline 20 & 300 & 7 & 1 & 2.4 & 0.048 & 3.96 & 1.76 \\
\hline 20 & 325 & 7.6 & 12 & 1.46 & 0.0292 & 4.67 & 1.19 \\
\hline 20 & 408 & 9.5 & 9 & 2.21 & 0.0442 & 3.67 & 1.71 \\
\hline 20 & 425 & 10 & 7 & 1.87 & 0.0374 & 2.92 & 1.55 \\
\hline 25 & 170 & 4 & 3 & 2.18 & 0.0436 & 2.97 & 1.78 \\
\hline 25 & 300 & 7 & 2 & 2.6 & 0.052 & 3.13 & 2.25 \\
\hline 25 & 300 & 7 & 5 & 2.44 & 0.0488 & 3.26 & 1.91 \\
\hline 25 & 425 & 10 & 6 & 2.33 & 0.0466 & 3.89 & 1.89 \\
\hline 30 & 170 & 4 & 4 & 2.89 & 0.0578 & 4.75 & 2.27 \\
\hline 30 & 300 & 7 & 10 & 2.3 & 0.046 & 4.46 & 1.81 \\
\hline 30 & 425 & 10 & 8 & 2.27 & 0.0454 & 3.19 & 1.86 \\
\hline \multicolumn{8}{|c|}{$\begin{array}{l}{ }^{a} \text { Other test conditions: (1) Test was conducted over a } 26 \text { - h period beginning } \\
\text { July 28, } 1999 \text {. (2) Mass flow of feed ranged between } 200 \text { and } 350 \mathrm{lb} / \mathrm{min} \text {. (3) Time } \\
\text { between backpulse: } 60 \mathrm{~min} \text {. (4) TSS content of feed was about } 0.33 \mathrm{wt} \% \text {. }\end{array}$} \\
\hline
\end{tabular}

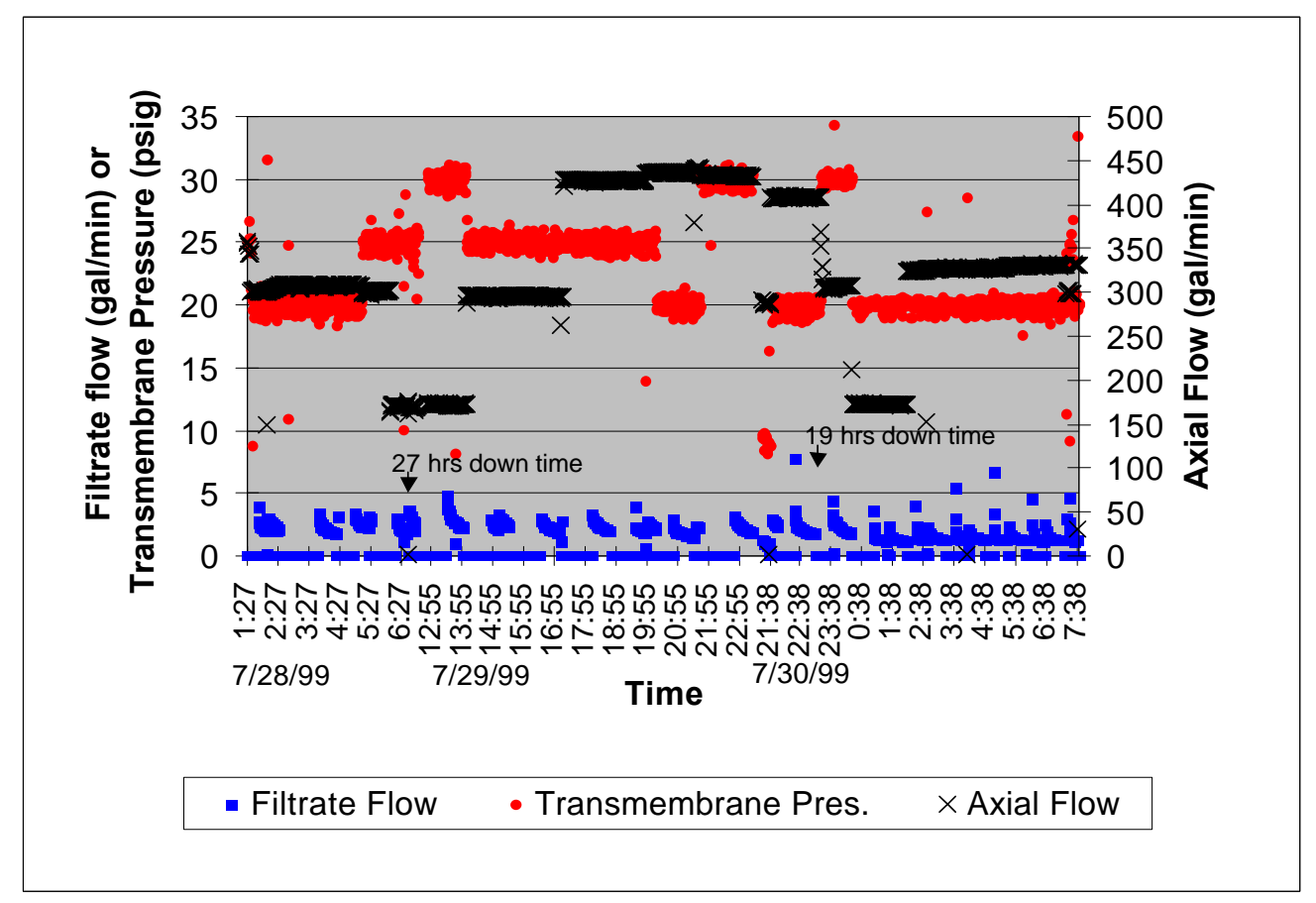

Fig. 28. Filtrate flow, axial flow, and transmembrane pressure as a function of time, Test Series 1, tank W-26. 


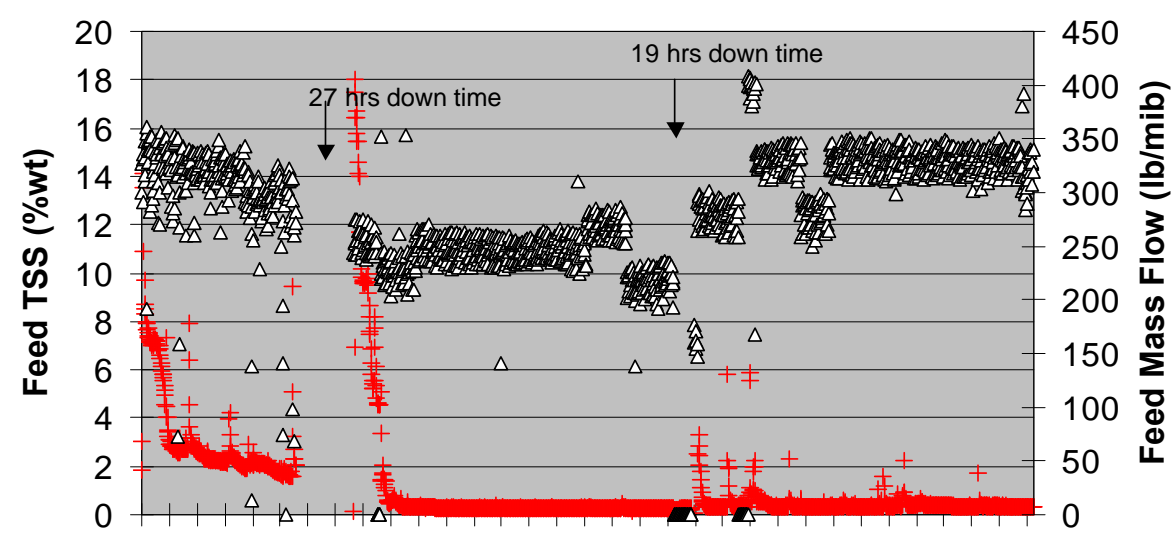

مي̣ 붑 7/28/99 7/29/99 Time 7/30/99

\section{+ Feed TSS \\ $\Delta$ Feed Mass Flow}

Fig. 29. Feed mass flow and TSS as a function of time, Test Series 1, tank W-26.

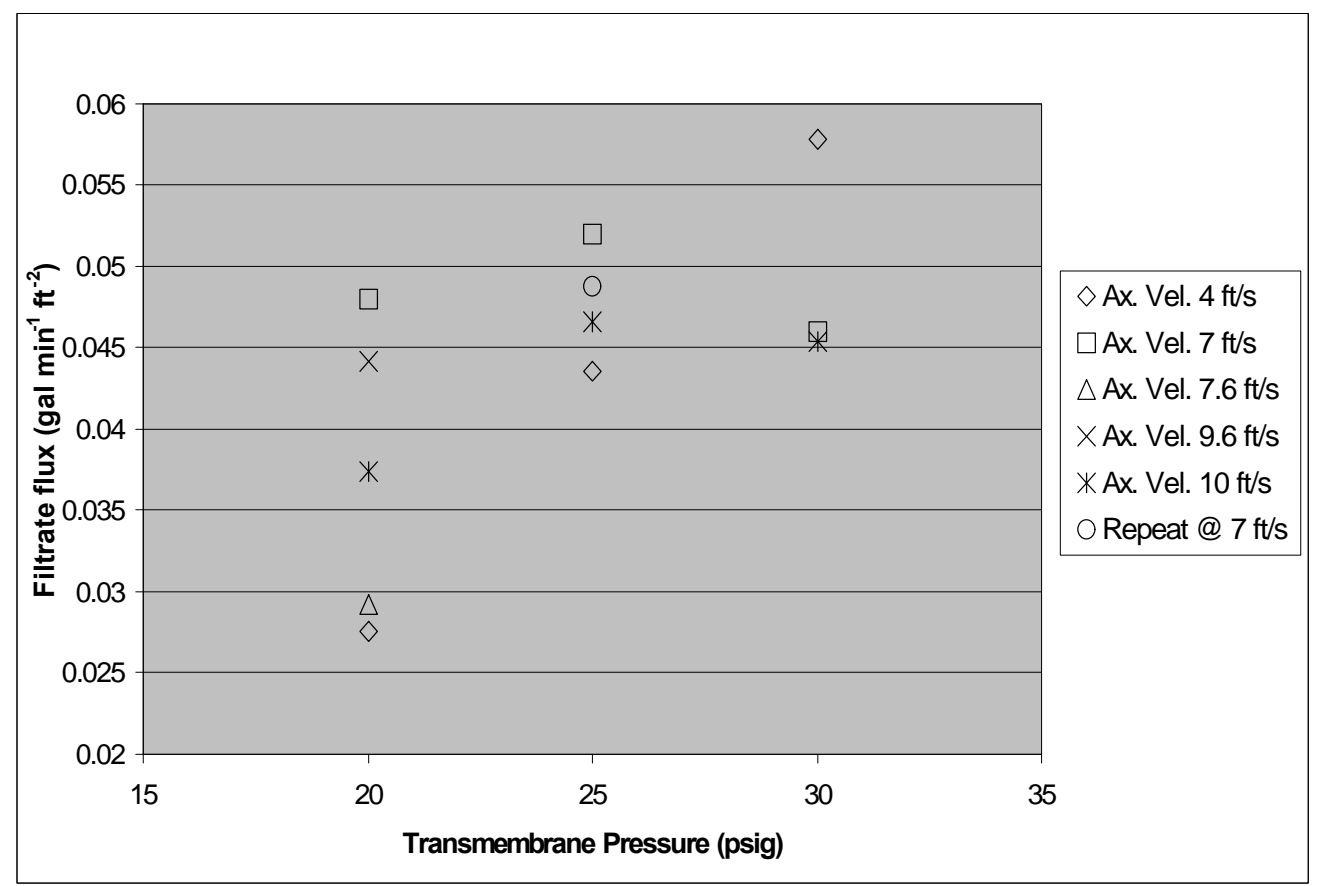

Fig. 30. Average filtrate flux as a function of transmembrane pressure, Test Series 1, tank W-26. 


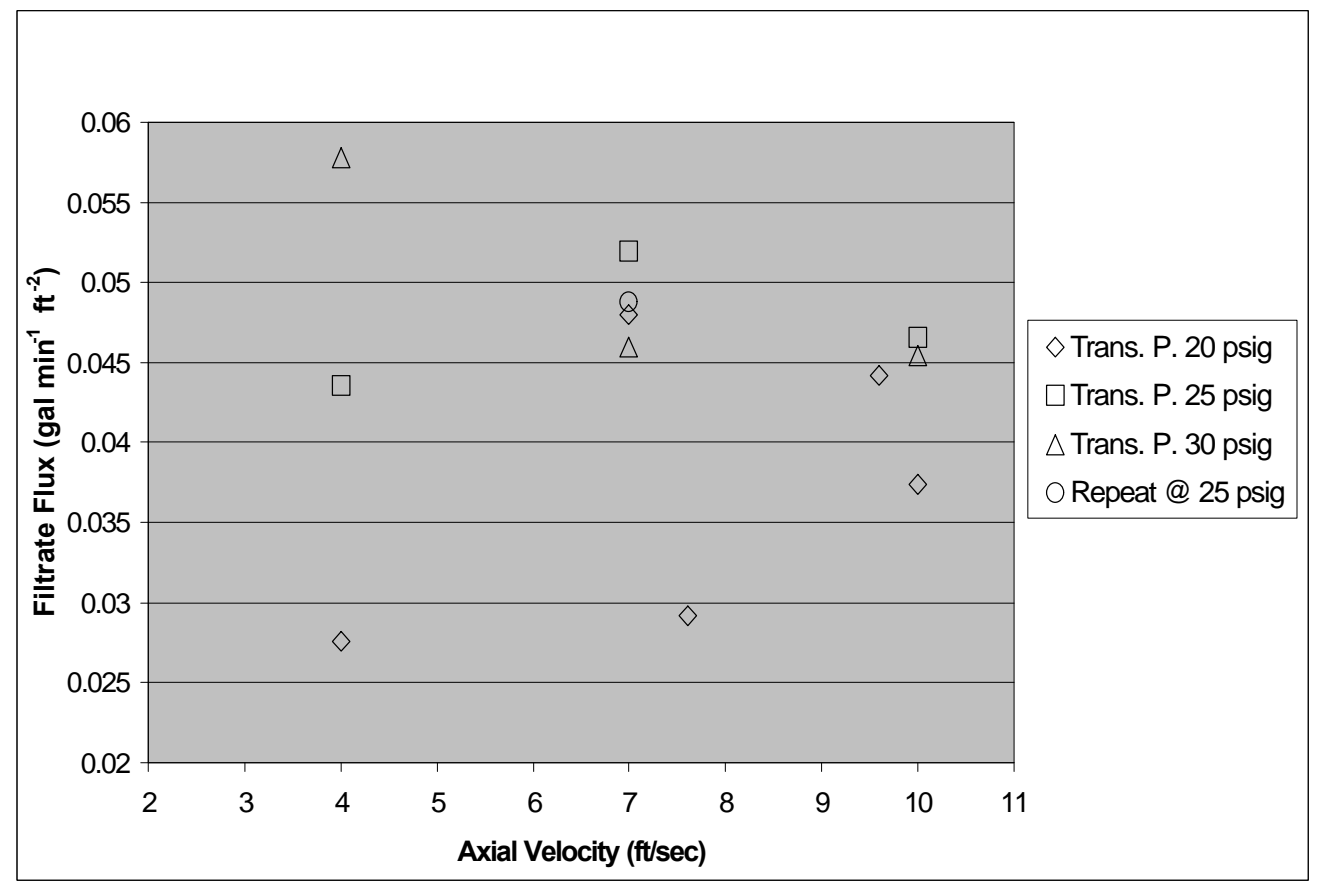

Fig. 31. Average filtrate flux as a function of axial velocity, Test Series 1, tank W-26.

axial velocity was increased. As in the W-31 tests, axial velocity was not influencing flux because the solids content of the feed was low $(0.33 \mathrm{wt} \%)$, and it was unlikely that filter cake had formed on filter surfaces.

On August 9-11, Series 2 testing was performed over a period of about $43 \mathrm{~h}$. The results of the tests are summarized in Table 5. Downtime was minimal during this test series, and the test parameters were reasonably well controlled. Additional tests were added to this series when it was determined that a transmembrane pressure of 10 psig could be adequately maintained when the feed flow was slightly reduced. The range of filtrate flow achieved during the tests was 0.5 to $7.9 \mathrm{gal} / \mathrm{min}(0.01$ to $0.16 \mathrm{gal}$ $\min ^{! 1} \mathrm{ft}^{! 2}$ ), with the higher flow values following a backpulse cycle. As shown in Fig. 32, a sharp increase in filtrate production followed the hourly backpulse cycle, but production quickly dropped to lower values within 10 to 20 min following the backpulse. Figure 33 shows a very steady and gradual increase in feed solids content from 0.6 to $0.83 \mathrm{wt} \%$ solids during the test series. In general, the performance of the filter was somewhat different from that observed in the Series 1 tests. Figure 34 shows the influence of transmembrane pressure on filtrate flux for the test series. Only the tests conducted at the highest axial velocity $(>10 \mathrm{ft} / \mathrm{s})$ showed a significant increase in filtrate flux as the pressure was increased. Data at axial velocities of 4 and $7 \mathrm{ft} / \mathrm{s}$ showed a minor increase in flux when the pressure was increased. This behavior is possibly due to the formation of filter cake that is not impacted or reduced in thickness unless the axial velocity is very high. Figure 35 shows that increasing axial velocity has a significant impact on filtrate flux, as would be expected when filter-cake material is building up. 


\begin{tabular}{|c|c|c|c|c|c|c|c|}
\hline \multirow{2}{*}{$\begin{array}{l}\text { Transmembrane } \\
\text { pressure (psig) }\end{array}$} & \multicolumn{2}{|c|}{ Axial flow } & \multirow{2}{*}{$\begin{array}{l}\text { Test } \\
\text { order }\end{array}$} & \multicolumn{2}{|c|}{ Avg. filtrate } & \multirow{2}{*}{$\begin{array}{c}\text { Filtrate flow } \\
\text { max. (gal/min) }\end{array}$} & \multirow{2}{*}{$\begin{array}{l}\text { Filtrate flow } \\
\text { min. (gal/min) }\end{array}$} \\
\hline & $\mathrm{gal} / \mathrm{min}$ & $\mathrm{ft} / \mathrm{s}$ & & $\mathrm{gal} / \mathrm{min}$ & gal min' $\mathrm{ft}^{! 2}$ & & \\
\hline 10 & 300 & 7.0 & 8 & 0.897 & 0.0179 & 4.29 & 0.51 \\
\hline 10 & 300 & 7.0 & 16 & 0.686 & 0.0137 & 1.37 & 0.48 \\
\hline 10 & 425 & 10.0 & 4 & 1.19 & 0.0238 & 3.53 & 0.38 \\
\hline 20 & 177 & 4.2 & 9 & 0.663 & 0.0133 & 1.30 & 0.54 \\
\hline 20 & 300 & 7.0 & 13 & 1.27 & 0.0254 & 6.56 & 0.60 \\
\hline 20 & 300 & 7.0 & 15 & 0.767 & 0.0153 & 1.91 & 0.62 \\
\hline 20 & 425 & 10.0 & 2 & 1.24 & 0.0248 & 4.21 & 0.86 \\
\hline 25 & 177 & 4.2 & 14 & 0.674 & 0.0135 & 2.87 & 0.56 \\
\hline 25 & 300 & 7.0 & 1 & 1.07 & 0.0214 & 2.57 & 0.52 \\
\hline 25 & 300 & 7.0 & 7 & 1.01 & 0.0202 & 6.19 & 0.59 \\
\hline 25 & 300 & 7.0 & 11 & 1.11 & 0.0222 & 4.98 & 0.72 \\
\hline 25 & 425 & 10.0 & 12 & 2.69 & 0.0538 & 7.91 & 0.87 \\
\hline 25 & 504 & 11.8 & 10 & 2.76 & 0.0552 & 7.93 & 1.10 \\
\hline 30 & 177 & 4.2 & 3 & 0.774 & 0.0155 & 1.59 & 0.63 \\
\hline 30 & 300 & 7.0 & 6 & 1.01 & 0.0202 & 3.85 & 0.48 \\
\hline 30 & 425 & 10.0 & 5 & 1.61 & $\begin{array}{l}0.0322 \\
\end{array}$ & 4.73 & 1.23 \\
\hline \multicolumn{8}{|c|}{$\begin{array}{l}{ }^{a} \text { Other test conditions: (1) Tests were conducted over a } 43-\mathrm{h} \text { time period beginning August } 9 \text {, } \\
\text { 1999. (2) Mass flow of feed ranged between } 240 \text { and } 440 \mathrm{lb} / \mathrm{min} \text {. (3) Time between backpulse, } \\
60 \mathrm{~min} \text {. (4) TSS content of feed was } 0.6 \text { to } 0.83 \mathrm{wt} \% \text {. }\end{array}$} \\
\hline
\end{tabular}

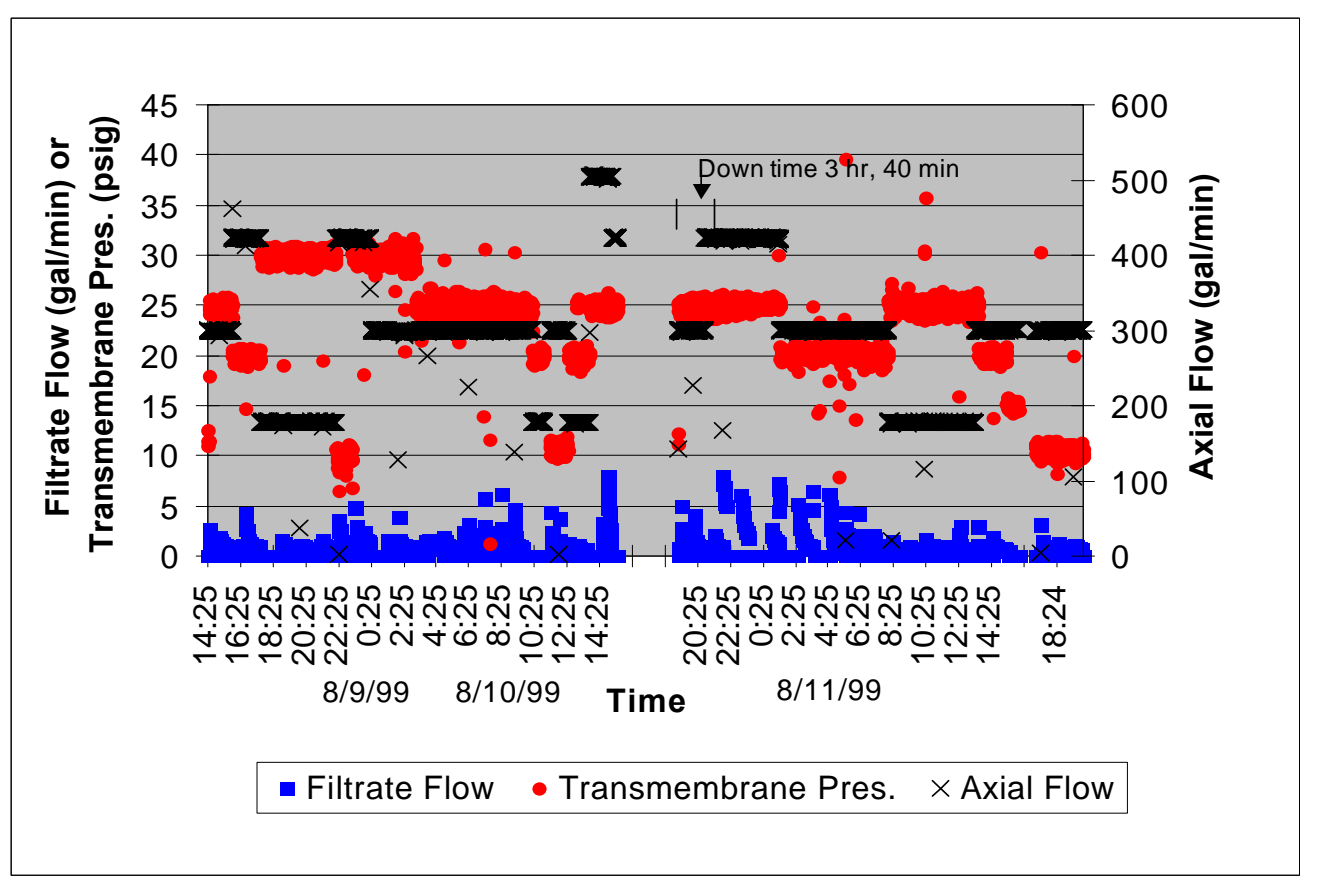

Fig. 32. Filtrate flow, transmembrane pressure, and axial flow as a function of time, Test Series 2, tank W-26. 


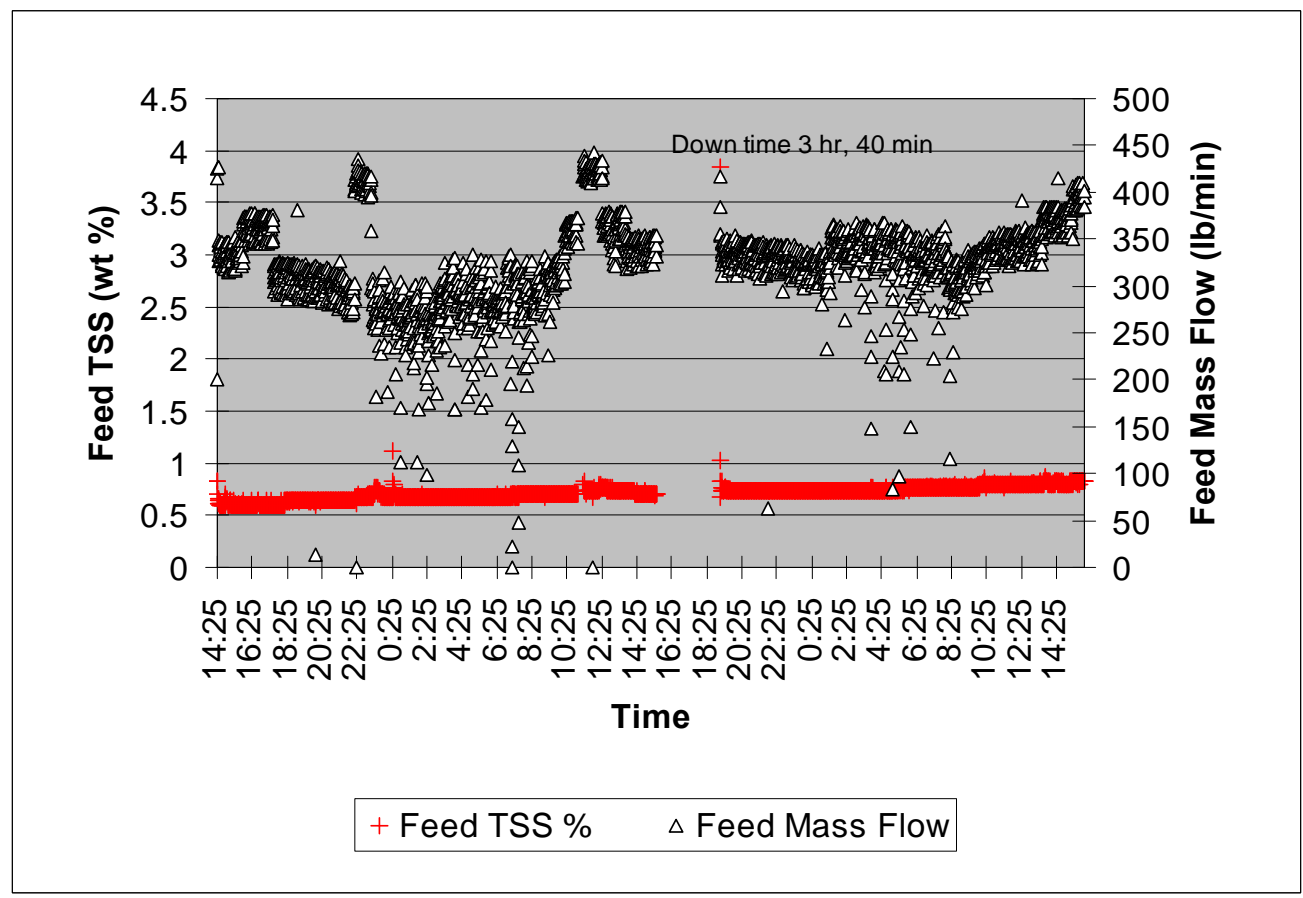

Fig. 33. Feed mass flow and TSS as a function of time, Test Series 2, tank W-26.

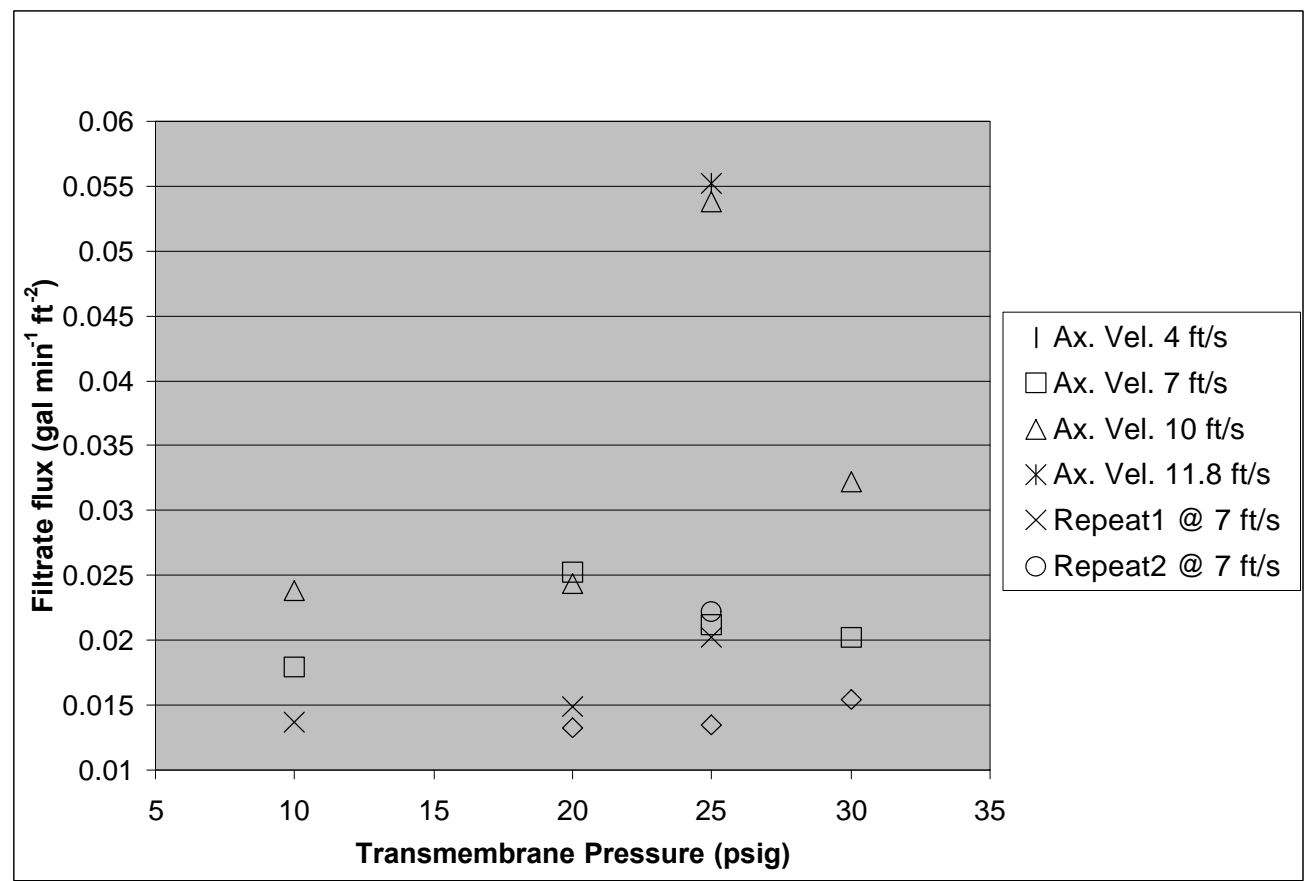

Fig. 34. Average filtrate flux as a function of transmembrane pressure, Test Series 2, tank W-26. 


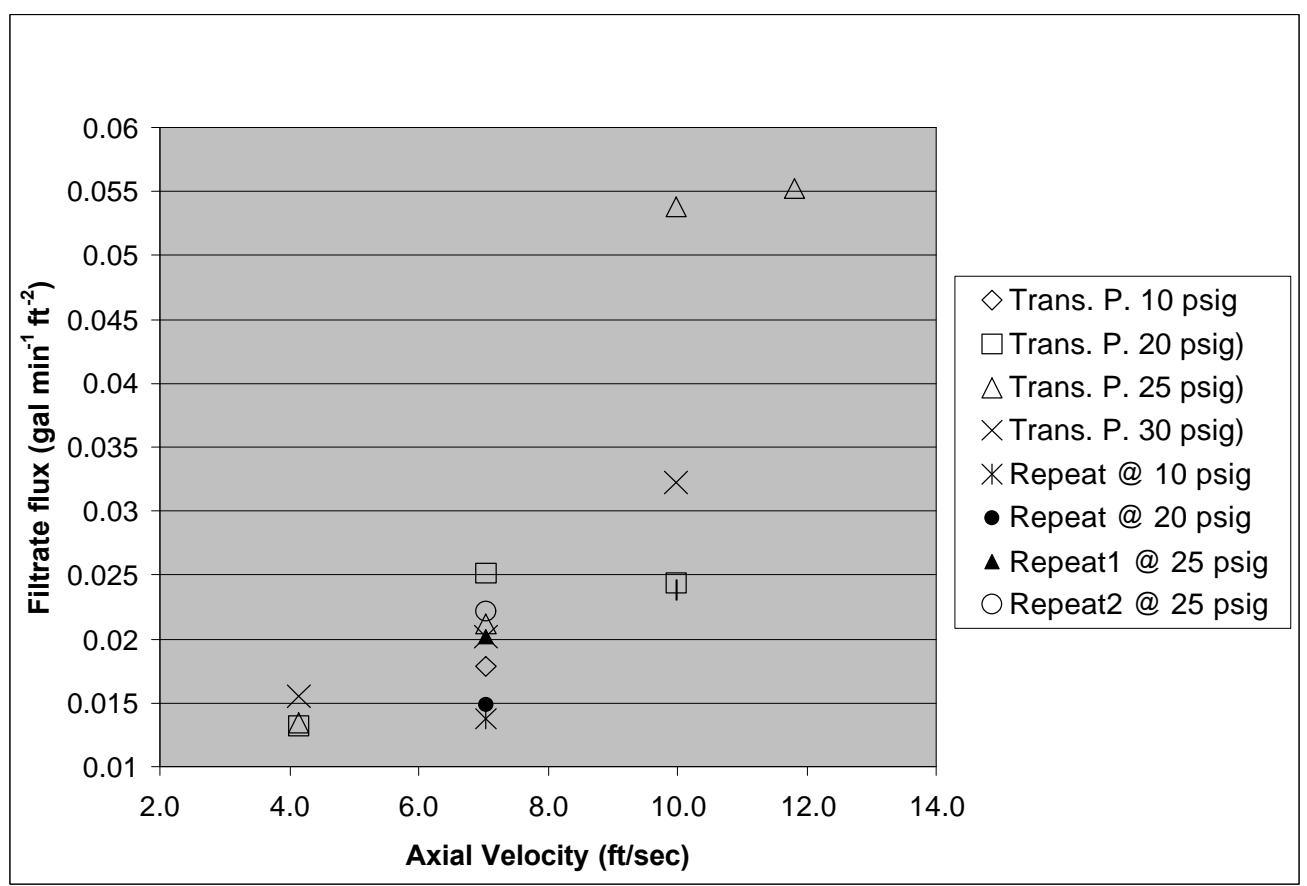

Fig. 35. Average filtrate flux as a function of axial velocity, Test Series 2, tank W-26.

A third series of tests was conducted on August 13 during a period when the solids content of the feed was increasing significantly. The results of these tests are given in Table 6 . The tests were conducted over a 25 -h period during which the feed solids content increased from 2.1 to $3.9 \mathrm{wt} \%$. Two additional tests were added to the series to evaluate filter performance at a slightly higher axial velocity. The filtrate flow range during this period was 0.63 to $4.0 \mathrm{gal} / \mathrm{min}\left(0.013\right.$ to $\left.0.08 \mathrm{gal} \mathrm{min}^{! 1} \mathrm{ft}^{\prime 2}\right)$. Figure 36 shows the increasing trend of feed solids content as well as the trend of high, then rapidly declining filtrate flow following the backpulse. Figure 37 shows that the axial flow and transmembrane pressure were well controlled during the tests. Figure 38 indicates a slightly greater influence of transmembrane pressure on filtrate flux than was shown in Series 2 tests. Figure 39 shows that increasing the axial velocity also increased filtrate flux by an amount similar to that caused by increasing the transmembrane pressure. However, the axial flow influence in this case was not as great as that shown in Series 2 testing. The high flux rates shown in Series 2 data at axial velocities of $10 \mathrm{ft} / \mathrm{s}$ and above were not reflected in Series 3 data. It is possible that the high suspended solids content could have dampened the influence of both the transmembrane pressure and the axial flow. 


\begin{tabular}{|c|c|c|c|c|c|c|c|}
\hline \multirow{2}{*}{$\begin{array}{c}\text { Transmembrane } \\
\text { pressure (psig) }\end{array}$} & \multicolumn{2}{|c|}{ Axial flow } & \multirow{2}{*}{$\begin{array}{l}\text { Test } \\
\text { order }\end{array}$} & \multicolumn{2}{|c|}{ Avg. filtrate } & \multirow{2}{*}{$\begin{array}{c}\text { Filtrate flow } \\
\text { max. (gal/min) }\end{array}$} & \multirow{2}{*}{$\begin{array}{l}\text { Filtrate flow } \\
\mathrm{min} \text {. (gal/min) }\end{array}$} \\
\hline & $\mathrm{gal} / \mathrm{min}$ & $\mathrm{ft} / \mathrm{s}$ & & gal/min & gal min! $\mathrm{ft}^{! 2}$ & & \\
\hline 20 & 175 & 4.1 & 9 & 0.84 & 0.0168 & 1.33 & 0.68 \\
\hline 20 & 300 & 7.0 & 7 & 0.98 & 0.0196 & 1.44 & 0.80 \\
\hline 20 & 425 & 10.0 & 4 & 1.043 & 0.0209 & 2.49 & 0.85 \\
\hline 25 & 177 & 4.1 & 6 & 0.97 & 0.0194 & 2.83 & 0.63 \\
\hline 25 & 300 & 7.0 & 3 & 1.14 & 0.0228 & 3.75 & 0.77 \\
\hline 25 & 300 & 7.0 & 8 & 1.056 & 0.0211 & 1.85 & 0.82 \\
\hline 25 & 300 & 7.0 & 12 & 1.062 & 0.0212 & 3.95 & 0.83 \\
\hline 25 & 425 & 10.0 & 5 & 1.241 & 0.0248 & 2.10 & 0.95 \\
\hline 25 & 425 & 10.0 & 11 & 1.132 & 0.0226 & 1.84 & 0.92 \\
\hline 25 & 460 & 10.8 & 1 & 1.31 & 0.0262 & 2.61 & 1.04 \\
\hline 25 & 460 & 10.8 & 14 & 1.2 & 0.0240 & 4.17 & 0.92 \\
\hline 30 & 175 & 4.1 & 13 & 1.048 & 0.0210 & 1.74 & 0.75 \\
\hline 30 & 300 & 7.0 & 2 & 1.124 & 0.0225 & 1.90 & 0.92 \\
\hline 30 & 425 & 10.0 & 10 & 1.29 & 0.0256 & 2.60 & 0.99 \\
\hline $\begin{array}{l}{ }^{a} \text { Other test con } \\
\text { (2) Mass flow of } \\
\text { (4) TSS content o }\end{array}$ & ions: (1 & Tests & were & nducted o & over a $25-\mathrm{h} \mathrm{pe}$ & iod beginning & $\begin{array}{l}\text { ugust } 13,1999 \text {. } \\
\text { pulse, } 60 \text { min. } \\
\end{array}$ \\
\hline
\end{tabular}

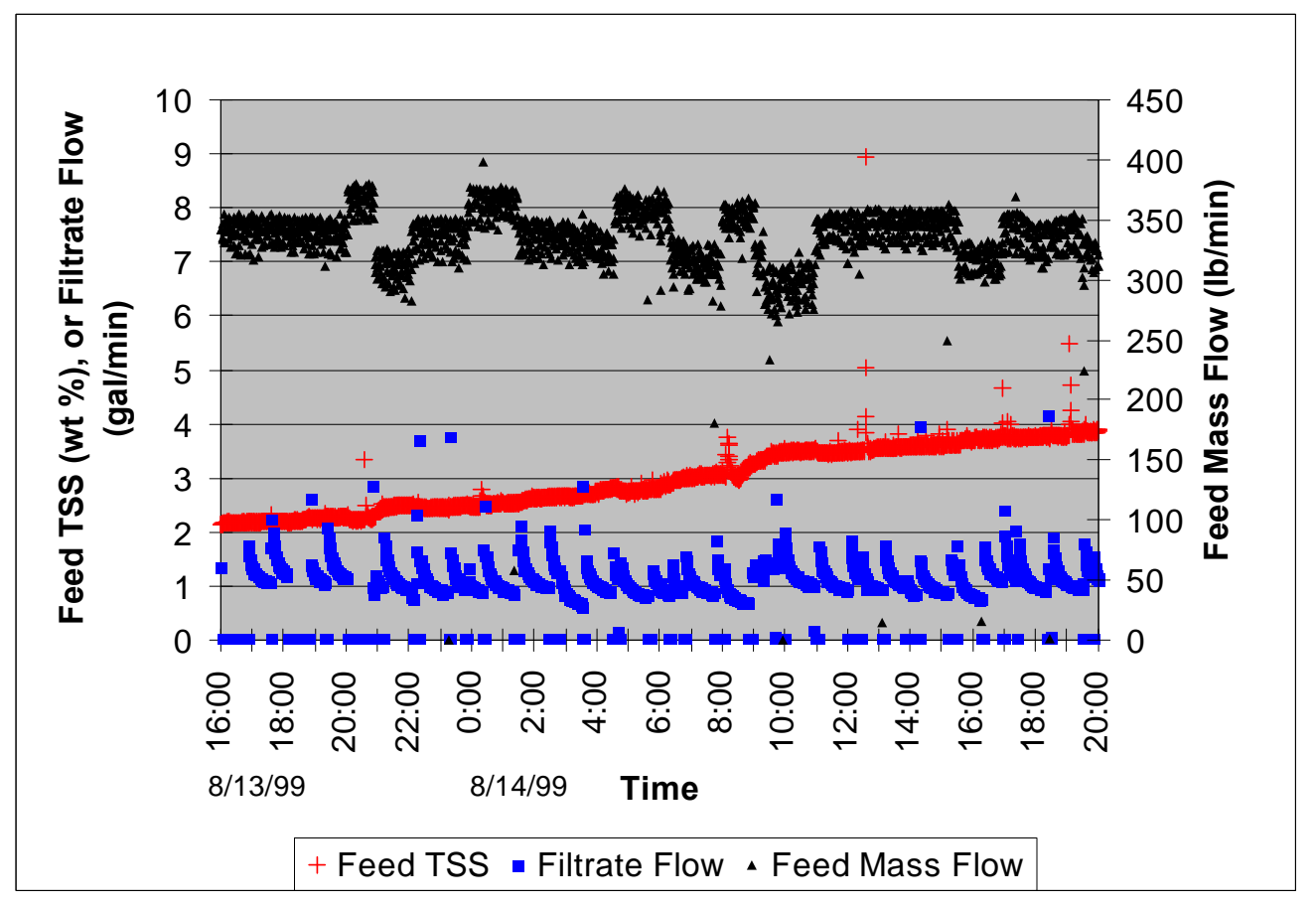

Fig. 36. Feed mass flow, feed TSS, and filtrate flow as a function of time for Test Series 3, tank W-26. 


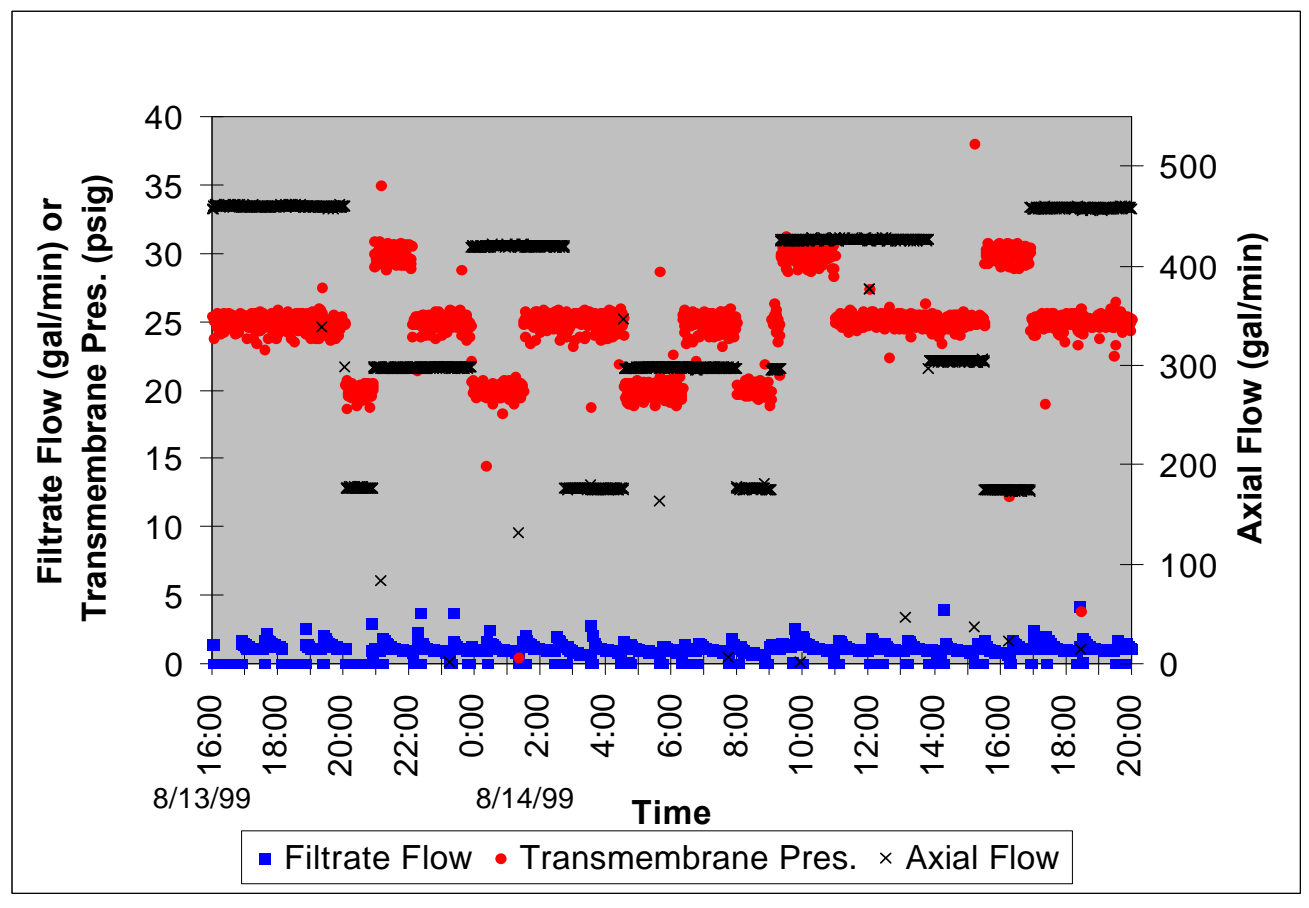

Fig. 37. Filtrate flow, axial flow, and transmembrane pressure as as function of time for Test Series 3, tank W-26.

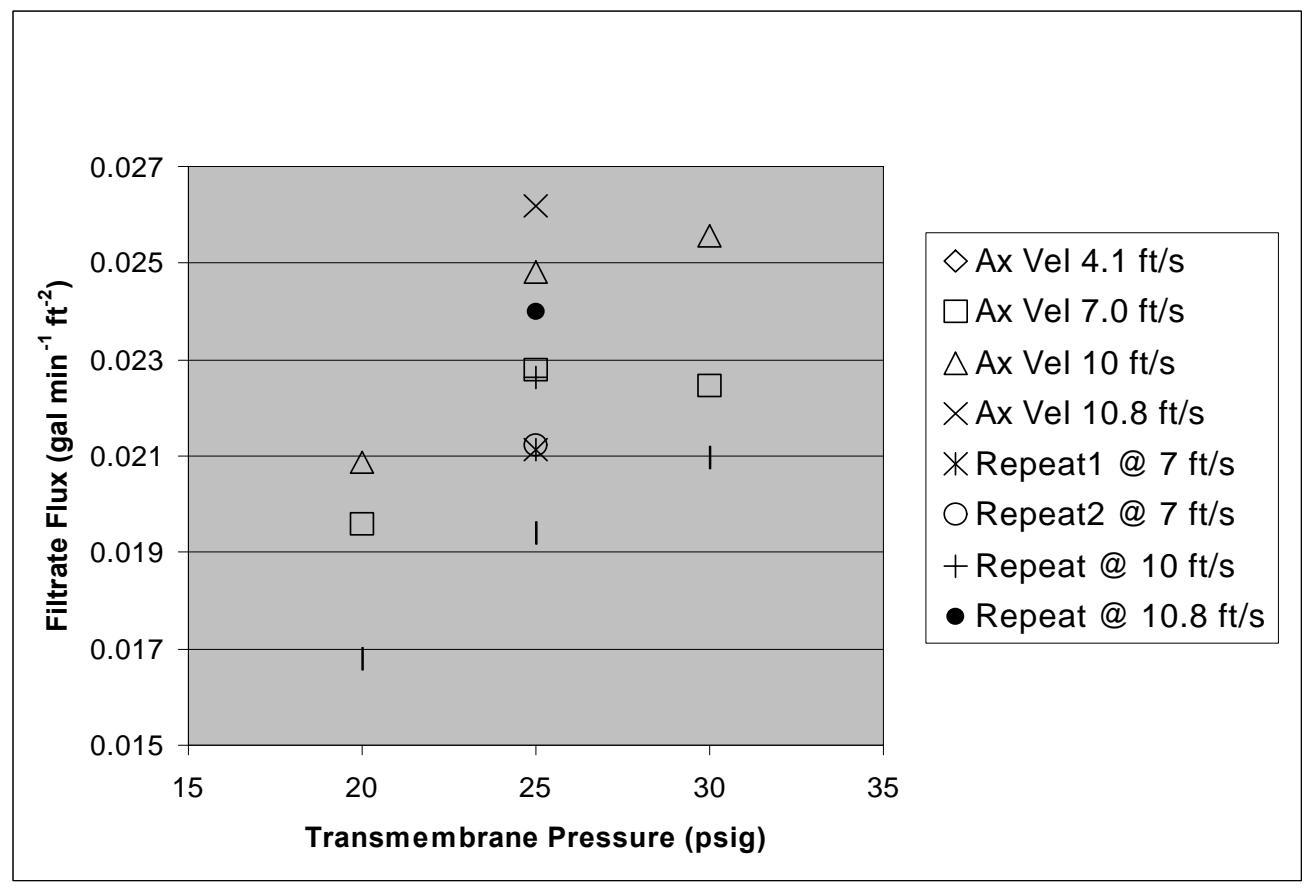

Fig. 38. Average filtrate flux as a function of transmembrane pressure for Test Series 3, tank W-26. 


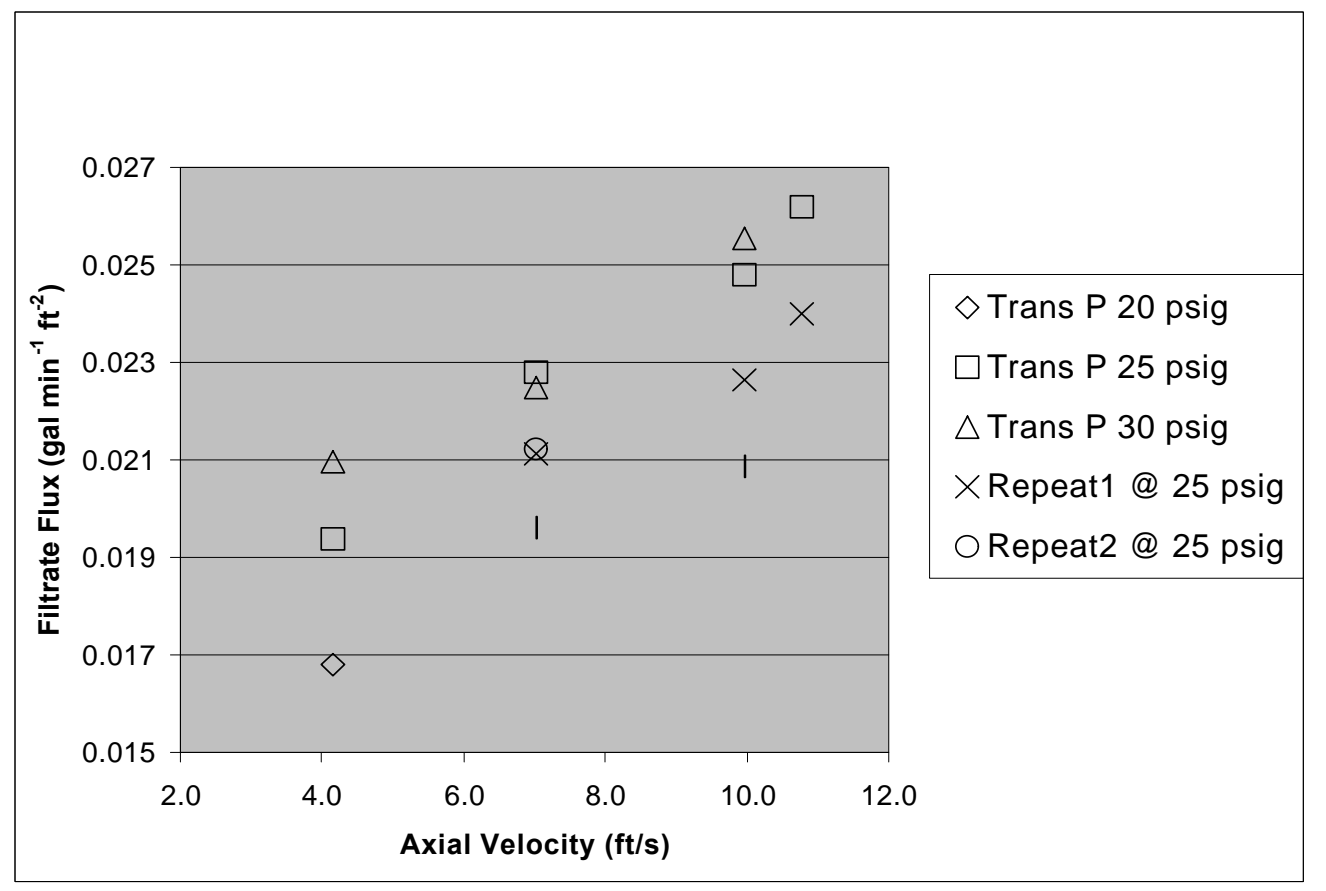

Fig. 39. Average filtrate flux as a function of axial velocity for Test Series 3, tank W-26.

A final test series, Series 4, was initiated on August 20, but operations were terminated before it could be concluded. Table 7 summarizes the results of the tests, which were conducted over a 21 -h period during which the feed solids content gradually increased from about 6.7 to $10 \mathrm{wt} \%$ (Fig. 40). The axial flow and the transmembrane pressure were reasonably controlled during the six tests that were performed. As shown in Fig. 41, the range of filtrate flow was about 0.53 to $4 \mathrm{gal} / \mathrm{min}\left(0.011\right.$ to $\left.0.08 \mathrm{gal} \mathrm{min}^{! 1} \mathrm{ft}^{\prime 2}\right)$, which is nearly the same as that achieved in the Series 3 tests. Little could be determined about the influence of transmembrane pressure and axial velocity due to the small number of tests. Figure 42 seems to indicate a positive influence of increasing the transmembrane pressure, while Fig. 43 shows a minor increase in filtrate flux as the axial velocity was increased at 20-psig transmembrane pressure.

\begin{tabular}{|c|c|c|c|c|c|c|c|}
\hline \multirow{2}{*}{$\begin{array}{l}\text { Transmembrane } \\
\text { pressure (psig) }\end{array}$} & \multicolumn{2}{|c|}{ Axial flow } & \multirow{2}{*}{$\begin{array}{l}\text { Test } \\
\text { order }\end{array}$} & \multicolumn{2}{|c|}{ Avg. filtrate } & \multirow{2}{*}{$\begin{array}{c}\text { Max. filtrate } \\
\text { flow (gal/min) }\end{array}$} & \multirow{2}{*}{$\begin{array}{c}\text { Min. filtrate } \\
\text { flow (gal/min) }\end{array}$} \\
\hline & $\mathrm{gal} / \mathrm{min}$ & $\mathrm{ft} / \mathrm{s}$ & & $\mathrm{gal} / \mathrm{min}$ & gal min ${ }^{! 1} \mathrm{ft}^{! 2}$ & & \\
\hline 15 & 292 & 6.8 & 1 & 0.79 & 0.0158 & 2.56 & 0.53 \\
\hline 20 & 170 & 4.0 & 6 & 0.819 & 0.0164 & 3.94 & 0.46 \\
\hline 20 & 292 & 6.8 & 2 & 0.977 & 0.0195 & 3.91 & 0.71 \\
\hline 20 & 300 & 7.0 & 5 & 0.845 & 0.0169 & 2.38 & 0.54 \\
\hline 20 & 425 & 10.0 & 4 & 0.963 & 0.0193 & 4.32 & 0.64 \\
\hline 30 & 300 & 7.0 & 3 & 1.055 & 0.0211 & 3.57 & 0.78 \\
\hline
\end{tabular}




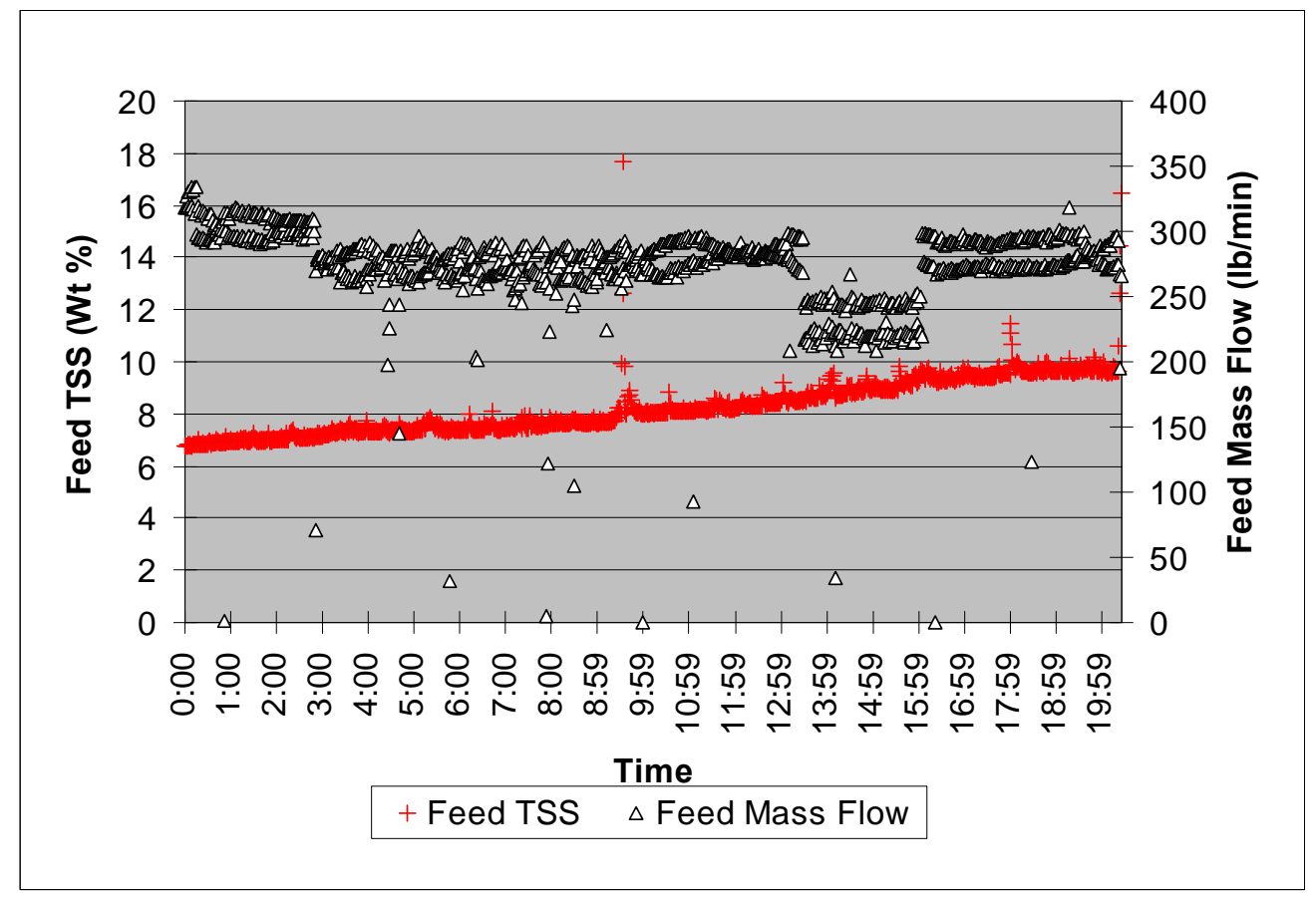

Fig. 40. Feed TSS and feed mass flow as a function of time for Test Series 4, tank W-26.

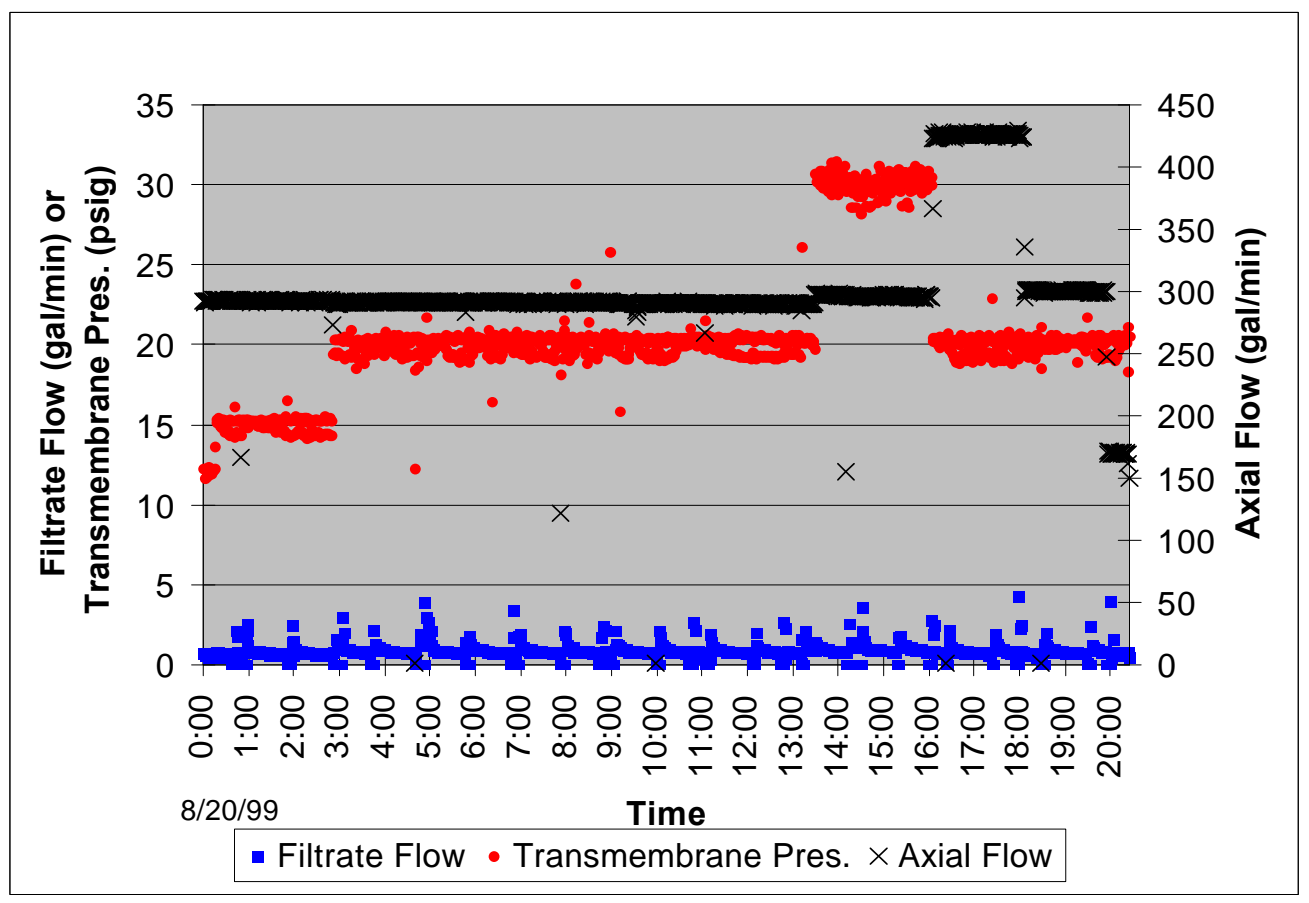

Fig. 41. Filtrate flow, transmembrane pressure, and axial flow as a function of time for Test Series 4, tank W-26. 


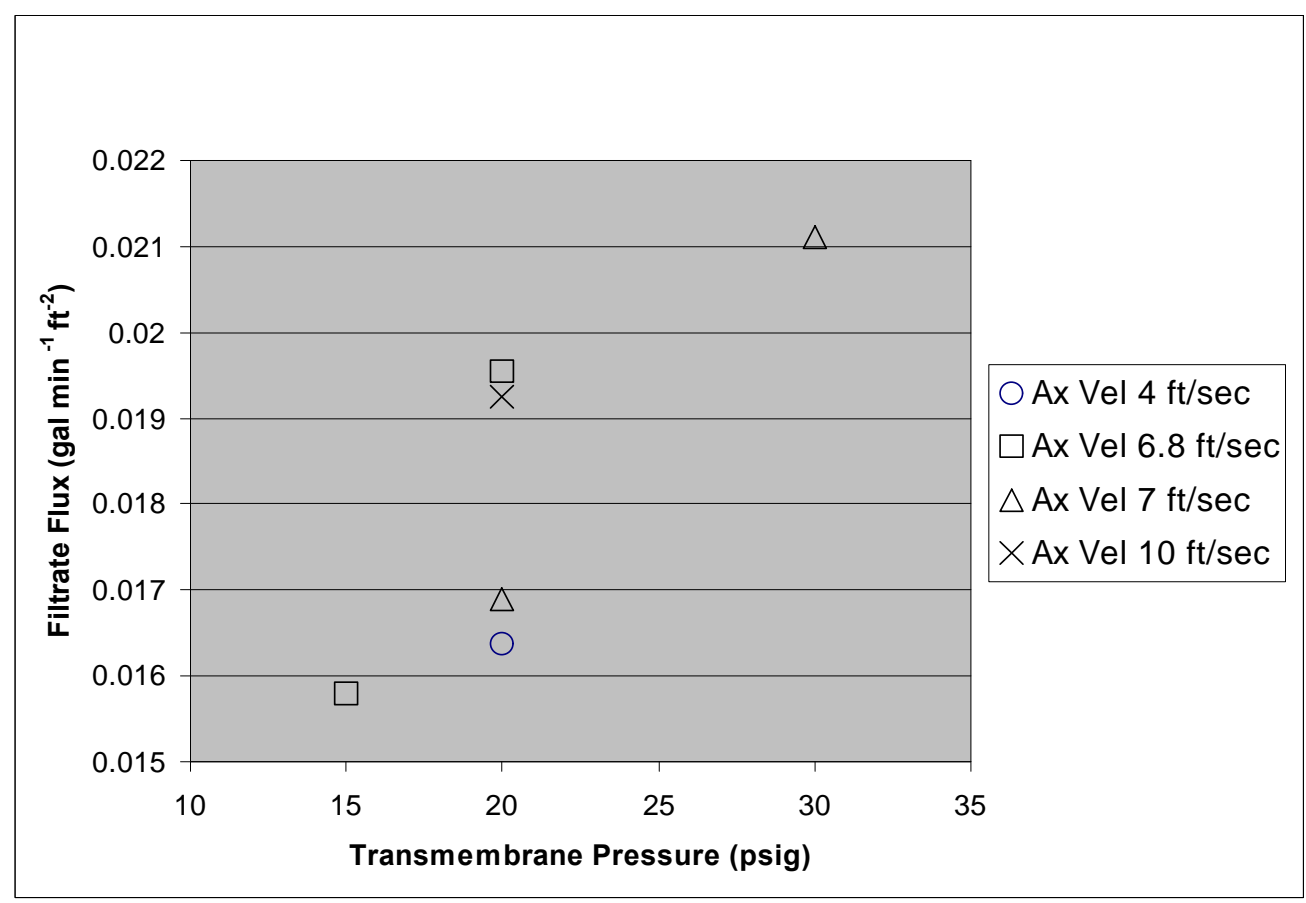

Fig. 42. Average filtrate flux as a function of transmembrane pressure for Test Series 4, tank W-26.

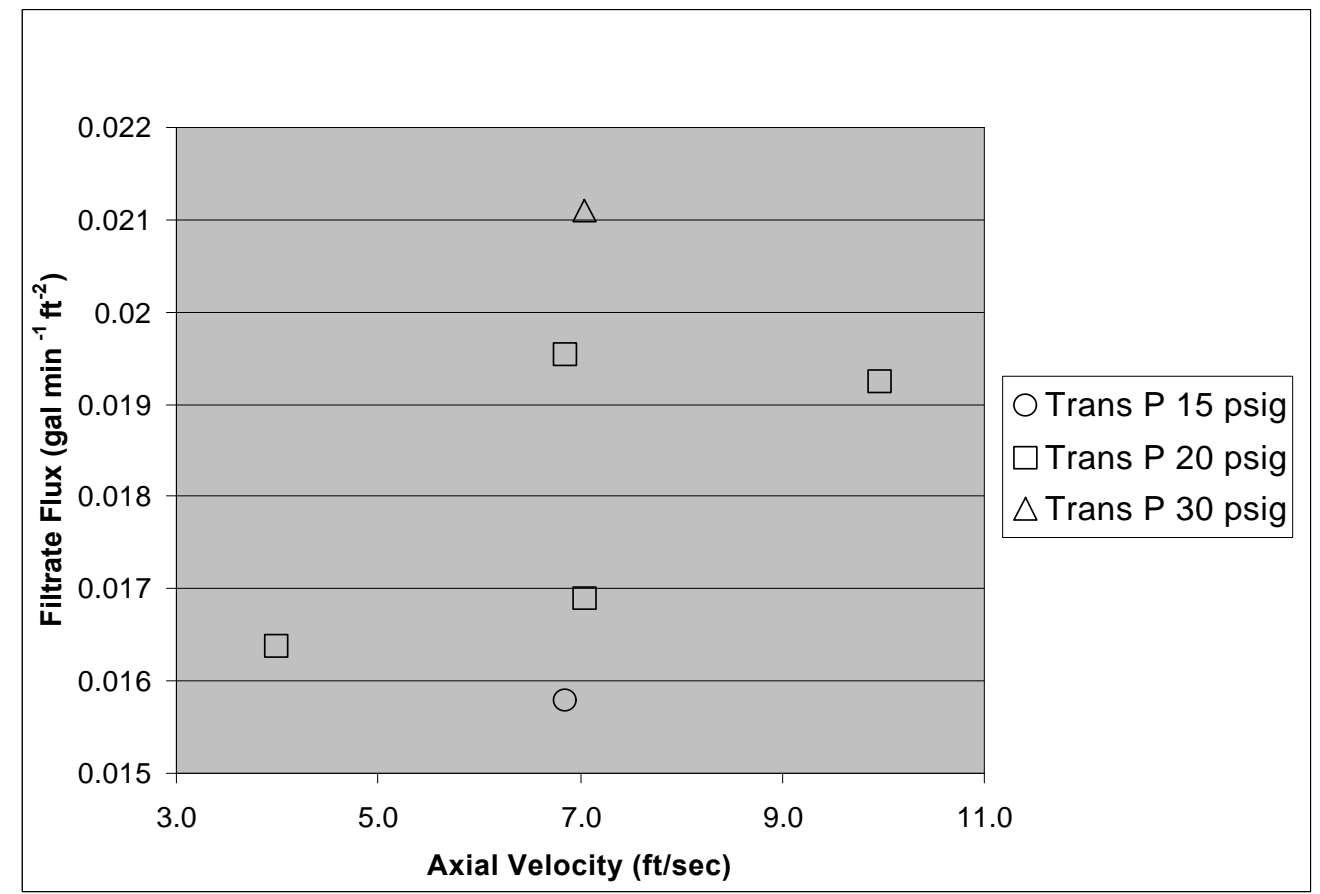

Fig. 43. Average filtrate flux as a function of axial velocity for Test Series 4, tank W-26. 
In Fig. 44, the results of all of the Series 1-4 tests are plotted as a function of the chronological order of the tests. These data collectively indicate that the filtrate flux declined and appeared to stabilize in the range between 0.8 and $1.25 \mathrm{gal} / \mathrm{min}\left(0.016\right.$ and $\left.0.025 \mathrm{gal} \mathrm{min}^{\prime 1} \mathrm{ft}^{\prime 2}\right)$. In a production-oriented mode, the transmembrane pressure and axial flow could be safely increased to values beyond those used in these tests. By maintaining reasonably high levels of transmembrane pressure and axial velocity, along with a regular schedule of chemical cleanings, the average filtrate production could likely be maintained at a significantly higher level.

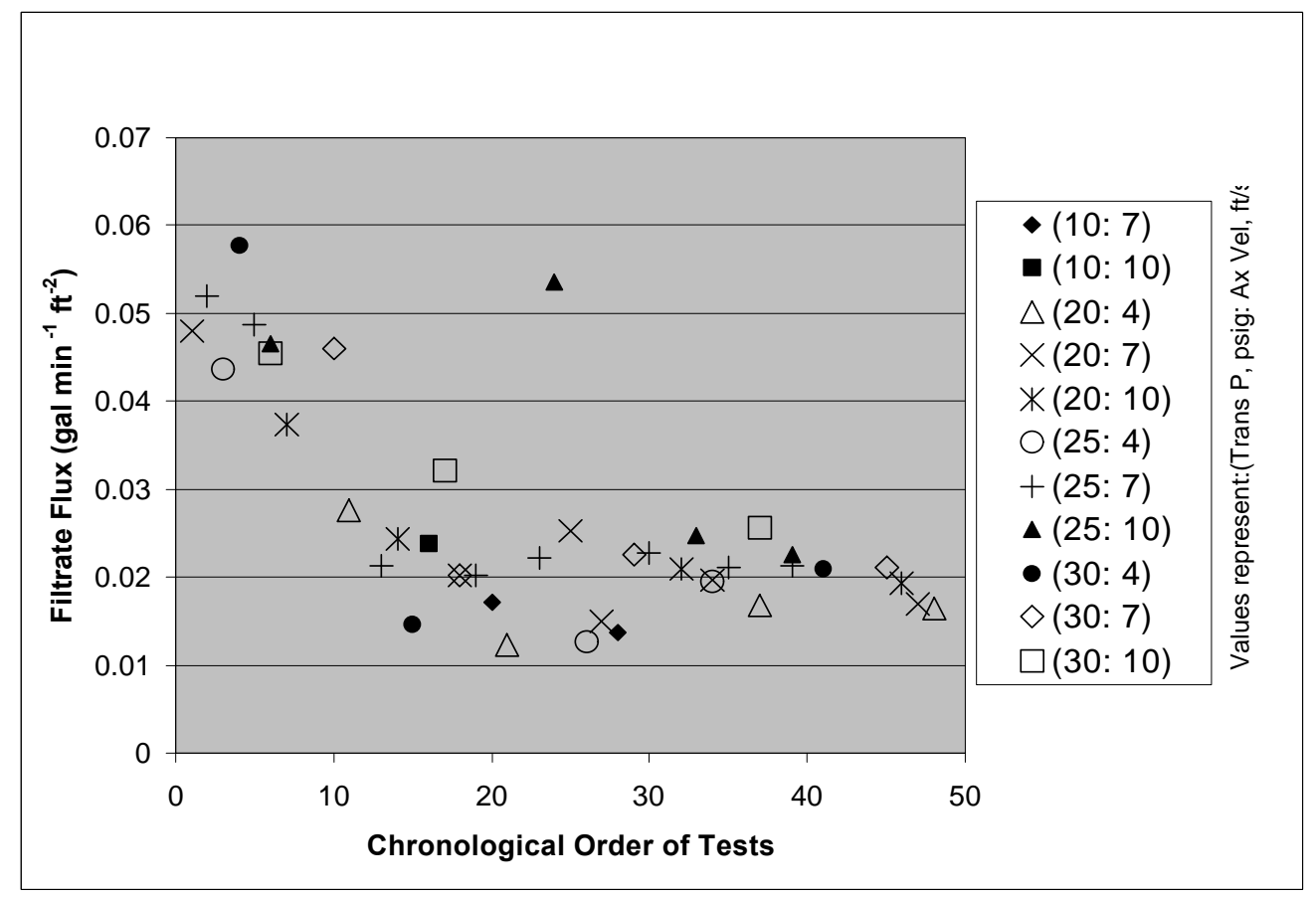

Fig. 44. Average filtrate flux as a function of test chronological order for tank W-26. 


\subsubsection{Results of Sample Analyses, Tank W-26}

The analytical results for samples taken during the W-26 operation are given in Appendix A, Tables A-8, A-9, and A-10. Table A-8 summarizes the analyses for the feed and filtrate samples taken during the first series of tests. The solids content of the feed was reasonably high, at about $2.0 \mathrm{wt} \%$. The decontamination factor $(\mathrm{DF}=$ concentration in the feed /concentration in the filtrate) was calculated to compare the quantities of cations and suspended solids in the two samples. The DFs for the individual cations vary due to the differing cation solubilities. The DF for calcium, a major component of the sludge and one of the least soluble at high pH levels, was the highest (1300). The DF for TSS was somewhat lower (220). As in the W-31 tests, the TSS analysis for samples containing dissolved salts was difficult because salt can be retained in the filter media and give false positive results when the TSS is low $(<0.5 \%)$. The DF for uranium was low (2.1), possibly due to the formation of soluble uranium carbonates. The DF for gross alpha was somewhat higher (33.7), and there was a notable change in the distribution of alpha isotopes caused by the filtration. The fractional quantity of uranium increased greatly while the amounts of ${ }^{244} \mathrm{Cm}$ and plutonium isotopes decreased significantly. Again, this may be due to the solubilities of the uranium carbonates, which could have passed through the filter. The concentration of transuranic (TRU) constituents, plutonium and americium, in the filtrate remained well below the $1814-\mathrm{Bq} / \mathrm{mL}$ limit necessary to maintain the IONSIV IE-911 ion exchanger as non-TRU waste.

A second set of samples was taken during the fourth series of tests when the solids content of the feed was relatively high (about $7.6 \mathrm{wt} \%$ ). The analytical results are given in Table A-9. The DF achieved for TSS was 166 in this case, and the DFs for calcium and iron were 807 and 480, respectively. The DF for gross alpha at 77 was slightly higher than that achieved in the first test series. As in previous samples, the concentration of TRU constituents in the filtrate remained below the $1814-\mathrm{Bq} / \mathrm{mL}$ limit.

Table A-10 gives the analytical results for several samples taken during operations to evaluate the gross alpha content of the filtrate and ensure that the $1814-\mathrm{Bq} / \mathrm{mL}$ TRU limit was not being exceeded. Feed and filtrate samples taken on July 26 indicate that the alpha constituents were removed and a DF of 59 was achieved. To ensure efficient separation of solids, the laboratory was asked to refilter a sample of filtrate using a $0.45-\mathrm{Fm}$ filter. The gross alpha content of the filtered sample was no different from that of the unfiltered filtrate, thus verifying efficient removal of solids.

\subsection{COMPARISON OF EXPERIMENTAL AND FULL-SCALE PERFORMANCE}

A comparison of the experimental data from the single-element cross-flow filter test system using actual waste samples with data from the full-scale deployment indicated that full-scale performance can be predicted with reasonable accuracy. The overall range of filtrate flux achieved in the full-scale SLS system operation for the W-26 tank (0.012 to $\left.0.058 \mathrm{gal} \mathrm{min}^{11} \mathrm{ft}^{{ }^{2}}\right)$ was remarkably similar to that achieved in the ORNL CUF test program (0.0069 to $0.057 \mathrm{gal} \mathrm{min}^{11} \mathrm{ft}^{!^{2}}$ ). Also, the range of suspended solids content during W-26 operations, 0.3 to $10 \mathrm{wt} \%$, was similar to that for the CUF tests (i.e., 0.33 to 15.6 wt \%). Comparing the full-scale SLS flux data from the W-31 tank (0.096 to $\left.0.164 \mathrm{gal} \mathrm{min}^{! 1} \mathrm{ft}^{! 2}\right)$ with the CUF data was not considered useful because of the low suspended solids content of the W-31 feed to the SLS system. Such results show the importance of using actual waste samples in tests. The results of single-element tests with simulated waste indicated much better filter performance than that achieved with actual waste samples. Using simulant data as a design basis would have resulted in undersizing the filter for the full-scale application. The range of filtrate flux for the $\mathrm{W}-26$ processing was somewhat lower than that chosen as the design basis $\left(0.02\right.$ to 0.1 gal $\left.\min ^{! 1} \mathrm{ft}^{! 2}\right)$. However, in a production-oriented mode of operation with the consistent use of higher transmembrane pressure and 
axial velocity, filtrate production could have been maintained closer to the design range. Despite the "performance evaluation" mode of operation, filtrate production consistently met the feed flow needs of the CsR and OTE processing systems.

The data from both the CUF experiments and the deployment data indicate that the transmembrane pressure has a significant influence on the flux rate at a wide range $(0.3$ to $15.6 \mathrm{wt} \%)$ of suspended solids concentrations. However, the influence of axial velocity on filtrate flux was different for the CUF and the full-scale systems. Experimental data from CUF testing showed little or no influence from changes in axial velocity, possibly due to the reduction in particle size or the lack of surface film formation over the short duration of the tests. Full-scale data showed that increasing the axial velocity tended to increase the flux rate when the solids content reached values of $0.6 \mathrm{wt} \%$ and higher. Full-scale data also indicated a dampening of the influence of transmembrane pressure and axial velocity when the solids content reached relatively high values ( 2 to $10 \mathrm{wt} \%$ ). It is important to reiterate the point that the particle size range of small tank samples recirculated within the single-element test loops can be reduced significantly, thereby reducing the flux rate and possibly leading to conservatively high filter area requirement estimates.

\subsection{EQUIPMENT PERFORMANCE}

\subsubsection{Performance of System Pumps}

Several of the system pumps experienced minor malfunctions during the operation, but downtime for the repairs was minimal. The filtrate discharge pump, a Price ${ }^{R}$ centrifugal pump, encountered an initial startup problem due to an amperage overload. This problem was easily addressed by resetting the overload switch to correspond with the appropriate setting for a replacement impeller installed to provide additional discharge head. During initial pressure testing of the pump piping, a pressure gage not included in the original design was installed on the discharge piping of the pump. This allowed for monitoring of pump operation and assurance that sufficient pressure was applied for the transfer of filtrate. The Discflo pump used for circulation of the concentrate through the cross-flow filter modules ran very smoothly. This pump was driven by a 25 -hp Baldor electric motor with an AC Tech variablespeed controller. Control of axial flow was very stable and required very little adjustment during operations. The pump also performed well when heavy sludge was fed to the system, and the amperage load never exceeded 40\% during operations. The Warren Rupp D/D pumps used to provide feed to the SLS system were reasonably effective for this application. The feed flow rate was erratic at times and declined significantly for high-solid-content feed, but the pumps were able to provide the consistent pressure needed for filtrate production for most of the operation. Shertech ${ }^{\mathrm{TM}}$ rotary gear pumps used for the chemical feed system operated in accordance with design; no problems were encountered.

\subsubsection{Performance of Instruments and Controls}

With very few exceptions, the instruments and controls of the SLS system operated very well. The Rosemount ${ }^{\mathrm{R}}$ magnetic flowmeters performed flawlessly in monitoring the flows of feed, filtrate, concentrate, and flush water. The pressure transmitters (also by Rosemount) operated with no difficulties in monitoring the discharge pressure of the Discflo pump, the pressure of the filtration loop, the differential pressure across the filter modules, and the pressure of the backpulse air reservoir. The banner ultrasonic level sensors operated efficiently for monitoring the levels of dilute acid and caustic used in the chemical feed system. A Burkert ultrasonic level sensor/transmitter used to monitor fluid level in the filtrate tank malfunctioned during preoperational testing and was replaced with another 
ultrasonic device manufactured by Co-Sense. The Co-Sense unit operated well throughout the project. No problems were experienced with the remote camera system by Panasonic. A color video would improve the contrast; however, the black-and-white format was sufficient for most of the observations.

The control system software and program developed by NUMET performed very well during the campaign. The user interface drawings were easy to understand, and the program was user friendly and reliable. The software (FIX-32 software by Intellution) was installed on a personal computer with an I/O module (MTL, Inc.) for interfacing the control system with the process equipment. During preoperational testing the computer provided with the system by NUMET experienced hard-drive problems and was replaced with a heavier-duty IBM model PC. The user interface consisted of a color monitor, mouse, and GUI flowsheet display (Appendix D), including updated instrument readouts, valve status, alarms, and data archiving. The control program was written to provide automated operation of the system in several different modes or cycles. Automated operating cycles were developed for filling the system with water, filling with waste feed, draining the system, draining the filtrate tank, chemical cleaning, and filtrate production. All of these cycles operated efficiently. An option to operate the system in manual mode was also provided for nonroutine operations and trouble-shooting. The dataarchiving function operated well and provided much of the data needed to evaluate the performance of the system. The data were exported from FIX-32 and imported into a spreadsheet for data analysis and graphing.

\subsubsection{Performance of Pipeline Slurry Monitor}

The Endress+Hauser Promass 63F Mass Flowmeter performed extremely well during the SLS operation. Using the principle of measuring the change in the Coriolis force, the flowmeter measures density and mass flow. The two measuring tubes of the meter are made to oscillate at a specified frequency. Flow of fluid through the tubes causes a change in the oscillation, which is measured by special sensors and translated to mass flow. The transmitter calculates the percent TSS, using the measured density of the solid/liquid mixture along with additional data on densities of the pure liquid and solids entered by the user. Analytical results, including density data for filtered supernatant, were available, and the density of the solid was estimated based on sludge composition. A solids density of $2.5 \mathrm{~g} / \mathrm{mL}$ was used based on literature data for the densities of calcium carbonate and calcium hydroxide, ${ }^{9}$ which are known to be major components of the sludge. To verify the solids monitor data, several samples of feed were analyzed in the RMAL at ORNL. Table 8 gives a summary of the RMAL data as compared with the solids monitor output at the time the sample was taken. As shown in the table, the Promass flowmeter was reasonably accurate at concentrations over $2 \mathrm{wt} \%$; however, the instrument does not appear to be sensitive enough to detect low concentrations of suspended solids. This instrument can measure density to an accuracy of $\pm 0.00025 \mathrm{~g} / \mathrm{mL}$, which translates to a solids content of $\pm 0.04 \mathrm{wt} \%$. However, the accuracy of the result depends on the accuracy of the density data for the solids-free liquid and the undissolved solid particles used in the formula as follows:

$$
W t \% \operatorname{TSS}=\left(D_{S} \times\left(D_{M} ! D_{L}\right)\right) /\left(D_{M} \times\left(D_{S} ! D_{L}\right)\right)
$$

where:

$$
\begin{aligned}
& \text { wt } \% \text { TSS }=\text { wt } \% \text { total suspended solids, } \\
& D_{S}=\text { density of the solid particle, } \\
& D_{L}=\text { density of the solids-free liquid, and } \\
& D_{M}=\text { density of the solid/liquid mixture. }
\end{aligned}
$$


The accuracy of the solids-free liquid laboratory measurement from RMAL was $\pm 0.001 \mathrm{mg} / \mathrm{L}$, which translates to $\pm 0.16 \mathrm{wt} \%$ solids for the calculation. The percent solids calculation is less sensitive to error in the value used for density of the solid particles, in this case $2.5 \mathrm{~g} / \mathrm{mL}$. If the actual density of the solid particles was double the estimated value $(5 \mathrm{~g} / \mathrm{mL})$, the corresponding solids concentration would decrease by $26 \%$.

Table 8. Comparison of Promass 63 data with results from RMAL analyses

\begin{tabular}{|l|l|l|c|c|}
\hline Date & Time & Tank ID & Promass output (wt \%) & RMAL (wt \%) \\
\hline $6 / 8 / 99$ & $11: 14$ & W-31 & 0.88 & 0.032 \\
\hline $6 / 14 / 99$ & $11: 49$ & W-31 & 0.00 & 0.016 \\
\hline $6 / 16 / 99$ & $04: 16$ & W-31 & 0.00 & 0.024 \\
\hline $6 / 21 / 99$ & $15: 00$ & W-31 & 0.00 & 0.068 \\
\hline $6 / 24 / 99$ & $09: 46$ & W-31 & 15.08 & 11.6 \\
\hline $7 / 26 / 99$ & $12: 59$ & W-26 & 3.31 & 3.3 \\
\hline $7 / 28 / 99$ & $04: 30$ & W-26 & 2.15 & 1.9 \\
\hline $8 / 20 / 99$ & $13: 30$ & W-26 & 8.56 & 7.0 \\
\hline
\end{tabular}

The accuracy of the Promass instrument was adversely affected by the variation in the density of the solids-free liquid from tank W-26. New sludges from the GAAT South Tank Farm had been added to this tank several months prior to SLS processing of the waste. The relatively dilute liquids used in retrieval and transfer of these sludges were not uniformly mixed with the interstitial liquids in the tank sludge. The density of the liquid increased due to the slow mixing of the supernatant with the high-salt interstitial liquids in the sludge. The increase in density, in turn, resulted in superficially high-percent solids output from the Promass meter. This was recognized when the results for the SLS feed sample were obtained from the laboratory and compared with those from the initial sampling of the tank supernatant. The solids monitor data were corrected by updating the density within the Promass percent-solids calculation parameters. Thus, continuous monitoring of the solids-free liquid density is needed to ensure accurate solids content data during the SLS operation.

The results for the initial four RMAL samples shown in Table 8 indicate low solids content. As explained previously, suspended solids analyses for samples containing high levels of dissolved salts are difficult because salt can be retained in the filter media and give false positive results when TSS is less than $0.5 \%$. The RMAL results may be slightly higher than the actual concentration. Seven of the eight Promass data points are in reasonable agreement with the RMAL results. The disagreement in the results for the first sample (June 8, 1999) may be due to the rapidly changing solids content during the initial startup of the system. The sampler may have sampled material that was truly different from the material present in the Promass detector at that time. 


\subsubsection{Performance of Valves}

Nearly all of the remotely operated process valves used in the system were full-port ball types manufactured by McCanna.UniTorq pneumatic actuators with UniTorq solenoid valves were used to operate the ball valves. None of these valves malfunctioned or leaked after hot operations began. They were very responsive and reliable throughout the operation. However, during leak-checking and preoperational testing, one of the McCanna valves developed a packing leak at the valve stem, which was easily fixed by retightening the packing to the specified torque value. It was also found that one of the 4 -in. valves required a minimum of 95-psig air supply to operate efficiently. Since the existing air supply could not deliver this pressure consistently, a small air compressor was procured and installed within the SLS module to boost the pressure of air supply piping to $100 \mathrm{psig}$. Some of the smaller (3/8 and 1/4 in.) manual ball valves manufactured by Whitey were also reliable and did not develop leaks. A relief valve manufactured by Kunkle began unseating prematurely, but this was caused by preoperational leak-testing at pressures equal to or slightly higher than the set pressure of the valve. The valve was replaced prior to hot operations.

\subsubsection{Performance of Sampling System}

The Isolok ${ }^{\mathrm{R}}$ sampling system manufactured by Bristol performed very well; no leaks or other difficulties were observed. The system was designed to provide real-time samples of the feed, filtrate, and concentrate streams. Sample lines were routed from high- and low-pressure taps of the process lines to provide a continuous flow of fluid through the Isolok sampling chamber. A plunger with O-ring fluid seals extends into the circulating sampling chamber and retracts into an annular spool where a 10-mL sample is deposited in a sample container. Additional plunger cycles are programmed for larger sample sizes, up to $50 \mathrm{~mL}$. The sample volumes were consistently accurate, and no leaks developed in the plunger seals.

\subsection{RADIOLOGICAL OBSERVATIONS}

Radiological survey information indicates that the shield enclosures provided with the SLS system performed as designed. The shielding was designed by NUMET to reduce radiation exposure to less than $5 \mathrm{mR} / \mathrm{h}$ at a distance of $5 \mathrm{ft}$ from the outer enclosure of the system. The assumed ${ }^{137} \mathrm{Cs}$ content of the waste used in the shielding calculations was $1.4 \mathrm{E}+6 \mathrm{~Bq} / \mathrm{mL}$. The initial survey dose-rate readings with an actual ${ }^{137} \mathrm{Cs}$ content of about $9.0 \mathrm{E}+5 \mathrm{~Bq} / \mathrm{mL}$ indicate dose rates between 3 and $4 \mathrm{mR} / \mathrm{h}$ at a distance of about $4 \mathrm{ft}$ from the south side of the SLS enclosure (sample cabinet side). The dose rate at the enclosure wall on the north side of the unit (near the chemical feed system) was about $1.5 \mathrm{mR} / \mathrm{h}$. On the east side of the unit at the enclosure wall nearest the shielded filter modules, the dose rate was $1.0 \mathrm{mR} / \mathrm{h}$. Dose rates inside the shielded maintenance area ranged between 100 and $200 \mathrm{mR} / \mathrm{h}$. Inside the shield curtains near the interface piping at the west side of the SLS module between the MVST vault and the SLS enclosure, the dose readings were 100 to $440 \mathrm{mR} / \mathrm{h}$. A radiation boundary chain with postings was provided around the south end and the west side of the SLS enclosure at a distance of about 5 to $7 \mathrm{ft}$. After the W-26 supernatant had been processed, the system was chemically cleaned. This operation reduced the general area dose rates inside the shielded maintenance area to $5-10 \mathrm{mR} / \mathrm{h}$. 


\section{PROJECT COSTS}

Table 9 provides the costs of the SLS system deployment from the design phase through initial operations.

Table 9. Summary of costs for SLS system deployment

\begin{tabular}{|l|c|}
\hline \multicolumn{1}{|c|}{ Cost element } & Cost (\$K) \\
\hline System design & 145 \\
\hline Fabrication & 830 \\
\hline Installation design & 50 \\
\hline Installation at MVST & 997 \\
\hline Preoperational testing & 77 \\
\hline QA support & 23 \\
\hline Analytical services & 20 \\
\hline Project management and reporting & 150 \\
\hline Safety document revisions & 29 \\
\hline IFE support & 72 \\
\hline Procedures and training & 60 \\
\hline Operations & 200 \\
\hline Total & 2653.00 \\
\hline
\end{tabular}

10. LESSONS LEARNED

The experience gained during this project will benefit future deployments of cross-flow filtration technology. Some key factors to consider when planning a similar project are as follows:

C Work closely with the user organization to gain detailed information regarding the application and technical risks that could interfere with the success of the project.

C Plan for testing with simulants and with actual waste samples. Evaluate the design limitations of the test system that could bias the test results.

C Estimate the costs of the deployment early and revisit the cost estimate when key equipment and facility modification requirements are known. 
C Establish equipment design requirements with the technology user, based on facility safety classification and requirements.

C Establish operational readiness review criteria as early as possible, and use these criteria to develop project requirements.

C Verify the traceability of instrument calibrations to certifiable source and standard (e.g., NIST), and obtain the records early in the system fabrication phase. If instruments are calibrated by the manufacturer, ensure that the records are shipped along with the instrument.

C In design specifications, require (1) that clearance be provided around all system components (mechanical and instruments) that may require access for maintenance or repairs and (2) that instrument transmitters be located outside radiation areas.

C Design the system, including the system containment pans, for complete drainage and capability for flushing with water and chemical cleaning. This is essential if equipment problems or leaks of radioactive fluids are encountered after starting hot operations. The SLS system containment pan drainage system was poorly designed and allowed wastes from piping drainage to back up into the pans under certain conditions. The containment-pan drain piping should include some means for preventing the backup of drainage into pans in case the drain piping should become obstructed.

C Design the system/facility interface piping to allow for functional testing with process water, and obtain equipment for hydrostatic testing at design pressures. Be aware of pressure relief valves or instrument sensors that may require isolation prior to leak-testing. Define an acceptable standard to use as a guide for hydrostatic testing.

C Early in the installation process, ensure that permanent labels are provided for all instruments, valves, pumps, and vessels. Label the process piping according to the type of fluid and direction of flow.

C Develop a functional test plan for cold testing the system so the operation of individual components and the integrated system can be verified and documented.

C Provide redundancy for system pumps where feasible and cost-effective. Due to space constraints, the SLS system has only one filtrate pump. This pump would be difficult to replace if failure should occur.

C Provide the best and most complete remote video-camera observation coverage possible (pan and tilt, zoom, etc.) . Use of color monitors would improve definition.

C Prepare operating procedures as early as possible, and validate each step in the procedure during cold-testing of the system.

C Get an early start in preparing for operational readiness assessments. Collecting and organizing the evidence, organizing review meetings, obtaining review/approval signatures, and negotiating with reviewers are very time-consuming steps. A team of about four individuals (QA specialist, ES\&H specialist, record- keeping manager, and the project manager) is necessary for a project of this magnitude. 


\section{SUMMARY AND CONCLUSIONS}

The results of this project indicate that cross-flow filtration technology can be deployed successfully in a full-scale operation as a self-contained processing system for the treatment of radioactive tank waste. The skid-mounted system used in this study operated extremely well; very little unscheduled downtime occurred. The system pumps, valves, sensors, monitors, and controls functioned quite satisfactorily during operations. The shielding and containment systems operated in accordance with design specifications. The quality of the filtrate consistently met the requirements for feed to the downstream processes.

A comparison of the experimental data from small-scale, single-element filter tests with data from the full-scale operation indicated that full-scale performance can be predicted with reasonable accuracy. There are limitations, however, associated with the use of CUF single-element data in predicting fullscale performance. The size range of sludge particles in tank samples that are recirculated in the CUF system can be reduced significantly, reducing flux rate and leading to conservatively high estimates of required filter area for a larger system. In addition, the CUF tests did not clearly show a positive influence of increasing the axial velocity (as was shown in full-scale performance). However, the use of real-waste CUF data for scaleup is clearly preferred over the use of data from simulant testing. The simulant data from single-element testing gave comparably higher flux rates and could have led to underestimation of the required filter area for the full-scale system.

The Endress+Hauser Promass 63F Mass Flowmeter (Coriolis) performed very well in providing in-line mass flow and density information. The weight percent solids was calculated by the instrument based on the solid particle density and the solids-free liquid density provided as constants for the equation. It was found, however, that it is important that very accurate data be made available for the density of the solids-free liquid as well as for the density of the solid particles. During the treatment of the W-26 tank waste, the density of the solids-free liquid varied due to the slow diffusion of salts from the sludge into the supernatant. This resulted in superficially high percent-solids data that had to be corrected after updating the density of the solids-free liquid.

Deployment data were collected for two different MVST wastes, but only the W-26 feed contained a significant level of suspended solids. Additional operations with variations in waste composition are needed to fully evaluate the SLS system performance. The performance of equipment and instrumentation components of the SLS system was shown to be excellent for the duration of the two campaigns. However, additional performance data for longer-term operation of the system is necessary to determine the capability of the system to accept the range of MVST supernatant/sludge compositions. Additional operational experience is also needed to evaluate the effectiveness of the SLS chemical cleaning system in removal of fouling deposits and restoring filtrate flux to acceptable values. 


\section{REFERENCES}

1. D. J. McCabe, Evaluation and Ranking of the Tank Focus Area Solid-Liquid Separation Needs, WSRC-TR-95-0337, Savannah River Technology Center, Westinghouse Savannah River Company, Aiken, S.C., August 17, 1995.

2. D. J. McCabe, B. W. Walker, and R. A. Peterson, Oak Ridge Gunite Simulant Filtration Test Results, WSRC-TR-96-0234, Savannah River Technology Center, Westinghouse Savannah River Company, Aiken, S.C., September 30, 1996.

3. V. L. Fowler and J. D. Hewitt, Cross Flow Filtration of Oak Ridge National Laboratory Liquid LowLevel Waste, ORNL/TM-10742, Oak Ridge National Laboratory, December 1989.

4. K. M. Billingsley, C. Mims, and S. M. Robinson, "Integrated Tank Waste Management Plan at Oak Ridge National Laboratory," p. 1376 in Proceedings of Spectrum '98, vol. 2, American Nuclear Society, La Grange Park, Ill., 1998.

5. D. J. McCabe, B. W. Walker, and R. A. Peterson, Oak Ridge Gunite Simulant Filtration Test Results, WSRC-TR-96-0234, Savannah River Technology Center, Westinghouse Savannah River Company, Aiken, S.C., September 30, 1996, p. 11.

6. D. J. McCabe, B. W. Walker, and R. A. Peterson, Oak Ridge Gunite Simulant Filtration Test Results, WSRC-TR-96-0234, Savannah River Technology Center, Westinghouse Savannah River Company, Aiken, S.C., September 30, 1996, p. 18.

7. Equipment Specification Solid-Liquid Separation for Melton Valley Storage Tanks Supernate Solids Removal, Specification JS-CT-020013-A001, U.S. Department of Energy, Oak Ridge Operations, May 30, 1997.

8. Specifications for Solid/Liquid Separation Demonstration, Report X-OE-814, Oak Ridge National Laboratory, September 1998.

9. R. H. Perry and C. H. Chilton, Chemical Engineers Handbook, 5th ed., McGraw-Hill Book Company, New York, 1973. 
Appendix A. SAMPLE ANALYSIS RESULTS 
Table A.1. Characterization data for samples used in CUF tests

\begin{tabular}{|c|c|c|c|}
\hline & $\begin{array}{c}\text { W6-W10 } \\
\text { sample } \\
\text { mixture }^{a}\end{array}$ & $\begin{array}{c}\text { W3-W4 } \\
\text { sample } \\
\text { mixture }^{a} \\
\end{array}$ & $\begin{array}{c}\text { W25 } \\
\text { sample }\end{array}$ \\
\hline \multicolumn{4}{|c|}{ Physical properties and miscellaneous data } \\
\hline Water, $\%$ & $8.14 \mathrm{E}+01$ & $8.59 \mathrm{E}+01$ & $4.10 \mathrm{E}+01$ \\
\hline Bulk density, g/mL & $1.23 \mathrm{E}+00$ & $1.20 \mathrm{E}+00$ & $1.52 \mathrm{E}+00$ \\
\hline $\mathrm{TIC}, \mathrm{mg} / \mathrm{kg}$ & $3.42 \mathrm{E}+03$ & $1.50 \mathrm{E}+03$ & \\
\hline $\mathrm{TC}, \mathrm{mg} / \mathrm{kg}$ & $7.74 \mathrm{E}+03$ & $4.78 \mathrm{E}+03$ & \\
\hline TOC, mg/kg & $4.32 \mathrm{E}+03$ & $3.28 \mathrm{E}+03$ & \\
\hline Total suspended solids, wt $\%$ & 17.6 & 6.6 & 27.1 \\
\hline \multicolumn{4}{|l|}{ RCRA metals, mg/kg } \\
\hline $\mathrm{Ag}$ & $4.49 \mathrm{E}+00$ & $2.39 \mathrm{E}+01$ & \\
\hline As & $1.97 \mathrm{E}+00$ & $5.00 \mathrm{E}-01$ & \\
\hline $\mathrm{Ba}$ & $9.53 \mathrm{E}+01$ & $6.32 \mathrm{E}+00$ & $3.00 \mathrm{E}+02$ \\
\hline $\mathrm{Cd}$ & $3.94 \mathrm{E}+00$ & $2.60 \mathrm{E}+00$ & $3.50 \mathrm{E}+01$ \\
\hline $\mathrm{Cr}$ & $2.62 \mathrm{E}+02$ & $2.52 \mathrm{E}+02$ & $3.50 \mathrm{E}+02$ \\
\hline $\mathrm{Hg}$ & $8.80 \mathrm{E}+01$ & $2.62 \mathrm{E}+01$ & $1.20 \mathrm{E}+02$ \\
\hline $\mathrm{Ni}$ & $1.06 \mathrm{E}+02$ & $8.44 \mathrm{E}+00$ & $2.40 \mathrm{E}+02$ \\
\hline $\mathrm{Pb}$ & $1.20 \mathrm{E}+03$ & $1.05 \mathrm{E}+01$ & $1.20 \mathrm{E}+03$ \\
\hline $\mathrm{Se}$ & $5.20 \mathrm{E}-01$ & $5.00 \mathrm{E}-01$ & \\
\hline $\mathrm{Tl}$ & $5.20 \mathrm{E}-01$ & $5.00 \mathrm{E}-01$ & $2.40 \mathrm{E}+02$ \\
\hline \multicolumn{4}{|l|}{ Process metals, mg/kg } \\
\hline $\mathrm{Al}$ & $1.25 \mathrm{E}+04$ & $2.98 \mathrm{E}+03$ & $1.52 \mathrm{E}+04$ \\
\hline B & $8.66 \mathrm{E}+00$ & $3.71 \mathrm{E}+00$ & \\
\hline $\mathrm{Be}$ & $8.24 \mathrm{E}+00$ & $3.52 \mathrm{E}+00$ & \\
\hline $\mathrm{Ca}$ & $8.92 \mathrm{E}+03$ & $7.67 \mathrm{E}+03$ & $5.67 \mathrm{E}+04$ \\
\hline Co & $4.13 \mathrm{E}+00$ & $4.06 \mathrm{E}+00$ & $2.40 \mathrm{E}+01$ \\
\hline $\mathrm{Cu}$ & $5.34 \mathrm{E}+01$ & $3.22 \mathrm{E}+01$ & $1.80 \mathrm{E}+02$ \\
\hline $\mathrm{Fe}$ & $5.03 \mathrm{E}+03$ & $5.25 \mathrm{E}+02$ & $5.10 \mathrm{E}+03$ \\
\hline $\mathrm{K}$ & $2.13 \mathrm{E}+03$ & $3.17 \mathrm{E}+02$ & $8.50 \mathrm{E}+03$ \\
\hline $\mathrm{Mg}$ & $3.77 \mathrm{E}+03$ & $6.06 \mathrm{E}+02$ & $7.90 \mathrm{E}+03$ \\
\hline $\mathrm{Mn}$ & $1.69 \mathrm{E}+02$ & $3.27 \mathrm{E}+01$ & $4.70 \mathrm{E}+02$ \\
\hline $\mathrm{Na}$ & $1.10 \mathrm{E}+04$ & $9.61 \mathrm{E}+03$ & $6.49 E+04$ \\
\hline $\mathrm{Sb}$ & $1.05 \mathrm{E}+01$ & $2.00 \mathrm{E}+01$ & \\
\hline $\mathrm{Si}$ & $6.17 \mathrm{E}+02$ & $3.23 \mathrm{E}+02$ & $9.00 \mathrm{E}+03$ \\
\hline $\mathrm{Sr}$ & $4.59 \mathrm{E}+01$ & $2.35 \mathrm{E}+01$ & $3.30 \mathrm{E}+02$ \\
\hline $\mathrm{Th}$ & $7.79 \mathrm{E}+03$ & $2.31 \mathrm{E}+03$ & $3.38 \mathrm{E}+04$ \\
\hline $\mathrm{U}$ & $1.47 \mathrm{E}+04$ & $4.50 \mathrm{E}+04$ & $1.62 \mathrm{E}+04$ \\
\hline $\mathrm{V}$ & $2.85 \mathrm{E}+00$ & $5.00 \mathrm{E}-01$ & \\
\hline $\mathrm{Zn}$ & $8.96 \mathrm{E}+01$ & 4.24E+00 & $4.70 \mathrm{E}+02$ \\
\hline $\mathrm{pH}$ & 10.2 & 10.6 & 12.6 \\
\hline
\end{tabular}


Table A.1 (continued)

\begin{tabular}{|c|c|c|c|}
\hline & $\begin{array}{c}\text { W6-W10 } \\
\text { sample } \\
\text { mixture }^{a}\end{array}$ & $\begin{array}{c}\text { W3-W4 } \\
\text { sample } \\
\text { mixture }^{a}\end{array}$ & $\begin{array}{c}\mathrm{W} 25 \\
\text { sample }\end{array}$ \\
\hline \multicolumn{4}{|l|}{ Anions, mg/kg } \\
\hline Bromide & $3.40 \mathrm{E}+01$ & $5.28 \mathrm{E}+00$ & $4.10 \mathrm{E}+02$ \\
\hline Chloride & $3.00 \mathrm{E}+02$ & $5.28 \mathrm{E}+00$ & $2.20 \mathrm{E}+03$ \\
\hline Fluoride & $3.12 \mathrm{E}+02$ & $1.96 \mathrm{E}+01$ & $1.10 \mathrm{E}+03$ \\
\hline Nitrate & $2.82 \mathrm{E}+03$ & $4.93 \mathrm{E}+02$ & $1.05 \mathrm{E}+05$ \\
\hline Phosphate & $1.65 \mathrm{E}+03$ & $1.08 \mathrm{E}+03$ & $1.74 \mathrm{E}+04$ \\
\hline Sulfate & $2.15 \mathrm{E}+03$ & $9.50 \mathrm{E}+02$ & $4.10 \mathrm{E}+03$ \\
\hline Carbonate & & & $6.76 \mathrm{E}+04$ \\
\hline \multicolumn{4}{|l|}{ Beta/gamma emitters, Bq/g } \\
\hline Gross beta & $5.65 \mathrm{E}+06$ & $3.79 \mathrm{E}+05$ & \\
\hline${ }^{60} \mathrm{Co}$ & $4.86 \mathrm{E}+03$ & $1.39 \mathrm{E}+02$ & $9.99 \mathrm{E}+04$ \\
\hline${ }^{134} \mathrm{Cs}$ & $3.55 \mathrm{E}+02$ & $2.59 \mathrm{E}+02$ & \\
\hline${ }^{137} \mathrm{Cs} /{ }^{137 \mathrm{~m}} \mathrm{Ba}$ & $4.94 \mathrm{E}+05$ & $9.24 \mathrm{E}+04$ & $8.14 \mathrm{E}+05$ \\
\hline${ }^{152} \mathrm{Eu}$ & $2.99 \mathrm{E}+03$ & $1.09 \mathrm{E}+03$ & \\
\hline${ }^{154} \mathrm{Eu}$ & $1.34 \mathrm{E}+04$ & $4.26 \mathrm{E}+02$ & $7.77 \mathrm{E}+04$ \\
\hline${ }^{155} \mathrm{Eu}$ & $2.12 \mathrm{E}+03$ & $7.92 \mathrm{E}+02$ & \\
\hline${ }^{90} \mathrm{Sr} r{ }^{90} \mathrm{Y}$ & $2.03 \mathrm{E}+06$ & $8.57 \mathrm{E}+04$ & $1.12 \mathrm{E}+07$ \\
\hline${ }^{241} \mathrm{Am}$ & $5.03 \mathrm{E}+03$ & $0.00 \mathrm{E}+00$ & $1.52 \mathrm{E}+04$ \\
\hline \multicolumn{4}{|c|}{ Alpha emitters by alpha spectrometry } \\
\hline Gross alpha, Bq/g & $3.62 \mathrm{E}+04$ & $8.73 E+03$ & \\
\hline${ }^{244} \mathrm{Cm}, \%$ & $5.97 \mathrm{E}+01$ & $1.90 \mathrm{E}+00$ & \\
\hline${ }^{244} \mathrm{Cm}, \mathrm{Bq} / \mathrm{g}$ & & & $1.89 \mathrm{E}+05$ \\
\hline${ }^{239} \mathrm{Pu} /{ }^{240} \mathrm{Pu}, \%$ & $1.60 \mathrm{E}+01$ & $4.90 \mathrm{E}+01$ & \\
\hline${ }^{238} \mathrm{Pu} /{ }^{241} \mathrm{Am}, \%$ & $2.29 \mathrm{E}+01$ & $1.76 \mathrm{E}+01$ & \\
\hline${ }^{234} \mathrm{U}, \%$ & $2.80 \mathrm{E}+00$ & $\begin{array}{r}2.46 \mathrm{E} \\
+01\end{array}$ & \\
\hline${ }^{238} \mathrm{U}, \%$ & $6.30 \mathrm{E}-01$ & $\begin{array}{r}6.69 \mathrm{E} \\
+00\end{array}$ & \\
\hline Total Pu alpha, Bq/g & $9.22 \mathrm{E}+03$ & $\begin{array}{r}4.36 \mathrm{E} \\
+03 \\
\end{array}$ & $2.85 \mathrm{E}+0$ \\
\hline
\end{tabular}

${ }^{a}$ Data were calculated from analyses reported for individual tank samples. 
Table A.2. Laboratory analyses of the MVST W-31 supernatant ${ }^{a}$

\begin{tabular}{|c|c|c|}
\hline \multicolumn{3}{|l|}{ Radiochemicals, $\mathrm{Bq} / \mathrm{mL}$} \\
\hline${ }^{60} \mathrm{Co}$ & $2.10 \mathrm{E}+03$ & $\pm 1.00 \mathrm{E}+02$ \\
\hline${ }^{137} \mathrm{Cs}$ & $8.00 \mathrm{E}+05$ & $\pm 1.00 \mathrm{E}+04$ \\
\hline${ }^{134} \mathrm{Cs}$ & $1.60 \mathrm{E}+04$ & $\pm 1.00 \mathrm{E}+03$ \\
\hline${ }^{99} \mathrm{Tc}$ & $5.32 \mathrm{E}+02$ & $\pm 5.30 \mathrm{E}+01$ \\
\hline Gross alpha & $6.90 \mathrm{E}+01$ & $\pm 5.00 \mathrm{E}+00$ \\
\hline $5.50-\mathrm{Mev}{ }^{238} \mathrm{Pu} /{ }^{241} \mathrm{Am}, \%$ & 15.4 & \\
\hline 5.80-Mev ${ }^{244} \mathrm{Cm}, \%$ & 84.6 & \\
\hline \multicolumn{3}{|l|}{ Cations, mg/L } \\
\hline $\mathrm{Al}$ & $4.71 \mathrm{E}+01$ & $\pm 4.71 \mathrm{E}+00$ \\
\hline As & $<3.19 \mathrm{E}-01$ & \\
\hline $\mathrm{Ba}$ & $<5.50 \mathrm{E}-02$ & \\
\hline $\mathrm{Ca}$ & $<6.00 \mathrm{E}-02$ & \\
\hline $\mathrm{Cd}$ & $3.73 \mathrm{E}+00$ & $\pm 3.73 \mathrm{E}-01$ \\
\hline $\mathrm{Cr}$ & $1.12 \mathrm{E}+01$ & $\pm 1.12 \mathrm{E}+00$ \\
\hline Cs & $1.07 \mathrm{E}+00$ & $\pm 1.07 \mathrm{E}-01$ \\
\hline $\mathrm{Cu}$ & $3.42 \mathrm{E}+00$ & $\pm 3.42 \mathrm{E}-01$ \\
\hline $\mathrm{Hg}$ & $1.87 \mathrm{E}-01$ & $\pm 1.87 \mathrm{E}-02$ \\
\hline $\mathrm{K}$ & $1.99 \mathrm{E}+04$ & $\pm 1.99 \mathrm{E}+03$ \\
\hline $\mathrm{Na}$ & $7.52 \mathrm{E}+04$ & $\pm 7.52 \mathrm{E}+03$ \\
\hline $\mathrm{Ni}$ & $5.28 \mathrm{E}+00$ & $\pm 5.28 \mathrm{E}-01$ \\
\hline $\mathrm{Pb}$ & $1.68 \mathrm{E}+00$ & $\pm 1.68 \mathrm{E}-01$ \\
\hline $\mathrm{Rb}$ & $2.24 \mathrm{E}+00$ & $\pm 2.24 \mathrm{E}-01$ \\
\hline $\mathrm{Si}$ & $1.79 \mathrm{E}+02$ & $\pm 1.79 \mathrm{E}+01$ \\
\hline $\mathrm{Sr}$ & $2.55 \mathrm{E}-01$ & $\pm 2.55 \mathrm{E}-02$ \\
\hline $\mathrm{U}$ & $<6.5 \mathrm{E}-01$ & \\
\hline $\mathrm{Zn}$ & $9.25 \mathrm{E}+00$ & $\pm 1.37 \mathrm{E}+00$ \\
\hline \multicolumn{3}{|l|}{ Anions, mg/L } \\
\hline $\mathrm{Br}$ & $4.68 \mathrm{E}+02$ & $\pm 4.70 \mathrm{E}+01$ \\
\hline $\mathrm{F}$ & $3.46 \mathrm{E}+02$ & $\pm 3.50 \mathrm{E}+01$ \\
\hline $\mathrm{Cl}$ & $4.58 \mathrm{E}+03$ & $\pm 4.60 \mathrm{E}+02$ \\
\hline $\mathrm{OH}, N$ & $4.00 \mathrm{E}-02$ & $\pm 4.00 \mathrm{E}-03$ \\
\hline $\mathrm{NO}_{2}$ & $6.94 \mathrm{E}+03$ & $\pm 6.90 \mathrm{E}+02$ \\
\hline $\mathrm{NO}_{3}$ & $1.76 \mathrm{E}+05$ & $\pm 1.80 \mathrm{E}+04$ \\
\hline $\mathrm{PO}_{4}$ & $5.45 \mathrm{E}+02$ & $\pm 5.50 \mathrm{E}+01$ \\
\hline $\mathrm{SO}_{4}$ & $5.56 \mathrm{E}+03$ & $\pm 5.60 \mathrm{E}+02$ \\
\hline \multicolumn{3}{|c|}{ 5.80 } \\
\hline $\mathrm{pH}$ & 12.66 & \pm 1.3 \\
\hline TIC, mg/L & $2.95 E+03$ & $\pm 2.95 \mathrm{E}+02$ \\
\hline $\mathrm{TOC}, \mathrm{mg} / \mathrm{L}$ & $2.06 \mathrm{E}+03$ & $\pm 2.06 \mathrm{E}+02$ \\
\hline Density, mg/L & 1.20 & \pm 0.1 \\
\hline $\mathrm{TDS}, \mathrm{mg} / \mathrm{L}$ & $3.37 \mathrm{E}+05$ & $\pm 3.37 \mathrm{E}+04$ \\
\hline $\mathrm{TS}, \mathrm{mg} / \mathrm{L}$ & $3.41 \mathrm{E}+05$ & $\pm 3.41 \mathrm{E}+04$ \\
\hline $\mathrm{TSS}, \mathrm{mg} / \mathrm{L}$ & $3.97 \mathrm{E}+03$ & $\pm 3.97 \mathrm{E}+02$ \\
\hline
\end{tabular}

${ }^{a}$ Samples withdrawn on December 16, 1998.

${ }^{b} \mathrm{TIC}=$ Total inorganic carbon; $\mathrm{TOC}=$ total organic carbon; TDS $=$ total dissolved solids; TS $=$ total solids; TSS $=$ total suspended solids . 
Table A.3. Analytical results from samples taken during Series 1 tests, tank W-31

\begin{tabular}{lccc}
\hline Parameter & Feed $^{a}$ & Filtrate $^{a}$ & Concentrate $^{a}$ \\
\hline Total solids, mg/L & $3.52 \mathrm{E}+05$ & & \\
Total suspended solids, ${ }^{b} \mathrm{mg} / \mathrm{L}$ & 390 & 1,310 & \\
Density, g/mL & 1.217 & 1.210 & 1.212 \\
$\mathrm{Al}, \mathrm{mg} / \mathrm{L}$ & 32.1 & 42 & \\
$\mathrm{Ca}, \mathrm{mg} / \mathrm{L}$ & $<0.12$ & $<0.12$ & \\
$\mathrm{Fe}, \mathrm{mg} / \mathrm{L}$ & $<0.24$ & $<0.24$ & \\
$\mathrm{Mg}, \mathrm{mg} / \mathrm{L}$ & $<0.41$ & $<0.41$ & \\
$\mathrm{U}, \mathrm{mg} / \mathrm{L}$ & $<1.3$ & $<1.3$ & $9.00 \mathrm{E}+05$ \\
$\mathrm{Zn}, \mathrm{mg} / \mathrm{L}$ & $<5.7$ & $<13.7$ & 95 \\
$\mathrm{G}-\mathrm{Beta}, \mathrm{Bq} / \mathrm{mL}$ & $9.20 \mathrm{E}+05$ & $9.20 \mathrm{E}+05$ & \\
$\mathrm{G}-\mathrm{Alpha}, \mathrm{Bq} / \mathrm{mL}$ & 91 & 66 & 8.5 \\
Alphaisotopic breakdown & & & 1.5 \\
${ }^{233,234} \mathrm{U}, \%$ & 8.2 & 11.1 & 6.7 \\
${ }^{239,240} \mathrm{Pu}, \%$ & 1.1 & 6.3 & 8.3 \\
${ }^{238} \mathrm{Pu} /{ }^{241} \mathrm{Am}, \%$ & 8.7 & & \\
${ }^{244} \mathrm{Cm}, \%$ & 85.0 & & \\
\hline
\end{tabular}

${ }^{a}$ Samples withdrawn on June 8, 1999.

${ }^{b}$ This method calls for filtration of the sample and weighing of filter medium. The medium can easily trap dissolved salts, which when dried can give a false positive indication. 
Table A.4. Analytical results from samples taken during Series 2 tests, tank W-31

\begin{tabular}{|c|c|c|c|c|}
\hline Parameter & Feed $^{a}$ & Filtrate $^{a}$ & $\mathrm{DF}$ & Concentrate $^{a}$ \\
\hline Total solids, $\mathrm{mg} / \mathrm{L}$ & $3.52 \mathrm{E}+05$ & & & \\
\hline Total suspended solids, ${ }^{b} \mathrm{mg} / \mathrm{L}$ & 290 & $<10$ & $>29$ & \\
\hline Density, $\mathrm{g} / \mathrm{mL}$ & & 1.215 & & 1.218 \\
\hline $\mathrm{Al}, \mathrm{mg} / \mathrm{L}$ & 55.8 & 51.1 & 1.1 & \\
\hline $\mathrm{Ca}, \mathrm{mg} / \mathrm{L}$ & $<1.07$ & $<0.25$ & Nil & \\
\hline $\mathrm{Fe}, \mathrm{mg} / \mathrm{L}$ & 1.49 & $<0.93$ & $>1.6$ & \\
\hline $\mathrm{Mg}, \mathrm{mg} / \mathrm{L}$ & 4.44 & $<1.64$ & $>2.7$ & \\
\hline $\mathrm{U}, \mathrm{mg} / \mathrm{L}$ & $<3.82$ & $<3.82$ & Nil & \\
\hline $\mathrm{Zn}, \mathrm{mg} / \mathrm{L}$ & $<12.4$ & $<12.4$ & Nil & \\
\hline G-Beta, Bq/mL & $9.10 \mathrm{E}+05$ & $9.10 \mathrm{E}+05$ & Nil & $9.20 \mathrm{E}+05$ \\
\hline G-Alpha, Bq/mL & 100 & 73 & 1.4 & 130 \\
\hline \multicolumn{5}{|l|}{ Alpha isotopic breakdown } \\
\hline${ }^{238} \mathrm{U}, \%$ & 0.4 & & & 0.2 \\
\hline${ }^{233,234} \mathrm{U}, \%$ & 5.9 & 9.8 & & 6.3 \\
\hline${ }^{239,240} \mathrm{Pu}, \%$ & 2.5 & & & 2.2 \\
\hline${ }^{238} \mathrm{Pu} /{ }^{241} \mathrm{Am}, \%$ & 12.7 & 7.9 & & 11.3 \\
\hline${ }^{244} \mathrm{Cm}, \%$ & 78.5 & 82.3 & & 80.0 \\
\hline
\end{tabular}

A - 7 
Table A.5. Analytical results from samples taken during Series 3 tests, tank W-31

\begin{tabular}{|c|c|c|c|c|}
\hline Parameter & Feed $^{a}$ & Filtrate $^{a}$ & DF & Concentrate $^{a}$ \\
\hline Total solids, $\mathrm{mg} / \mathrm{L}$ & $3.52 \mathrm{E}+05$ & & & \\
\hline Total suspended solids, ${ }^{b} \mathrm{mg} / \mathrm{L}$ & 830 & $<10$ & $>83$ & \\
\hline Density, $\mathrm{g} / \mathrm{mL}$ & & 1.217 & & 1.227 \\
\hline $\mathrm{Al}, \mathrm{mg} / \mathrm{L}$ & 44.8 & 29.8 & 1.5 & \\
\hline $\mathrm{Ca}, \mathrm{mg} / \mathrm{L}$ & 88.1 & 8.87 & 10 & \\
\hline $\mathrm{Fe}, \mathrm{mg} / \mathrm{L}$ & 6.68 & $<0.07$ & $>95$ & \\
\hline $\mathrm{Mg}, \mathrm{mg} / \mathrm{L}$ & 9.46 & $<0.24$ & $>39$ & \\
\hline $\mathrm{U}, \mathrm{mg} / \mathrm{L}$ & 37.1 & $<0.38$ & $>98$ & \\
\hline $\mathrm{Zn}, \mathrm{mg} / \mathrm{L}$ & 5.2 & 3.27 & 1.6 & \\
\hline G-Beta, $\mathrm{Bq} / \mathrm{mL}$ & $9.10 \mathrm{E}+05$ & $8.70 \mathrm{E}+05$ & Nil & $9.40 \mathrm{E}+05$ \\
\hline G-Alpha, Bq/mL & 100 & 66 & 1.5 & 370 \\
\hline \multicolumn{5}{|l|}{ Alpha isotopic breakdown } \\
\hline${ }^{238} \mathrm{U}, \%$ & 0.2 & 1.2 & & 0.0 \\
\hline${ }^{233,234} \mathrm{U}, \%$ & 3.7 & 6.7 & & 4.1 \\
\hline${ }^{239,240} \mathrm{Pu}, \%$ & 4.2 & 1.5 & & 2.6 \\
\hline${ }^{238} \mathrm{Pu} /{ }^{241} \mathrm{Am}, \%$ & 15.6 & 7.3 & & 11.7 \\
\hline${ }^{244} \mathrm{Cm}, \%$ & 76.2 & 83.3 & & 81.6 \\
\hline
\end{tabular}

${ }^{a}$ Samples were withdrawn on June 21, 1999.

${ }^{b}$ This method calls for filtration of the sample and weighing of filter medium. The medium can easily trap dissolved salts, which when dried can give a false positive indication. 
Table A.6. Analytical data from routine operational samples, tank W-31

\begin{tabular}{lcccccc}
\hline \multicolumn{1}{c}{ Parameter } & Feed $^{a}$ & Filtrate $^{a}$ & Filtrate $^{b}$ & Filtrate $^{c}$ & Filtrate $^{d}$ & Concentrate $^{d}$ \\
\hline $\begin{array}{c}\text { Total suspended } \\
\text { solids, }{ }^{e} \mathrm{mg} / \mathrm{L}\end{array}$ & 200 & $<10$ & 30 & 20 & $250^{\mathrm{f}}$ & $1.51 \mathrm{E}+05$ \\
$\begin{array}{c}\text { Density, g/mL } \\
\text { G-Beta, } \mathrm{Bq} / \mathrm{mL}\end{array}$ & 1.215 & 1.214 & 1.216 & 1.217 & 1.229 & 1.304 \\
G-Alpha, Bq/mL & $8.60 \mathrm{E}+05$ & $9.10 \mathrm{E}+05$ & & & $7.80 \mathrm{E}+05$ & \\
Alphaisotopic breakdown & 120 & 68 & 65 & 74 & 65 & \\
${ }^{238} \mathrm{U}, \%$ & 0.5 & 0.3 & 0.7 & & & \\
${ }^{233,234} \mathrm{U}, \%$ & 7.9 & 8.9 & 10.4 & & 2.1 & \\
${ }^{239,240} \mathrm{Pu}, \%$ & 2.1 & 2.0 & 1.0 & & 2.4 & \\
${ }^{238} \mathrm{Pu} /{ }^{241} \mathrm{Am}, \%$ & 10.4 & 6.9 & 7.2 & & 10.7 \\
${ }^{244} \mathrm{Cm}, \%$ & 79.1 & 81.9 & 80.8 & & 84.7 & \\
\hline
\end{tabular}

${ }^{a}$ Sample withdrawn on June 14, 1999.

${ }^{b}$ Sample withdrawn on June 18, 1999.

'Sample withdrawn on June 21, 1999.

${ }^{d}$ Sample withdrawn on June 24, 1999.

${ }^{e}$ This method calls for filtration of the sample and weighing of filter medium. The medium can easily trap dissolved salts, which when dried can give a false positive indication.

${ }^{f} \mathrm{DF}$ with respect to wt \% TSS, when compared with the concentrate sample of June 24, $1999=580$. 
Table A.7. Laboratory analysis of the MVST W-26 supernatant ${ }^{a}$

\begin{tabular}{|c|c|c|}
\hline \multicolumn{3}{|l|}{ Radiochemicals, Bq/mL } \\
\hline${ }^{60} \mathrm{Co}$ & $1.50 \mathrm{E}+03$ & $\pm 4.00 \mathrm{E}+02$ \\
\hline${ }^{137} \mathrm{Cs}$ & $7.50 \mathrm{E}+05$ & $+1.00 \mathrm{E}+04$ \\
\hline${ }^{134} \mathrm{Cs}$ & $1.20 \mathrm{E}+04$ & $\pm 1.00 \mathrm{E}+03$ \\
\hline${ }^{106} \mathrm{Ru}$ & $7.20 \mathrm{E}+03$ & $\pm 5.30 \mathrm{E}+03$ \\
\hline Gross alpha & $6.80 \mathrm{E}+01$ & $\pm 5.00 \mathrm{E}+00$ \\
\hline $4.80-\mathrm{Mev}^{233} \mathrm{U} /{ }^{234} \mathrm{U}, \%$ & 10.9 & \\
\hline 5.50- $\mathrm{Mev}^{238} \mathrm{Pu} /{ }^{241} \mathrm{Am}, \%$ & 8.2 & \\
\hline $5.80-\mathrm{Mev}^{244} \mathrm{Cm}, \%$ & 80.9 & \\
\hline \multicolumn{3}{|l|}{ Cations, $\mathrm{mg} / \mathrm{L}$} \\
\hline $\mathrm{Ag}$ & $<5.85 \mathrm{E}-02$ & \\
\hline As & $<2.5 \mathrm{E}-01$ & \\
\hline $\mathrm{Ba}$ & $1.50 \mathrm{E}-01$ & $\pm 1.50 \mathrm{E}-02$ \\
\hline $\mathrm{Cd}$ & $4.25 \mathrm{E}+00$ & $\pm 4.25 \mathrm{E}-01$ \\
\hline $\mathrm{Cr}$ & $1.36 \mathrm{E}+01$ & $\pm 1.36 \mathrm{E}+00$ \\
\hline $\mathrm{Hg}$ & $1.08 \mathrm{E}+00$ & $\pm \quad 1.00 \mathrm{E}-01$ \\
\hline $\mathrm{Ni}$ & $5.47 \mathrm{E}+00$ & $\pm \quad 5.50 \mathrm{E}-01$ \\
\hline $\mathrm{Pb}$ & $1.32 \mathrm{E}+00$ & $\pm \quad 1.30 \mathrm{E}-01$ \\
\hline $\mathrm{Se}$ & $<2.5 \mathrm{E}-01$ & \\
\hline Th & $2.24 \mathrm{E}+00$ & $\pm 2.20 \mathrm{E}-01$ \\
\hline $\mathrm{Tl}$ & $<2.5 \mathrm{E}-01$ & \\
\hline $\mathrm{U}$ & $<1.91 \mathrm{E}+00$ & \\
\hline \multicolumn{3}{|l|}{ Anions, mg/L } \\
\hline $\mathrm{Cl}$ & $2.59 \mathrm{E}+02$ & $\pm 2.60 \mathrm{E}+01$ \\
\hline $\mathrm{F}$ & $3.82 \mathrm{E}+02$ & $\pm \quad 3.80 \mathrm{E}+01$ \\
\hline $\mathrm{NO}_{2}$ & $1.52 \mathrm{E}+03$ & $\pm 1.50 \mathrm{E}+02$ \\
\hline $\mathrm{NO}_{3}$ & $2.75 \mathrm{E}+03$ & $\pm 2.80 \mathrm{E}+02$ \\
\hline $\mathrm{PO}_{4}$ & $8.66 \mathrm{E}+02$ & $\pm 8.70 \mathrm{E}+01$ \\
\hline $\mathrm{SO}_{4}$ & $1.12 \mathrm{E}+03$ & $\pm \quad 1.10 \mathrm{E}+02$ \\
\hline \multicolumn{3}{|l|}{ Other $^{a}{ }_{4}$} \\
\hline $\mathrm{pH}$ & 9.89 & \pm 1.0 \\
\hline Density, $\mathrm{g} / \mathrm{mL}$ & 1.018 & +0.01 \\
\hline
\end{tabular}

${ }^{a}$ Sample was withdrawn on June 29,1999 . It was filtered through a $0.45-\mu$ m filter.

A - 10 
Table A.8. Analytical results from samples taken during Series 1 tests, tank W-26

\begin{tabular}{|c|c|c|c|}
\hline Parameter & Feed $^{a}$ & Filtrate $^{a}$ & DF \\
\hline Total solids, mg/L & $3.80 \mathrm{E}+04$ & & \\
\hline Total suspended solids, ${ }^{b} \mathrm{mg} / \mathrm{L}$ & $2.00 \mathrm{E}+04$ & $9.00 \mathrm{E}+01$ & 222 \\
\hline Density, g/mL & 1.050 & 1.038 & \\
\hline $\mathrm{Al}, \mathrm{mg} / \mathrm{L}$ & $3.66 \mathrm{E}+02$ & $1.45 \mathrm{E}+01$ & 25.2 \\
\hline $\mathrm{Ca}, \mathrm{mg} / \mathrm{L}$ & $2.73 E+03$ & $2.10 \mathrm{E}+00$ & 1,300 \\
\hline $\mathrm{Fe}, \mathrm{mg} / \mathrm{L}$ & $2.20 \mathrm{E}+02$ & $1.07 \mathrm{E}+00$ & 206 \\
\hline $\mathrm{Mg}, \mathrm{mg} / \mathrm{L}$ & $7.86 \mathrm{E}+02$ & $3.91 \mathrm{E}+01$ & 20 \\
\hline $\mathrm{U}, \mathrm{mg} / \mathrm{L}$ & $5.32 \mathrm{E}+03$ & $2.58 \mathrm{E}+03$ & 2.1 \\
\hline $\mathrm{Zn}, \mathrm{mg} / \mathrm{L}$ & $5.28 \mathrm{E}+01$ & $<4.45 \mathrm{E}+00$ & $>11.9$ \\
\hline G-Beta, Bq/mL & $5.40 \mathrm{E}+05$ & $1.90 \mathrm{E}+05$ & 2.8 \\
\hline G-Alpha, Bq/mL & $6.40 \mathrm{E}+03$ & $1.90 \mathrm{E}+02$ & 33.7 \\
\hline \multicolumn{4}{|l|}{ Alpha isotopic breakdown } \\
\hline${ }^{238} \mathrm{U}, \%$ & 0.9 & 12.1 & \\
\hline${ }^{233,234} \mathrm{U}, \%$ & 12.7 & 81.8 & \\
\hline${ }^{232} \mathrm{U}^{228} \mathrm{Th}, \%$ & & 4.4 & \\
\hline${ }^{239,240} \mathrm{Pu}, \%$ & 4.7 & & \\
\hline${ }^{238} \mathrm{Pu} /{ }^{241} \mathrm{Am}, \%$ & 15.4 & & \\
\hline${ }^{244} \mathrm{Cm}, \%$ & 66.4 & 1.7 & \\
\hline
\end{tabular}


Table A.9. Analytical results from samples taken during Series 4 tests, $\operatorname{tank}$ W-26

\begin{tabular}{lccc}
\hline Parameter & Feed $^{a}$ & Filtrate $^{a}$ & DF \\
\hline Total suspended solids ${ }^{b}, \mathrm{mg} / \mathrm{L}$ & $7.62 \mathrm{E}+04$ & $4.60 \mathrm{E}+02$ & 166 \\
Density, g/mL & 1.094 & 1.047 & \\
$\mathrm{Al}, \mathrm{mg} / \mathrm{L}$ & $1.30 \mathrm{E}+03$ & $1.71 \mathrm{E}+01$ & 76 \\
$\mathrm{Ca}, \mathrm{mg} / \mathrm{L}$ & $1.59 \mathrm{E}+04$ & $1.97 \mathrm{E}+01$ & 807 \\
$\mathrm{Fe}, \mathrm{mg} / \mathrm{L}$ & $8.02 \mathrm{E}+02$ & $1.67 \mathrm{E}+00$ & 480 \\
$\mathrm{Mg}, \mathrm{mg} / \mathrm{L}$ & $4.07 \mathrm{E}+03$ & $4.27 \mathrm{E}+01$ & 95 \\
$\mathrm{U}, \mathrm{mg} / \mathrm{L}$ & $1.25 \mathrm{E}+04$ & $2.63 \mathrm{E}+03$ & 4.8 \\
$\mathrm{Zn}, \mathrm{mg} / \mathrm{L}$ & $1.60 \mathrm{E}+02$ & $<4.45 \mathrm{E}+00$ & $>36$ \\
$\mathrm{G}-\mathrm{Beta}, \mathrm{Bq} / \mathrm{mL}$ & $1.60 \mathrm{E}+06$ & $2.40 \mathrm{E}+05$ & 6.7 \\
$\mathrm{G}-\mathrm{Alpha}, \mathrm{Bq} / \mathrm{mL}$ & $2.70 \mathrm{E}+04$ & $3.50 \mathrm{E}+02$ & 77 \\
$\mathrm{Alphaisotopic} \mathrm{breakdown}$ & & & \\
${ }^{238} \mathrm{U}, \%$ & 0.6 & 8.3 & \\
${ }^{233,234} \mathrm{U}, \%$ & 11.0 & 82.0 & \\
${ }^{243} \mathrm{Am} /{ }^{232} \mathrm{U} /{ }^{210} \mathrm{Po}, \%$ & & 5.4 & \\
${ }^{239,240} \mathrm{Pu} \%$ & & & \\
${ }^{238} \mathrm{Pu} /{ }^{241} \mathrm{Am}, \%$ & 6.3 & \\
${ }^{244} \mathrm{Cm}, \%$ & & & \\
\hline
\end{tabular}

${ }^{\mathrm{a}}$ Samples withdrawn on August 20,1999.

${ }^{\mathrm{b}}$ This method calls for filtration of the sample and weighing of filter medium. The medium can easily trap dissolved salts, which when dried can give a false positive indication. 
Table A.10. Analytical data from routine operational samples, tank W-26

\begin{tabular}{lcccc}
\hline Parameter & Feed $^{a}$ & Filtrate $^{a}$ & Filtrate $^{a, b}$ & Filtrate $^{c}$ \\
\hline Total suspended solids, ${ }^{d} \mathrm{mg} / \mathrm{L}$ & $3.53 \mathrm{E}+04$ & & & \\
Density, $\mathrm{g} / \mathrm{mL}$ & & 1.036 & & 1.040 \\
G-Alpha, $\mathrm{Bq} / \mathrm{mL}$ & $1.0 \mathrm{E}+04$ & $1.70 \mathrm{E}+02^{e}$ & $1.70 \mathrm{E}+02$ & $2.10 \mathrm{E}+02$ \\
Alphaisotopic breakdown & & & & \\
${ }^{238} \mathrm{U}, \%$ & 0.7 & 11.5 & 12.1 & 10.8 \\
${ }^{233,234} \mathrm{U}, \%$ & 71.4 & 82.9 & 81.3 \\
${ }^{228} \mathrm{Th}, \%$ & 5.7 & 3.0 & \\
${ }^{239,240} \mathrm{Pu}, \%$ & & & 2.4 \\
${ }^{238} \mathrm{Pu} /{ }^{241} \mathrm{Am}, \%$ & 4.9 & & & 10.7 \\
${ }^{243} \mathrm{Am} /{ }^{232} \mathrm{U} /{ }^{210} \mathrm{Po}, \%$ & 16.2 & & & 5.8 \\
${ }^{244} \mathrm{Cm}, \%$ & 67.2 & 5.4 & 2.0 & 2.1 \\
& & & & \\
\hline
\end{tabular}

${ }^{a}$ Samples withdrawn on July 26, 1999.

${ }^{b}$ Filtrate sample withdrawn on July 26,1999 , and filtered through $0.45-\mu \mathrm{m}$ laboratory disc filter.

'Sample withdrawn on August 6,1999.

${ }^{d}$ This method calls for filtration of the sample and weighing of filter medium. The medium can easily trap dissolved salts, which when dried can give a false positive indication.

${ }^{e}$ Decontamination factor for gross alpha: $1.04 \mathrm{E}+04 / 170=59$.

A - 13 
Appendix B. ORNL CUF TEST RESULTS 


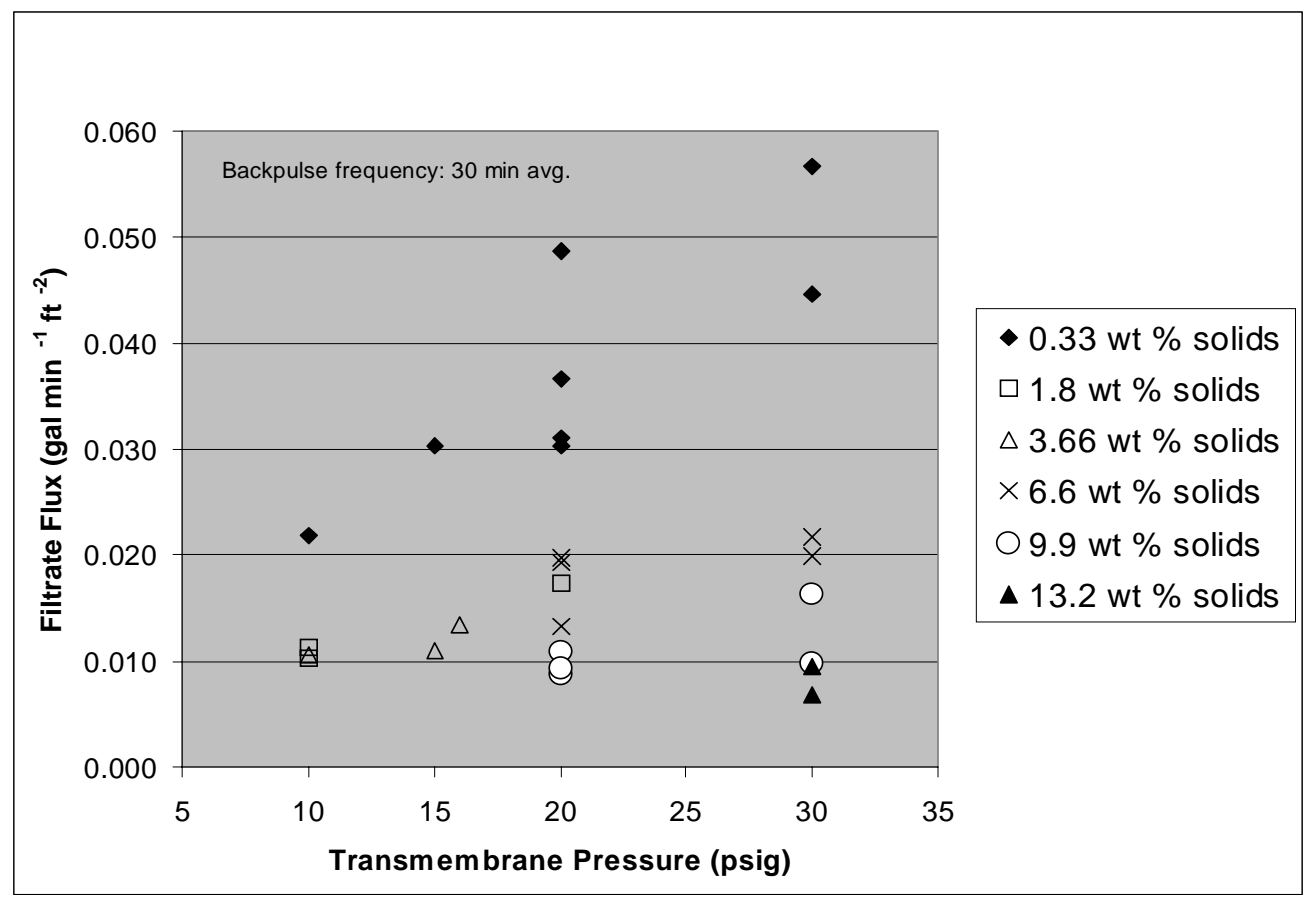

Fig. B-1. Filtrate flux as a function of transmembrane pressure for W3-W4 sample mixture.

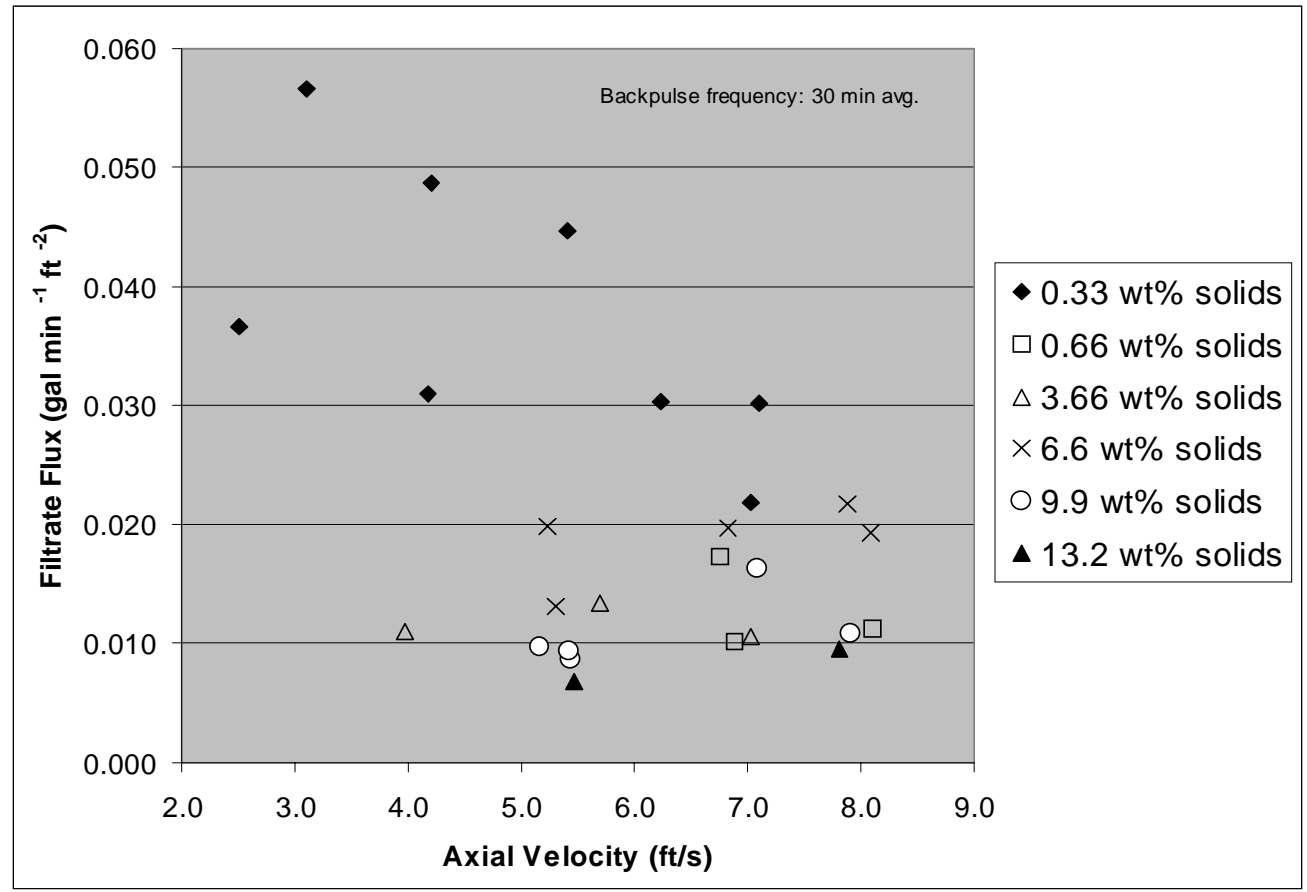

Fig. B-2. Filtrate flux as a function of axial velocity for W3-W4 sample mixture. 


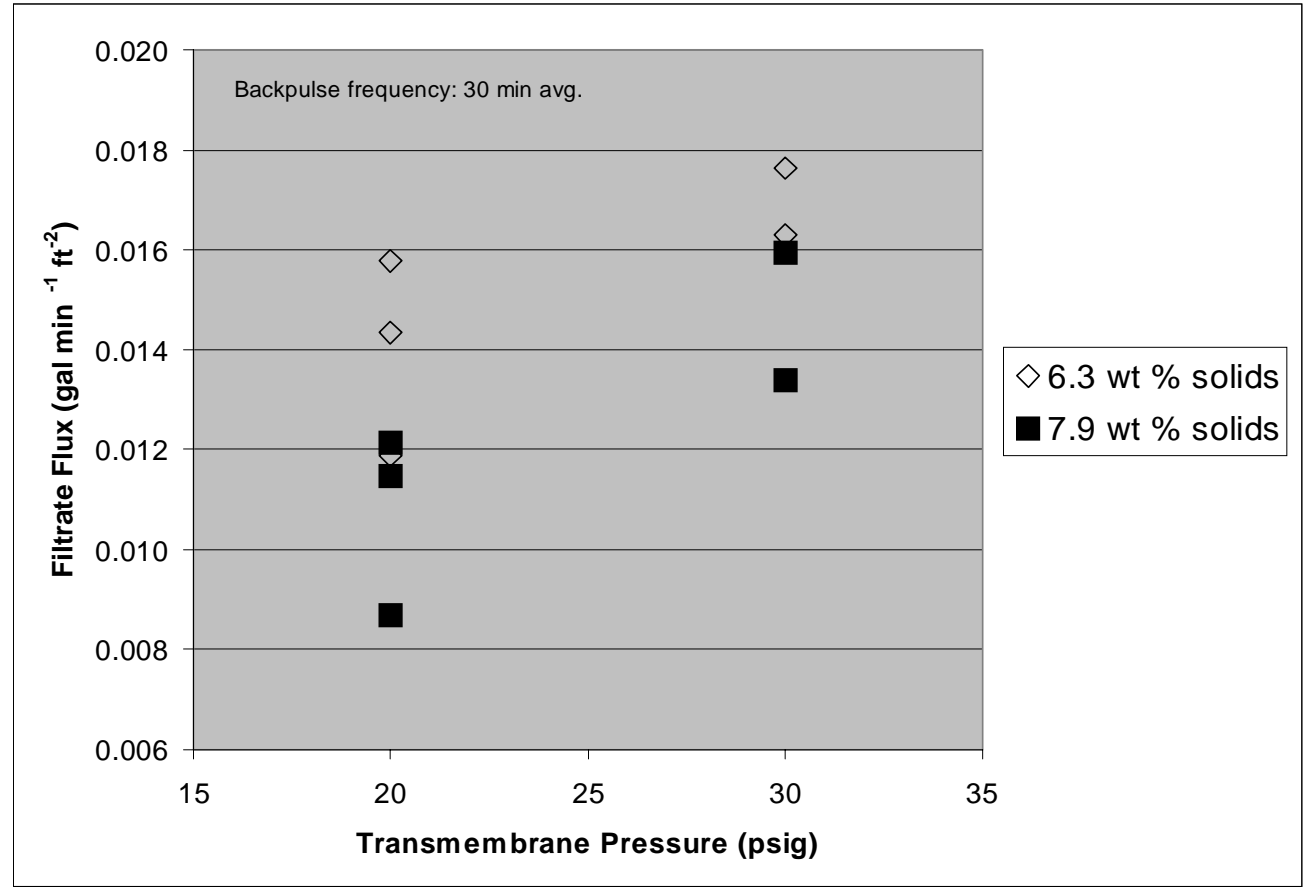

Fig. B-3. Filtrate flux as a function of transmembrane pressure for W6-W10 sample mixture.

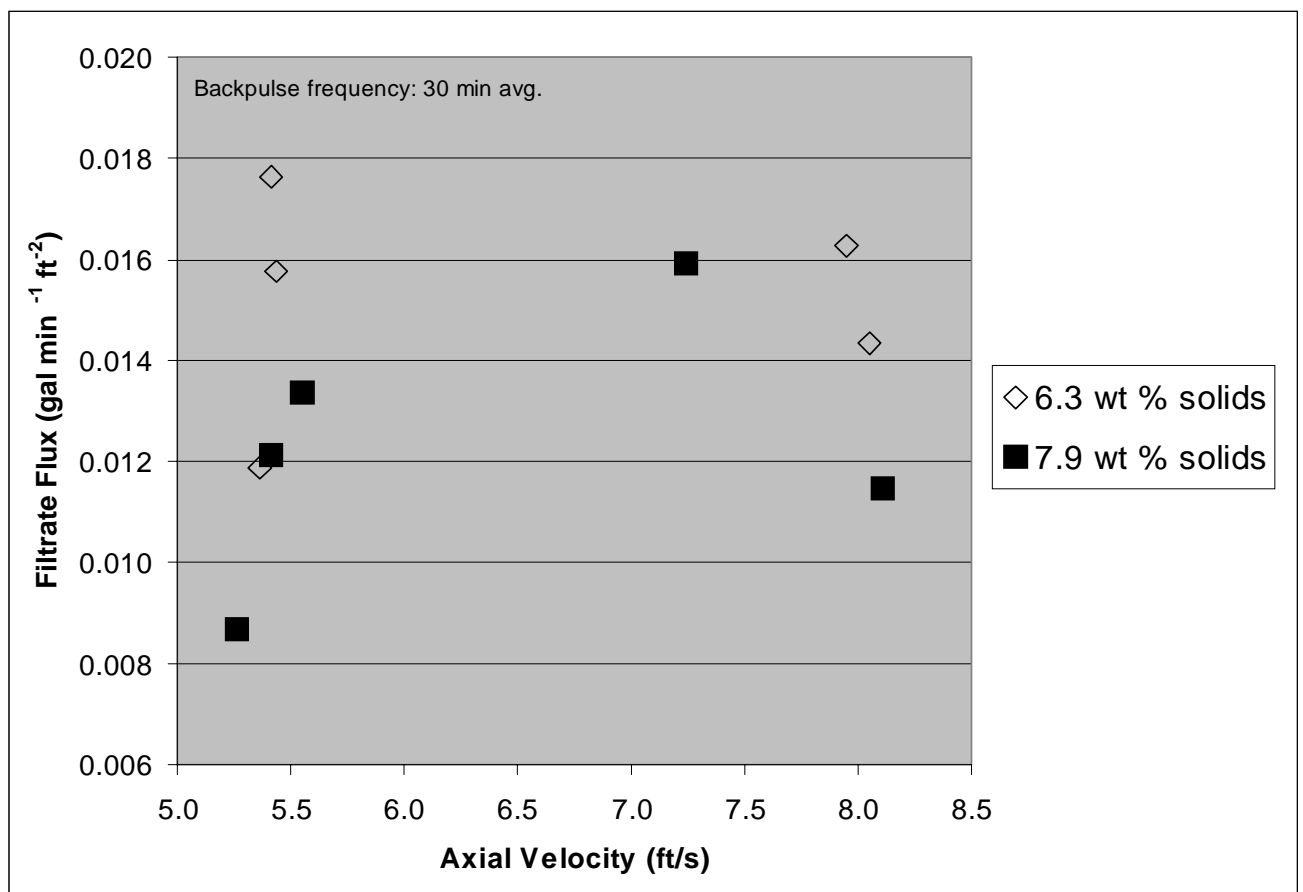

Fig. B-4. Filtrate flux as a function of axial velocity for W6-W10 sample mixture. 


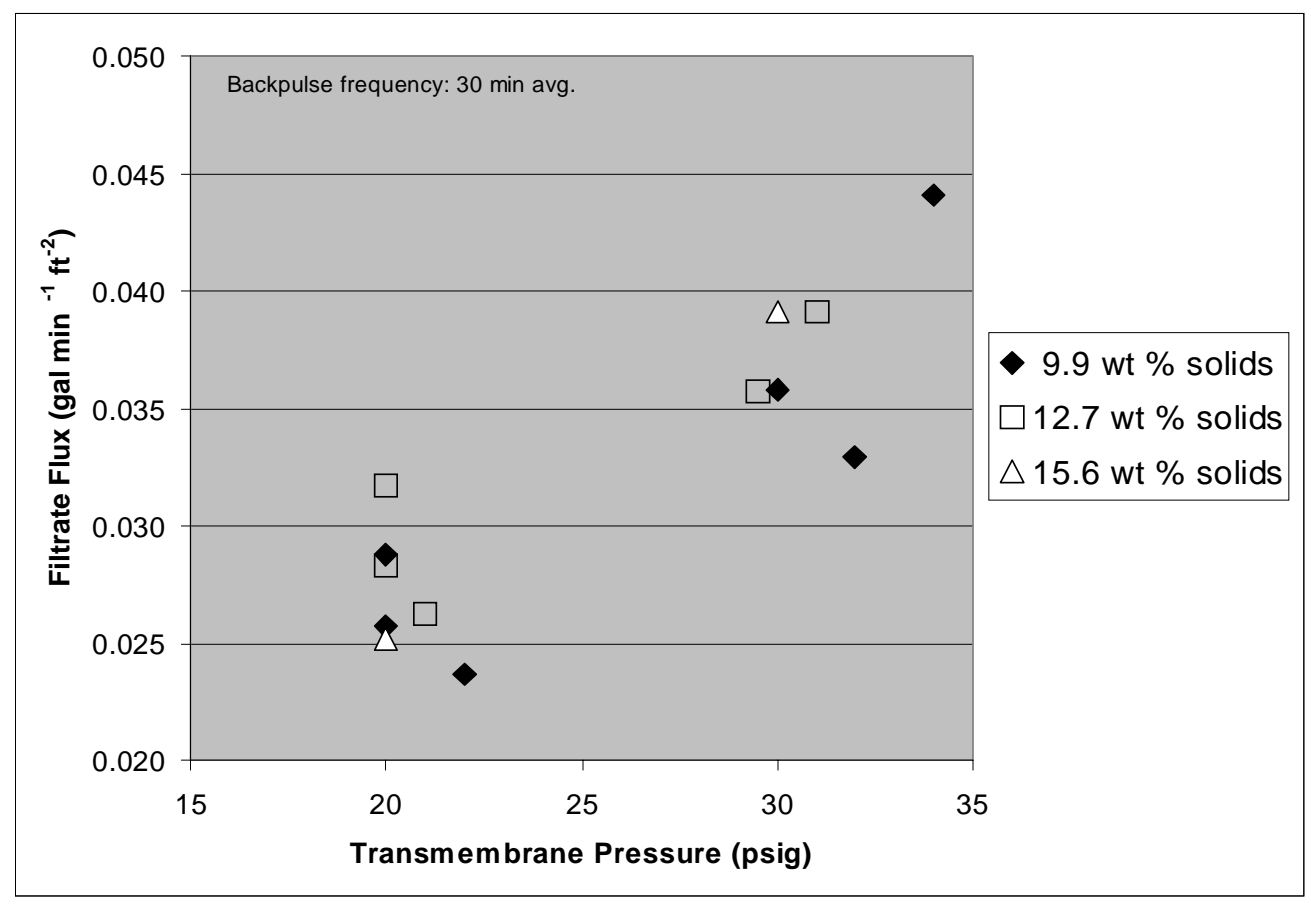

Fig. B-5. Filtrate flux as a function of transmembrane pressure for $\mathrm{W}-25$ sample.

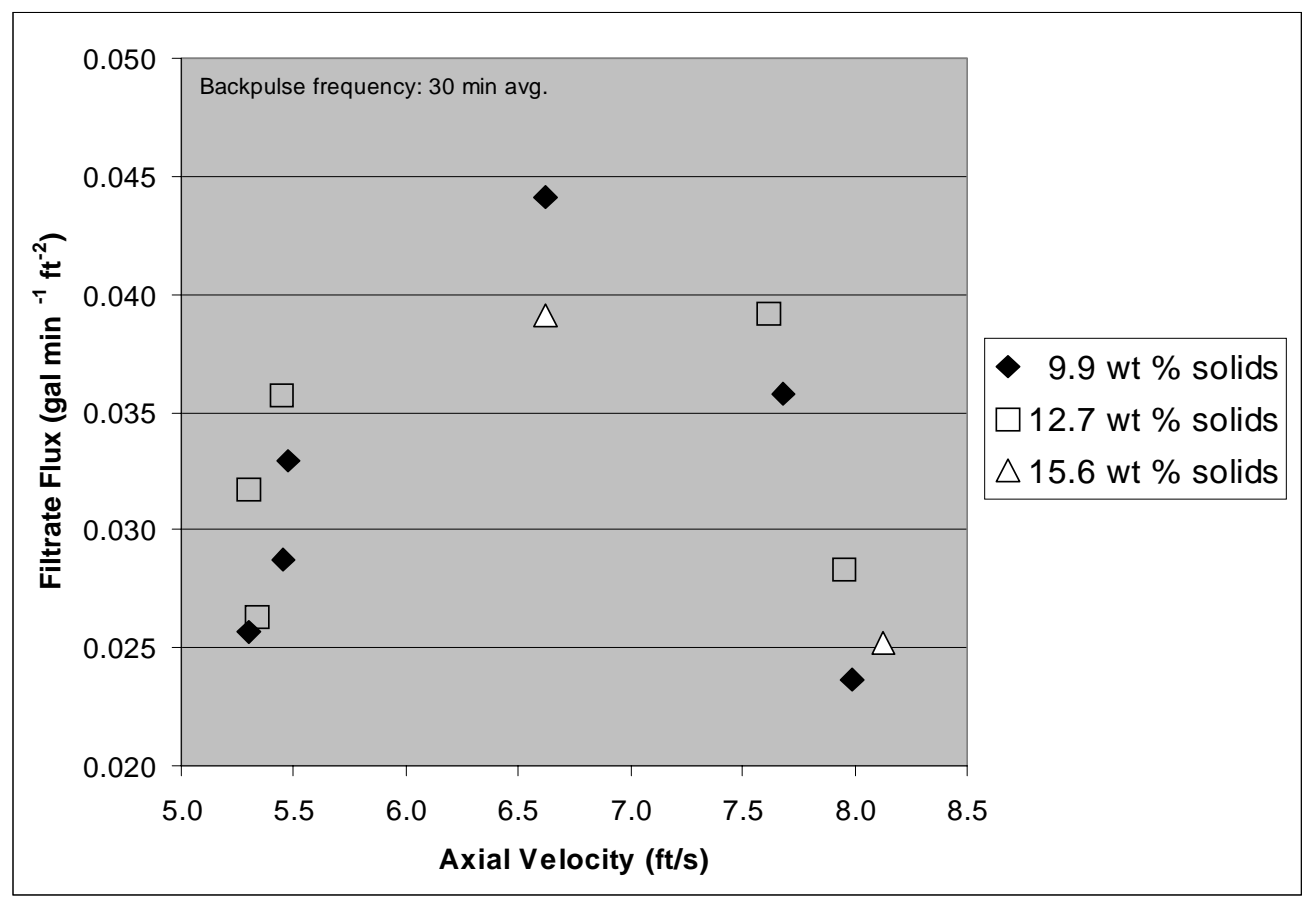

Fig. B-6. Filtrate flux as a function of axial velocity for W-25 sample. 
Appendix C. INFORMATION ON SLS DESIGN SPECIFICATION 


\section{Excerpt from Equipment Specification Solid-Liquid Separation for Melton Valley Storage Tanks Supernate Solids Removal, Specification JS-CT-020013-A001}

\subsection{TECHNICAL REQUIREMENTS}

The Seller shall be responsible for the detailed design of the components to meet the requirements of this specification. The Seller shall provide materials of construction, fabrication, inspection, tests, calculations, and reports in full compliance with this specification.

\subsection{Design}

The Seller shall design, fabricate, shop assemble for inspection, test, disassemble, and deliver a skid-mounted Solid-Liquid Separation system in accordance with this specification. The Solid-Liquid Separation system shall be developed to satisfy the following performance characteristics:

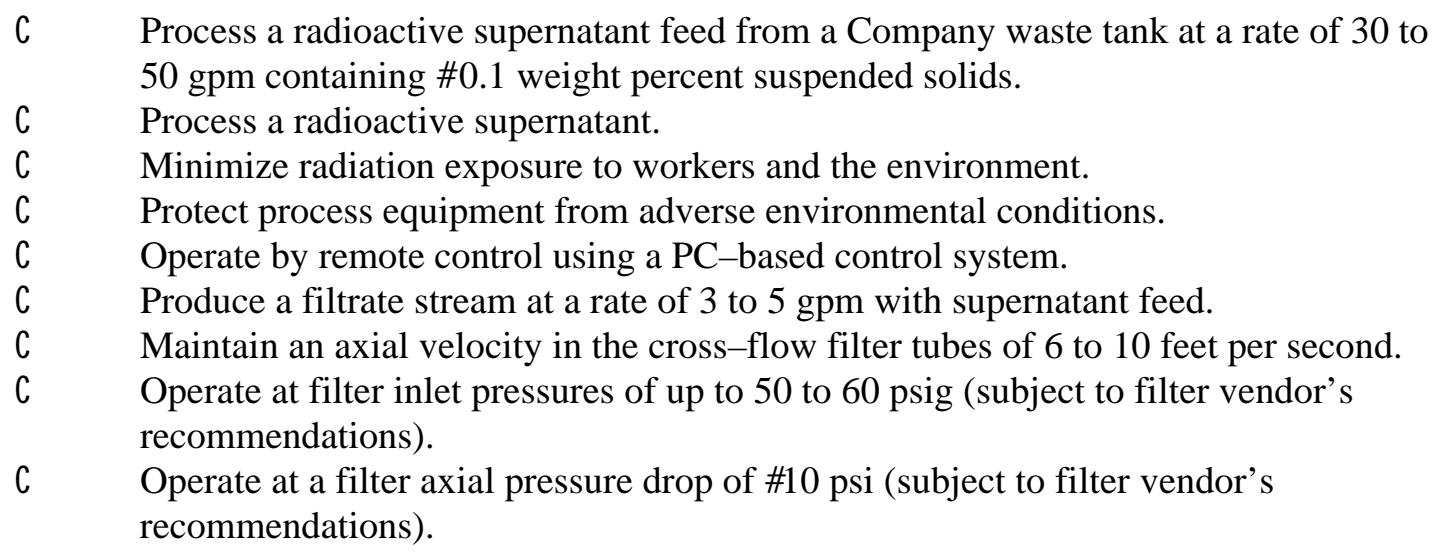

System design parameters are described in the main body of this document. The attachments to this document present the certain design parameters in a more concise format. In particular, Attachments 5 and 6 address the design parameters for the cross-flow filter and the filter circulation pump, respectively. Attachment 7 describes general design parameters, as well as those for the system enclosure and the filtrate and chemical tanks.

The Solid-Liquid Separation system shall consist of two cross-flow filters in series, filter circulation pump, filtrate collection tank, structural support skid, radiological shielding, enclosure, and associated pumps, valves, pipe, and instrumentation as referenced per Dwg. P3E020013C036. The process equipment shall be mounted on a structural steel skid supplied with sufficient lifting points to allow for vertical lifting. The skid shall include a liquid collection pan integral with the structural members of the skid. The enclosure shall be mounted on the equipment perimeter. The enclosure shall be designed to serve as a splash guard by preventing process liquid from spraying beyond the skid boundary. Spilled or sprayed liquid shall be diverted into the liquid collection pan. The enclosure shall also prevent snow or rain from entering the liquid collection pan. The completed SLS System shall be no larger than $10 \mathrm{ft}$ wide by $20 \mathrm{ft}$ length with a height limit of $8 \mathrm{ft}$ for the process equipment and a minimum of $1-\mathrm{ft}$ clearance between the process equipment and the top of the enclosure. 
The Seller shall obtain ASME form U-1A from the filter manufacturer, which certifies that the filter housing and air reservoir are manufactured in accordance with the ASME B\&PVC,

Sections II, VIII (Division 1), and IX, and provide it along with a certificate of compliance to the Company. This certificate shall document that the delivered equipment meets the requirements of this specification and of the standards referenced in this specification. The filter housing and air reservoir shall bear the ASME Section VIII stamp of authorization.

The SLS System tanks, valves, and piping shall be constructed of Type 304L stainless steel or Company approved substitute material (such as nonwelded 316 stainless steel valves and pumps). Valving shall allow isolation of each tank, instrument, and pump. The structural support skid shall be constructed of A36 structural steel and coated with epoxy paint system. The liquid collection pan shall be constructed of type 304L stainless steel.

The SLS System shall be designed to operate in all weather conditions. Components shall be configured to allow complete draining of liquids and prevent dead legs. The SLS System enclosure shall be maintained at a minimum temperature of 40EF. A CCTV camera shall be provided to monitor the status of the system.

Component drains shall be routed to a common drain header which will be connected to the Company waste tank, i.e., MVST tanks inlet header. Vents shall be routed to a common vent header, which also will be connected to the Company waste tank.

The enclosure dimensions, the overall system dimensions, capacities, estimated total shipping and operating weight, center of mass, anchor point loads, and special features shall be provided to the Company.

The SLS System shall be designed for remote operation.

The complete SLS System shall include the following:

1) structural support skid, liquid collection pan, enclosure, mounting plates, and hardware

2) cross-flow filter and associated backpulse system

3) filtrate collection tank

4) filter circulation pump (DS-CT-020013-A003)

5) chemical addition system

6) radiological shielding

7) process/utility piping (air/water)

8) process/utility valves (air/water)

9) flush connections 
10) panel box (for wire interface)

11) instrument and control package

12) attachments to facilitate lifting of tanks and motors for installation and removal or maintenance

13) special tools required to maintain, repair, and/or adjust the equipment

14) filtrate tank pump (specified by Seller)

15) central control station

16) software and license

17) data collection system

18) video monitoring system

19) list of manufacturer-recommended spare parts based on availability and lead time for procurement (to be provided at completion of design).

The Seller shall recommend utility requirements for air, process water, and backwash water pressures and flow rates.

Seismic and wind design shall be in accordance with Attachment 2.

Deficiencies or errors in these representations do not relieve the Seller from the responsibility of furnishing correct and suitable components and systems:

a. $\quad$ For a design based on the paramount principles of safety and reliability and not compromised by other consideration.

b. For the satisfaction of performance characteristics as described above.

c. For the field conditions existing at the time of purchase order award.

Recommended changes in design by the Seller may be made as agreed upon by the Company. 
Appendix D. SLS SYSTEM DRAWINGS

Skid General Arrangement (Isometric)

Skid General Arrangement (Outside Enclosure)

System Flowsheet (P\&ID)

Filter Module Piping Interface

Graphical User Interface Layout - Filtrate Cycle Mode 


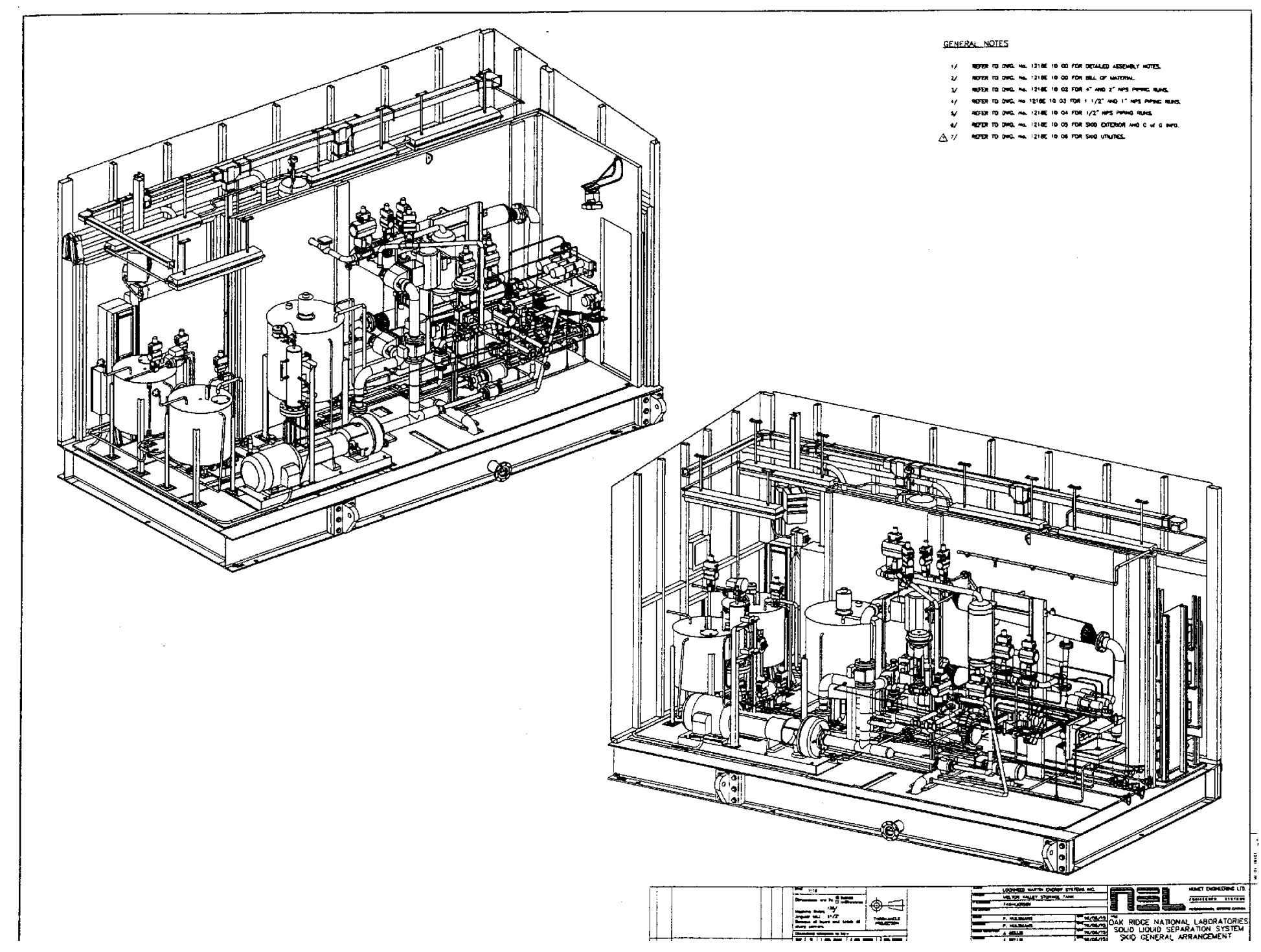

Skid General Arrangement (Isometric) 

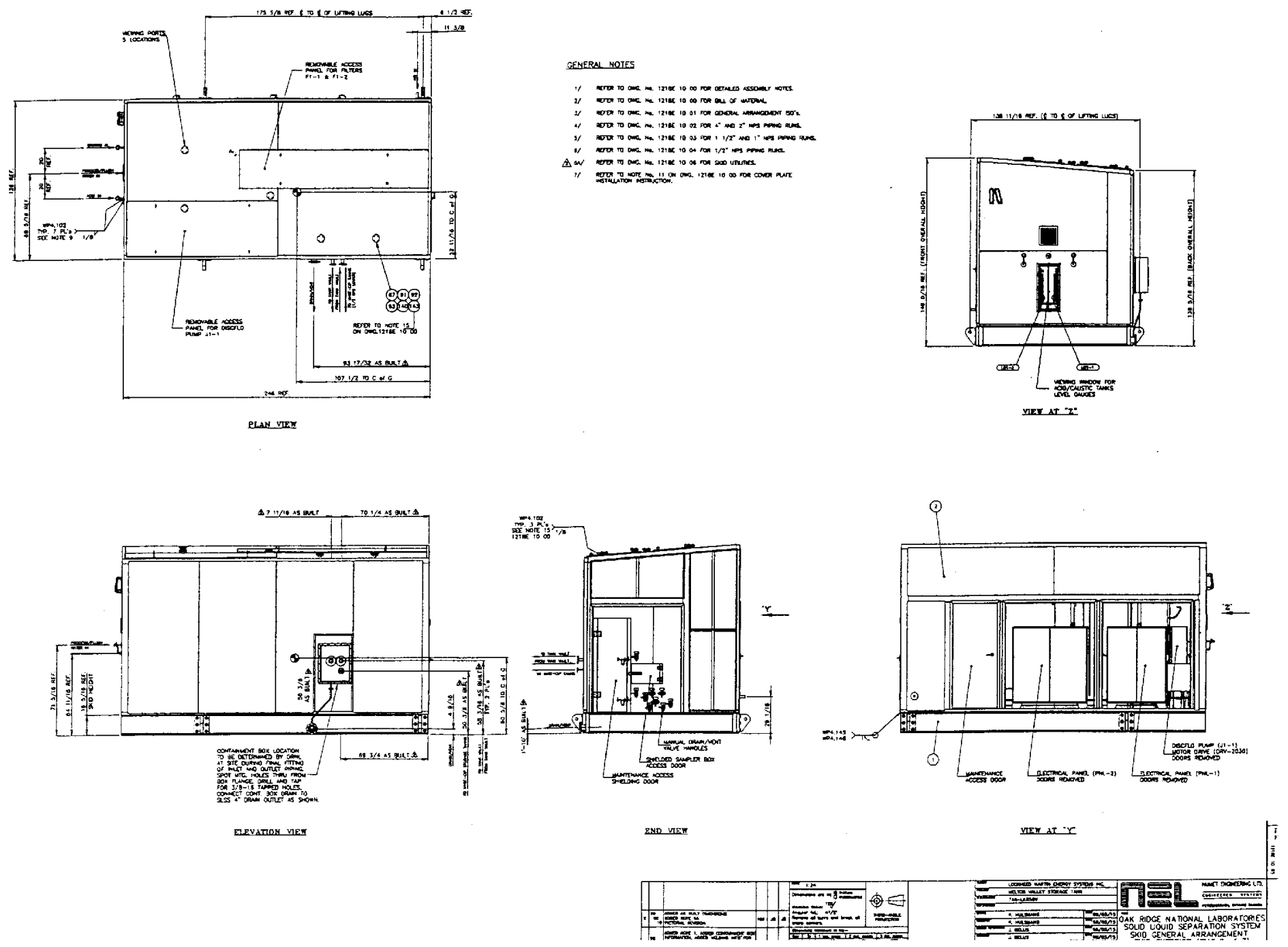

Skid General Arrangement (Outside Enclosure) 


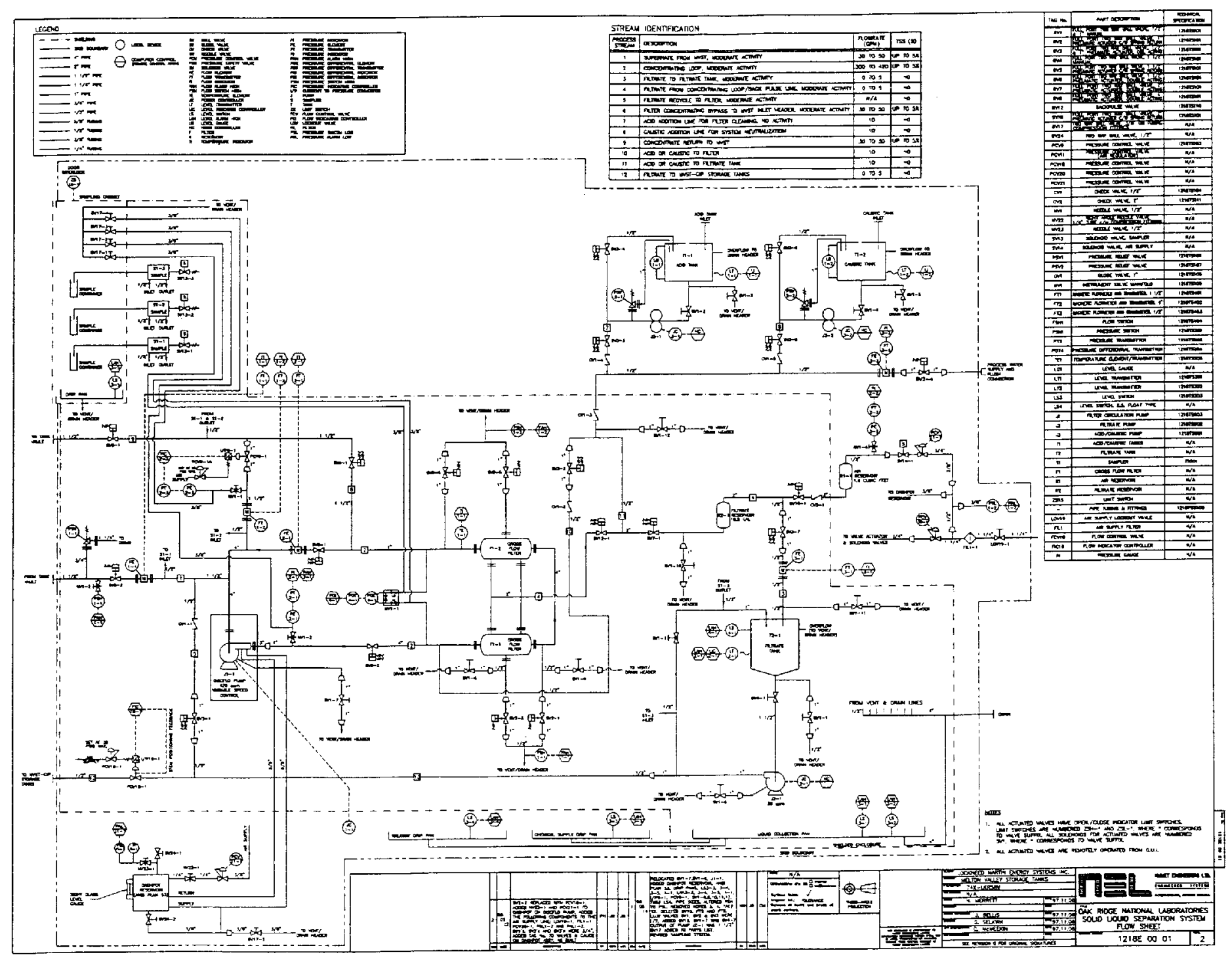

System Flowsheet (P\&ID) 


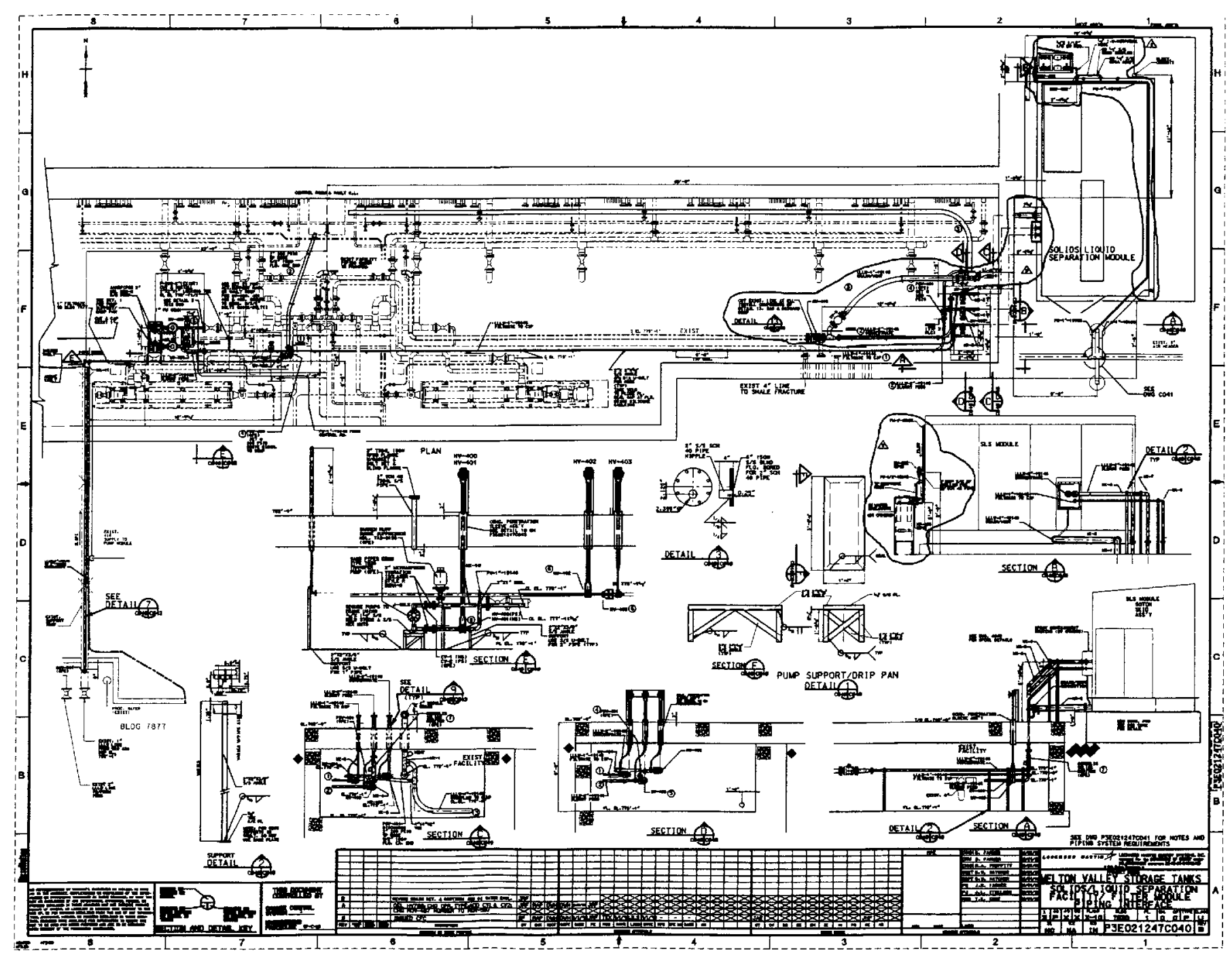

Filter Module Piping Interface 


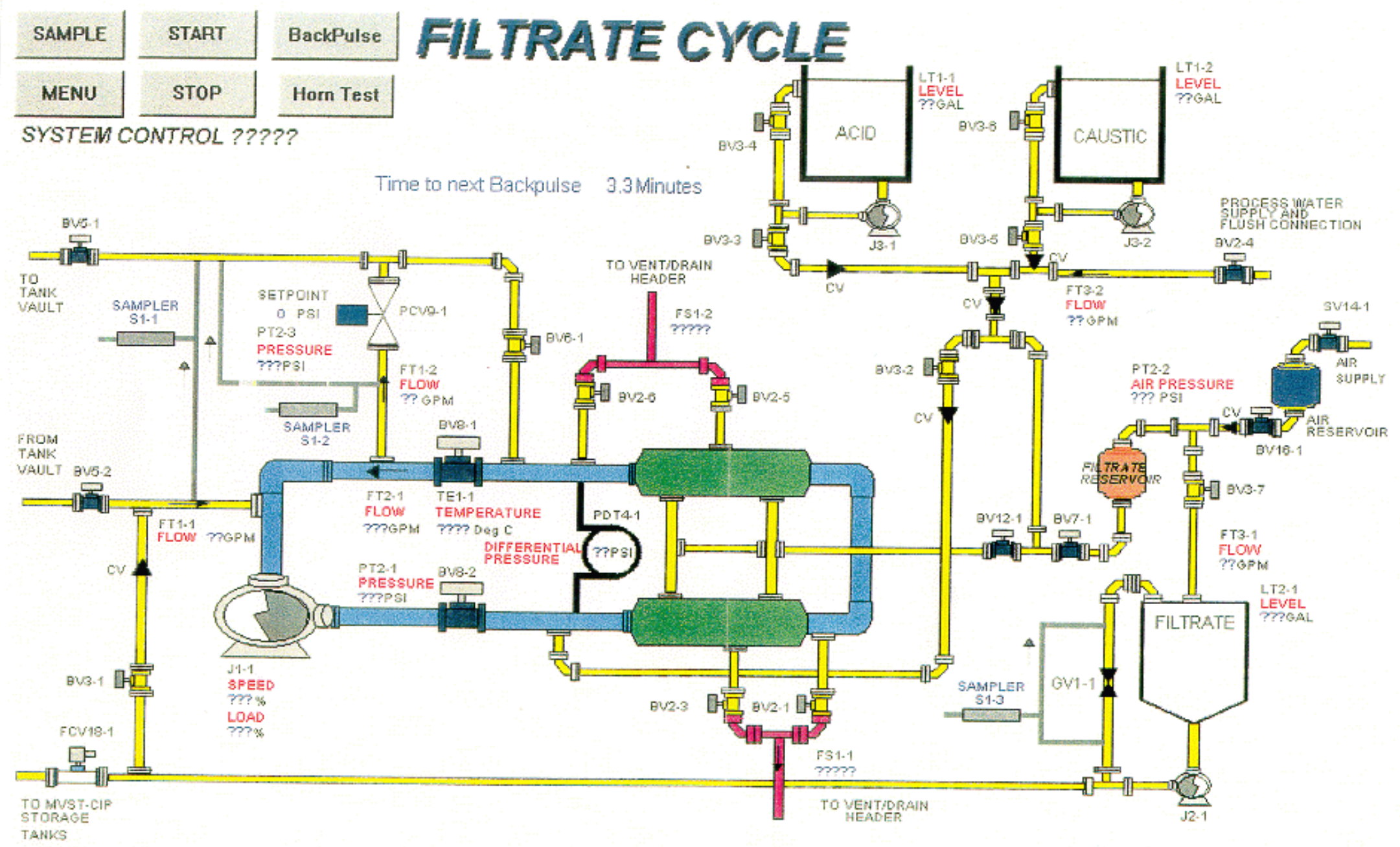

Graphical User Interface Layout - Filtrate Cycle Mode 
Appendix E. TABLE OF CONTENTS FOR NUMET SLS MANUALS 


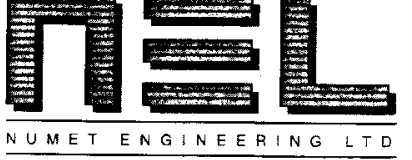

\title{
SOLID-LIQUID SEPARATION SYSTEM
}

\author{
MELTON VALLEY STORAGE TANKS \\ SUPERNATE SOLIDS REMOVAL
}

\section{INSTALLATION, OPERATION \& MAINTENANCE MANUAL}

\author{
VOLUME i OF IV
}

Lockheed Martin Energy Systems

P.(1. No. 74 X-LKR58V

Assigned NEL Document No.: 1218-IOMM

Eastern \& Head Office:

Western Office:
P.O. Box 1776, 678 Neal Drive, Peterborough, ON K9J $7 \times 6$ Canada E-mail: numet@numet.com Website: http:/www.numet.com 8924 Tumbo Place, Sidney, British Columbia, Canada V8L 4L8
Tel: (705) 743-2708 Fax: (705) 743-3216 Tel: (250) 655-0851 Fax: (250) 655-1038 
Oak Ridge National Laboratories Solid-Liquid Separation System

\section{TABLE OF CONTENTS}

VOLUME I

0.

REVISION RECORD

Page

1. INTRODUCTION

2. EQUIPMENT DESCRIPTION AND CAPABILITIES...............6

$2.1 \quad$ Equipment Description and Layout $\ldots \ldots \ldots \ldots \ldots \ldots \ldots \ldots \ldots$

2.1.1 Supernate Supply Loop $\ldots \ldots \ldots \ldots \ldots \ldots \ldots \ldots \ldots \ldots$

2.1.2 Filtrate Output Loop ...........................

2.1.3 Sampling System $\ldots \ldots \ldots \ldots \ldots \ldots \ldots \ldots \ldots \ldots \ldots$

2.1.4 Chemical Clean System ....................... 9

2.1.5 Video Observation System ...................... 10

2.1.6 Power and Control System ................... 10

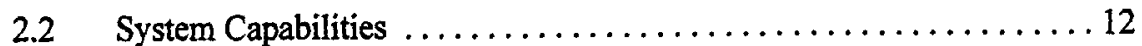

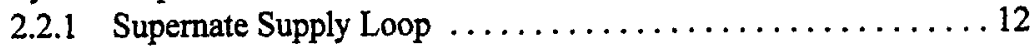

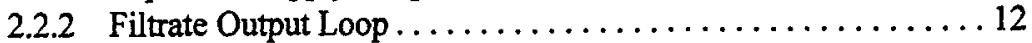

2.2.3 Sampling System ........................... 13

2.2.4 Chemical Clean System ........................ 14

2.2 .5 Video Observation System ..................... 14

2.3 Equipment Description and Capabilities $\ldots \ldots \ldots \ldots \ldots \ldots \ldots \ldots$ User Notes

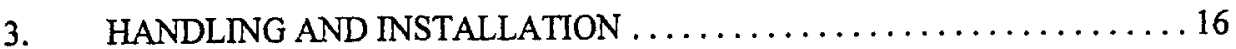

3.1 Transportation and Packaging Removal $\ldots \ldots \ldots \ldots \ldots \ldots \ldots \ldots$

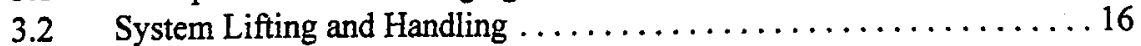

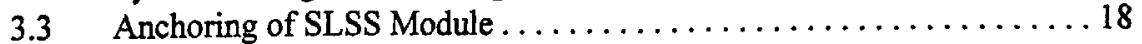

3.3.1 Pad Requirements $\ldots \ldots \ldots \ldots \ldots \ldots \ldots \ldots \ldots \ldots \ldots \ldots$

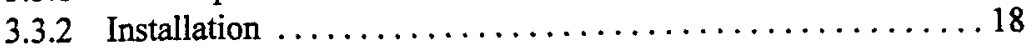

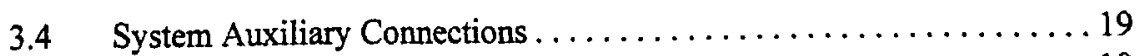

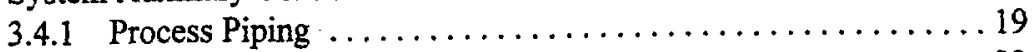

3.4.2 Drain/Vent Outlet ............................. 22

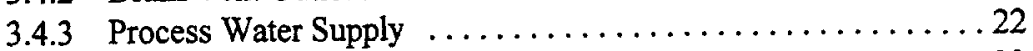

3.4.4 Electrical Power Supply ......................... 23

3.4.5 Remote Control Room Interface $\ldots \ldots \ldots \ldots \ldots \ldots \ldots 24$

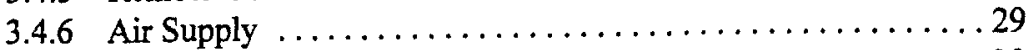

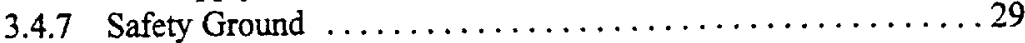

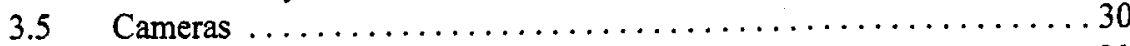

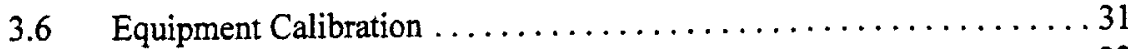

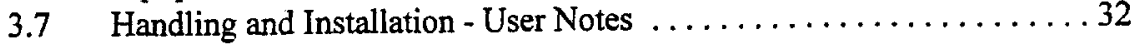

C:IWP61IPROJECTSU1218112181OM 
Oak Ridge National Laboratories Solid-Liquid Separation System

TABLE OF CONTENTS, Continued

4. SYSTEM STARTUP AND COMMISSIONING $\ldots \ldots \ldots \ldots \ldots \ldots \ldots$

4.1 Initial System Startup Verification Checklist $\ldots \ldots \ldots \ldots \ldots \ldots \ldots 33$

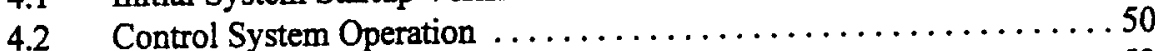

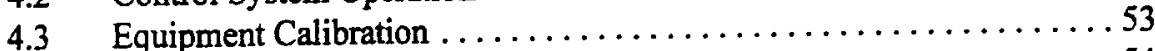

4.4 Auxiliary Connections Leak Tests .................... 54

4.5 System Startup and Commissioning - User Notes ............. 56

5. SYSTEM OPERATING INSTRUCTIONS $\ldots \ldots \ldots \ldots \ldots \ldots \ldots \ldots \ldots$

5.1 General and Operational Safety Considerations $\ldots \ldots \ldots \ldots \ldots \ldots 57$

5.2 Enabling Main Power Supply and Associated $\ldots \ldots \ldots \ldots \ldots \ldots$

Equipment

5.3 Fault Handling and Recovery Overview ................. 58

5.4 System Control Enable and Emergency Shutdown $\ldots \ldots \ldots \ldots \ldots \ldots 6$

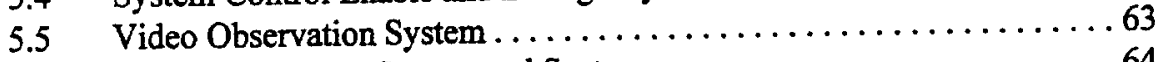

5.6 Control Computer Startup and System $\ldots \ldots \ldots \ldots \ldots \ldots \ldots \ldots 64$ Operations Menu

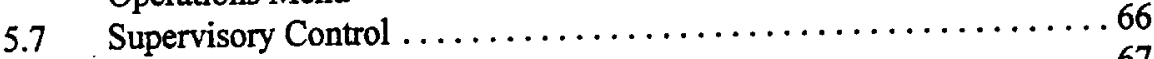

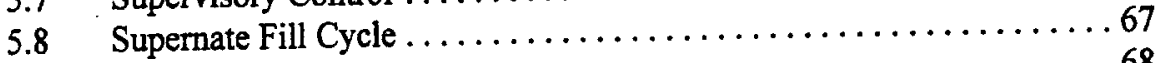

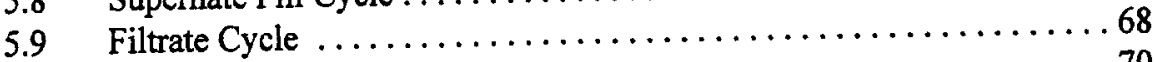

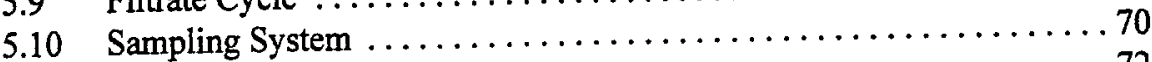

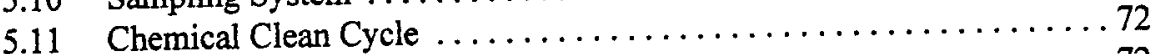

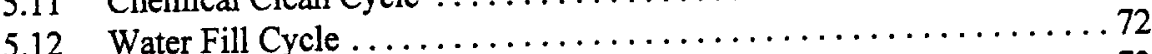

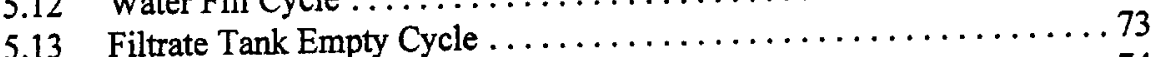

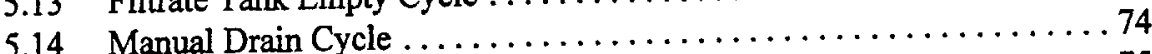

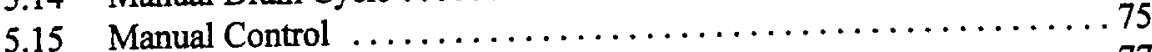

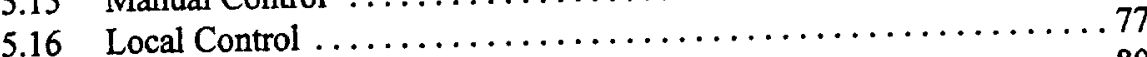

5.17 System Operating Instructions - User Notes $\ldots \ldots \ldots \ldots \ldots \ldots \ldots 80$

6. TROUBLESHOOTING AND REPAIR $\ldots \ldots \ldots \ldots \ldots \ldots \ldots \ldots \ldots$

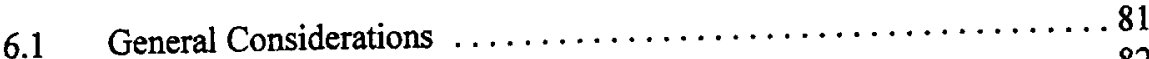

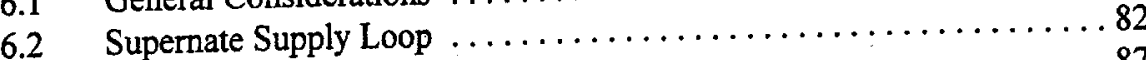

6.3 Filtrate Output Loop ............................... 87

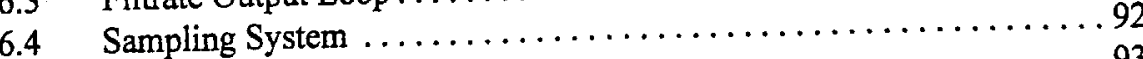

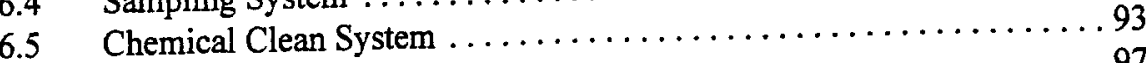

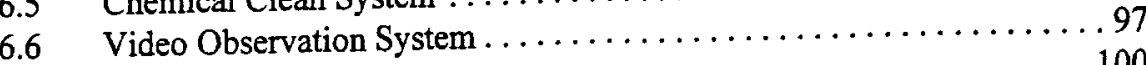

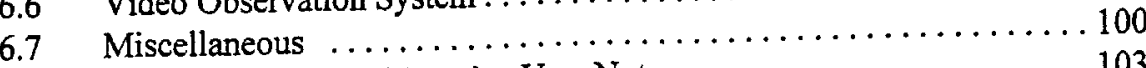

6.8 Troubleshooting and Repair - User Notes $\ldots \ldots \ldots \ldots \ldots \ldots \ldots$ 
TABLE OF CONTENTS, Continued

7. MAINTENANCE AND CALIBRATION .................... 104

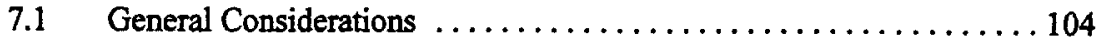

7.2 Routine Maintenance .............................. 104

7.3 Instrument Calibration/Adjustment ...................... 109

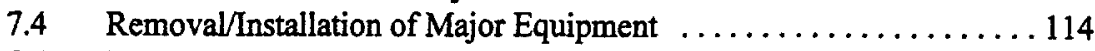

7.5 Instrumentation and Equipment $\ldots \ldots \ldots \ldots \ldots \ldots \ldots \ldots \ldots \ldots \ldots \ldots \ldots \ldots$

Programming

7.5 Maintenance and Calibration - User Notes ................ 131

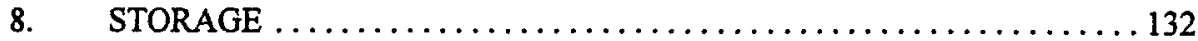

8.1 General Considerations .......................... 132

8.2 System Draining, Venting and Washdown ................. 133

8.2.1 Supernate Supply Loop . . . . . . . . . . . . . . . . . . . . 133

8.2 .2 Filtrate Output Loop........................ 134

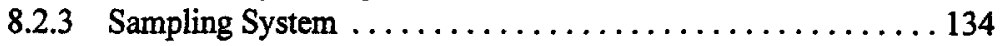

8.2.4 Chemical Clean System ........................ 134

8.2.5 System Air Supply $\ldots \ldots \ldots \ldots \ldots \ldots \ldots \ldots \ldots \ldots \ldots \ldots \ldots \ldots \ldots \ldots \ldots$,

8.3 Disassembly and Recommended .................... 134

Equipment States

8.4 Sealing, Capping and External Protection ................. 135

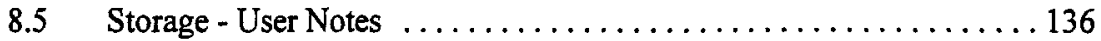

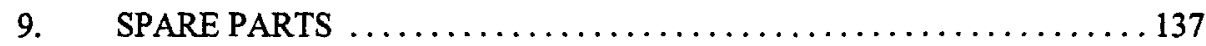

9.1 Recommended Spare Parts $\ldots \ldots \ldots \ldots \ldots \ldots \ldots \ldots \ldots \ldots \ldots \ldots \ldots$

and Components

9.2 Manufacturer's Addresses . ....................... 137

APPENDIX A SEQUENCE OF OPERATIONS

APPENDIX B FIX MMI SYSTEM SCREENS

APPENDIX C SYSTEM FAULTS AND WARNINGS

APPENDIX D SYSTEM STARTUP AND COMMISSIONING - Table D1

VOLUME II

(Valve Actuator and Limit Switch Operation Test Data Sheet)

APPENDIX E DRAWINGS

APPENDIX F FIX/MTL PROGRAM AND CONFIGURATION SOFTWARE

VOLUME III

APPENDIX G COMPONENT TECHNICAL INFORMATION (Sections GI thru G18)

VOLUME IV

APPENDIX G COMPONENT TECHNICAL INFORMATION (Sections G19 thru G34) 
Appendix F. SLS PROJECT EVIDENCE FILE INDEX 


\section{WT PROJECT EVIDENCE FILE INDEX}

Phase 2 - SLS

A. Personnel Availability and Training

\begin{tabular}{|c|c|c|c|c|c|}
\hline & Criteria & Evidence (Document Title) & Document No. & $\mathbf{M T}^{a}$ & $\mathbf{E R B}^{b}$ \\
\hline A. 1 & $\begin{array}{l}\text { A well-defined and documented operations } \\
\text { plan exists that defines the types of jobs } \\
\text { needed for project completion, how many } \\
\text { of each function are required, and who will } \\
\text { be serving in each function }\end{array}$ & $\begin{array}{l}\text { Training Matrices for WT Project } \\
\text { Job Task Analysis for SLS operating } \\
\text { procedures }\end{array}$ & $\begin{array}{l}\text { ORNL Triad Project Training Program } \\
\text { Manual, Liquid and Gaseous Waste } \\
\text { Operations Project, March } 1999 \\
\text { (separate three-ring binder) }\end{array}$ & AVG & JK \\
\hline A. 2 & $\begin{array}{l}\text { The minimum staff that must be present } \\
\text { and/or on call for safe operations has been } \\
\text { well defined; staffing requirements must } \\
\text { consider both project staff and matrix } \\
\text { support staff }\end{array}$ & $\begin{array}{l}\text { Wastewater Triad MOU } \\
\text { Problem Safety Summary (PSS) provides a } \\
\text { listing of CTD support staff (phone } \\
\text { number, address) } \\
\text { LGWOP Web page provides a listing of } \\
\text { LGWOP contacts (name, phone, pager) }\end{array}$ & $\begin{array}{l}\text { MOU, January 22, } 1999 \\
\text { PSS WT Operations, E.D.S. 99-02-23, } \\
\text { 4/19/99, Rev. 2 } \\
\text { LGWOP Web site address: } \\
\text { http://lgwo.ct.ornl.gov/overview/Liqdt.htm }\end{array}$ & $\mathrm{TK}$ & $\mathrm{CS}$ \\
\hline A. 3 & $\begin{array}{l}\text { Training requirements have been defined } \\
\text { for each operation and safety-related job } \\
\text { function. These training requirements must } \\
\text { be inclusive of all ES\&H related training } \\
\text { (HAZWOPER, HazCom, RadWorker II, } \\
\text { RCRA generator, etc.) and any job-specific } \\
\text { training required to conduct the assigned } \\
\text { functions (Operating procedures, Safety } \\
\text { Plans, QA Plans, NCSA, etc.) }\end{array}$ & $\begin{array}{l}\text { Required Training Matrix for CTD staff } \\
\text { personnel and operators } \\
\text { Required Training Matrix for C. B. Scott, J. J. } \\
\text { Maddox, D. J. Peterson, and LGWOP } \\
\text { operators } \\
\text { (GET, LOTO, Shift Emergency Squad } \\
\text { Training, LLLW System and LGWO } \\
\text { Operations, and EDS Procedural Training) }\end{array}$ & $\begin{array}{l}\text { ORNL Triad Project Training Program } \\
\text { Manual (separate three-ring binder) }\end{array}$ & AVG & JK \\
\hline A. 4 & $\begin{array}{l}\text { Review of training program indicated it is } \\
\text { geared toward ensuring and verifying that } \\
\text { personnel actually learn something and is } \\
\text { not a paperwork exercise just for creating a } \\
\text { file }\end{array}$ & $\begin{array}{l}\text { See previous RAs of WMOD's Training } \\
\text { Program (PUEs/PDC) - Management Plan } \\
\text { for the WMOD - Section 7, The Training } \\
\text { Program (BJC has blue-sheeted this } \\
\text { document) }\end{array}$ & $\begin{array}{l}\text { MVST-CIP RA (MVST.CR02) } \\
\text { WMOD-AD-119/R3, Section } 7\end{array}$ & AVG & JK \\
\hline A. 5 & Training program is performance based & Same as A.4 (PUEs and PDC) & Same as A.4 & AVG & JK \\
\hline
\end{tabular}




\section{WT PROJECT EVIDENCE FILE INDEX}

Phase 2 - SLS

\begin{tabular}{|c|c|c|c|c|c|}
\hline & Criteria & Evidence (Document Title) & Document No. & $\mathbf{M T}^{a}$ & $\mathbf{E R B}^{b}$ \\
\hline A.6 & $\begin{array}{l}\text { Training records are complete for all staff } \\
\text { required for safe operations }\end{array}$ & $\begin{array}{l}\text { Documentation of trainer qualification to } \\
\text { operate the SLS System: Trainer } \\
\text { Qualifications for the Wastewater Triad } \\
\text { Systems } \\
\text { Training records of CTD staff personnel and } \\
\text { operators (PUEs and PDCs for project } \\
\text { procedures) } \\
\text { Training Records for C. B. Scott, J. J. Maddox, } \\
\text { and D. J. Peterson }\end{array}$ & $\begin{array}{l}\text { ORNL Triad Project Training Program } \\
\text { Manual (separate three-ring binder) }\end{array}$ & AVG & JK \\
\hline A. 7 & $\begin{array}{l}\text { A sufficient number of trained backup staff } \\
\text { is available }\end{array}$ & Training Records & $\begin{array}{l}\text { ORNL Triad Project Training Program } \\
\text { Manual (separate three-ring binder) }\end{array}$ & TK & CS \\
\hline A. 8 & $\begin{array}{l}\text { Interviews with operations and matrix } \\
\text { support staff indicate that they are fully } \\
\text { knowledgeable of their assigned tasks and } \\
\text { can conduct the operation in a safe and } \\
\text { effective manner (staff appear to know and } \\
\text { respect the safety-related hazards of the job) }\end{array}$ & To be assessed by the Independent Team & Checklist Appraisal Form & N/A & JK \\
\hline A.9 & $\begin{array}{l}\text { Emergency staff readiness has been verified } \\
\text { through site drills }\end{array}$ & $\begin{array}{l}\text { Emergency Drill Program will not change. The } \\
\text { recently conducted MVST-CIP RA (an } \\
\text { adjacent facility to TRIAD operations) } \\
\text { assessed the Emergency Drill Program; see } \\
\text { MVST CR09 } \\
\text { Wastewater Triad Emergency Drill }\end{array}$ & $\begin{array}{l}\text { MVST-CIP (MVST.CR09) } \\
\text { Local Emergency Manual, Rev. 3, January } \\
1999 \\
\text { Module No. 10024, 5/12/99 }\end{array}$ & TK & CS \\
\hline A. 10 & $\begin{array}{l}\text { The contractor readiness evaluation has } \\
\text { adequately covered items (1) to (9) above }\end{array}$ & & Checklist Appraisal Form & TK & $\mathrm{JK}$ \\
\hline
\end{tabular}




\section{WT PROJECT EVIDENCE FILE INDEX}

Phase 2 - SLS

B. Procedures and Management Controls

\begin{tabular}{|c|c|c|c|c|c|}
\hline & Criteria & Evidence (Document Title) & Document No. & $\mathbf{M T}^{a}$ & $\mathbf{E R B}^{b}$ \\
\hline B. 1 & $\begin{array}{l}\text { Safety and Health responsibilities are } \\
\text { defined, understood, and accepted by all } \\
\text { levels. An appropriate level of safety and } \\
\text { health support and oversight is being } \\
\text { provided to the project }\end{array}$ & $\begin{array}{l}\text { MOUs define responsibilities: } \\
\text { WT Project MOU } \\
\text { The Site-wide safety and environmental } \\
\text { awareness culture programs will not } \\
\text { change (see the recently conducted RA for } \\
\text { the MVST-CIP for support organizational } \\
\text { to LGWOP facilities) }\end{array}$ & $\begin{array}{l}\text { (WT Project) MOU, January 22, } 1999 \\
\text { MVST-CIP RA (MVST.CR08) }\end{array}$ & $\mathrm{TH}$ & JJM \\
\hline B. 2 & $\begin{array}{l}\text { The activities that constitute routine and } \\
\text { emergency operations have been defined, } \\
\text { and written procedures have been approved } \\
\text { and issued to cover these activities }\end{array}$ & $\begin{array}{l}\text { WT Project SLS } \\
\text { WT Project Flowpath: MVST }(W-31)-S L S- \\
\quad \text { CsR - OTE (Evaporator ON) - CIP }\end{array}$ & $\begin{array}{l}\text { EDS-SLS-001, Rev. 1, 5/18/99 } \\
\text { EDS-WTP-004, Rev 1, 5/18/99 } \\
\text { (Rev. } 1 \text { includes PPE: JHA requirements) }\end{array}$ & JFW & JJM \\
\hline B. 3 & $\begin{array}{l}\text { Written procedures contain the appropriate } \\
\text { level of detail for safe operations and have } \\
\text { been prepared in a stepwise manner that is } \\
\text { readily usable by the intended operator }\end{array}$ & $\begin{array}{l}\text { Verification of EDS Procedures: } \\
\text { Prefunctional tests } \\
\text { Review records }\end{array}$ & $\begin{array}{l}\text { Wastewater Triad Project, Surveillance } \\
\text { Checklist/Report, S457EDS, 5/10/99 - } \\
\text { 5/12/99 } \\
\text { See B.4 for Review Records }\end{array}$ & JFW & JJM \\
\hline B. 4 & $\begin{array}{l}\text { The project has verified by walkdown that } \\
\text { the procedures match the actual working } \\
\text { conditions and the required actions to be } \\
\text { performed }\end{array}$ & $\begin{array}{l}\text { Example of marked up/review comments to the } \\
\text { drafted procedures }\end{array}$ & $\begin{array}{l}\text { EDS-SLS-001 and EDS-WTP-004 draft } \\
\text { procedures marked up and Tim Kent's } \\
\text { validation of procedures }(5 / 12 / 99)\end{array}$ & JFW & JJM \\
\hline
\end{tabular}




\section{WT PROJECT EVIDENCE FILE INDEX}

Phase 2 - SLS

\begin{tabular}{|c|c|c|c|c|c|}
\hline & Criteria & Evidence (Document Title) & Document No. & $\mathbf{M T}^{a}$ & $\mathbf{E R B}^{b}$ \\
\hline B.5 & $\begin{array}{l}\text { The project has developed a Health and } \\
\text { Safety Plan, a Waste Management Plan, and } \\
\text { a QA Plan }\end{array}$ & $\begin{array}{l}\text { Site Specific Health and Safety Plan Matrix: } \\
\text { Implementing Documents/References } \\
\text { See previous MVST-CIP RA for the OSHP } \\
\text { support program } \\
\text { See previous MVST-CIP RA for the RPP } \\
\text { ALARA support program } \\
\text { WT Project ALARA Plan } \\
\text { Waste Management Plan } \\
\text { LGWOP QA Plan } \\
\text { The PSS addresses project-specific QA }\end{array}$ & $\begin{array}{l}\text { Matrix title (no document number): } \\
\text { required sections of Health and } \\
\text { Safety Plan from DOE Health and } \\
\text { Safety Plan Guidelines } \\
\text { MVST-CIP RA (MVST.CR08) } \\
\\
\text { MVST-CIP RA (MVST.CR08) } \\
\\
\text { Wastewater Triad ALARA Plan, 4/20/99 } \\
\text { Legacy Waste Project Management Plan, } \\
\text { 3/31/99, Rev. 1 } \\
\text { MVST-CIP RA (MVST.CR08) } \\
\text { EDS 99-02-23, Rev. 2 }\end{array}$ & TK & JJM \\
\hline B.6 & $\begin{array}{l}\text { A Job Hazards Analysis has been } \\
\text { completed to ensure an adequate review of } \\
\text { planned operations for any safety-related } \\
\text { hazards and required hazard-mitigating } \\
\text { measures; this review must be documented } \\
\text { in the Health and Safety Plan or by itself }\end{array}$ & $\begin{array}{l}\text { CsR/OTE/SLS Systems JHA } \\
\text { CsR/OTE/SLS JHA for Maintenance and } \\
\text { Calibration Activities }\end{array}$ & $\begin{array}{l}\text { JHA No. EDS-WTP-JHA-01, R1,5/21/99 } \\
\text { EDS-WTP-JHA-02, 5/20/99 }\end{array}$ & $\mathrm{TH}$ & $\mathrm{JK}$ \\
\hline B.7 & $\begin{array}{l}\text { Operating instructions and/or procedures } \\
\text { ensure that staff use the appropriate } \\
\text { protective measures to mitigate any work- } \\
\text { related hazards that have been identified in } \\
\text { the Job Hazard Analysis and the Safety } \\
\text { Authorization Basis document (BIO or } \\
\text { SAR); e.g., if PPE are required, the } \\
\text { operating procedures spell out PPE } \\
\text { requirements. }\end{array}$ & $\begin{array}{l}\text { EDS operating procedures } \\
\text { JHA } \\
\text { RWPs } \\
\text { ES\&H Surveillance Checklist }\end{array}$ & $\begin{array}{l}\text { See B. } 2 \\
\text { See B.6 } \\
\text { See B.10 (d) } \\
\text { See C.1 (d) }\end{array}$ & TH & JJM \\
\hline B. 8 & $\begin{array}{l}\text { A document control system is in place to } \\
\text { ensure that staff has the most recent } \\
\text { versions of plans and procedures }\end{array}$ & $\begin{array}{l}\text { EDS Development, Review, and Control of } \\
\text { Procedures (References LGWOP Conduct of } \\
\text { Operations Manual) }\end{array}$ & EDS-WTP-01, Rev 1, 5/11/99 & GC & JJM \\
\hline
\end{tabular}




\section{WT PROJECT EVIDENCE FILE INDEX}

Phase 2 - SLS

\begin{tabular}{|c|c|c|c|c|c|}
\hline & Criteria & Evidence (Document Title) & Document No. & $\mathbf{M T}^{a}$ & $\mathbf{E R B}^{b}$ \\
\hline B.9 & $\begin{array}{l}\text { A routine program of assessments is } \\
\text { planned, including surveillance and } \\
\text { inspections of routine operations; these } \\
\text { assessments are geared toward verifying } \\
\text { that the job is being conducted in } \\
\text { accordance with procedures and that all } \\
\text { required safety controls are being met }\end{array}$ & $\begin{array}{l}\text { The WMOD WSS Self-Assessment Program } \\
\text { has been reviewed previously during the } \\
\text { C-Tanks RA } \\
\text { Schedule of ES\&H surveillance for EDS }\end{array}$ & $\begin{array}{l}\text { C-Tanks RA (File 7.1) } \\
\text { WT Project }-1999 \text { Assessment Schedule } \\
\quad \text { - Rev 1. }\end{array}$ & $\begin{array}{c}\mathrm{GC} \\
\mathrm{AVG}\end{array}$ & JJM \\
\hline B. 10 & $\begin{array}{l}\text { All required operating permits and } \\
\text { approvals have been issued. Examples } \\
\text { include Radiation Work Permits (RWPs), } \\
\text { Nuclear Criticality Safety Approvals } \\
\text { (NCSAs), Safety Work Permits, Drilling } \\
\text { Permits, Regulatory Approvals, Lift Plans, } \\
\text { Labor Standards Determinations, } \\
\text { Environmental Permits (Clean Air Act, } \\
\text { NESHAPS, NPDES, etc.), NEPA and } \\
\text { NEPA-related statutes, Hot Work Permits }\end{array}$ & $\begin{array}{l}\text { NCSAs - Copy of Criticality Safety Review } \\
\text { for SLS System } \\
\text { Don Mueller's NCSA review } \\
\text { RWP(s) - to be provided by LMER } \\
\text { SLS system environmental permits not } \\
\text { required (distillate tied into existing } \\
\text { monitored off-gas system) } \\
\text { SLS PRS and NEPA CX } \\
\text { SLS System NEPA checklist (for routine } \\
\text { operations) submitted to James Hall }\end{array}$ & $\begin{array}{l}\text { Memo from John Alexander, 1/11/99, with } \\
\text { attachment of T. E. Kent's NCSA } \\
\text { Calculations for SLS Project } \\
\text { E-mail from Don Mueller, 5/17/99 } \\
\text { ORNL RWP HAZWL-4229. SLS } \\
\text { E-mail from Charlie Valentine, April 21, } \\
1999 \\
\text { Project Review Summary and NEPA CX } \\
\text { for SLS Demonstration, July 7, 1998 } \\
\text { ORNL NEPA Project Review Checklist, } \\
\text { SLS System Routine Operations, } \\
\text { 3/10/99 }\end{array}$ & TK & $\mathrm{CS}$ \\
\hline B. 11 & $\begin{array}{l}\text { The Safety Authorization Basis is defined } \\
\text { and approved, including SARs, BIOs, ASA, } \\
\text { USQDs, etc. }\end{array}$ & $\begin{array}{l}\text { Basis for Interim Operation, Liquid Low-Level } \\
\text { Waste Management Systems } \\
\text { Operational Safety Requirements for the } \\
\text { Liquid Low-Level Waste System } \\
\text { USQD Change Package for Operation of the } \\
\text { LLLW Solid-Liquid Separation System } \\
\text { Installation of the Solids-Liquid Separation } \\
\text { Module at the Melton Valley Storage } \\
\text { Tanks Facility (Building 7830) }\end{array}$ & $\begin{array}{l}\text { ORNL/WM-LGWO/LLLW/BIO/R1 } \\
\text { WM-LGWO-LLLW-OSR, R9 } \\
\text { USQD No. WM-LGWO-USQD-1999-5, } \\
\text { Rev. 0, 3-31-99 } \\
\text { USQD No. WM-LGWO-USQD-1998-23, } \\
\text { Nov. 30, } 1998\end{array}$ & JP & JJM \\
\hline B. 12 & $\begin{array}{l}\text { Contractors involved in the project must } \\
\text { have an ISMS that meet the requirements of } \\
\text { DOE P } 450.4\end{array}$ & $\begin{array}{l}\text { CTD Web page provides their ISMS program } \\
\text { BJC Guideline }\end{array}$ & $\begin{array}{l}\text { a. CTD Web site address: } \\
\text { http://www- } \\
\text { internal.ornl.gov/ctd/ctd/ismsR1.htm } \\
\text { b. Guidelines BJC/OR } 087 \text { and } 146\end{array}$ & JW & JK \\
\hline
\end{tabular}


WT PROJECT EVIDENCE FILE INDEX

\begin{tabular}{|l|l|l|l|l|}
\hline & \multicolumn{1}{|c|}{ Criteria } & \multicolumn{1}{|c|}{ Evidence (Document Title) $^{-1}$} & \multicolumn{1}{|c|}{ Document No. $^{\text {MT }^{a}}$} & ERB $^{b}$ \\
\hline B.13 & $\begin{array}{l}\text { Project specific Work Smart Standards must } \\
\text { be flowed down to each contractor involved } \\
\text { in the project }\end{array}$ & $\begin{array}{l}\text { Comparison of WSS from BJC to LMER's } \\
\text { WSS, by David McGinty } \\
\text { BJC WSS are in compliance in accordance } \\
\text { with DOE contract }\end{array}$ & $\begin{array}{l}\text { MVST-CIP RA; CR07 } \\
\text { C-Tanks Transfer Project RA; Review } \\
\text { Area 7 }\end{array}$ & JW \\
\hline
\end{tabular}

\section{Facilities and Equipment}

\begin{tabular}{|c|c|c|c|c|c|}
\hline & Criteria & Evidence (Document Title) & Document No. & $\mathbf{M T}^{\mathbf{a}}$ & $\mathbf{E R B}^{\mathbf{b}}$ \\
\hline C. 1 & $\begin{array}{l}\text { The project meets all applicable structural } \\
\text { and safety code requirements } \\
\text { Walkdowns shall verify that required } \\
\text { personnel protective equipment has been } \\
\text { provided and is available on-site }\end{array}$ & $\begin{array}{l}\text { MK-Ferguson Certification for Construction } \\
\text { LMES procurement specification and } \\
\quad \text { certification of vendor material } \\
\text { ES\&H Surveillance Checklist } \\
\text { P\&E weld certification and tests }\end{array}$ & $\begin{array}{l}\text { Closure of SLS Package, from Bob } \\
\text { Farmer (MK-Ferguson construction } \\
\text { test reports) } \\
\text { NUMET Engineering QA Records, } \\
\text { addressed to Robert Gray, 3/5/99 } \\
\text { ES\&H Surveillance Checklist } \\
\text { - S458EDS, 5/14/99 } \\
\text { Tim Kent's letter to file, 5/12/99 } \\
\text { (Weld examination reports; pressure } \\
\text { test reports; radiographic report) }\end{array}$ & $\mathrm{TH}$ & JK \\
\hline C. 2 & $\begin{array}{l}\text { The facility and site meet all applicable } \\
\text { signage, posting, and boundary control } \\
\text { requirements for Radiological Control } \\
\text { according to } 10 \text { CFR } 835\end{array}$ & ES\&H Surveillance Checklist & $\begin{array}{l}\text { ES\&H Surveillance Checklist } \\
\text {-S458EDS, 5/14/99 }\end{array}$ & $\mathrm{TH}$ & $\mathrm{JK}$ \\
\hline C. 3 & $\begin{array}{l}\text { The site is adequately equipped with } \\
\text { personnel monitoring equipment (e.g., frisk } \\
\text { stations, continuous air monitors, volatile } \\
\text { organics emissions monitors, LEL monitors, } \\
\text { etc.) }\end{array}$ & ES\&H Surveillance Checklist & $\begin{array}{l}\text { ES\&H Surveillance Checklist - } \\
\text { S458EDS, 5/14/99 }\end{array}$ & $\mathrm{TH}$ & $\mathrm{JJM}$ \\
\hline C. 4 & $\begin{array}{l}\text { Adequate eyewash and safety showers are } \\
\text { set up in areas where they are needed for } \\
\text { their intended purpose }\end{array}$ & $\begin{array}{l}\text { ES\&H Surveillance Checklist } \\
\text { Documented closure of open items }\end{array}$ & $\begin{array}{l}\text { ES\&H Surveillance Checklist } \\
\text { —S458EDS, 5/14/99 } \\
\text { Tim Kent's E-mail to file, 5/17/99 }\end{array}$ & $\mathrm{TH}$ & JJM \\
\hline C. 5 & $\begin{array}{l}\text { Hazards labeling is complete for chemicals, } \\
\text { physical hazards, and explosion potential } \\
\text { (e.g., No Smoking signs around ignitable } \\
\text { chemicals). Material Safety Data Sheets are } \\
\text { available }\end{array}$ & $\begin{array}{l}\text { ES\&H Surveillance Checklist } \\
\text { MSDS for the WT operations }\end{array}$ & $\begin{array}{l}\text { ES\&H Surveillance Checklist } \\
\text { —S458EDS, 5/14/99 } \\
\text { SLS MSDS: verified on checklist }\end{array}$ & $\mathrm{TH}$ & JJM \\
\hline
\end{tabular}




\section{WT PROJECT EVIDENCE FILE INDEX}

\section{Phase 2 - SLS}

\begin{tabular}{|c|c|c|c|c|c|}
\hline & Criteria & Evidence (Document Title) & Document No. & $\mathbf{M T}^{\mathbf{a}}$ & ERB $^{\mathbf{b}}$ \\
\hline C. 6 & $\begin{array}{l}\text { Key process piping, equipment components, } \\
\text { and valves are labeled to provide easy } \\
\text { location and adequate implementation of } \\
\text { operating procedures }\end{array}$ & $\begin{array}{l}\text { Verified during procedure validation. } \\
\text { Facility walkdown and documentation on the } \\
\text { ES\&H Surveillance Checklist }\end{array}$ & $\begin{array}{l}\text { See B.4 evidence } \\
\text { ES\&H Surveillance Checklist - } \\
\text { S458EDS, 5/14/99 }\end{array}$ & $\mathrm{TH}$ & JJM \\
\hline C.7 & $\begin{array}{l}\text { All process- and safety-related } \\
\text { instrumentation, monitoring equipment, and } \\
\text { gages are calibrated with a certified and } \\
\text { traceable source (e.g., NIST), and } \\
\text { building/site emergency contacts have been } \\
\text { contacted and coordinated with concerning } \\
\text { the project and site/building lock-out/tag-out } \\
\text { procedures }\end{array}$ & $\begin{array}{l}\text { SLS equipment list of calibration requirements by } \\
\text { EDS } \\
\text { Calibration standards } \\
\text { See C. } 8 \text { below for SLS system } \\
\text { List emergency preparedness equipment unique } \\
\text { for the operating systems }\end{array}$ & $\begin{array}{l}\text { SLS calibration list from Joe Walker to } \\
\text { Bob Gallaher, 3/26/99 } \\
\text { NUMET Engineering Quality } \\
\text { Control Manual, Rev. 5 } \\
\text { Recall Program (C.8 below) } \\
\text { Correspondence with site contacts: } \\
\text { E-mail from Bill Eldridge, LSS, } \\
\text { 3/31/99 } \\
\text { E-mail from David Baity, Fire } \\
\text { Department Manager, 4/15/99 } \\
\text { E-mails from Randy Landum, Fire } \\
\text { Department Engineer, 5/12/99 }\end{array}$ & TK & $\mathrm{JJM}$ \\
\hline C.8 & $\begin{array}{l}\text { A routine calibration recall and preventive } \\
\text { maintenance program is established for } \\
\text { equipment and instrumentation, and a } \\
\text { formal mechanism is in place to ensure that } \\
\text { required frequencies for calibration and } \\
\text { preventative maintenance are not exceeded } \\
\text { (includes HEPA filters, radiological } \\
\text { monitors, valves, gages, flowmeters, etc.) }\end{array}$ & $\begin{array}{l}\text { SLS equipment vendor literature is available for } \\
\text { maintenance programs } \\
\text { SLS: P\&E equipment entered into Recall } \\
\text { Program } \\
\text { LGWOP inspection/maintenance program of } \\
\text { SLS portable eyewash } \\
\text { SLS: I\&C instrumentation entered into Recall } \\
\text { Program } \\
\text { Critical Spare Parts List provided }\end{array}$ & $\begin{array}{l}\text { Letter ref.: Submittal of SLS Operating } \\
\text { and Maintenance Manuals, T. E. } \\
\text { Kent to J. J. Maddox, April 6, } 1999 \\
\text { P\&E Recall Program sheets for SLS } \\
\text { equipment (FAMMIS) } \\
\text { Steve Rudell's E-mail to Tim Kent, } \\
\text { 5/21/99 } \\
\text { I\&C Recall Program sheet for SLS } \\
\text { instrumentation, 5/21/99 } \\
\text { TTI Engineering packing list, 9/18/96 }\end{array}$ & TK & JJM \\
\hline
\end{tabular}




\section{WT PROJECT EVIDENCE FILE INDEX}

Phase 2 - SLS

\begin{tabular}{|c|c|c|c|c|c|}
\hline & Criteria & Evidence (Document Title) & Document No. & $\mathbf{M T}^{\mathbf{a}}$ & ERB $^{\mathbf{b}}$ \\
\hline C. 9 & $\begin{array}{l}\text { Equipment operability checks have been } \\
\text { performed using operating procedures to } \\
\text { ensure that the equipment functions as } \\
\text { intended and that the procedures reflect the } \\
\text { actual work that is to be accomplished }\end{array}$ & $\begin{array}{l}\text { Functional test plan of SLS system or partial } \\
\text { systems that require operability testing. This } \\
\text { includes ensuring utility support systems are } \\
\text { available and operable (water, air, electrical, } \\
\text { HEPA filter systems) } \\
\text { Documentation of preoperational testing (cold } \\
\text { test) of SLS system } \\
\text { Documentation of SLS System's portables } \\
\text { eyewash and hand sprayer functional tests } \\
\text { Documentation of required operability tests of } \\
\text { safety interlocks } \\
\text { Documentation/verification of readiness of } \\
\text { emergency preparedness equipment (as listed } \\
\text { in C. } 7 \text { above) }\end{array}$ & $\begin{array}{l}\text { Wastewater Triad Project Work Plan, } \\
\text { Rev. 3, April 1, } 1999 \\
\\
\text { Wastewater Triad Project Functional } \\
\text { Test Plan for the SLS System, } \\
\text { approved 5/19/99 } \\
\text { Confirmation of closure action item on } \\
\text { ES\&H Checklist that the P\&E } \\
\text { maintenance tag is directly on } \\
\text { eyewash. See C.4 } \\
\text { Verification Log for WTP System Safety } \\
\text { Interlocks (WTP Safety Interlock } \\
\text { Verification, 4/7/99, Rev. 1) } \\
\text { See C.7(c) evidence material: } \\
\text { correspondence from supporting } \\
\text { organizations (Fire Department) }\end{array}$ & TK & JJM \\
\hline C. 10 & $\begin{array}{l}\text { As-built or redlined drawings have been } \\
\text { prepared and coordinated with building/site } \\
\text { personnel to reflect the actual site } \\
\text { conditions, location of equipment, piping } \\
\text { layout, and any safety-related system that } \\
\text { could potentially be involved or affect the } \\
\text { project }\end{array}$ & $\begin{array}{l}\text { SLS drawings to be issued as-constructed upon } \\
\text { completion of cold testing } \\
\text { Vendor drawings and information }\end{array}$ & $\begin{array}{l}\text { MK-F Drawing Package } \\
\text { Letter from Greg Chitwood to J. Maddox, } \\
\text { Transmittal of Drawings and Vendor } \\
\text { Information for SLS System, 5/20/99 }\end{array}$ & TK & JJM \\
\hline
\end{tabular}


Appendix G. SLS OPERATING PLAN 


\section{Operating Plan for SLS}

\section{SLS System Condition After Functional Tests}

1) With WDS (D. Peterson) approval, empty the concentrate loop by operating the manual drain cycle while valved into W-28 (or other tank as designated by the WDS). Leave the filtrate piping full. The filtrate tank should be at minimum level (around 20 gal).

2) Label and place the first set of sample bottles in the sample cabinet per procedure EDS-SLS-001.

3) Make up the dilute acid and base for chemical cleaning per procedure EDS-SLS-001.

4) Make sure all historical data collection assignments are active on computer.

5) Lock up all SLS doorways.

\section{Operations and Sampling}

1) Hold prejob briefing using the outline provided in the log book.

2) Start with Procedure EDS-SLS-001. Check the operating conditions log sheet as follows and in the log book for the initial operating conditions to set up in the Supervisory screen. Note that the J1-1 flow rate and back-pressure settings of PCV9-1 will change according to the following operating plan. The system will operate in the Filtrate Recirculate mode until the condition of the filtrate is acceptable for treatment by the CSR/OTE systems. When sampling and analysis indicate the gross alpha content is below $1000 \mathrm{~Bq} / \mathrm{L}$, the filtrate is adequate for feed to the CSR/OTE processes. At this point, the SLS Filtrate Recirculate cycle is shut down and valving is aligned for feed to 7877 using procedure EDS-WTP-004 and the Filtrate to OTE, CSR cycle. 
Startup Date:

WDS (or designee):

\begin{tabular}{|c|c|c|c|}
\hline SLS Run Condition & Value & SLS Run Condition & Value \\
\hline MVST tank number & $\mathrm{W}-31$ & Acid soak time (min) & 60 \\
\hline Volume to process (gal) & 25,000 to 35,000 & Caustic soak time (min) & 15 \\
\hline Feed flow rate (gal/min) & 30 to 50 & Time between backpulses & 60 \\
\hline $\begin{array}{l}\text { Transmembrane pressure } \\
\text { (psi) }\end{array}$ & 10 to 40 & Number of flush cycles & 1 \\
\hline $\mathrm{J} 1-1$ flow rate (gpm) & 150 to 450 & Number of drain timeouts & 1 \\
\hline $\begin{array}{l}\text { Targeted filtrate flow rate } \\
\text { (gpm) }\end{array}$ & 0.02 to 5.0 & Feed pump selection & $\begin{array}{l}\text { J3-SLS or J4-SLS } \\
\text { (circle desired pump) }\end{array}$ \\
\hline Filtrate destination & $\begin{array}{l}\text { CsR/OTE, CIP, Recirculate } \\
\quad \text { (circle desired path) }\end{array}$ & & \\
\hline
\end{tabular}

3) Be sure to have an HP on site during initial filling of the SLS system using the Supernate Fill cycle. The background around the system will increase as the filtrate tank level increases, so a period check by the HP will be necessary. A confirmatory check of radiation background will be necessary when the filtrate tank approaches the 100-gal level.

4) Note the flow rate of the feed pumps during the Supernate Fill Cycle. The flow should be between 30 and $50 \mathrm{gpm}$. If the flow is greater than $50 \mathrm{gpm}$, the feed flow can be adjusted while in the Filtrate Cycle operation by having an operator throttle the manual air supply valve in the 7830 control room that feeds ROV-234 and ROV-235. Follow the RWP for access to this valve. If the flow is less than $30 \mathrm{gpm}$, stop the cycle and enable both pumps in the Supervisory screen. Throttle the air supply valve if both pumps provide more than $50 \mathrm{gpm}$.

5) When the filtrate tank level reaches 90 gal, take samples of the feed, concentrate, and filtrate. Wait until the filtrate tank is pumped down before retrieving samples. This should decrease background radiation in the area. Request fast turnaround on the gross alpha analysis for the filtrate sample. If the analysis indicates greater than $100 \mathrm{~Bq} / \mathrm{L}$ gross alpha, take another filtrate sample (not feed and concentrate samples) once the level in the tank has reached approximately 90 gal. Continue taking filtrate samples (one per batch) until the gross alpha content is less than $100 \mathrm{~Bq} / \mathrm{L}$. After the initial samples, additional samples of feed and concentrate are only taken at the beginning of each of the three test series described below. Once this level is reached, the filtrate need only be sampled once during each of the three test series described below. 
6) After adjustments have been made and operations are reasonably steady, begin evaluating and optimizing system operation using the following plan, which is in accordance with work plan EDS-WTP-01. The following test series (Series 1, 2, and 3) are to be performed. The tests may be initiated while in the Filtrate Recirculate mode if operational parameters have stabilized, even if the gross alpha content is too high for processing in CSR/OTE. Series 1 should be conducted early in the treatment campaign as soon as the SLS system reaches a steady operating condition. The feed flow to the system should be steady at a value between 30 and $50 \mathrm{gpm}( \pm 5 \mathrm{gpm})$. The system must be operated for a minimum of $1 \mathrm{~h}$ at each set of test conditions in the order shown in the table. Note that the order is different for each test series. Series 2 should be run after processing approximately 10,000 gal of feed. Series 3 should be conducted after processing approximately 20,000 gal of feed.

\begin{tabular}{|c|c|c|}
\hline \multicolumn{3}{|c|}{ Series 1 } \\
\hline $\begin{array}{c}\text { PCV9-1 Pressure } \\
\text { (psig) }\end{array}$ & $\begin{array}{c}\text { J1-1 Flow } \\
\text { (gal/min) }\end{array}$ & $\begin{array}{c}\text { Order of } \\
\text { performance }\end{array}$ \\
\hline 10 & 170 & 3 \\
\hline 10 & 300 & 7 \\
\hline 10 & 425 & 6 \\
\hline 20 & 170 & 2 \\
\hline 20 & 300 & 9 \\
\hline 20 & 300 & 12 \\
\hline 20 & 300 & 10 \\
\hline 20 & 425 & 11 \\
\hline 20 & 425 & 5 \\
\hline 30 & 170 & 1 \\
\hline 30 & 300 & 4 \\
\hline 30 & 425 & 8 \\
\hline $\begin{array}{l}\text { Feed flow: gal/min (Enter feed flow value. } \\
\text { Must be constant during test.) }\end{array}$ \\
\hline Time between backpulse: 60 min \\
\hline \multicolumn{3}{|c|}{} \\
\hline
\end{tabular}




\begin{tabular}{|c|c|c|}
\hline \multicolumn{3}{|c|}{ Series 2 } \\
\hline $\begin{array}{c}\text { PCV9-1 Pressure } \\
\text { (psig) }\end{array}$ & $\begin{array}{c}\text { J1-1 Flow } \\
\text { (gal/min) }\end{array}$ & $\begin{array}{c}\text { Order of } \\
\text { performance }\end{array}$ \\
\hline 10 & 170 & 12 \\
\hline 10 & 300 & 1 \\
\hline 10 & 425 & 9 \\
\hline 20 & 170 & 3 \\
\hline 20 & 300 & 2 \\
\hline 20 & 300 & 5 \\
\hline 20 & 300 & 6 \\
\hline 20 & 425 & 7 \\
\hline 20 & 425 & 8 \\
\hline 30 & 170 & 4 \\
\hline 30 & 300 & 11 \\
\hline 30 & 425 & 10 \\
\hline \multicolumn{3}{|c|}{ gal/min (Enter feed flow value. } \\
\hline $\begin{array}{l}\text { Feed flow: } \\
\text { Must be constant during test.) }\end{array}$ \\
\hline Time between backpulse: 60 min \\
\hline
\end{tabular}

\begin{tabular}{|c|c|c|}
\hline \multicolumn{3}{|c|}{ Series 3 } \\
\hline $\begin{array}{c}\text { PCV9-1 Pressure } \\
\text { (psig) }\end{array}$ & $\begin{array}{c}\text { J1-1 Flow } \\
\text { (gal/min) }\end{array}$ & $\begin{array}{c}\text { Order of } \\
\text { performance }\end{array}$ \\
\hline 10 & 170 & 8 \\
\hline 10 & 300 & 11 \\
\hline 10 & 425 & 2 \\
\hline 20 & 170 & 12 \\
\hline 20 & 300 & 1 \\
\hline 20 & 300 & 6 \\
\hline 20 & 300 & 7 \\
\hline 20 & 425 & 10 \\
\hline 20 & 425 & 9 \\
\hline 30 & 170 & 3 \\
\hline 30 & 300 & 5 \\
\hline 30 & 425 & 4 \\
\hline $\begin{array}{l}\text { Feed flow: gal/min (Enter feed flow value. } \\
\text { Must be constant during test.) }\end{array}$ \\
\hline Time between backpulse: 60 min \\
\hline
\end{tabular}

G-6 
7) Sampling Schedule

Summary

1) Initial feed, concentrate, and filtrate after system startup.

2) Filtrate for each batch until level is less than $1000 \mathrm{~Bq} / \mathrm{L}$ gross alpha.

3) Feed, concentrate, and filtrate near the beginning of each test series.

4) Routine sample of filtrate every 60 th batch at $80 \mathrm{gal} / \mathrm{batch}$.

5) Final feed sample.

Refer to the following sampling plan table as a guide for sampling frequency, sample volume, and analysis request information.

8) After completing the campaign, flush the feed piping from J-3SLS/4SLS to the system while in manual mode by opening a flow path from the feed to the concentrate discharge and clicking the water supply button near the top of the manual screen. The pumps J3SLS/4SLS do not need to be run during the rinse. Watch the change in density on the SM-1 readout and stop the rinse when the specific gravity is 1.00 . This should be followed by the normal drain, decontamination, and water fill of the system. 


\begin{tabular}{|c|c|c|c|c|}
\hline Sample Source & Frequency & $\begin{array}{l}\text { Volume } \\
(\mathrm{mL})\end{array}$ & $\begin{array}{l}\text { Turnaround } \\
\text { time }\end{array}$ & Analysis \\
\hline \multicolumn{5}{|c|}{ INITIAL SAMPLES WHILE IN FILTRATE-RECIRCULATE MODE } \\
\hline Concentrate & (1) Initial sample & 50 & 1 week & Gross alpha, gross beta, density \\
\hline \multicolumn{5}{|c|}{ SAMPLES TAKEN DURING SERIES 1, 2, AND 3 TESTING } \\
\hline Feed & $\begin{array}{l}\text { Sample near the beginning of the } \\
\text { series (total, three) }\end{array}$ & 50 & 1 week & $\begin{array}{l}\text { Gross alpha, gross beta, gamma scan, alpha isotopic, density, total } \\
\text { suspended solids (TSS), total solids (TS), cation analysis by ICP, } \\
\text { total nitrate }\end{array}$ \\
\hline Filtrate & $\begin{array}{l}\text { Sample near the beginning of the } \\
\text { series, preferably when filtrate tank } \\
\text { is nearly full (total, three) }\end{array}$ & 50 & 1 week & $\begin{array}{l}\text { Density, TSS, alpha isotopic, gross alpha, gross beta, gamma scan, } \\
\text { total cations by ICP }\end{array}$ \\
\hline \multicolumn{5}{|c|}{ ROUTINE SAMPLES BETWEEN TEST SERIES } \\
\hline Filtrate & $\begin{array}{l}\text { Approx. every } 5000 \text { gal per FT-01- } \\
\text { TO (CSR totalizer) }\end{array}$ & 50 & 1 week & Gross alpha, gross beta, gamma scan, density, TSS \\
\hline Feed & One near end of campaign & 50 & 1 week & Gross alpha, gross beta, density, TSS \\
\hline \multicolumn{5}{|c|}{$\begin{array}{l}\text { NOTES: } \\
\text { 1) Instruct laboratory to hold all samples for two months before disposal. } \\
\text { 2) The routine filtrate sample can be replaced by the Series } 1,2,3 \text { filtrate sample if taken within the 60th batch frequency. } \\
\text { 3) Send samples to RMAL with "chain-of-custody" paperwork unless the TRU laboratory is needed for quick turnaround. }\end{array}$} \\
\hline
\end{tabular}




\section{INTERNAL DISTRIBUTION}

$\begin{aligned} \text { 1. } & \text { R. L. Cummins } \\ 2 . & \text { B. S. Evans } \\ 3 . & \text { J. R. Farmer } \\ 4 . & \text { L. L. Farr } \\ 5 . & \text { J. D. Hewitt } \\ 6 . & \text { T. D. Hylton } \\ 7 . & \text { H. L. Jennings } \\ 8 . & \text { R. T. Jubin } \\ 9 . & \text { C. M. Kendrick } \\ 10-12 . & \text { T. E. Kent } \\ \text { 13. } & \text { D. D. Lee } \\ 14 . & \text { J. J. Maddox }\end{aligned}$

1. R. L. Cummins

15. C. P. McGinnis

16. L. E. McNeese

17. B. D. Oakley

18. S. A. Richardson

19. S. M. Robinson

20. C. B. Scott

21. P. A. Taylor

22-24. J. F. Walker, Jr.

25. ORNL Central Research Library

26. Laboratory Records, RC

27. Laboratory Records, OSTI

\section{EXTERNAL DISTRIBUTION}

28. J. T. Carter, Westinghouse Savannah River Company, P.O. Box 616, 704-3N, Room S151, Aiken, SC 29808

29. Samuel D. Fink, Westinghouse Savannah River Company, P.O. Box 616, 773-A, Room B112, Aiken, SC 29808

30. K. D. Gerdes, TFA Headquarters Program Manager, DOE Office of Science and Technology, 19901 Germantown Rd., 1154 Cloverleaf Bldg., Germantown, MD 20874-1290

31. Roger L Gilchrist, Pacific Northwest National Laboratory, P.O. Box 999, MS:K9-91, Richland, WA 99352

32. Tim Hallman, Foster Wheeler Environmental Company, 111 Union Valley Road, Oak Ridge, TN 37830-8045

33. N. R. Mann, Idaho National Engineering and Environmental Laboratory P.O. Box 1625, Idaho Falls, ID 83415-5218

34. D. J. McCabe, Westinghouse Savannah River Company, P.O. Box 616, 773-42A, Room 152, Aiken, SC 29808

35. C. McMeekin, NUMET Engineering Ltd., P.O. Box 1776, Peterborough, ON K9J7X6 Canada

36. C. A. Nash, Westinghouse Savannah River Company, P.O. Box 616, 773-42A, Room 182, Aiken, SC 29808 
37. J. R. Noble-Dial, U.S. Department of Energy, Oak Ridge Operations Office, P.O. Box 2001, Oak Ridge, TN 37831-8620

38. T. P. Pietrok, TFA Program Lead, U.S. Department of Energy, Richland Operations Office, P.O. Box 550, MS: K8-50, Richland, WA 99352

39. W. L. Tamosaitis, Westinghouse Savannah River Company, P.O. Box 616, 773-A, Room A-231, Aiken, SC 29808

40. T. A. Todd, Idaho National Engineering and Environmental Laboratory, Building 637, MS-5218, Idaho Falls, ID 83415-5218

41. J. H. Wilson, NUKEM Nuclear Technologies, 250 Berryhill Rd. Suite 500 Columbia, SC 29210.

42. Tanks Focus Area Technical Team, c/o B. J. Williams, Pacific Northwest National Laboratory, P.O. Box 999, MSIN K9-69, Richland, WA 99352 